Portland State University

PDXScholar

$1-2012$

\title{
Climate Change Impact Assessment for Surface Transportation in the Pacific Northwest and Alaska
}

John MacArthur

Portland State University

Philip Mote

Oregon State University

Miguel A. Figliozzi

Portland State University, figliozzi@pdx.edu

Jason Ideker

Oregon State University

Ming Lee

University of Alaska Fairbanks

Follow this and additional works at: https://pdxscholar.library.pdx.edu/cengin_fac

Part of the Environmental Engineering Commons, and the Transportation Engineering Commons Let us know how access to this document benefits you.

\section{Citation Details}

MacArthur, John, Philip Mote, Miguel A. Figliozzi, Jason Ideker and Ming Lee . Climate Change Impact Assessment for Surface Transportation in the Pacific Northwest and Alaska . OTREC-RR-12-01. Portland, OR: Transportation Research and Education Center (TREC), 2012. http://dx.doi.org/10.15760/trec.122

This Report is brought to you for free and open access. It has been accepted for inclusion in Civil and Environmental Engineering Faculty Publications and Presentations by an authorized administrator of PDXScholar. Please contact us if we can make this document more accessible: pdxscholar@pdx.edu. 

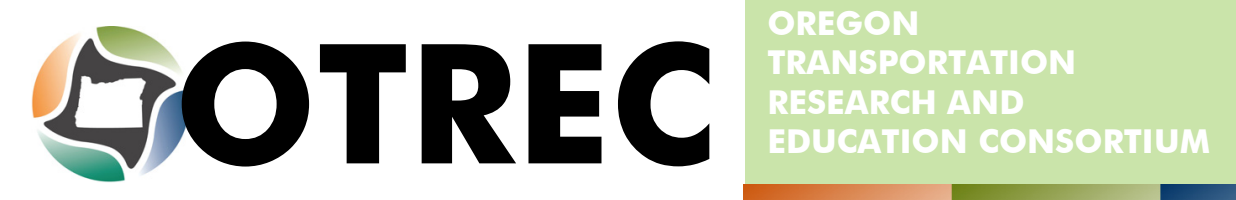

FINAL REPORT

Climate Change Impact Assessment for Surface Transportation in the Pacific Northwest and Alaska

OTREC-RR-12-01

January 2012 



\title{
CLIMATE CHANGE IMPACT ASSESSMENT FOR SURFACE TRANSPORTATION IN THE PACIFIC NORTHWEST AND ALASKA
}

\author{
by
}

John MacArthur

Sustainable Transportation Program Manager/Oregon Transportation Research and Education Consortium

\author{
Dr. Philip Mote \\ Director, Oregon Climate Change Research \\ Institute/Oregon State University
}
Dr. Jason Ideker
Assistant Professor, School of Civil and Construction Engineering/Oregon State
University
Dr. Ming Lee
Assistant Professor, Department of Civil and Environmental Engineering/University
of Alaska, Fairbanks

for

\section{Region X Northwest Transportation Consortium} Alaska Department of Transportation \& Public Facilities Idaho Transportation Department Oregon Department of Transportation Washington Department of Transportation $\&$ University of Alaska Transportation Center National Institute for Advanced Transportation Technology Oregon Transportation Research and Education Consortium TransNow

Technical Monitor Carol Lee Roalkvam Policy Branch Manager, Environmental Services Office Washington State Department of Transportation

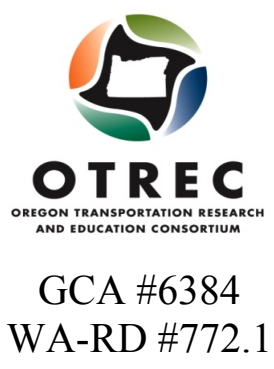

January 2012 

TECHNICAL REPORT STANDARD TITLE PAGE

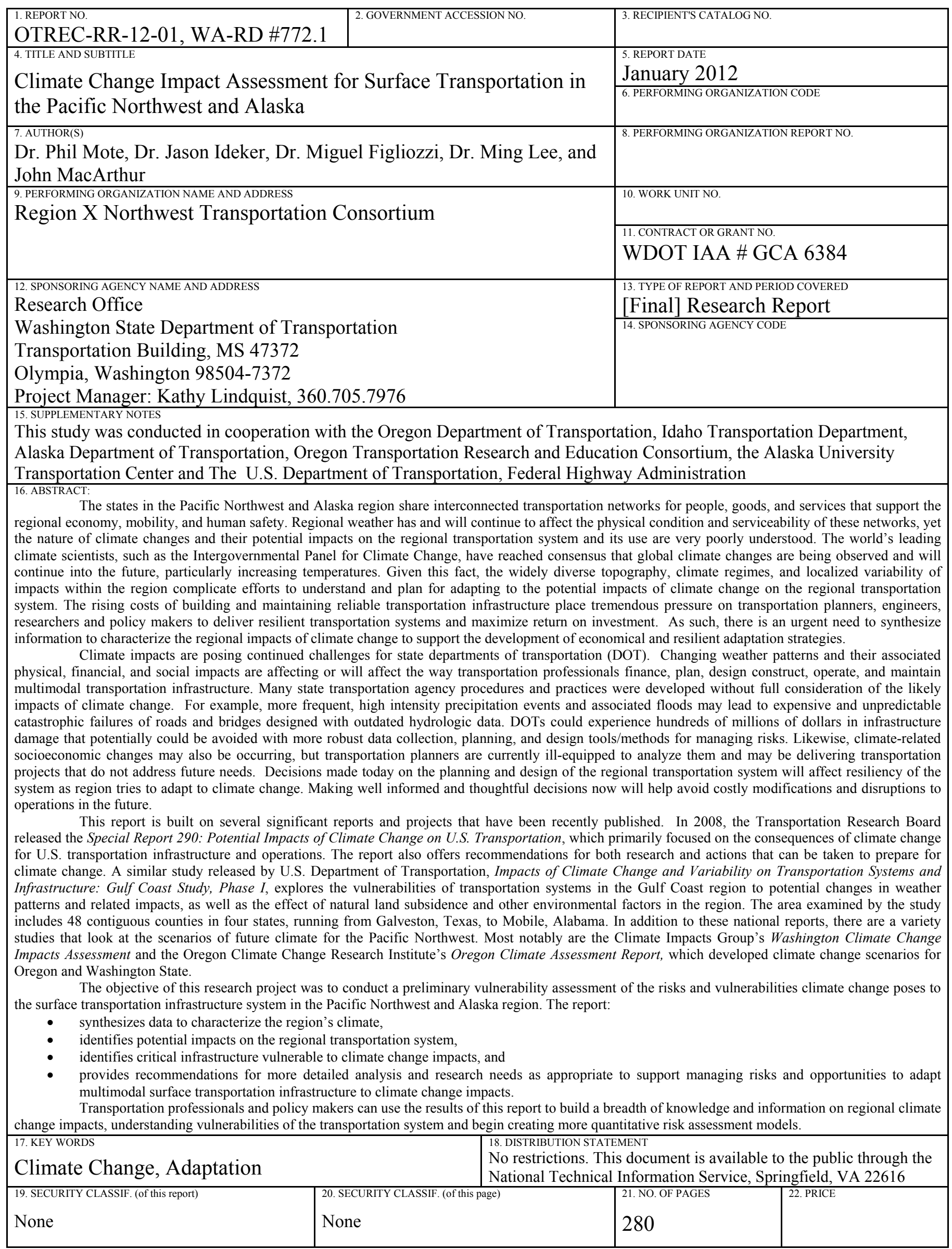




\section{ACKNOWLEDGMENTS}

The authors thank the Alaska University Transportation Center, OTREC (Oregon Transportation Research and Education Consortium), and Region X Transportation Consortium for providing the necessary financial support to carry out this research. Additional co-authors on the report are Darrin Sharp and Dan Brown (OCCRI), Dr. Ashley Haire and Lindsay Walker (Portland State University), and Trish Gitschlag and Thanh Phan (Oregon State University), all of whom put many hours into the content of this report.

A special thanks to the Technical Advisory Committee for the report:

- Clint Adler, Alaska DOT

- Ned Parrish, Idaho TD

- Rodney Stewart, ODOT

- Matthew Mabey, ODOT

- Carol Lee Roalkvam, WSDOT

- Kathy Lindquist, WSDOT (Research Manager)

The authors also acknowledge the collaboration and assistance provided by Marjorie Bradway and Elizabeth Hormann at the Oregon Department of Transportation and Peter Hurley and Peter Koonce at the Portland Bureau of Transportation. In addition, we acknowledge the survey collaboration provided by Dan Bower, Kelly McGourty, Carol Lee Roalkvam, Sandy Salisbury, and Nancy Boyd. Any error, mistake or omission related to this research paper is the sole responsibility of the authors.

\section{DISCLAIMER}

The contents of this report reflect the views of the authors, who are responsible for the facts and the accuracy of the data presented herein. The contents do not necessarily reflect the official views or policies of the Washington State Department of Transportation, Oregon Department of Transportation, Idaho Transportation Department, Alaska Department of Transportation and The U.S. Department of Transportation, Federal Highway Administration. This report does not constitute a standard, specification, or regulation. 


\section{Table of Contents}

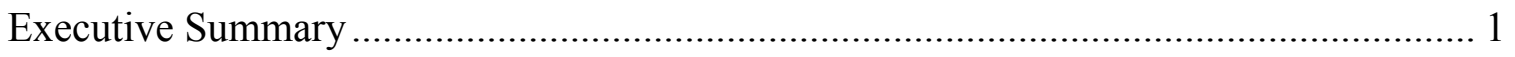

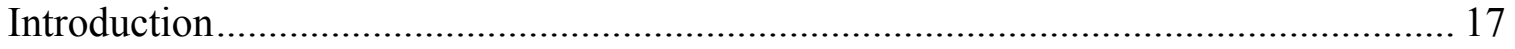

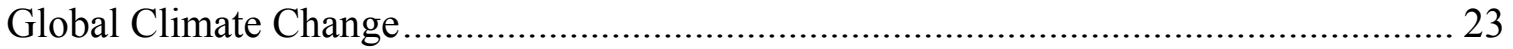

Regional and Subregional Climate Change Assessment in the Pacific Northwest and

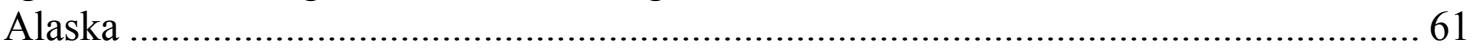

Impacts of Projected Climate Change on Surface Transportation in the Pacific

Northwest and Alaska

Assessing Climate Change Vulnerability on Surface Transport and Building an

Adaptation Response ....

Incorporating Adaptation into Current and Long-range Planning and Project

Development............................................................. 229

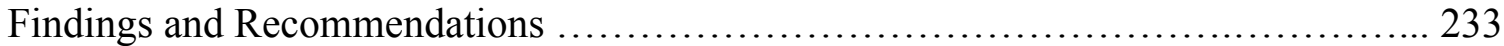

Appendix A Definitions and List of State Resources.............................. 243

Appendix B Portland, Oregon Case Study ........................................ 247

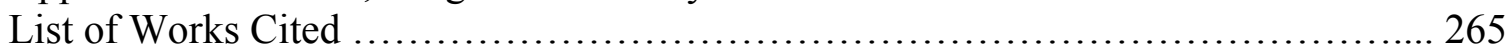




\section{EXECUTIVE SUMMARY}

Pacific Northwest states and Alaska share interconnected transportation networks for people, goods and services that support the regional economy, mobility and human safety. Regional weather has and will continue to affect the physical condition and serviceability of these networks, yet the nature of climate changes and their potential impacts on the regional transportation system and its use are very poorly understood. The world's leading climate scientists, such as the Intergovernmental Panel for Climate Change, have reached consensus that global climate changes are being observed and will continue into the future, particularly the increasing temperatures. Given this fact, the widely diverse topography, climate regimes, and localized variability of impacts within the region complicate efforts to understand and plan for adapting to the potential impacts of climate change on the regional transportation system. The rising costs of building and maintaining reliable transportation infrastructure place tremendous pressure on transportation planners, engineers, researchers and policymakers to deliver resilient transportation systems and maximize return on investment. As such, there is an urgent need to synthesize information to characterize the regional impacts of climate change to support the development of economical and resilient adaptation strategies.

Climate impacts are posing continued challenges for state departments of transportation (DOTs). Changing weather patterns and their associated physical, financial and social impacts are affecting or will affect the way transportation professionals finance, plan, design, construct, operate and maintain multimodal transportation infrastructure. Many state transportation agency procedures and practices were developed without full consideration of the likely impacts of climate change. For example, more 
frequent, high-intensity precipitation events and associated floods may lead to expensive and unpredictable catastrophic failures of roads and bridges designed with outdated hydrologic data. DOTs could experience hundreds of millions of dollars in infrastructure damage that potentially could be avoided with more robust data collection, planning and design tools/methods for managing risks. Likewise, climate-related socioeconomic changes may also be occurring, but transportation planners are currently ill-equipped to analyze them and may be delivering transportation projects that do not address future needs. Decisions made today on the planning and design of the regional transportation system will affect the system's resiliency as the region tries to adapt to climate change. Making well-informed and thoughtful decisions now will help avoid costly modifications and disruptions to operations in the future.

This report is built on several significant reports and projects that have been recently published. In 2008, the Transportation Research Board released the Special Report 290: Potential Impacts of Climate Change on U.S. Transportation, which primarily focused on the consequences of climate change for U.S. transportation infrastructure and operations. The report also offers recommendations for both research and actions that can be taken to prepare for climate change. A similar study released by the U.S. Department of Transportation, Impacts of Climate Change and Variability on Transportation Systems and Infrastructure: Gulf Coast Study, Phase I, explores the vulnerabilities of transportation systems in the Gulf Coast region to potential changes in weather patterns and related impacts, as well as the effect of natural land subsidence and other environmental factors in the region. The area examined by the study includes 48 contiguous counties in four states, running from Galveston, Texas, to Mobile, AL. In 
addition to these national reports, a variety of studies look at future climate scenarios for the Pacific Northwest. Most notably are the Climate Impacts Group's Washington Climate Change Impacts Assessment and the Oregon Climate Change Research Institute's Oregon Climate Assessment Report, which developed climate change scenarios for Oregon and Washington.

The objective of this research project was to conduct a preliminary assessment of the risks and vulnerabilities climate change poses to the surface transportation infrastructure system in the Pacific Northwest and Alaska. The report:

- synthesizes data to characterize the region's climate;

- identifies potential impacts on the regional transportation system;

- identifies critical infrastructure vulnerable to climate change impacts; and

- provides recommendations for more detailed analysis and research needs as appropriate to support managing risks and opportunities to adapt multimodal surface transportation infrastructure to climate change impacts.

Transportation professionals and policymakers can use the results of this report to build a breadth of knowledge and information on regional climate change impacts, understand vulnerabilities of the transportation system, and begin creating more quantitative risk-assessment models. 


\section{KEY FINDINGS}

\section{REGIONAL PROJECTIONS OF CLIMATE CHANGE}

The primary focus of this study was to develop the base case for potential climate change in the Pacific Northwest (PNW) and Alaska, and characterize the region's current conditions and trends. The research synthesized available information about the likely impact of climate change on:

- regional temperatures, including extreme hot days and heat waves

- arctic temperatures, permafrost and freeze/thaw events

- sea levels

- the intensity of precipitation events

The research team collected and analyzed data summarizing trends and projected changes in the Pacific Northwest and Alaska region, drawing on historic data, developed simulation model data and published literature.

\section{Increases in temperature over this century}

Average annual air temperatures will increase through the 21 st century. The amount of warming depends partly on the rate of greenhouse gas emissions. The Pacific Northwest (ID, OR and WA) is expected to experience an approximate $2-3^{\circ} \mathrm{C} / 3.6-5.4^{\circ} \mathrm{F}$ increase in average annual regional temperatures over the course of this century. Seasonal changes of climate are typically more relevant for decision makers and for studying impacts. Temperatures are projected to increase approximately $1.5-2.5^{\circ} \mathrm{C} / 2.7-4.5^{\circ} \mathrm{F}$ during summer months, and $3.5-7^{\circ} \mathrm{C} / 6.3-12.6^{\circ} \mathrm{F}$ during winter months. Less increase and more modest seasonal variation is expected in some regions, especially near the coast. 
Alaska is expected to experience greater temperature changes compared to the Pacific Northwest, with an average annual regional temperature increase of approximately $3.5-5^{\circ} \mathrm{C} / 6.3-9^{\circ} \mathrm{F}$. Temperatures are projected to increase approximately 2 $2.5^{\circ} \mathrm{C} / 3.6-4.5^{\circ} \mathrm{F}$ during summer months and $3.5-10^{\circ} \mathrm{C} / 6.3-18^{\circ} \mathrm{F}$ during winter months, with greater temperature increases occurring in the northernmost parts of Alaska due to a reduced period of snow cover. These temperatures will significantly affect the upper layer of permafrost and Arctic ice.

Additionally, the region will see an increase in extreme hot days and heat waves. It is highly likely that heat extremes and heat waves will continue to become more intense, longer lasting and more frequent in the region, but will significantly affect the area like other regions in the country.

\section{Increases in precipitation and extreme precipitation events}

Though trends in extreme daily precipitation over the 20th century have been ambiguous in the Pacific Northwest and Alaska, there is some indication that such events will increase in the 21 st century and will continue to become more frequent.

Average annual precipitation in the Pacific Northwest as a whole is projected to increase by up to 10 percent. During summer months, precipitation is expected to decrease approximately 5-15 percent, and increase during winter months approximately 30 percent. "Rain-on-snow" events are expected to increase, potentially causing extreme runoff and contributing to severe flooding along waterways. Average annual precipitation in Alaska is projected to increase approximately $10-15$ percent. Precipitation is expected 
to increase in both summer and winter seasons; approximately 10-20 percent during summer months, and 15-30 percent during winter months.

Spring snowpack in the Pacific Northwest for the 21th century is projected to decrease, and earlier melts may significantly shift seasonal stream-flow timing in snowmelt-dominated and transient (mixed rain and snow) watersheds. Snowmeltdominated watersheds will likely become transient, resulting in reduced peak spring stream flow, increased winter stream flow and reduced late summer flow. Transient basins will likely become rain-dominant as winter precipitation falls more as rain and less as snow. Watersheds that are rain-dominated will likely experience higher winter stream flow because of increases in average winter precipitation, but will experience relatively little change with respect to stream-flow timing.

\section{Rising sea levels}

The projected global range in sea level rise (SLR) is from $18 \mathrm{~cm} / 7.1$ in. to 59 $\mathrm{cm} / 23.2$ in. by 2100 , but the rise will not be geographically uniform. By the mid-21st century, the SLR rate will exceed vertical land movement on the Oregon and Washington coast. Submerged areas will experience erosion and flooding impacts. As a result of the limitations in regional modeling, it is difficult to accurately project SLR on a regional scale. Each site must be considered individually and the local factors added to or subtracted from the expected global SLR of $18-59 \mathrm{~cm} / 7-23$ in (or more) by 2100 . For this report, a possible range (very low, medium, very high) of SLR are presented for several areas on the Washington coast, for the years 2050 and 2100, ranging from a low of $12 \mathrm{~cm} /-4.7$ inches in the Olympic Peninsula to a high of $128 \mathrm{~cm} / 50.4$ inches in the Puget 
Sound. It should be noted that the "Very Low" and "Very High" scenarios are low probability.

\section{Regional scaling of climate projections}

Climate scientists have greater confidence in global or continental scale projections of changes in mean temperature and precipitation than in projections of regional or city-scale changes. As better data and models have been developed, climate scientists are beginning to project future climate conditions for regional subdomains. This project analyzed several subdomains within the PNW and Alaska to update previous modeling efforts and extend climate metrics beyond annual and seasonal temperature and precipitation to include data on temperature and precipitation extremes, including heat waves. North American Regional Climate Change Assessment Program (NARCCAP) is used as the source for climate model projections in this report. The NARCCAP suite of models consists of six Regional Climate Models (RCMs) and four Atmosphere-Ocean General Circulation Models (AOGCMs). This allows for 50 kilometers on a side grid cells for NARCCAP, as compared to the hundreds of kilometers on a side grid cells of the typical AOGCM. The results of the analysis are presented in the following tables: 


\section{Table A - Changes in Average Temperature and Precipitation}

\begin{tabular}{|c|c|c|}
\hline Subdomain & Change in Temperature & Change in Precipitation \\
\hline Coast & \multirow{5}{*}{$\begin{array}{l}\text { NARCCAP projections are broadly } \\
\text { consistent with FHWA and } \mathrm{CIG} \text {, with a } \\
\text { slightly greater than } 2{ }^{\circ} \mathrm{C} / 3.6^{\circ} \mathrm{F} \text { annual } \\
\text { warming by mid-century. As with the } \\
\text { FHWA and CIG projections, a } \\
\text { disproportionate amount (compared to } \\
\text { the other seasons) of this warming is } \\
\text { projected to occur in the summer. } \\
\text { The number of freeze/thaw cycles is } \\
\text { projected to decrease, on average. This } \\
\text { effect is most pronounced in the Coast } \\
\text { and Cascades subdomains. }\end{array}$} & \multirow{3}{*}{$\begin{array}{l}\text { NARCCAP projections are broadly } \\
\text { consistent with FHWA and CIG by } \\
\text { projecting a slight decrease in } \\
\text { precipitation annually. Spring and } \\
\text { summer are projected to be drier, with } \\
\text { fall slightly wetter and winter essentially } \\
\text { unchanged. }\end{array}$} \\
\hline & & \\
\hline Cascades & & \\
\hline Desert & & \multirow{2}{*}{$\begin{array}{l}\text { NARCCAP projections are broadly } \\
\text { consistent with FHWA and CIG by } \\
\text { projecting essentially no change in } \\
\text { annual precipitation. Winter and spring } \\
\text { are projected to be essentially } \\
\text { unchanged, while summer is projected } \\
\text { to be drier and fall wetter. }\end{array}$} \\
\hline Rockies & & \\
\hline Yukon Flats & $\begin{array}{l}\text { NARCCAP projects greater warming for } \\
\text { this subdomain than elsewhere. In } \\
\text { contrast to the PNW subdomains, a } \\
\text { disproportionate amount of the warming } \\
\text { is projected to be in the winter and } \\
\text { spring, while the summer is (relatively) } \\
\text { cooler. } \\
\text { A slight decrease in the average number } \\
\text { of freeze/thaw cycles is projected. }\end{array}$ & $\begin{array}{l}\text { Across the board, annually and } \\
\text { seasonally, NARCCAP projects this } \\
\text { subdomain to be wetter. Spring is } \\
\text { projected to see the greatest increase in } \\
\text { precipitation. The uncertainty in these } \\
\text { projections (measured by the spread of } \\
\text { the models) is relatively high. }\end{array}$ \\
\hline
\end{tabular}

Table B - Extreme Warm and Cold Days

\begin{tabular}{|c|c|c|}
\hline Subdomain & $\begin{array}{l}\text { Change in Number of } \\
\text { Extreme Warm Days }\end{array}$ & $\begin{array}{l}\text { Change in Number of } \\
\text { Extreme Cold Days }\end{array}$ \\
\hline Coast & \multirow{4}{*}{$\begin{array}{l}\text { NARCCAP projections suggest an increase } \\
\text { in the number of extreme warm } \\
\text { days/year. However, there is broad } \\
\text { disagreement among the models. For any } \\
\text { of these subdomains, projections run the } \\
\text { gamut from essentially no increase to an } \\
\text { additional } 20+\text { days/year. }\end{array}$} & \multirow{5}{*}{$\begin{array}{l}\text { NARCCAP projects a large decrease in } \\
\text { the number of extreme cold days/year } \\
\text { for all subdomains. The data suggests } \\
\text { that the Cascades subdomain may see } \\
\text { the largest decrease. However there is } \\
\text { some disagreement between models for } \\
\text { all subdomains. }\end{array}$} \\
\hline Cascades & & \\
\hline Desert & & \\
\hline Rockies & & \\
\hline Yukon Flats & $\begin{array}{l}\text { All the NARCCAP models are in } \\
\text { agreement in projecting no increase in } \\
\text { extreme warm days/year. It is unusual to } \\
\text { have even one extreme warm day } \\
\text { (historical or future)/year in this } \\
\text { subdomain. }\end{array}$ & \\
\hline
\end{tabular}




\section{Table C - Number of Heat Waves/Year and Duration of Heat Waves}

\begin{tabular}{|c|c|c|}
\hline Subdomain & Change in Number of Heat Waves/Year & Change in Duration of Heat Waves \\
\hline Coast & \multirow{4}{*}{$\begin{array}{l}\text { NARCCAP projections suggest an increase } \\
\text { in the number of heat waves/year. } \\
\text { However, the suggested increase is small, } \\
\text { and there is broad disagreement among } \\
\text { the models. In any case, the number of } \\
\text { heat waves/year, historical or future, is } \\
\text { small (low single digits) }\end{array}$} & \multirow{2}{*}{$\begin{array}{l}\text { NARCCAP projections suggest the } \\
\text { duration of heat waves will stay } \\
\text { essentially the same, or possible } \\
\text { shorten. There is broad disagreement } \\
\text { among the models. }\end{array}$} \\
\hline Cascades & & \\
\hline Desert & & \multirow{2}{*}{$\begin{array}{l}\text { NARCCAP projections suggest an } \\
\text { increase in the duration of heat waves. } \\
\text { Model disagreement is high. }\end{array}$} \\
\hline Rockies & & \\
\hline Yukon Flats & $\begin{array}{l}\text { All the NARCCAP models are in agreement } \\
\text { in projecting no increase in heat } \\
\text { waves/year. It is extremely unusual to have } \\
\text { even one heat wave (historical or } \\
\text { future)/year. }\end{array}$ & $\begin{array}{l}\text { Due to the rarity of heat waves in } \\
\text { Yukon Flats, no conclusions can be } \\
\text { drawn. }\end{array}$ \\
\hline
\end{tabular}

\section{Preliminary Vulnerability Assessment - Identification of Critical Infrastructure}

Adaptation planning generally includes three processes that fall under the umbrella of risk management: hazard identification, vulnerability analysis and risk assessment (see Figure A below). Hazard identification involves identifying the potential threats for a particular location and its infrastructure. In coastal locations, SLR, erosion and increased storm activity are known hazards. Vulnerability analysis involves identifying the susceptibility to loss or reduction in service from identified hazards. For example, identifying which roadways may be impacted by landslides and the relative importance of each segment within the system. Risk analysis involves estimating the likelihood of an event along with the magnitude of consequences of impacts. 


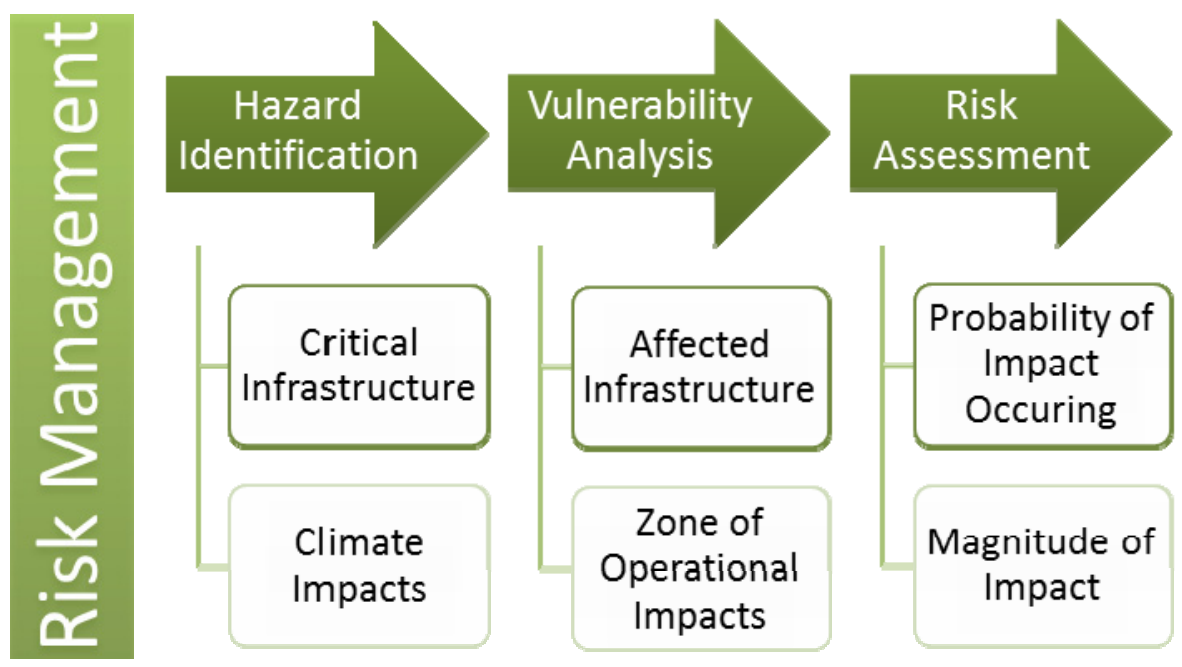

\section{Figure A - Risk Management Processes}

Based on the analysis of climate data and projections, the report characterizes potential impacts and hazards to regional infrastructure, and develops a description of how climate variability and change may affect existing transportation infrastructure and long-range plans for transportation systems in the region. This includes maintenance and design as well as operations and planning implications. The report summarizes potential impacts to regional infrastructure roadways, bridges, culverts, rail, water transport, airports and ports.

\section{Table D - Potential Regional Climate Change Impacts on Transport}

\begin{tabular}{|l|l|l|}
\hline Climate Change & \multicolumn{2}{l}{ Impact on Operations } \\
\hline $\begin{array}{l}\text { Increases in very hot days } \\
\text { and heat waves }\end{array}$ & $\begin{array}{l}\text { - Limited rail operating speeds } \\
\text { - Delays due to wildfire }\end{array}$ & $\begin{array}{l}\text { - Railroad track deformities } \\
\text { - Reduced pavement } \\
\text { performance and life, } \\
\text { increased maintenance }\end{array}$ \\
\hline $\begin{array}{l}\text { Increases in Arctic } \\
\text { temperatures }\end{array}$ & $\begin{array}{l}\text { - Shortened seasonal access to ice } \\
\text { roads } \\
\text { - Longer marine transport seasons and } \\
\text { new routes }\end{array}$ & $\begin{array}{l}\text { - Damage to roadway } \\
\text { integrity due to thawing of } \\
\text { permafrost }\end{array}$ \\
\hline Rising sea levels & $\begin{array}{l}\text { - Increased travel interruptions due to } \\
\text { more frequent flooding }\end{array}$ & $\begin{array}{l}\text { - Damage to coastal facilities } \\
\text { due to erosion and } \\
\text { inundation }\end{array}$ \\
\hline $\begin{array}{l}\text { Increases in intense } \\
\text { precipitation events }\end{array}$ & $\begin{array}{l}\text { - Increased travel delays and closures } \\
\text { caused by flooding and severe storms }\end{array}$ & $\begin{array}{l}\text { - Increased risk of landslide } \\
\text { and roadway washouts } \\
\text { - Bridge support scour }\end{array}$ \\
\hline Adapted from Special Report 290: Potential Impacts of Climate Change on U.S. Transportation. \\
\hline
\end{tabular}


The analysis presented in this report integrates this information and applies these variables into a conceptual framework to evaluate vulnerability of the regional system using geographic information systems (GIS). Two case studies are used to show how this framework could be applied using GIS. The first case study focuses on identifying critical roadway, rail and airport infrastructure in Alaska, Idaho, Oregon and Washington, and utilizing a conceptual model developed by the Federal Highway Administration (FHWA). The analysis specifically focuses on impacts from flooding, landslides, permafrost thawing and sea level rise. The second case study examines localized impacts to Portland, OR., using GIS to illustrate the impacts to major arterials, rail lines (passenger and freight), bicycle facilities (bicycle routes and multiple-use paths), bus routes, and streetcar/light rail (including planned improvements). These studies not only highlight the extent and location of various climate impacts to regional transportation systems, but illustrate the application of GIS as a tool for vulnerability assessments. Tables E-H present the miles of at-risk roadways and railroads for different climate impacts. 
Table E - At-risk Roadways \& Railroads for the 2100 "Very High" Sea Level Rise Scenario (Oregon and Washington)

\begin{tabular}{|l|c|}
\hline At-risk Roadways & Total Miles \\
\hline Urban-Principal-Arterial & 21.94 \\
\hline Urban-Other-Principal-Arterial & 1.25 \\
\hline Urban-Minor-Arterial & 9.51 \\
\hline Urban-Interstate & 10.23 \\
\hline Rural-Principal-Arterial & 114.96 \\
\hline Rural-Major-Collector & 27.69 \\
\hline Rural-Interstate & 0.21 \\
\hline Rural Other Principal Arterial & 6.88 \\
\hline Total & $\mathbf{1 9 2 . 6 9}$ \\
\hline At-risk Railroads & Total Miles \\
\hline Passenger & 0.1 \\
\hline Freight & 0.89 \\
\hline Total & $\mathbf{0 . 9 9}$ \\
\hline
\end{tabular}

Table F - Highways and Railroads in FEMA Floodplains (Idaho, Oregon and Washington)

\begin{tabular}{|c|c|c|c|c|c|}
\hline State & Facility & $\begin{array}{l}\text { Miles in } \\
100 \text { Year } \\
\text { Floodplains }\end{array}$ & $\begin{array}{l}\text { Miles in } \\
500 \text { Year } \\
\text { Floodplains }\end{array}$ & $\begin{array}{c}\text { Miles in } \\
\text { "Undetermined, } \\
\text { but possible" zones }\end{array}$ & $\begin{array}{l}\text { Total } \\
\text { Miles }\end{array}$ \\
\hline \multirow[t]{2}{*}{ WA } & Highways & 876 & 125 & 421 & 1422 \\
\hline & Railroads & 772 & 70 & 52 & 894 \\
\hline \multirow[t]{2}{*}{ OR } & Highways & 750 & 108 & 852 & 1710 \\
\hline & Railroads & 300 & 52 & 212 & 595 \\
\hline \multirow[t]{2}{*}{ ID } & Highways & 113 & 26 & 146 & 286 \\
\hline & Railroads & 88 & 10 & 27 & 125 \\
\hline Total & & 2,899 & 391 & 1,710 & 5,032 \\
\hline
\end{tabular}


Table G - Roadways and Railroads Subject to Landslide Damages (Idaho, Oregon and Washington)

\begin{tabular}{|lccc|}
\hline Functional Classes & $\begin{array}{c}\text { Oregon } \\
\text { (miles) }\end{array}$ & $\begin{array}{c}\text { Washington } \\
\text { (miles) }\end{array}$ & $\begin{array}{c}\text { Idaho } \\
\text { (miles) }\end{array}$ \\
\hline Highway Usage & 479 & 299 & 172 \\
\hline Rural Interstate & 592 & 531 & - \\
\hline Rural Major Collector & 768 & 715 & 791 \\
\hline Rural Minor Arterial & 18 & - & - \\
\hline Rural Minor Collector & 1,235 & 785 & 1,896 \\
\hline Other Rural Principal Arterial & 13 & - & - \\
\hline Urban Collector & 272 & 260 & 21 \\
\hline Urban Interstate & 75 & 110 & - \\
\hline Urban Minor Arterial & & & - \\
\hline $\begin{array}{l}\text { Other Urban Freeways and } \\
\text { Expressways }\end{array}$ & 95 & 146 & 21 \\
\hline Other Urban Principal Arterial & 411 & 225 & $\mathbf{2 , 9 0 5}$ \\
\hline Highway Total & $\mathbf{3 , 9 5 7}$ & $\mathbf{3 , 0 6 9}$ & 120 \\
\hline Railroads Usage & & & 853 \\
\hline Passenger & 309 & 447 & $\mathbf{9 7 3}$ \\
\hline Non Passenger & 1,200 & 935 & \\
\hline Railroad Total & $\mathbf{1 , 5 0 9}$ & $\mathbf{1 , 3 8 2}$ & \\
\hline
\end{tabular}

Table H - Mileage Distribution of Highways in High-Melting Risk Area (Discontinuous Permafrost with Thawing Index $>$ 3000)

\begin{tabular}{|l|c|}
\hline Functional Class & Total Miles \\
\hline Rural Interstate & 393 \\
\hline Rural Minor Arterial & 506 \\
\hline Rural Principal Arterial & 8 \\
\hline State Route & 225 \\
\hline Urban Interstate & 14 \\
\hline Urban Principal Arterial & 16 \\
\hline Total & $\mathbf{1 , 1 6 3}$ \\
\hline
\end{tabular}

\section{RECOMMENDATIONS}

Resources such as high-resolution climate change models and transportation asset management systems (TAMs) offer methods to incorporate climate change adaptation into current and long-range planning processes. Specifically, this project shows that the use of GIS is promising for vulnerability assessments. Below follows some of the research needs for future vulnerability assessments: 
- GIS remains a critical tool for climate change adaptation research at regional and local levels. Additional data needs to be aggregated and added into the model used for this report; specifically more state-level data could be integrated into the GIS platform. As more information is integrated - including travel volumes, historic maintenance records, and enriched and updated flood maps - the tool's power will be greatly enhanced.

- Compounding uncertainties within the risk management stages are a significant concern. Each stage within the climate change risk management framework contains uncertainties. There are uncertainties associated with inputs, assumptions and results of climate models, magnitude of vulnerabilities, and with predicting the probability of events occurring. One of the biggest challenges for planners, designers and decision makers is to understand the degrees of uncertainty throughout the adaptation evaluation decision process. These uncertainties will be better understood with better data and the development and refinement of models, thus enriching the decision-making process.

\section{- Planning and engineering staffs require guidance for developing} conservative yet adequate adaptation response alternatives. As a result of the compounding uncertainties with risk management, professional staff lack guidance in order to design systems and infrastructure that are adequate to withstand future climate impacts, yet are conservative in cost and not "overengineered." Agencies will need to evaluate how to adjust standard practices and overcome institutional and discipline inertia that slow change. Agencies 
should spend time developing institutional knowledge and dialogue that will foster the discussions and improve decision making.

- Expand NARCCAP Coverage. Alaska is an exceptionally climatologically diverse locale. This leads to significant challenges when considering the impacts climate change may have on the state's transportation infrastructure. Unfortunately, NARCCAP coverage for Alaska is limited. However, an approach similar to that employed here for NARCCAP (using different data sets) may be useful in evaluating regional climate change effects within Alaska.

- Continued research to improve GCMs and RCMs is needed. Improving climate models requires the continued development and evaluation of both GCMs and RCMs.

- While models continue to improve, guidelines should be used in climate science studies to provide consistently produced data. Overall, planning entities need useful climate projections that allow them to adequately plan for infrastructure demand and the needed resources.

- More research on road vulnerability to thermal conditions is needed. Thresholds for the extreme heat events and the heat wave metrics examined in this study need to be revisited. Definitions for "extreme temperatures" and "heat wave" need to be developed that are based on material performance, and operational and construction practices. Once these definitions are more developed, they can be incorporated into additional analysis to help evaluate the impacts of extreme events. Additionally, research should be conducted on the vulnerabilities of roads to changes in thermal conditions and the significance of 
extreme weather events and variability, including freeze and thaw effects on pavements. There is much to be learned from other areas of the country that already are experiencing temperatures the region may see in the future. Best practices, tools, standards and criteria should be researched and transferred to the region.

- Site-specific research is needed to gauge impacts on coastal infrastructure. The research should focus on impacts to specific ports and marinas from elements such as sea level rise and storm surge. Additional research should focus on the impacts, including regional economic impacts, of the reduction of winter Arctic ice and the possible increases of shipping routes in the Northwest Passage.

- Expand climate impacts analysis. Additional impacts which were not examined in detail - such as extreme rainfall events, coastal storm surge, fog and high winds - warrant further research and evaluation. The region has the potential to experience more frequent and higher magnitude extreme rainfall events. These not only can cause flash flooding and landslides but unsafe conditions on the roadways. In addition, the region will potentially experience more fog, high winds, and ice/sleet/snow events. All of these cause unsafe conditions to the traveling public and freight community. 


\section{INTRODUCTION}

In early January 2009, a severe winter storm hit the Pacific Northwest (PNW). Heavy snow, followed by abundant, warm rain led to extreme flooding and destructive landslides throughout the state of Washington, forcing emergency closures of multiple state and local highway routes, including Interstate 5 and Interstate 90 , and the interruption of freight and passenger rail service. The economic consequences from storm effects on the transportation system, including freight disruptions and infrastructure damage, were estimated in the tens of millions of dollars. Governor Christine Gregoire eventually requested disaster relief from the federal government (Gregoire, 2009). However, this weather event was not an isolated case. During the previous winter, a similar storm created crippling conditions in the same areas. The costs of freight delays alone were estimated around $\$ 75$ million for the winter storm and flooding that closed Interstate 5 and Interstate 90 in the winter of 2007-08 (WSDOT, 2008).

While we must be careful to distinguish individual extreme weather events, such as those above, from long-term trends in climate, consensus in the scientific community projects an increased frequency and intensity of major storms, temperature increases, and changes in seasonal precipitation as a very likely outcome of global climate change. Patterns that today are considered "extreme" may instead become a new normal. This is a potentially very costly problem as our existing surface transportation system has been

designed and constructed based upon historical climate trends. Assumptions that have been used historically to design facilities and respond to weather-related "emergencies" may no longer work. 
A transportation system built without planning for changing climate will likely experience a variety of costly impacts in terms of damage and traveler delay. Among these impacts are inundation of coastal roads from SLR; erosion of roadways and bridge supports from heavy precipitation and storms; increased road and rail maintenance due to flooding and temperature extremes; and travel delays due to weather events and more widespread wildfires.

As a major source of greenhouse gas (GHG) emissions (28 percent nationally), transportation was one of the early sectors to begin responding to the climate change threat, primarily through efforts to account for and reduce the amount of GHGs released into the atmosphere (Center for Transportation and the Environment, 2008). Strategies involve a wide range of activities, including improvements in vehicle and fuel technologies, and land use planning and transportation operation improvements that reduce vehicle miles travelled and increase the overall efficiency of travel (Table 1). These activities are collectively referred to as climate mitigation (Cambridge Systematics, 2009). Recent studies indicate that climate change planning efforts conducted by governments have thus far overwhelmingly focused on mitigation strategies to reduce GHGs, while relatively few are working towards climate adaptation (Wheeler, 2008).

Table 1 - Climate Change Mitigation in Transportation

\begin{tabular}{|c|c|}
\hline Mitigation & Example \\
\hline Improvements in vehicle and fuel technologies & $\begin{array}{l}\text { Electric and hybrid-electric vehicles, } \\
\text { biofuels }\end{array}$ \\
\hline $\begin{array}{l}\text { Land use planning that reduces vehicle miles } \\
\text { travelled }\end{array}$ & Transit-oriented development \\
\hline $\begin{array}{l}\text { Operational improvements that increase the overall } \\
\text { efficiency of travel }\end{array}$ & Adaptive traffic systems \\
\hline
\end{tabular}


Climate change mitigation is indeed an important goal since it may reduce the magnitude of future climate change and possibly help to avoid or delay the worst potential impacts of climate change. However, there is growing recognition that GHGs already released into the atmosphere have caused measurable changes in the climate and will continue to warm the planet for several decades. Regardless, even in the highly unlikely circumstance that all GHG emissions were immediately halted worldwide, we would still be committed to some climate changes that can affect surface transportation. Thus, while we continue to mitigate climate change, there is a growing interest across sectors to begin adapting to the changing and projected climate in order to moderate or avoid damages and delays in transportation.

Climate change adaptation includes actions taken to reduce the vulnerability of natural and human systems to climate change effects, and to capitalize on any opportunities presented by climate change. Adaptation strategies can be either reactive (addressing existing risks) or proactive (addressing anticipated future risks), and can be addressed through technological, policy-based, behavioral, and/or managerial actions (Table 2) (McNeil, 2009).

Table 2 - Approaches to Climate Change Adaptation

\begin{tabular}{|ll|}
\hline Approach & Example \\
\hline Technological/Investment & $\begin{array}{l}\text { Enhanced monitoring or additional construction } \\
\text { improvements of infrastructure such as a sea wall \& slope } \\
\text { stabilization }\end{array}$ \\
\hline Policy-based & $\begin{array}{l}\text { Incorporating climate change projections into project } \\
\text { planning processes }\end{array}$ \\
\hline Behavioral & Restricting road access \\
\hline Managerial & $\begin{array}{l}\text { A change in management of roadside vegetation to } \\
\text { reduce wildfire and/or landslide risk }\end{array}$ \\
\hline
\end{tabular}


There are many challenges to adaptation, including institutional barriers, lack of localized data, forecast uncertainties, and the difficulty of selecting the "best" alternative among a variety of adaptation alternatives considering these uncertainties. In contrast to climate change mitigation, which has received much of the focus by policymakers and the public alike, climate change adaptation is a fledgling field still relatively unknown to many (Walker et al., 2010). This creates institutional challenges (such as obtaining adequate funding for adaptation work) and limits public support for adaptation. However, mitigation and adaptation are complementary practices. Successful mitigation will likely reduce the extent of adaptation required in the future, and potentially "buy time" for communities to implement adaptation strategies. Due to this relationship between mitigation and adaptation, mitigation has been referred to as the "number one preparedness strategy" (Climate Impacts Group, 2007). However, adaptation is a necessary approach to identify present and future system vulnerability, build resiliency in the existing and future system, and reduce risk and cost.

While GHGs sourced from transportation can be fairly well accounted for and estimated under a variety of policy scenarios, adaptation requires dealing with multiple levels of uncertainty. There are several assumptions involved in developing climate models and scaling these models to regional and local levels. Variation among the results of these models can leave key projections undetermined. From this, additional uncertainty lies in translating the available model projections, such as changes in temperature or precipitation, into local impacts upon transportation infrastructure or operations. Furthermore, once climate projections and impacts have been estimated, additional uncertainty lies in choosing among a variety of adaptation responses. Planners 
and engineers want adaptation responses that balance fiscally conservative approaches with adequate protection. Lastly, there is the challenge of planning while climate projections continue to be updated, an activity requiring an often resource-intensive, iterative planning process.

While these challenges are indeed substantial, considering the impacts to transportation and other systems, a "wait-and-see" approach may not be prudent and can end up being very costly in the long run. Thus, scientists, engineers and planners must proceed with the best data and assumptions available, and attempt to approach adaptation planning for climate change in ways that are flexible enough to accommodate working with multiple unknowns and moving targets.

Utilizing the latest research, this report details and, when possible, addresses these issues by answering the following questions:

- How is the climate in the PNW region and Alaska expected to change over the next century?

- How will the impacts of climate change on surface transportation vary throughout the PNW region and Alaska?

-What strategies are agencies using to plan for and adapt to climate change, and how might they be integrated into existing planning, design and construction efforts?

- What areas require further research and what institutional challenges need to be addressed?

In the following sections, an overview of climate change in the PNW and Alaska is provided based upon existing climate modeling efforts. Next, results of new climate projections conducted by Oregon State University's Oregon Climate Change Research 
Institute at a sub-regional level are presented. Next, a discussion of likely surface transportation impacts by mode is presented with details for impacts that occur subregionally, when available. Following this, summaries of adaptation planning efforts, including discussion of vulnerability and risk assessments, are delivered along with recommendations for incorporating these methods into planning efforts in the PNW and Alaska. Lastly, a discussion of summary topics requiring focus and further research is described.

This report is intended for transportation planners, engineers and other agency decision makers. When discussing climate change, it is helpful to clarify terminology commonly used. Therefore, a listing a key terms and their definition has been provided in Appendix A. 


\section{GLOBAL CLIMATE CHANGE}

The global climate is constantly changing and clearly has been throughout earth's history. Natural drivers such as solar activity, the earth's orbit and volcanic activity are all processes that have affected the climate for millennia. However, in the past few centuries, anthropogenic (caused by human activity) drivers have entered the equation through the release of greenhouse gases into the atmosphere. Today, there is consensus among the world's leading climate scientists (as represented by the Intergovernmental Panel on Climate Change (IPCC), the U.S. National Academy of Science, the American Geophysical Union, and many other professional association of scientists) that "most of the observed increase in global average temperatures since the mid- $20^{\text {th }}$ century is very likely due to the observed increase in anthropogenic greenhouse gas (GHG) concentrations (IPCC, 2007)." Continued unchecked, this increase in global temperatures will have significant consequences on both natural and manmade systems.

In 1990 the IPCC, a leading international body for the study of climate change established by the United Nations Environmental Programme (UNEP) and the World Meteorological Organization (WMO), released its first Assessment Report. This document, produced and reviewed by climate experts, compiled scientific evidence of a changing climate as a result of human actions, provided early models depicting projected global climate scenarios, and described some of the impacts likely to occur on natural and man-made systems as a result of a changing climate. This groundbreaking report introduced climate change to the general public and established climate change as a topic of importance to governments worldwide. 
Since 1990 the IPCC, along with a variety of other governmental and nongovernmental organizations, have produced refined global and regional models to better explore projected climate scenarios and their potential consequences (Figure 1). Numerous studies have closely examined methods to account for and eliminate or reduce GHGs and, in some cases, begin to prepare for unavoidable impacts as a result of past and continued release of climate change gases into the atmosphere. Lacking a comprehensive national climate action plan, many of these planning efforts, including regional-scale modeling, have occurred at the regional and local level.

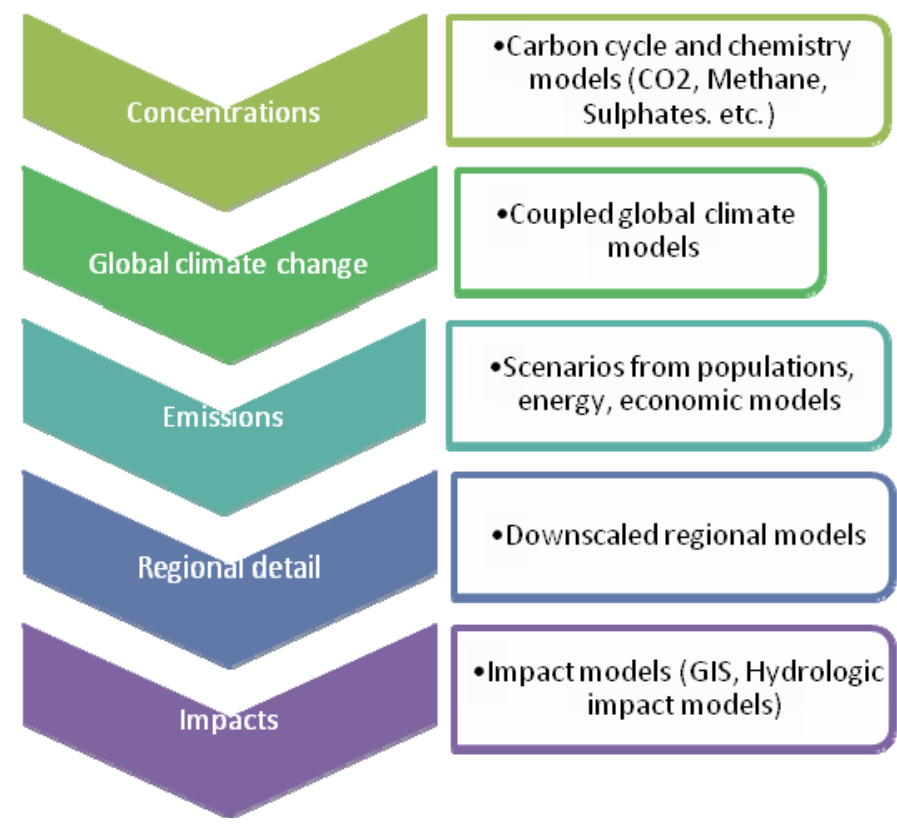

Figure 1 - Predicting impacts of climate change (Adapted from Met Office, http://www.metoffice.gov.ak)

\section{CLIMATE MODELING: MODEL COMPOSITION}

A Global Climate Model (GCM) simulates the physical processes that govern the earth's climate. According to the United States Global Change Research Program (USGCRP), most modern, computer-based climate models include "representations of 
the oceans, atmosphere, cryosphere and land surface, and their interactions" which, in addition to inputs for natural and anthropogenic emissions, yield a projected climate. These models project changes in the "frequency and characteristics of weather phenomena (such as droughts and hurricanes) and average seasonal weather patterns" (USGCRP, 2011).

\section{CLIMATE MODELING: MODEL UNCERTAINTY}

All climate models come with some level of uncertainty in how well they will accurately represent future climate. Uncertainties arise from three sources: the internal variability of the climate system; model (or response) uncertainty; and emissions scenario uncertainty (Hawkins and Sutton, 2009).

Internal variability is defined as the natural climatic fluctuations that occur in the climate system in the absence of any radiative forcing (such as the forcing GHGs provide). In other words, internal variability is the variability in the climate in the absence of any anthropogenic GHGs. This variability has the potential to reverse (for time periods of up to a decade) any long-term trends in the climate system (Hawkins and Sutton, 2009). Model uncertainty refers to the different response that models may give to the same forcings. This is due to differences in the internal algorithms (such as climate system feedbacks) that the models use. Another source of model uncertainty is the approximations models used to represent the physical world. Lastly, emissions uncertainty refers to the unknown trajectory for the emissions of GHGs in the coming years. Depending on societal action (or inaction), the amount of GHGs emitted in the 21 st century could vary considerably. 
In terms of relative importance, short-term (to approximately 2050) climate projection uncertainty is dominated by model uncertainty and internal variability. The smaller the spatial scale involved in a particular projection, the larger a role internal variability assumes. Beyond about the middle of the $21^{\text {st }}$ century, emissions uncertainty takes on a much more significant role. With these longer timescales (i.e., several decades and more), the relative importance of internal variability is greatly reduced.

In an effort to better communicate and understand the uncertainty inherent in estimating future emissions of GHGs, a set of "emissions scenarios" has been developed by the IPCC (see Emission Scenarios text box below). Scenarios are alternative futures as to how future GHG emissions (and other factors that affect climate change) might develop. The scenarios attempt to cover a variety of developmental and societal action/inaction activities related to GHGs. These alternative futures are often referred to as "storylines." The storylines include many factors such as population growth, energy use and efficiency, and land use change. 


\section{Emission Scenarios}

Future greenhouse gas emissions will be the product of complicated dynamic systems driven largely by socio-economic development and technological advances. The magnitude and rate of greenhouse gas emissions is therefore highly uncertain. Each emission scenario is a plausible emissions future. They are used to analyze how different driving forces may influence future emission outcomes and to assess the associated uncertainties. Emission scenarios provide a range of potential forcings on the climate system that can be simulated to assess potential impacts as well as mitigation and adaptation strategies. The probability that any single emissions path will occur exactly as described is uncertain.

There are several commonly described emissions scenarios, all falling into emissions families or storylines. Each attempts to represent a combination of plausible human adaptation and mitigation responses. The scenarios are described in the IPCC Special Report: Emission Scenarios, 2007.

- The A1 scenario family describes a future world of rapid economic growth, global population that peaks in mid-century and declines thereafter, and the rapid introduction of new and more efficient technologies. The convergence among regions, increased cultural and social interactions, and a substantial reduction in regional differences in per capita income are key themes. The A1 scenario family describes alternative directions of technological change in the energy system. The three A1 groups emphasize different energy technologies: fossil intensive (A1FI), non-fossil energy sources (A1T), or a balance across all sources (A1B).

- The A2 scenario family describes a very heterogeneous world. Regional self-reliance and the preservation of local and national identities are key themes. Populations are simulated as continuing to increase. Economic development and technological change are more fragmented and slower than in other storylines.

- The B1 scenario describes a convergent world with the same global population that peaks in midcentury and declines thereafter, as in the A1 storyline, but with rapid changes in economic structures toward a service and information economy, with reductions in material intensity, and the introduction of clean and resource-efficient technologies. Emphasis is placed on global solutions to economic, social, and environmental sustainability.

- The B2 scenario describes a world in which the emphasis is on local solutions to economic, social and environmental sustainability. The population increases at a rate lower than A2. Economic development is intermediate. Technological change is less rapid and more diverse than in the B1 and A1 storylines. The scenario is focused on environmental protection and social equity at local and regional levels.

- Six alternative IPCC scenarios (IS92a to f) were published in the 1992 Supplementary Report to the IPCC Assessment. These scenarios made a wide array of assumptions on how future greenhouse gas emissions might evolve in the absence of climate policies beyond those already adopted. IS92a was widely adopted as a standard scenario for use in impact assessments. Population was assumed to increase through 2100 and greenhouse gas emissions were assumed to be largely unaffected by public policy.

It will be many years before the greenhouse gas concentrations projected by the scenarios differ enough to appropriately gauge which scenario anthropogenic emissions have followed. The A1B and A2 emission scenarios are, however, generally regarded as the best reflection of current rates of greenhouse gas emissions that have received significant scientific scrutiny. These scenarios are detailed in the Special Report on Emissions Scenarios (SRES) at http://www.grida.no/publications/other/ipcc sr/. 


\section{Emission Scenarios}

(a) $\mathrm{CO}_{2}$ emissions

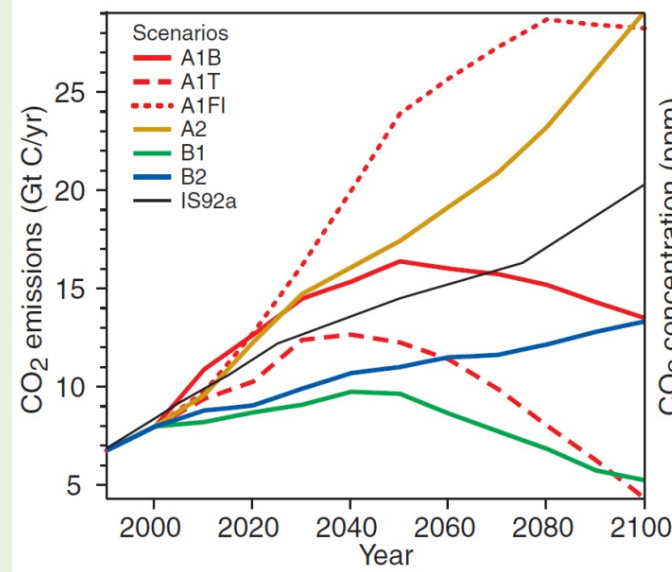

(b) $\mathrm{CO}_{2}$ concentrations

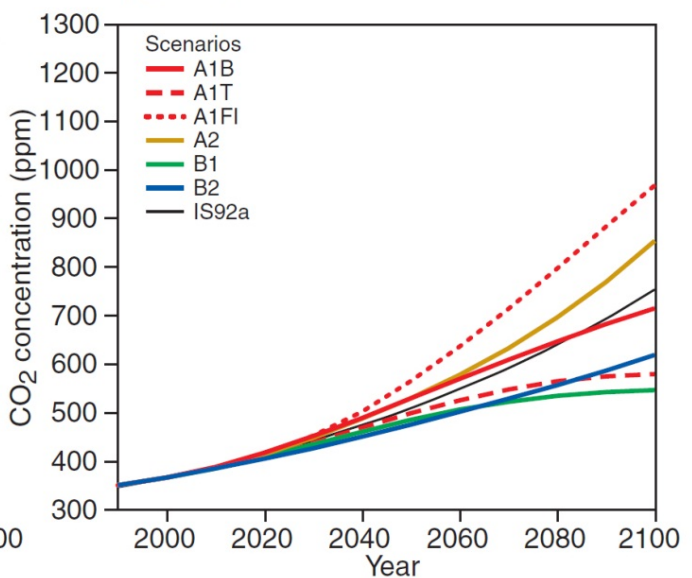

Comparison of carbon dioxide emissions (a) and concentrations (b) projected through 2100 for several emission scenarios. (From supplemental material to the IPCC Fourth Assessment Report, 2007.)

The two scenarios labeled A1B and A2 in the "Emissions Scenarios" text box above are often chosen as "marker" scenarios and are frequently used for developing future potential realizations of climate change. The A1B and A2 scenarios are somewhat comparable in terms of projected future climate change (i.e., warming), but the A2 scenario is the "warmer" of the two by a slight margin (IPCC, 2007). A1B is colloquially referred to as a "balanced" emission scenario, reflecting some potential reductions in fossil-fuel dependence. A2 is colloquially referred to as the "business-as-usual" scenario, reflecting fossil fuel usage much as it is today, yet adjusted for potential socioeconomic changes and increase in the global population.

Given the above, it is best to think of model results as "projections of possible climate realizations" rather than "predictions." There is a subtle difference: A climate prediction is a most-likely description of the climate in the future; climate projections describe the climate of the future based on a number of assumptions (e.g., societal and 
technology trends) that may or may not come to fruition. It is unwise to rely on one climate scenario as the "best" or "most accurate" when addressing impacts and adaptation issues.

An accepted approach to representing the uncertainty inherent in climate projections is to communicate the "ensemble mean" and/or the range of results produced by the ensemble of models. Of course, to employ this approach an ensemble of two or more models must be used. The range and ensemble mean approach is used throughout this report.

According to the IPCC, model uncertainties can be both structural and valuebased. Structural uncertainties are those that arise from an incomplete understanding of the processes that control particular variables. Value uncertainties are those that result from "incomplete determination of values," such as inaccurate data. Climate modelers generally address uncertainties by assigning standard levels of confidence that a model is correct as well as standard levels of probability for the likelihood that certain projected outcomes/impacts will occur (IPCC, 2007).

In reports such as the IPCC's, uncertainties are further addressed through extensive review and evaluation by climate experts, as well as verification of how well a particular model has predicted climate historically, and corroboration by similar findings among multiple independent models. The 2007 IPCC Physical Science Basis report states:

"There is considerable confidence that climate models provide credible quantitative estimates of future climate change, particularly at continental scales and above. This confidence comes from the foundation of the models in accepted physical principles and from their ability to reproduce observed features of current climate and past climate changes. Confidence 
in model estimates is higher for some climate variables (e.g., temperature) than for others (e.g., precipitation). Over several decades of development, models have consistently provided a robust and unambiguous picture of significant climate warming in response to increasing greenhouse gases (IPCC, 2007)."

While some uncertainties have been largely minimized (but not eliminated) in modern climate models, further uncertainties arise when attempting to translate climate model results to impact assessment, such as estimating the impact that a given percentage increase in annual or seasonal precipitation is likely to have on local hydrology and the likelihood of flooding in a particular location as a result. However, the uncertainties inherent in both developing climate models and in assessing impacts on individual systems do not justify inaction. Rather, it calls for continued refinement of regional models and development of climate change planning strategies that can accommodate and adapt to uncertainty.

\section{GLOBAL CLIMATE MODELS AND DOWNSCALING}

A Global Climate Model (GCM) consists of equations that attempt to approximate the physical process that govern the earth's climate. GCMs model the atmosphere, oceans, land surface and sea ice, indicating large-scale changes in global temperature, precipitation and sea level rise (SLR). Because of the technological limitations in running these complex simulations, GCMs divide the world into grid cells that are typically 100 to a few hundred kilometers across. While GCMs are effective at simulating processes over large geographic areas and longtime scales, the large grids used are unable to resolve many factors of climate on smaller scales, such as the effects 
of local geographic features. Instead, GCMs model these regional features with simplified processes. This leads to greater uncertainty in some climate attributes than others. Figure 2 highlights that the relative uncertainties in observed and projected precipitation totals for the Pacific Northwest are greater than uncertainties in average temperatures at GCM resolutions.
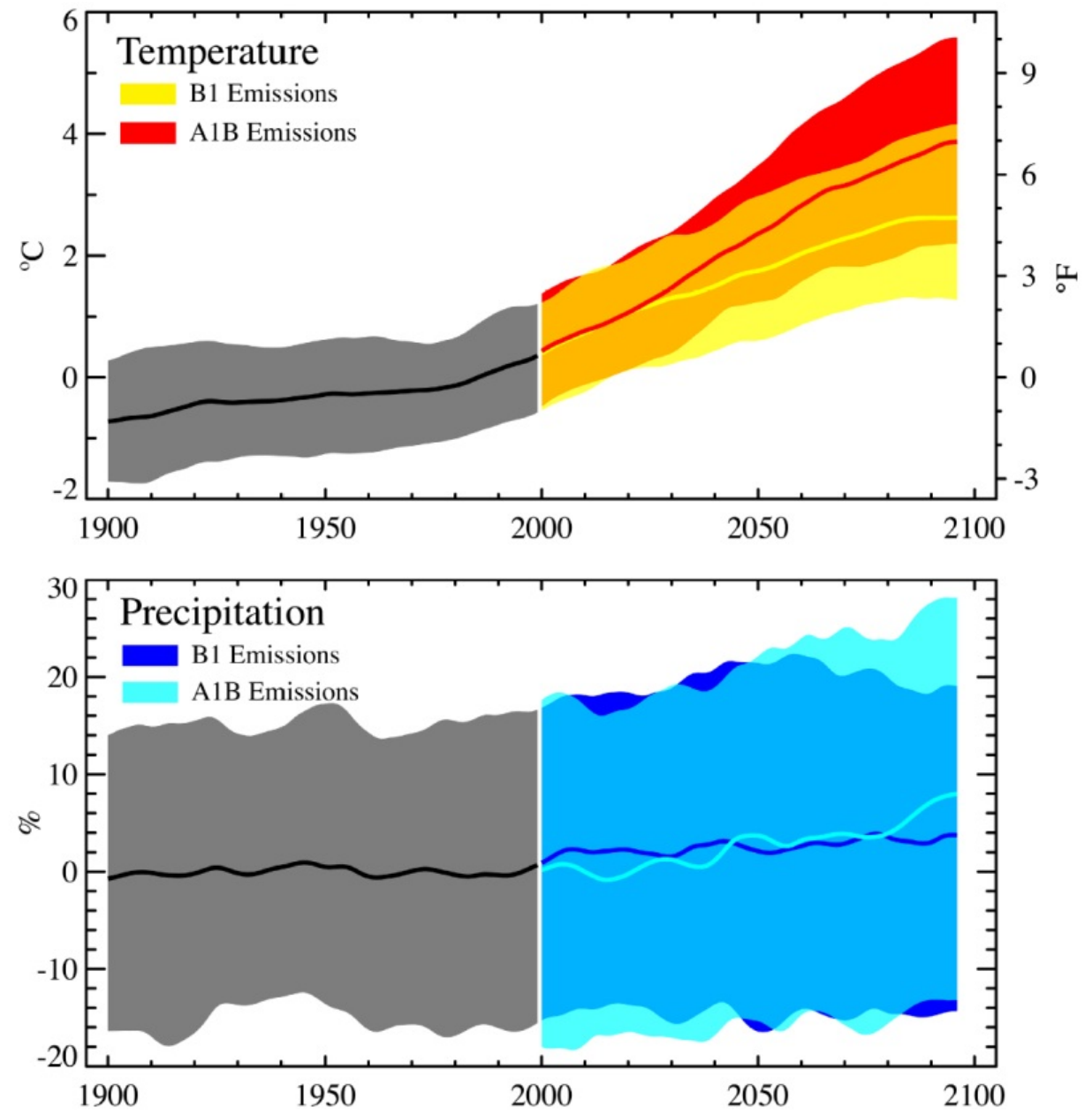

Figure 2 - Regionally averaged temperature (top) and precipitation (bottom) for an emission scenario in which fossil fuel use is limited (B1), and an emission scenario in which fossil fuel use is balanced with alternative energy sources (A1B) simulations for the PNW, relative to the 1970-1999 mean. The signal-to-noise ratio in precipitation is much larger relative the signal-to-noise ratio in temperature (Mote and Salathe, 2010.) For a more detailed description of these and other common emission scenarios, see the above inset text, Emission Scenarios. 
Although the resolution of GCMs continues to improve, their coarse resolution still requires additional modeling to obtain high-resolution regional projections. Consequently, researchers have developed methods to relate global-scale climate features to a smaller, regional scale in order to better understand likely changes in temperature and precipitation at particular locations of interest. This process, known as "downscaling," increases the resolution of GCM data to produce more locally relevant data.

Downscaling simulates local climate processes that are not included in the GCMs. There are two types of downscaling: statistical and dynamical. Statistical downscaling models use statistical relationships of global climate simulations to local climate observations, and assume these relationships will remain unchanged for future climate projections. Dynamical downscaling employs regional climate models (RCMs). Like GCMs, RCMs simulate the fundamental mechanics of the earth's system, but only cover a particular portion of the world. This allows the models to be run at higher resolution and provides greater detail of the effects of topography and local weather patterns on climate.

RCMs can be embedded into GCMs. In the cases discussed in this document, the RCM is run for the specific region while the GCM simulates large-scale climate and exchanges information at the boundaries of the region in question. In other words, the GCM supplies input at the boundaries of the RCM. The difference in the resolution between a typical GCM and a typical RCM is shown in Figure 3. 


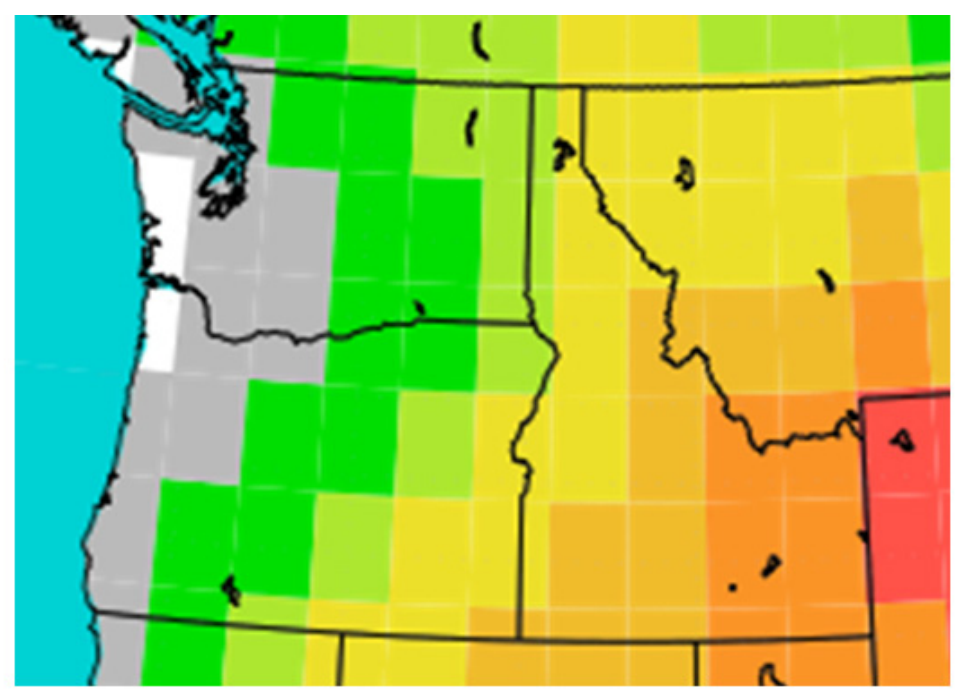

a) $300 \mathrm{~km}$ resolution

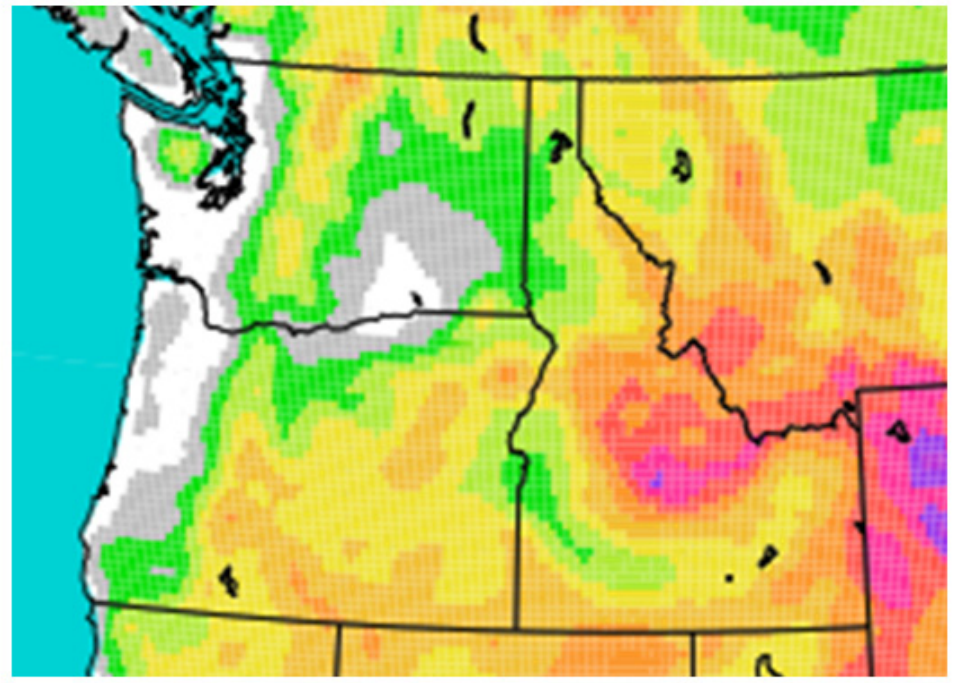

b) $24 \mathrm{~km}$ resolution

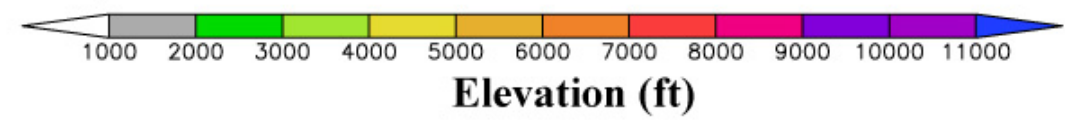

Figure 3 - Elevation profiles of the Pacific Northwest at resolutions of a) $300 \mathrm{~km} / 186$ miles, as in a typical global climate model, and at b) $24 \mathrm{~km} / 15 \mathrm{miles,}$ as used in the regional climate models of climateprediction.net. Credit: Robert Mera, UCARPACE.

For the next several years, it is unlikely that GCM output will provide the specificity needed for transportation and infrastructure planners. Until GCMs are capable 
of fulfilling these needs, downscaling will be required to provide climate change projections at the temporal and spatial scales necessary.

\section{GLOBAL CLIMATE MODELS RESULTS}

IPCC's The Physical Science Basis report is regarded as the most comprehensive and most high-profile assessment of climate change at the global scale. As discussed above, projections of future global climate produced by models vary based on several factors, including the levels of GHGs anticipated in the atmosphere for a given scenario. GHGs present in the atmosphere in the future depend upon the aggressiveness of climate change policies that limit or reduce emissions as well as the likelihood and timing of their successful implementation. To account for a variety of potential emission levels, climate models generally include multiple scenarios, from a status quo "no action" alternative to a successful "aggressive" alternative. Projections presented in this section are derived from a composite of 20 different global climate models that assume a "medium" or moderate emission scenario (IPCC, 2007).

The IPCC Fourth Assessment Report projects that the global average temperature will increase between $1.1^{\circ}$ and $6.4^{\circ} \mathrm{C}\left(2.0\right.$ to $\left.11.5^{\circ} \mathrm{F}\right)$ by the end of the $21^{\text {st }}$ century (IPCC, 2007). Warming is projected to be greatest at high northern latitudes and over land, and least over the southern ocean and the North Atlantic. They also project an average SLR of between about 19 and 59 centimeters ( 7.5 to 23.2 inches) over this time period. Due to the limited understanding of certain processes affecting SLR, there still exists considerable uncertainty in these estimates. As a result, $59 \mathrm{~cm} / 23.2$ in should not be considered an upper bound on SLR. Regarding precipitation, the IPCC considers it 
very likely that precipitation in high latitudes will increase, and likely that subtropical land regions will see a decrease in precipitation. The IPCC also projects a very likely increase in frequency of hot extremes, heat waves and heavy precipitation.

Due to a number of factors, including the unique physical characteristics of individual regions, the impacts of climate change are not similar throughout the globe. Latitude and location in relation to oceans and mountain ranges are significant factors affecting the level of temperature and precipitation change an area is projected to experience (IPCC, 2007).

Global climate change modeling occurs at a resolution of hundreds of kilometers. However, data at this scale has limited utility when preparing for the impacts of climate change at the regional or local level. For example, regional climate projections described in the IPCC report IPCC 2007: The Physical Science Basis, describe variations in climate for the entire North American continent with extremely large subregions (e.g., southwestern U.S. and Mexico). Relatively few of the subregional descriptions discuss climate changes in the PNW or Alaska specifically, but rather generalize projected trends for the Western U.S. or Arctic. Below is a summary of climate projections for the PNW and Alaska derived from the IPCC North American regional model.

\section{TEMPERATURE AND PRECIPITATION IN THE PACIFIC NORTHWEST $\underline{\text { (GCM BASED) }}$}

According to the IPCC report, all of North America is likely to warm during the $21^{\text {st }}$ century (Figure 4). Despite the spatial and temporal variability associated with the

climate of the Pacific Northwest, the overall upward temperature trend over the last 
century is consistent with global carbon emissions; the region's climate is already changing. The observed $0.8^{\circ} \mathrm{C} / 1.5^{\circ} \mathrm{F}$ increase in the Pacific Northwest (1920-2003) is consistent with the global warming trend. As in the global case, only a very small percentage of that temperature increase can be attributed to natural variability. While the increase in regional temperature is consistent with rising greenhouse gas concentrations, regionally averaged precipitation has fluctuated substantially. Additionally, trends in extreme precipitation are ambiguous and have received less attention from researchers (OCAR Executive Summary, 2010).
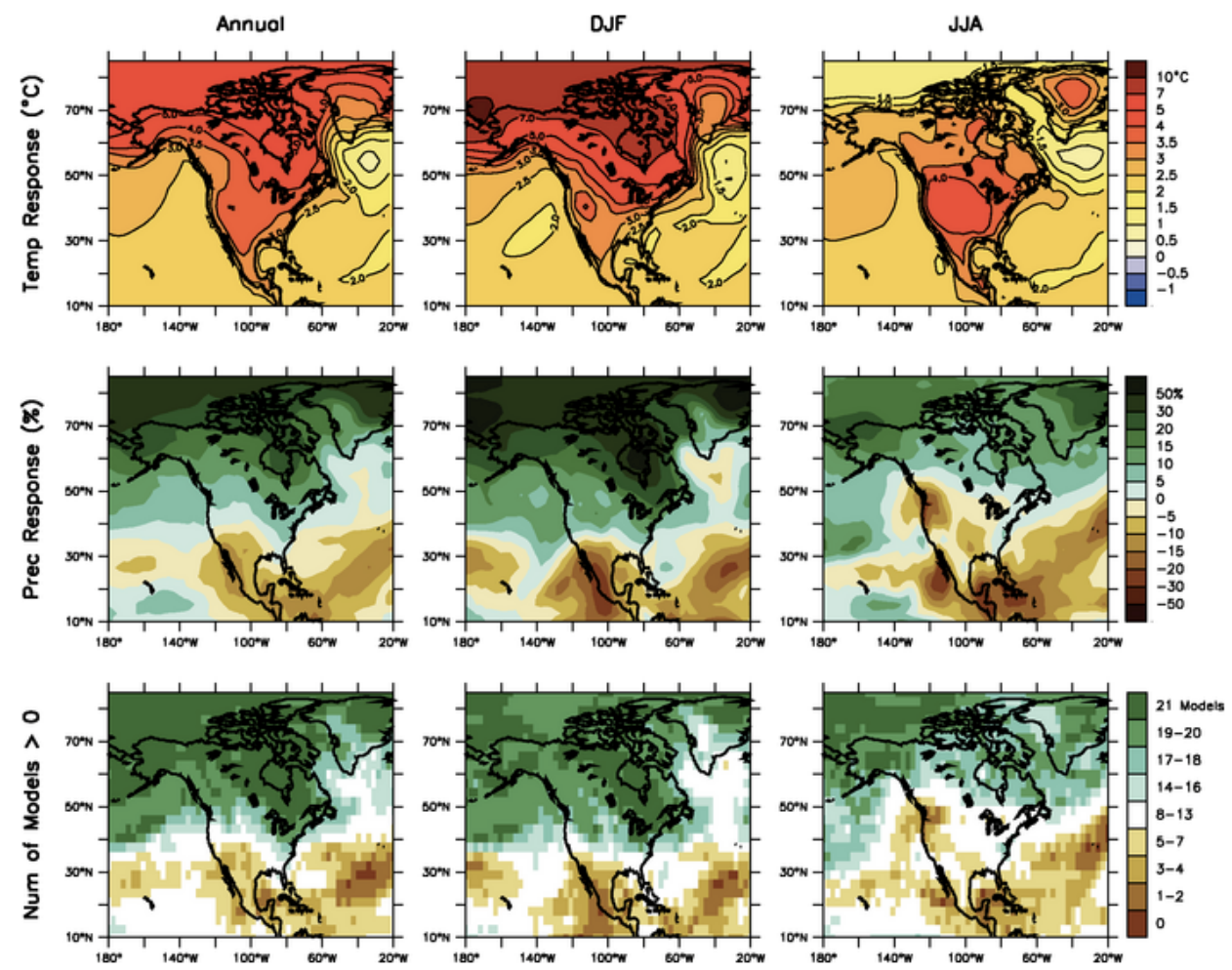

Figure 4 - Global climate projections at the continental scale for temperature response (top) precipitation response (middle) and the number of models showing positive precipitation response (lower) for annual (left), December through February (middle), and June through August (right). 
The Pacific Northwest is expected to experience an approximate $2-3^{\circ} \mathrm{C} / 3.6-5.4^{\circ} \mathrm{F}$ increase in average annual regional temperatures over the course of this century. Temperatures are projected to increase approximately $1.5-2.5^{\circ} \mathrm{C} / 2.7-4.5^{\circ} \mathrm{F}$ during summer months and $3.5-7^{\circ} \mathrm{C} / 6.3-12.6^{\circ} \mathrm{F}$ during winter months. Less and more modest seasonal variation is expected in some areas, especially near the coast.

Annual precipitation is expected to generally increase over most of the continent except the southwestern U.S. and Mexico. Average annual change in precipitation in the Pacific Northwest as a whole is projected to increase by up to 10 percent. During summer months, precipitation is expected to decrease approximately 5-15 percent, and increase during winter months approximately 30 percent. "Rain-on-snow" events are expected to increase, potentially causing extreme runoff and contributing to severe flooding along waterways. 


\section{Significant Features and Prevailing Climate in the Pacific Northwest \& Alaska}

\section{Pacific Northwest}

Major features of the Pacific Northwest are the Columbia and Snake rivers; and the Olympic, Coast, Rocky and Cascade mountain ranges. The Pacific Northwest has a generally mild climate. West of the Cascade mountain range, the average annual precipitation is more than 30 inches, with 120-200 inches annually on much of the coast range. Average summer temperatures are about $21^{\circ} \mathrm{C} / 70^{\circ} \mathrm{F}$ west of the Cascades. East of the Cascades, summer temperatures average $26-32^{\circ} \mathrm{C} / 80-90^{\circ} \mathrm{F}$ with average annual precipitation of 20 inches or less. The figure below illustrates average monthly precipitation. The eastern and western regions receive about the same precipitation during the summer months, but precipitation in the western region increases significantly during the winter whereas it is relatively more constant throughout the year in the eastern region (CIG, 2009).

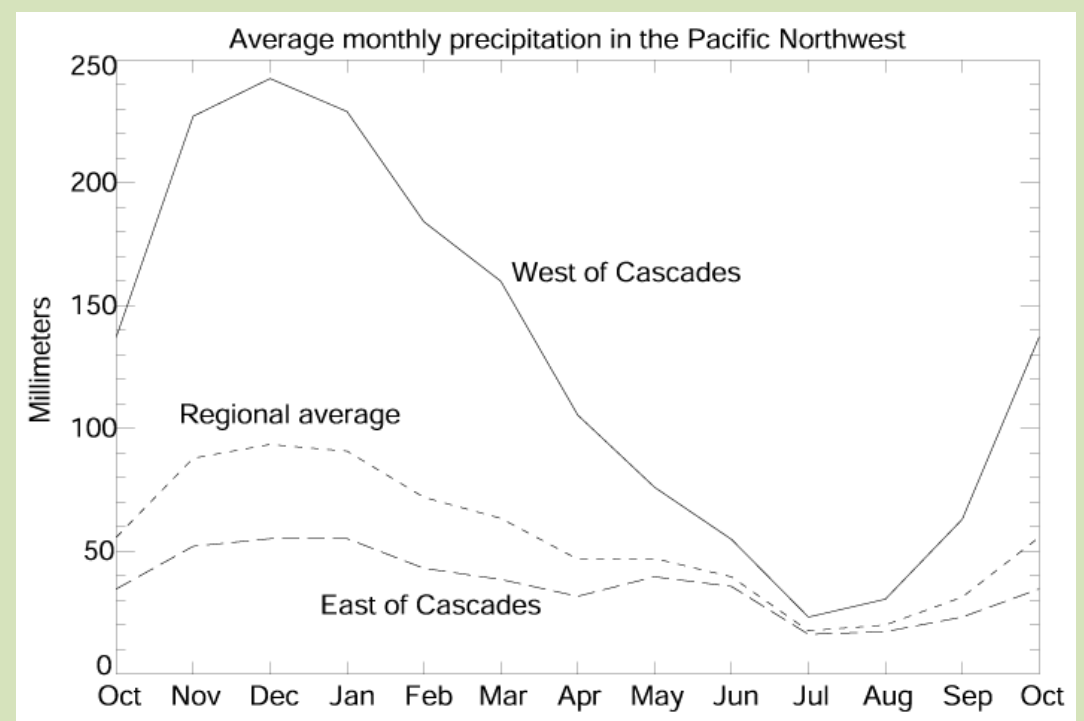

Average monthly precipitation east and west of the Cascades (CIG, 2009)

\section{Alaska}

The climate in Alaska is influenced by the Bering Sea and the Pacific Ocean. Coastal areas are more temperate than inland or northern areas due to the moderating influence of the sea. Around Anchorage, temperatures average around $15^{\circ} \mathrm{C} / 55^{\circ} \mathrm{F}$ in the summer and $-9^{\circ} \mathrm{C} /-15^{\circ} \mathrm{F}$ in the winter. More inland, around Fairbanks, summer and winter temperatures average $13^{\circ} \mathrm{C} / 55^{\circ} \mathrm{F}$ and $-21^{\circ} \mathrm{C} /-50^{\circ} \mathrm{F}$, respectively. In the polar North Slope region, average temperatures only rise above freezing in June to August (Wendler, et. al., 2010). The heaviest winter snowfalls occur in the coastal mountains (The Alaska Climate Research Center, http://climate.gi.alaska.edu). 


\section{TEMPERATURE AND PRECIPITATION IN ALASKA (GCM BASED)}

Temperature and precipitation changes for the Alaska region were also obtained from the IPCC report following the same modeling assumptions and timeframe as that described for the Pacific Northwest.

Alaska is expected to experience greater temperature changes compared to the Pacific Northwest, with an average annual regional temperature increase of approximately $3.5-5^{\circ} \mathrm{C} / 6.3-9^{\circ} \mathrm{F}$. Temperatures are projected to increase approximately 2$2.5^{\circ} \mathrm{C} / 3.6-4.5^{\circ} \mathrm{F}$ during summer months and $3.5-10^{\circ} \mathrm{C} / 6.3-18^{\circ} \mathrm{F}$ during winter months, with greater temperature increases occurring in the northernmost parts of the state due to a reduced period of snow cover. Significant increases in summer season length (i.e., the season when mean temperatures remain above $0^{\circ} \mathrm{C} / 32^{\circ} \mathrm{F}$ ) are projected across the south central, interior and northern regions of the state (SNAP, 2008).

Average annual precipitation in Alaska is projected to increase approximately 1015 percent. Precipitation is expected to increase in both summer and winter seasons; approximately $10-20$ percent during summer months and 15-30 percent during winter months.

\section{HYDROLOGY IN THE PACIFIC NORTHWEST AND ALASKA}

Water resources in the western U.S. have always been climate sensitive. The region receives most of its precipitation from October to March. Therefore, water storage in mountain snowpack is critical for providing sufficient surface-water resources during the summer. Summer water supply is projected to decline in most areas while the supply 
of water in other seasons may increase. Snowmelt-related hydrologic variables such as earlier peak flow, lower summer flow and lower spring snowpack have been observed.

The overall effect of climate variability on water resources in the region depends on hydrologic mechanisms operating at various temporal and spatial scales. There are three key aspects of regional geography and hydrology that determine whether climate change effects exceed interannual variability:

1. The extent of basin area affected by changes in snow-water storage and snowmelt;

2. Ecosystem adaptation and resilience to climate variability; and

3. The relative magnitude and rate of climate-induced changes compared to changes induced by anthropogenic activities.

The discussions of model projections included here should be read with caution for several reasons when considering climate change impacts on water resources. For instance, in Oregon, few universal trends in runoff are apparent in streamflow records. The direction and magnitude of change in streamflow varies by season, by basin size, and by surrounding ecosystem type. Second, observed trends in streamflow may be explained by factors that are not directly related to global climate change. For example, recent lowflow years are likely attributable to low precipitation and interannual variations in snowpack associated with cyclical variation in ocean temperatures. Long-term decreases in summer flows, however, are likely attributable to the combination of summer precipitation decline and increasing water consumption. And last, model projections do not account for possible adaptations in ecosystems that may alter water use and lead to smaller than expected changes in streamflow. A more robust coupling of vegetation and 
hydrology simulations within atmosphere-ocean climate models is needed. Modeling hydrology as an element of climate yields additional challenges, as even the best and highest-resolution climate models are incapable of resolving all the local factors on the hydrology of individual watersheds and currently use simplistic representations of land surface effects.

Many statements regarding hydrological projections can still be made, however. In the future, across the region, as winter temperatures warm, mountain snowpacks will likely diminish and summer water supply will likely decline. Earlier spring snowmelts would shift the timing of peak flows, and some streams would peak earlier in the year. A decrease in summer precipitation is also likely in the future, and the amount of precipitation that the region receives in the summer will likely be even less in the future.

A viable water supply is crucial for all types of water use and overall ecosystem health. Transient rain-snow basins, such as those in the Western Cascade and Northern Rockies basins, are projected to be sensitive to changes in precipitation and temperature. Cascade snowpacks are projected to be less than half of what they are today by midcentury. Across the region, lower-elevation snowpacks will be the most sensitive to temperature and precipitation changes. Figure 5 illustrates the winter precipitation type and sensitivity to warming across the region. In this context, "sensitive" indicates an increased likelihood of changes to timing and volume of flows (CIG, 2005). 


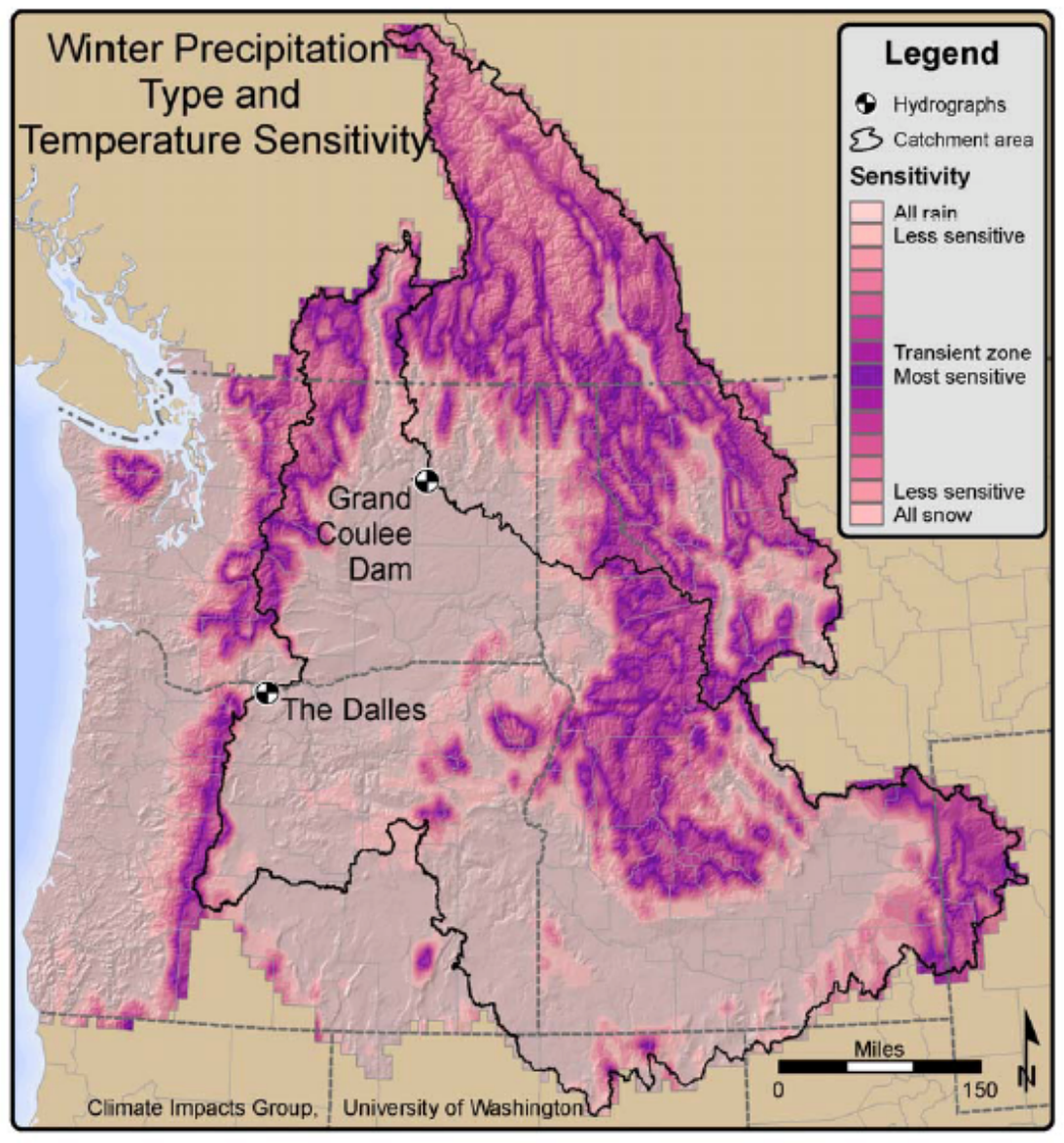

Figure 5 - Winter precipitation type and sensitivity to warming across the Pacific Northwest. Areas in the transient rain/snow zone (dark purple) are most sensitive to climate warming; areas of either predominantly rain or snow (pink) are less sensitive to climate warming.

Other factors such as increased demand will pose additional stressors to water availability. Water demands are projected to increase throughout the 21 st century, particularly in urban areas. Part of the increased demand will likely be due to summer temperatures. Additional increases in demand can be partially attributed to overall population growth in the region. Data from the Portland Water Bureau shows that there is a relationship between annual average water consumption and annual average temperature. While demand during winter months is expected to remain constant, 
research on urban water demand suggests that temperature is the most influential climate variable on water consumption, particularly among single-family residential households. These impacts are also evident at multiple scales, including the household, neighborhood, and region.

Water quality is also likely to be impacted with rising air temperature and seasonal shifts in flow availability. Water temperatures are expected to rise as air temperature increases in the $21^{\text {st }}$ century, particularly in urban streams where natural riparian vegetation is typically lacking. A decline in summer stream flow will exacerbate water temperature increases, because the low volume of water will absorb the sun's rays more than during times with larger flows. However, an increase in air temperature alone does not lead to major changes in stream temperature.

Changes in riparian vegetation will influence streamflow and water temperature. Changes in water temperature can have significant implications for stream ecology and salmon habitat. Smaller streams in transient rain-snow basins in the region will be the most vulnerable to increasing summer air temperature and diminished low flows. There is little research on long-term trends in water temperature in undisturbed watersheds; sites with long-term data are rare.

Sediment and phosphorus loads typically increase during high-flow events. As winter flows are projected to increase with a changing climate, the temporal variability of sediment and phosphorous loading may change as well.

Seasonal patterns of runoff vary across the Pacific Northwest depending on precipitation type, topography and geology. Runoff in the region is strongly seasonal. For example, over 75 percent of streamflow occurs from October to April for the Willamette 
and John Day rivers in Oregon. Land surface type can lead to large variations. Some small basins on weathered old volcanic rocks in the Cascades see greater seasonality, while streamflow from basins on recent, porous lavas of the High Cascades have low seasonal variability as a result of being sustained by groundwater from deep storage. (Tague et al., 2008; Chang and Jung, 2010). Flow in the western Cascades, which is typically fed by shallow subsurface flow, diminishes rapidly during the dry summer season.

Figures 6 and 7 illustrate monthly hydrographs for basins and rivers representative of the region. The basins and rivers are located in different hydrologic and ecoregions, which reflect different climate and vegetation regimes. In Figure 6, basins A (Oregon coastal basin) and B (Willamette Valley) are rain-dominated. Flow in basin C (Hood River) is characteristic of a transient rain-snow watershed, and basins east of the Cascade Range (D, E, and F) are snowmelt-dominated. Basins A and B have a rainfalldominated peak in December. Basin C has a rainfall-dominated peak in December and a snowmelt-dominated peak in April. Basins D, E, and F have a single snowmeltdominated peak in late winter and spring. Figure 7 illustrates three rivers in the region which are also representative of different hydrological regimes: the Chehalis (raindominated); the Yakima (transient rain-snow); and the Columbia (snow-dominated). 

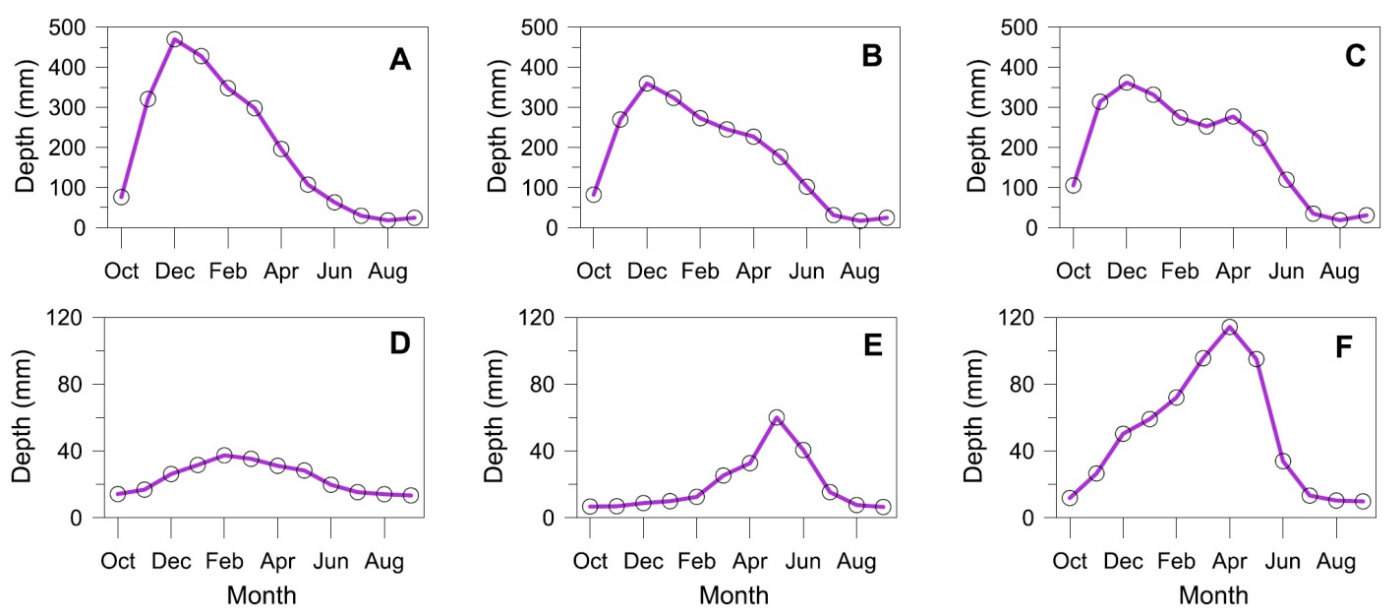

Figure 6 - Monthly mean runoff for annual total runoff and the ratio of summer flow to annual flow (Source: Chang et al., in preparation) for (a) Wilson River near Tillamook, (b) Little North Santiam River near Mehama, (c) Blazed Alder Creek near Rhododendron, (d) Warm Springs River near Kahneeta Hot Springs, (e)

Donner und Blitzen River near French Glen, and (f) Umatilla River above Meacham Creek near Gibbon. 

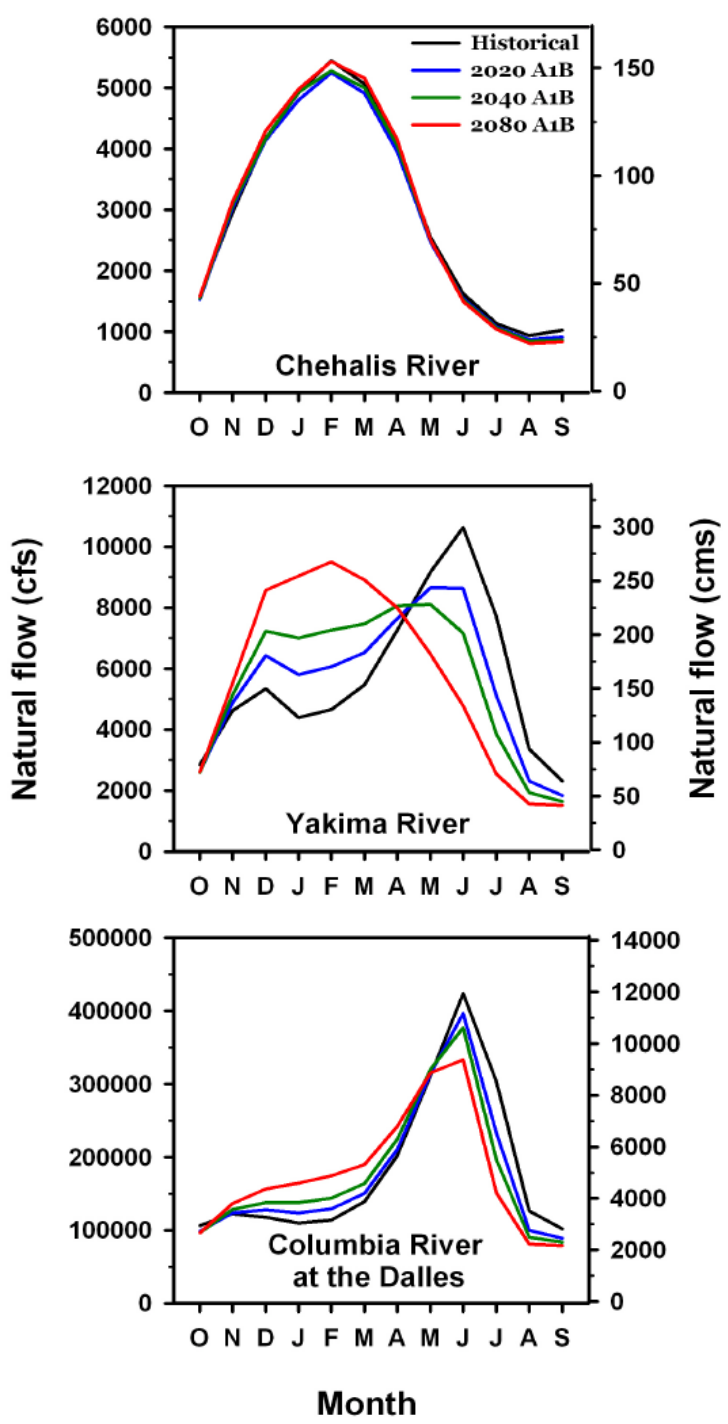

Figure 7- Historical and projected future hydrographs for three rivers under a scenario of balanced greenhouse gas emissions (A1B). The Chehalis River represents a rain-dominated watershed, the Yakima River represents a transient watershed (mixed rain and snow), and the Columbia River represents a snowmeltdominated watershed. Projected climate changes will influence the timing of peak streamflow differently in different types of hydrologic basins. The timing of peak

streamflow does not change in rain-dominated basins because most of the precipitation falls as rain, both currently and in the future, and is therefore available for runoff as it falls. Timing of peak flow shifts earlier as climate warms in the transient and snowmelt-dominated basins because precipitation that historically fell as snow later falls as rain - snowpack melting ceases to dominate the timing of peak flow as the snowpack declines (CIG Assessment Report, 2009). 
Regularly collected measurements indicate the Pacific Northwest springtime snow declined substantially between 1950 and 1997, in part due to a reduction in precipitation and in part due to rising winter temperature during this period (Mote, 2003; Mote et al., 2005a). Figure 8 illustrates this regional trend.

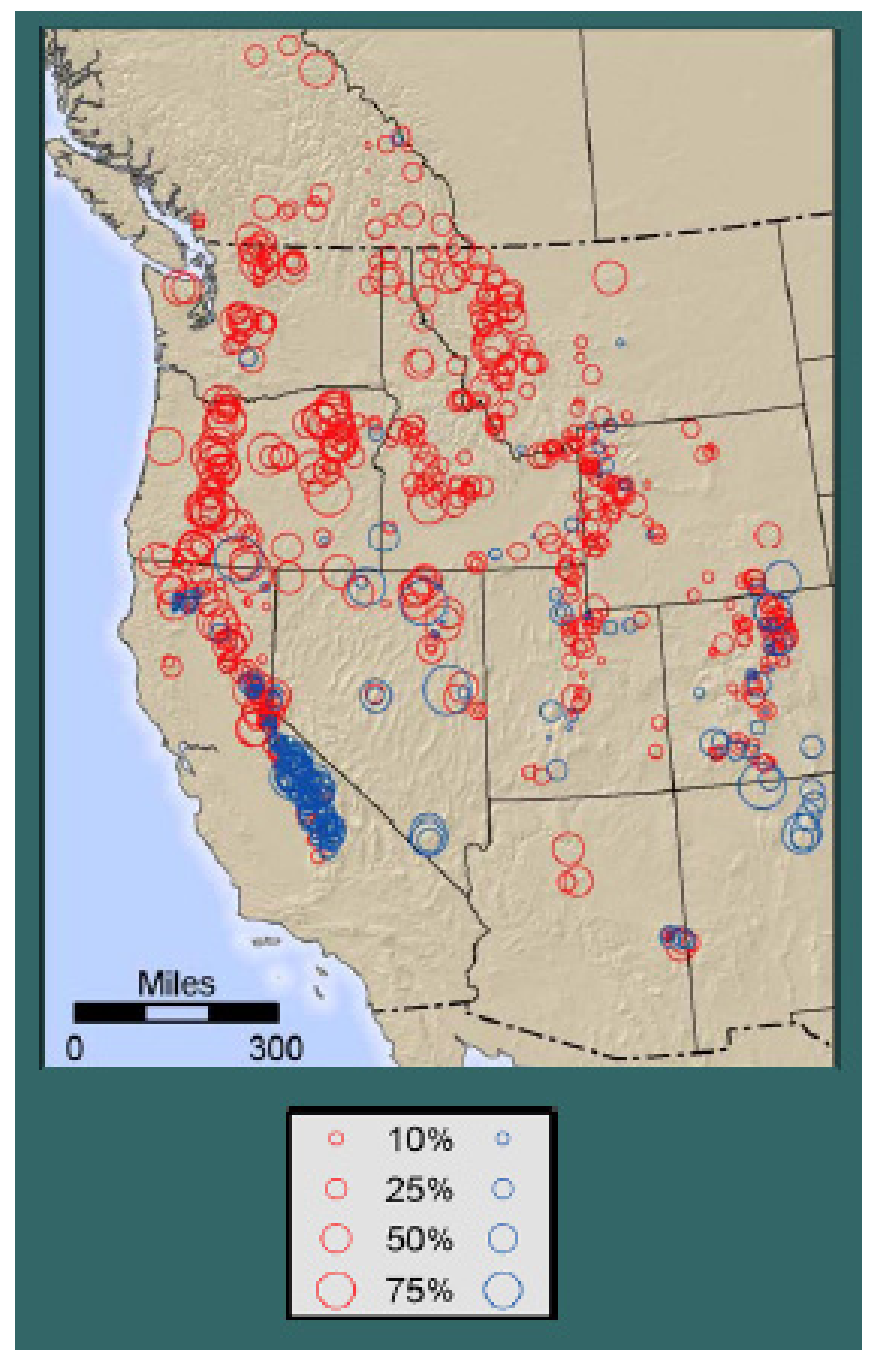

Figure 8 - Changes in April 1 Snow Water Equivalent in the western United States. Linear trends in April 1 snow water equivalent (SWE) relative to 1950 at 798 snow course locations in the western U.S. and Canada for the period 1950-1997. Negative trends are shown in blue circles and positive trends are shown in red circles. SWE is a common measurement for the amount of water contained in snowpack if it were melted instantaneously. Figure adapted from Mote et al. (2005b). 
Figure 9 illustrates projected spring snowpack (inches of snow-water equivalent) in the Pacific Northwest in 2003, the 2020s and the 2040s. By the 2080s, decrease in snowpack and earlier melts may significantly shift seasonal streamflow timing in snowmeltdominated and transient rain-snow watersheds (CIG, 2009). Snowmelt-dominated watersheds will likely become transient, resulting in reduced peak spring streamflow, increased winter streamflow and reduced late-summer flow. Transient basins will likely become rain-dominant as winter precipitation falls more as rain and less as snow. Watersheds that are rain-dominated will likely experience higher winter streamflow because of increases in average winter precipitation, but will experience relatively little change with respect to streamflow timing. These changes carry important implications for water availability and storage (CIG, 2009). 


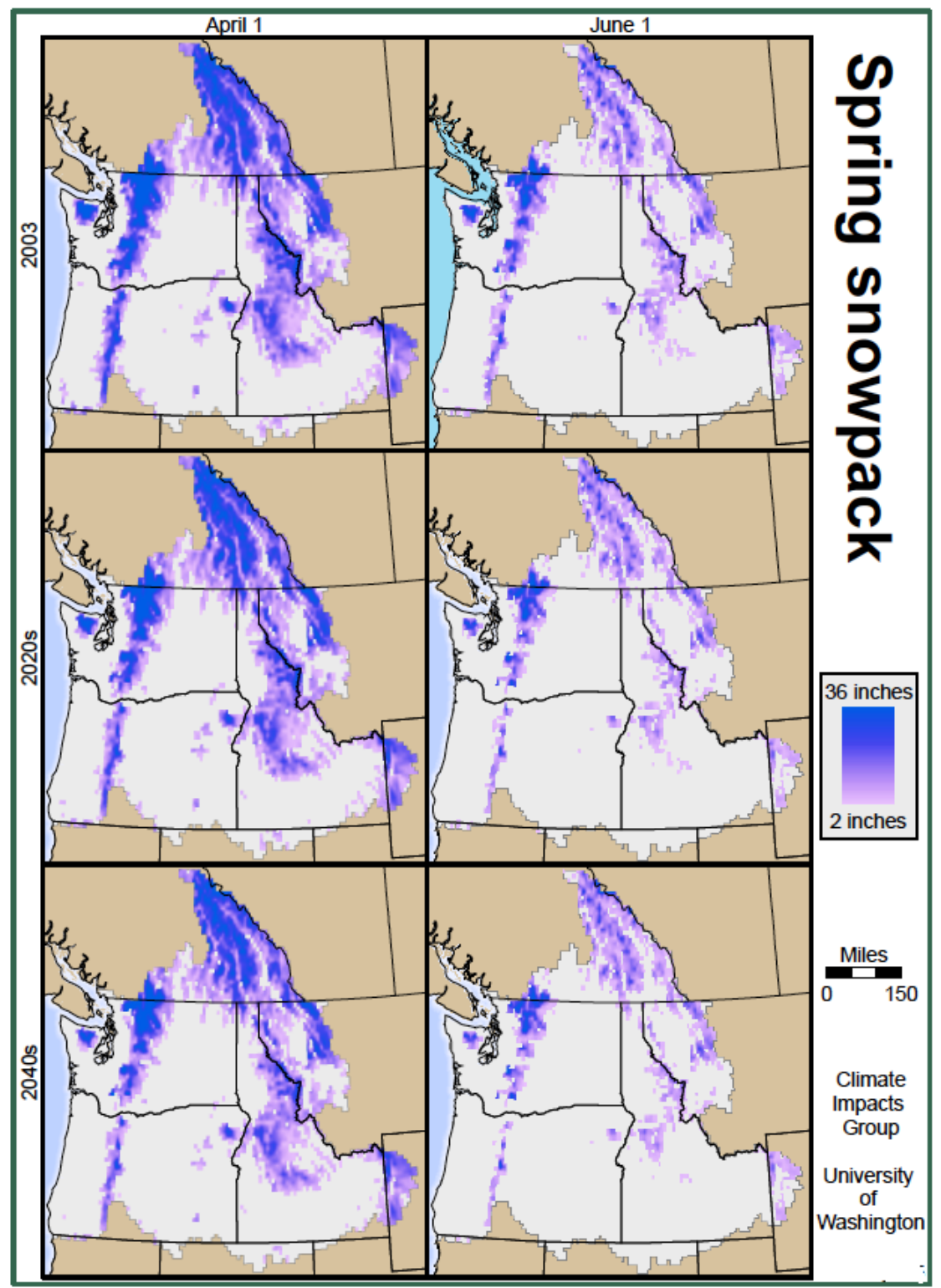

Figure 9 - Projected spring snowpack across the region. Areas in white are snowfree; areas in pink have some snowpack; areas in purple have relatively heavy snowpack. Future projections indicate that less snow is likely to accumulate during the winter and the snow melt is likely to occur earlier in the year. The projections have been made with an average of four climate models, one relatively wet model, one relatively dry model, one relatively warm model, and one relatively cool model. This four-model composite can be considered a "middle-of-the-road projection"

(Mote et al., 2005b). 
As mentioned previously, the growing season in Alaska is projected to become longer, as well as warmer and drier. The Yukon Flats will see an increase in precipitation in the spring but a reduction in snowpack. Without an equivalent increase in precipitation, this can lead to an increase in landscape water loss through vegetative processes. This may lead to an overall lessening of water availability. Decreases in water availability are likely to have significant impacts on wildlife, vegetation and human communities.

Due in part to its northerly location, Alaska has a number of unique features in its hydrologic cycle. Among them are permafrost, large glaciers and sea ice. Much uncertainty remains as to how these features will react to a changing climate (SNAP, 2009).

\section{EXISTING CLIMATE MODELING IN THE PACIFIC NORTHWEST AND $\underline{\text { ALASKA }}$}

Other published reports provide climate projections at a higher resolution than described in The Physical Science Basis, and have been generated specifically to examine climate change in the Pacific Northwest and/or Alaska. These reports vary in the level of detail provided and often cite common downscaled models. Table 3 below provides a summary of the climate change projections from these reports. 


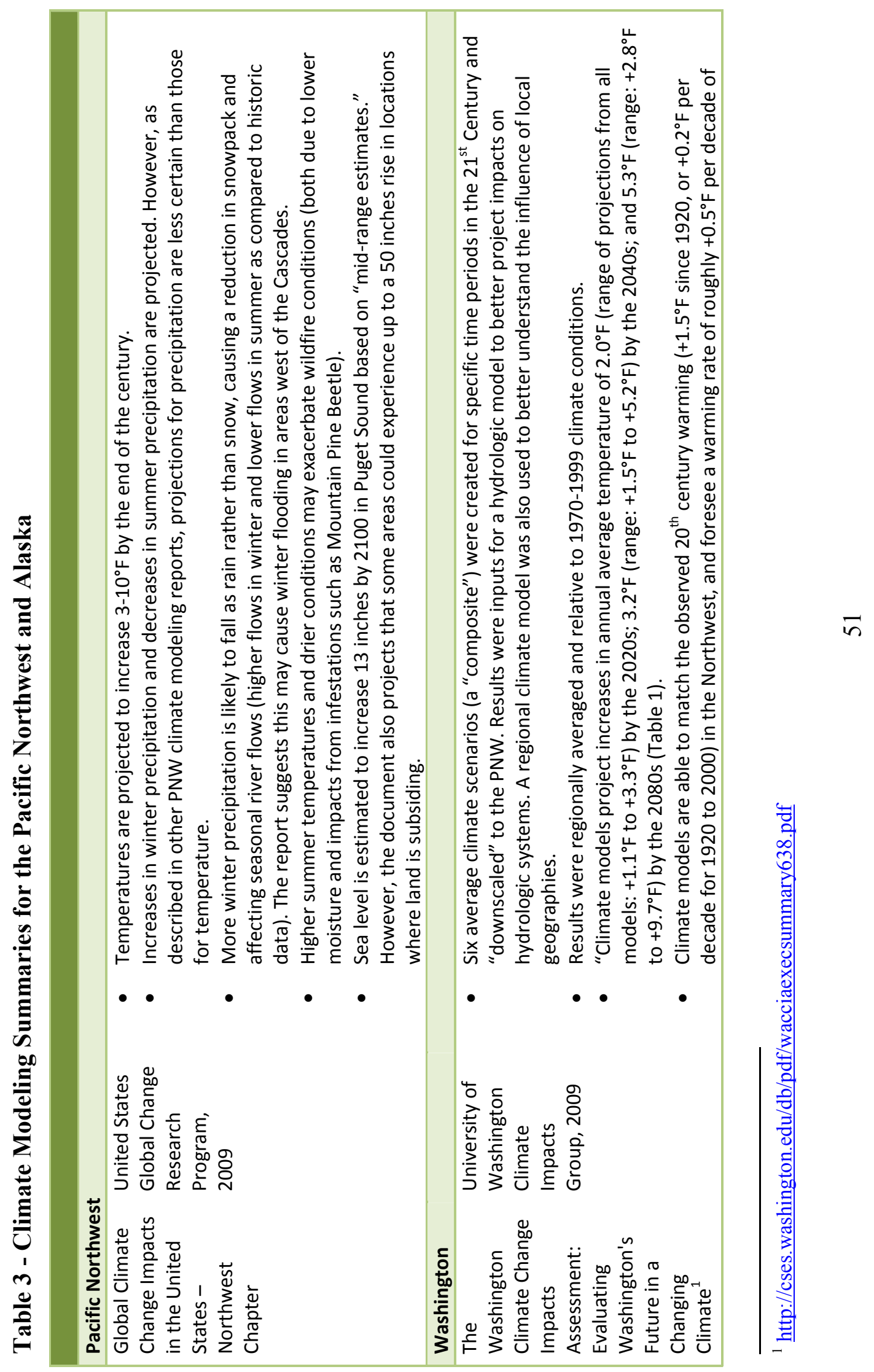




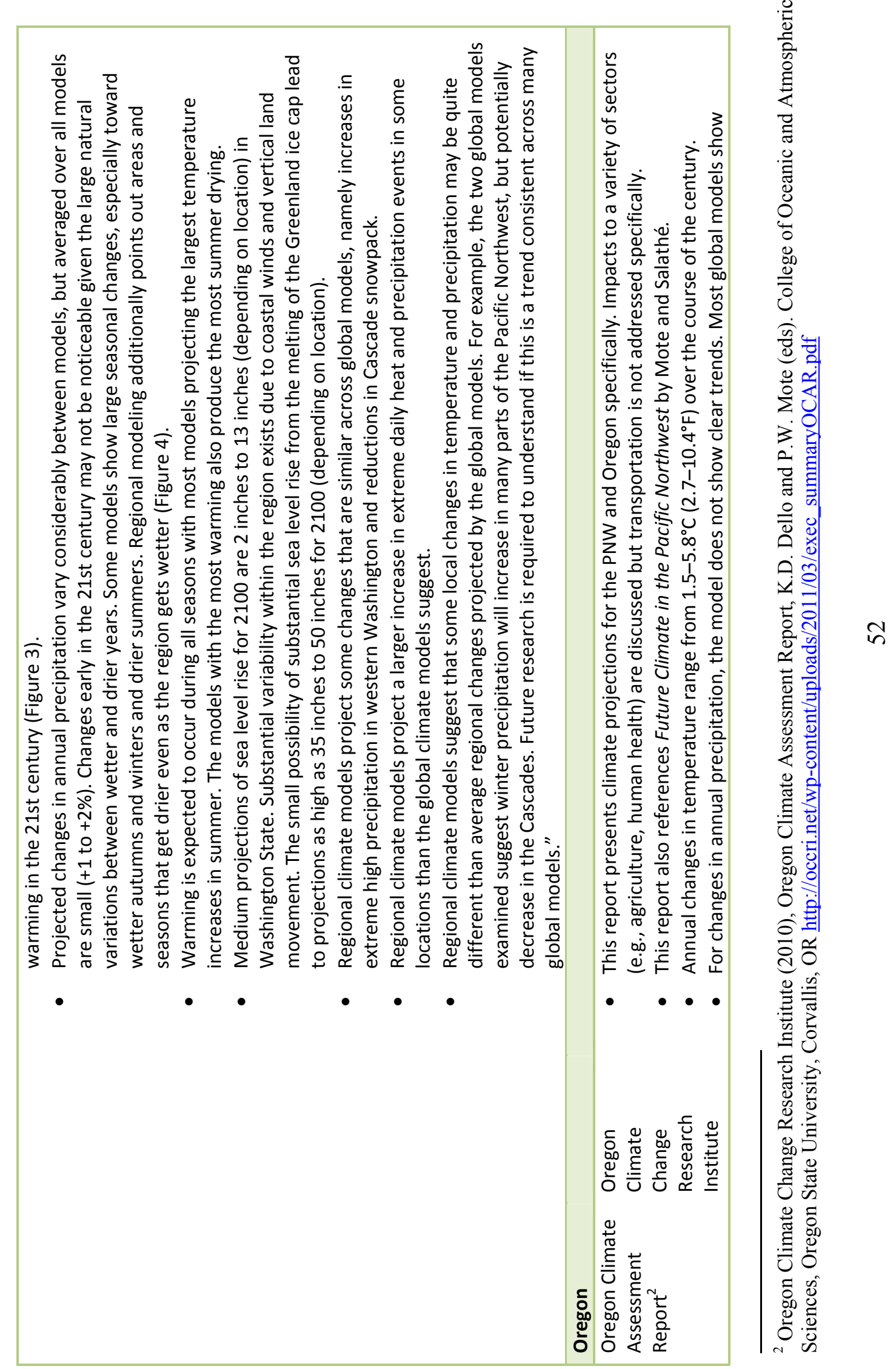




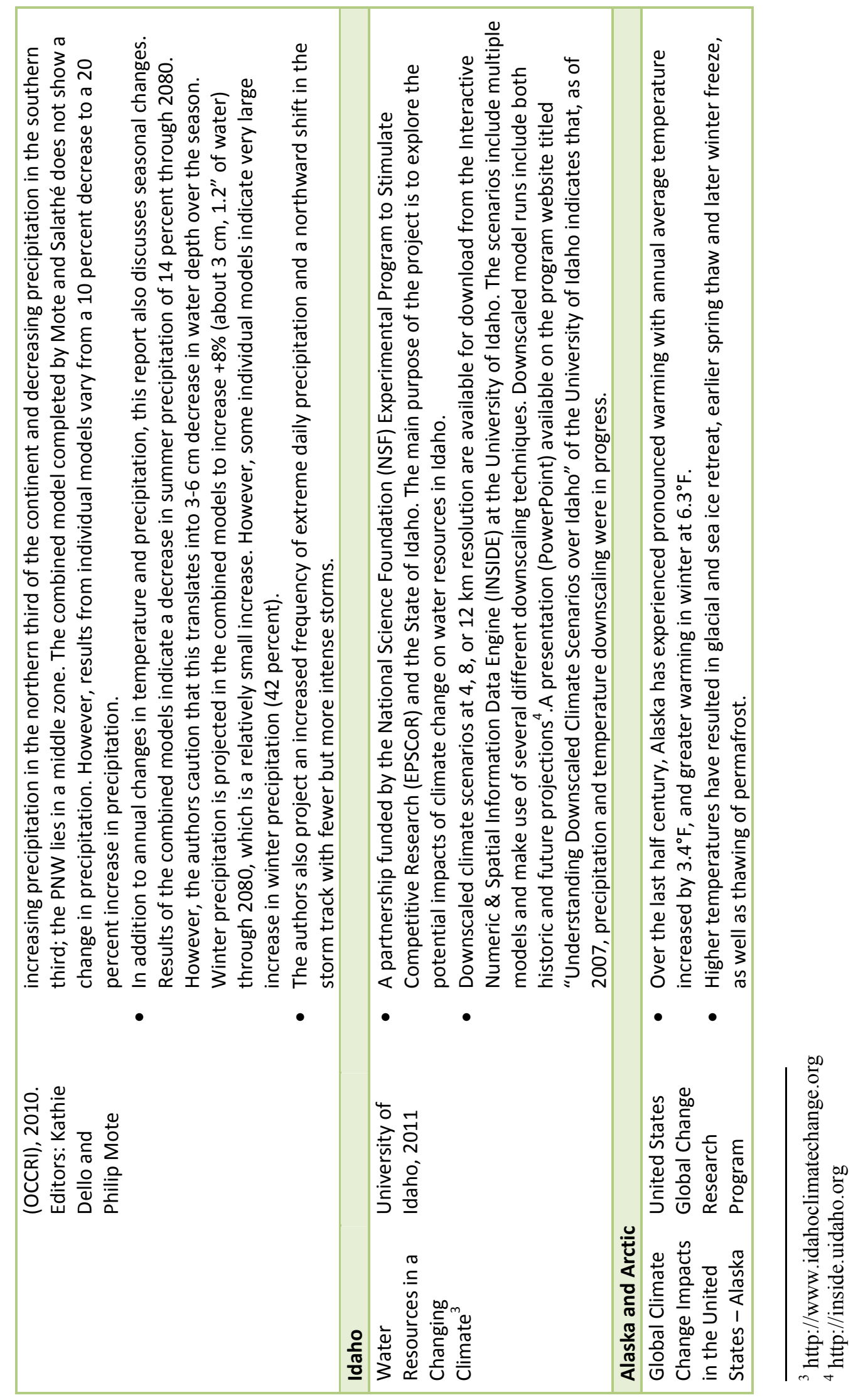




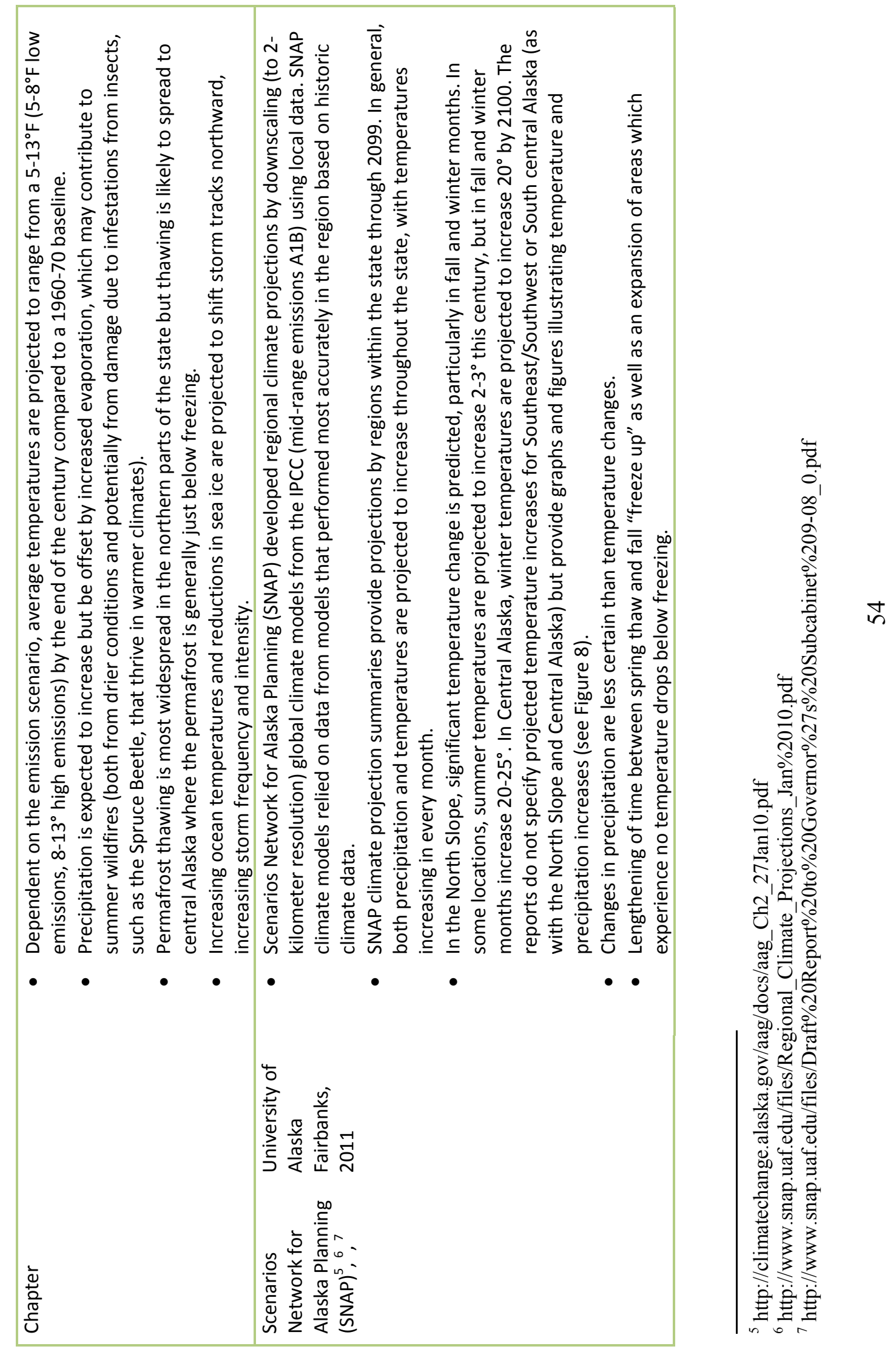


Most of the downscaled regional model reports provide projections for average annual temperature and precipitation as well as seasonal changes. However, with the exception of some Alaskan reports (for example, the "Regional Climate Projections" at http://www.snap.uaf.edu/downloads/fact-sheets-and-short-documents-0), most do not detail how climate changes will vary subregionally, such as throughout a single state. The large western states covered within this study contain multiple individual climates, including desert, coastal and alpine. Temperature, precipitation and seasonal changes as a result of climate change are likely to vary between these individual areas and may call for different adaptation responses. Figure 10 shows SNAP's temperature projections for subregions of Alaska.

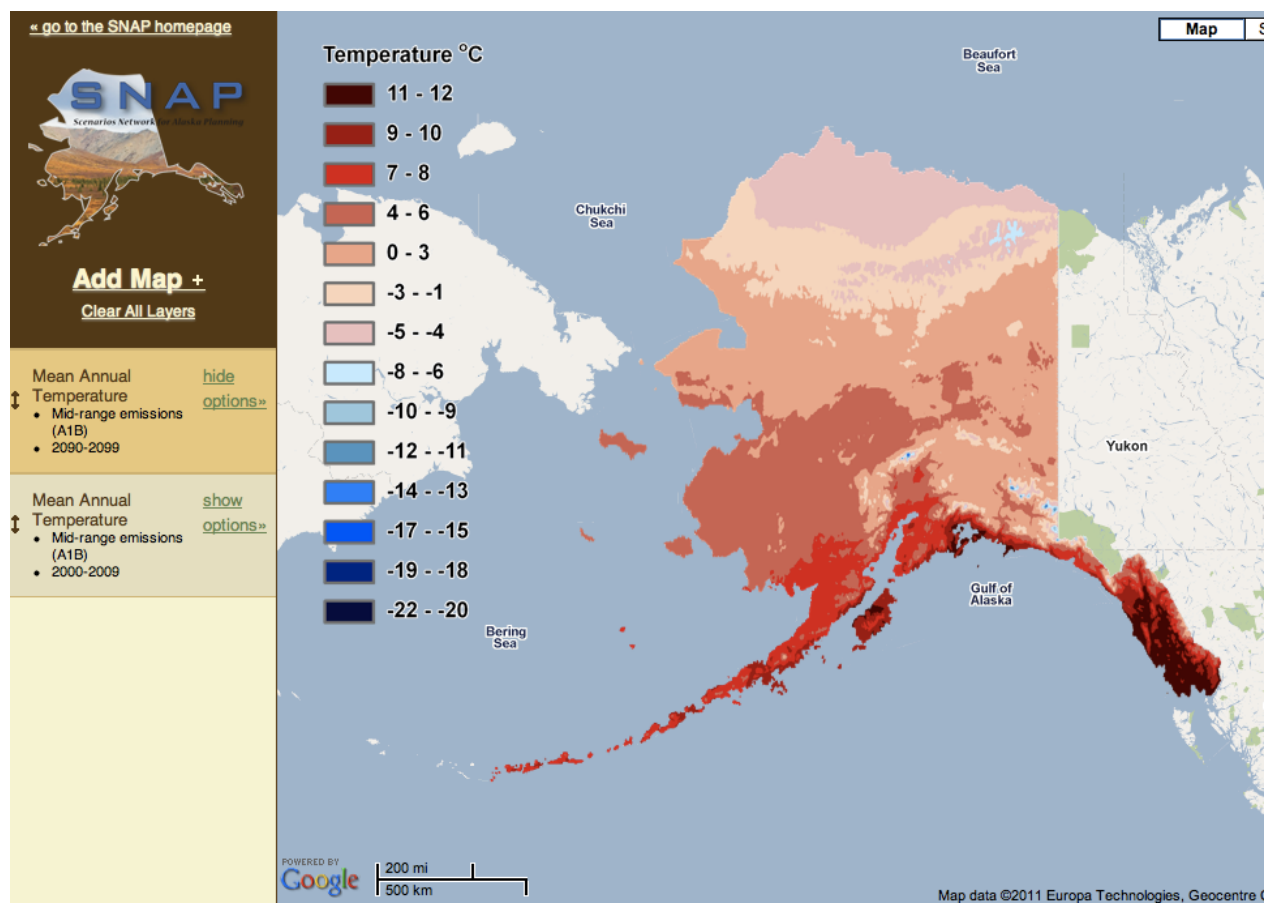

Figure 10 - Interactive temperature projections for Alaska. 
Several entities have attempted to address the issue of regional climate change in the Pacific Northwest. For example, the Federal Highway Administration (FHWA) with the "Highways and Climate Change Report"; the Climate Impacts Group (CIG) at the University of Washington with the "Washington Climate Change Impacts Assessment" (and other publications); the Oregon Climate Change Research Institute (OCCRI) with the "Oregon Assessment Report (OCAR)"; the University of Idaho Experimental Program to Stimulate Competitive Research (EPSCOR) climate downscaling project; and Alaska's Scenarios Network for Alaska Planning (SNAP) downscaled scenarios. This report offers important updates to these efforts.

Previous reports relied on Atmospheric Oceanic Global Climate Model (AOGCM) model output as the original source for their climate data. As mentioned earlier, by relying on AOGCMs, this means that the native resolution for these models was on the order of hundreds of kilometers/miles. In a topographically and climatologically complex area like the PNW, this level of resolution may not be adequate to capture the relevant processes. An analysis like the North American Climate Change Assessment Program (NARCCAP), run at $50 \mathrm{~km} / 31$ mile resolution may be better to capture these processes.

Also, the FHWA and CIG reports treat the whole PNW as one entity. As mentioned above, the PNW is a very topographically and climatologically diverse region. In a subsequent section this report attempts to address this by subdividing the PNW (and Alaska) into five subdomains (described in the following section). Finally, this report extends the metrics available in previous reports. In addition to annual and seasonal 
temperature and precipitation projections, this report also includes data on temperature and precipitation extremes, including heat waves.

In a subsequent section, the development of these finer resolution models is described along with climate change projections. The range of impacts anticipated as a result of these projections on transportation infrastructure in the PNW and Alaska are then discussed.

\section{SEA LEVEL RISE}

As a result of the limitations in regional modeling described above, it is not possible to accurately project sea level rise (SLR) on a regional scale. Each site must be considered individually and the local factors added to or subtracted from the expected global SLR of 19$59 \mathrm{~cm} / 17-23$ in (or more) by 2100 .

The global rate of SLR is expected to affect coastal Washington, Oregon and Alaska. Rates of SLR by the end of the century are likely to lie within the range of 1.5 to $9.7 \mathrm{~mm}$ (.06-.38 in)/year (IPCC, 2007; Figure 10.3). However, this is highly variable regionally. Other, more recent studies have concluded that global mean SLR could be on the order of 1-2 m/3.3-6.6 ft (Rahmstorf, 2007; Grinstead et al., 2009; Rohling et al., 2009; Pfeffer et al., 2008). Pfeffer et al., for instance, argue that there are strong physical constraints on SLR that make more than $2 \mathrm{~m} / 6.6 \mathrm{ft}$ of sea level rise "physically untenable." They find a "more plausible" low-end scenario to be in the vicinity of $0.8 \mathrm{~m} / 2.6 \mathrm{ft}$ of SLR (i.e., their estimated range of SLR to 2100 is $0.8-2.0 \mathrm{~m} / 2.6-6.6 \mathrm{ft}$ ).

Projections of local SLR are complicated by the fact that local SLR is influenced not only by the "background" global SLR, but local factors such as: sedimentation and erosion; 
changes in ocean circulation; gravitational changes; changes in ocean density (affected by regional changes in ocean salinity and ocean temperature); and vertical land motion. The PNW and Alaska, both located in geologically active zones, experience significant impacts on local relative SLR due to vertical land motion.

Data from the National Oceanic and Atmospheric Administration (NOAA) illustrates the end result that the influence of local factors can have on local SLR. Figure 11 shows that historic mean SLR trends for the PNW (excluding Alaska) are clustered between -3 to +3 $\mathrm{mm} /$ year. In other words, some locations have experienced a relative SLR, while others have seen relative sea level drop (due primarily to positive vertical land motion). Due to very significant positive vertical land motion, several Alaskan coastal areas have experienced a drop in relative sea level of up to -9 to $-12 \mathrm{~mm} / \mathrm{year}$ compared with the global mean SLR of about $1.8 \mathrm{~mm} /$ year over a similar period. This positive vertical land motion may be a combination of ongoing geological processes (such as subduction) and/or a "rebound" effect as glaciers melt (and weight is removed) from the land surface.

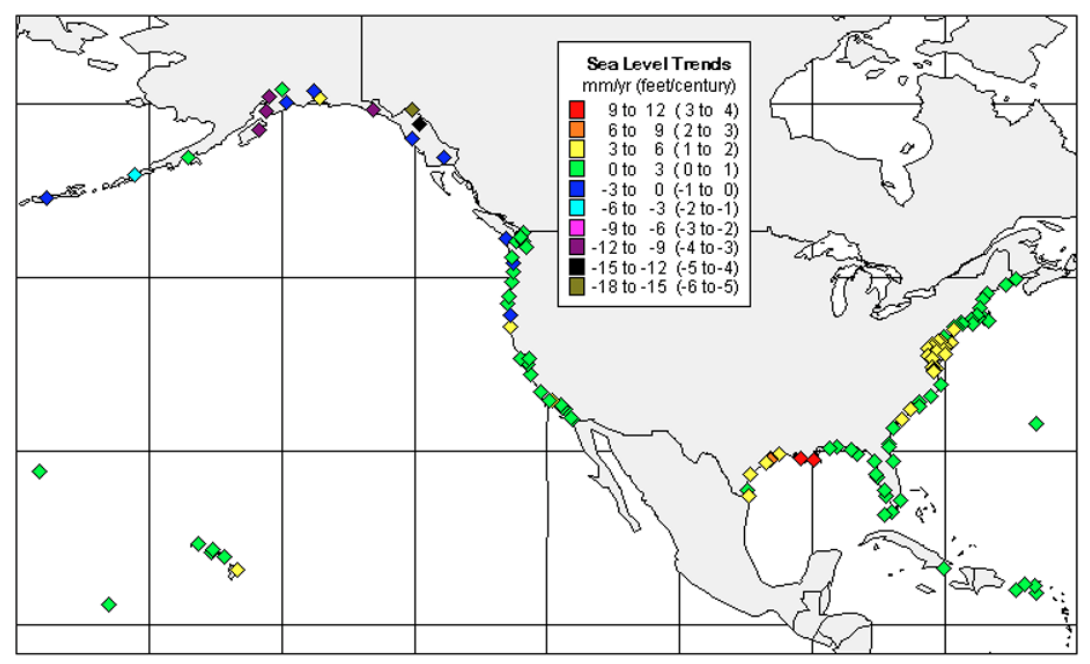

Figure 11 - Historic rate of sea level rise for selected locations. 
Due to the complications outlined above, projecting local regional SLR is difficult and engenders high levels of uncertainty. Nonetheless, Mote et al. (2008) attempted to estimate SLR for several locations on the Washington coast for the years 2050 and 2100. They stress that:

1. Their calculations have not formally quantified the probabilities;

2. Sea level rise cannot be estimated accurately at specific locations; and

3. Their findings are for advisory purposes only and should not be taken as predictions.

The possible range (very low, medium, very high) of SLR they calculated for several areas on the Washington coast, for the years 2050 and 2100, is detailed in Table 4 below. They note that the "Very Low" and "Very High" scenarios are low probability.

Table 4 - Projected Sea Level Rise in Washington State (cm/in)

\begin{tabular}{|rcccccc|}
\hline $\begin{array}{r}\text { SLR Estimate } \\
\text { (centimeters } \\
\text { /inches) }\end{array}$ & $\begin{array}{c}\text { NW } \\
\text { Olympic } \\
\text { Peninsula }\end{array}$ & $\begin{array}{c}\text { Central \& } \\
\text { Southern } \\
\text { Coast }\end{array}$ & $\begin{array}{c}\text { Puget } \\
\text { Sound }\end{array}$ & $\begin{array}{c}\text { NW } \\
\text { Olympic } \\
\text { Peninsula }\end{array}$ & $\begin{array}{c}\text { Central \& } \\
\text { Southern } \\
\text { Coast }\end{array}$ & $\begin{array}{c}\text { Puget } \\
\text { Sound }\end{array}$ \\
\hline Very Low & $-12 /-4.7$ & $3 / 1.2$ & $8 / 3.1$ & $-24 /-9.4$ & $6 / 2.4$ & $16 / 6.3$ \\
\hline Medium & 0 & $12.5 / 4.9$ & $15 / 5.9$ & $4 / 1.6$ & $29 / 11.4$ & $34 / 13.4$ \\
\hline Very High & $35 / 13.8$ & $45 / 17.7$ & $55 / 21.7$ & $88 / 34.7$ & $108 / 42.6$ & $128 / 50.4$ \\
\hline
\end{tabular}

In addition to SLR, consideration should be given to increasing wave height (and/or storm surge) along the coast. Since 1975, average significant wave height (SWH) has increased $15+/-10 \mathrm{~mm} /$ year. However, the average annual maximum SWH over the same period has increased by $95+/-73 \mathrm{~mm} /$ year (Ruggiero et al., 2010). While climate controls for this effect have not been established, it is an area of active research. Figure 12 below illustrates these trends. 


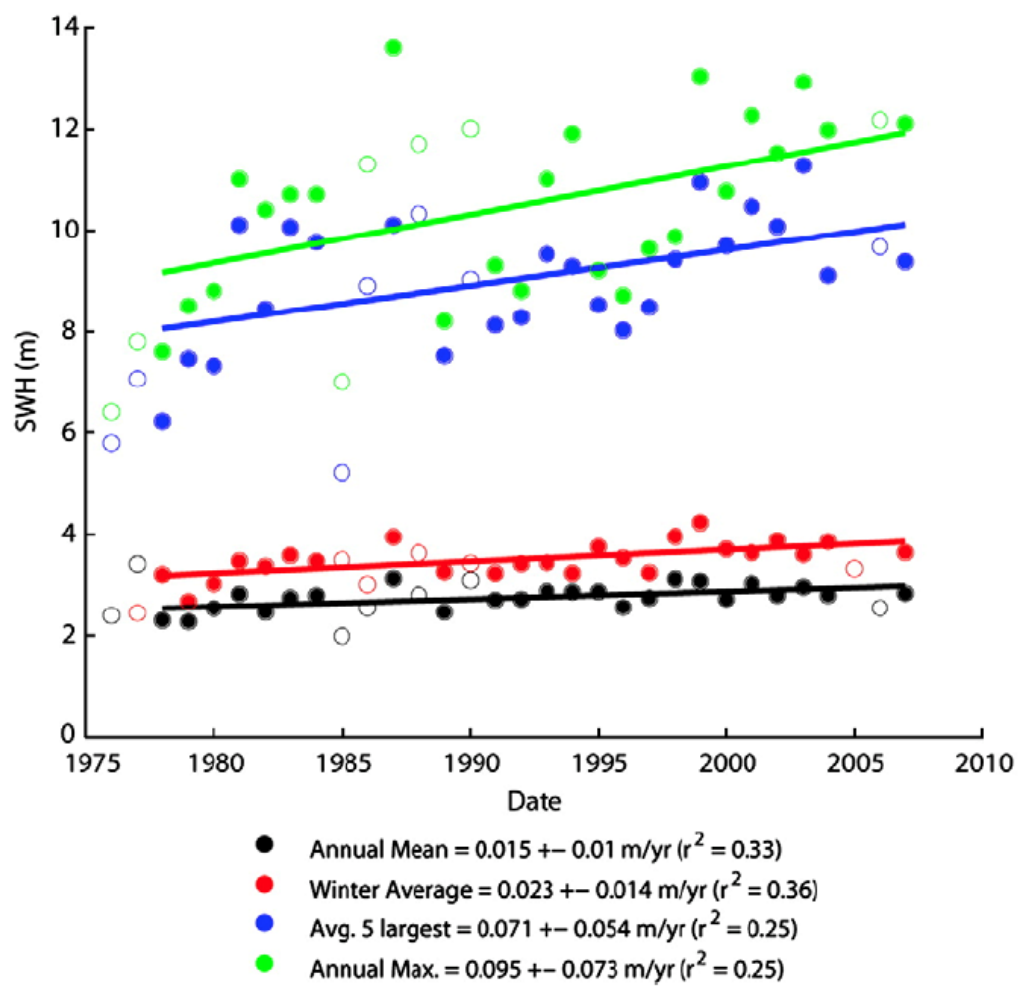

Figure 12 - Increased wave heights over time. 


\section{REGIONAL AND SUBREGIONAL CLIMATE CHANGE ASSESSMENT IN THE PACIFIC NORTHWEST AND ALASKA}

\section{INTRODUCTION}

The above section surveys and summarizes a variety of sources of available climate change information for the PNW and Alaska. In addition to this survey, in order to achieve more detailed climate projections and capture topographic and climatological diversity, this project commissioned the analysis of several subdomains within the PNW and Alaska. It also updates the results of previous modeling efforts and extends climate metrics beyond annual and seasonal temperature and precipitation to include data on temperature and precipitation extremes, including heat waves.

A dynamical downscaling approach was used to achieve this more detailed analysis. Specifically, the North American Regional Climate Change Assessment Program (NARCCAP), a project homed at the University Center for Atmospheric Research (UCAR) in Boulder, CO., was used as the source for downscaled climate data. The NARCCAP climate variables examined for this project were precipitation and temperature, both on multiple temporal scales at $50 \mathrm{~km} / 31$ mile resolution.

\section{NORTH AMERICAN REGIONAL CLIMATE CHANGE ASSESSMENT PROGRAM}

The North American Regional Climate Change Assessment Program was initiated in 2006 and is an international effort to develop climate scenarios specific to the United States, Canada and Mexico. Goals of the program include exploring and addressing uncertainties in the development of climate model scenarios and producing highresolution regional climate projections that can be used for impact assessment. 
NARCCAP is used as the source for climate model projections in this report. The NARCCAP suite of models consists of six Regional Climate Models (RCMs) and four Atmosphere-Ocean General Circulation Models (AOGCMs). An RCM is paired with (i.e., "embedded" within) an AOGCM to provide high-resolution climate projections. This allows for 50 kilometers on a side grid cells for NARCCAP, as compared to the hundreds of kilometers on a side grid cells of the typical AOGCM. At the writing of this report, only a subset of the 24 possible RCM-AOGCM combinations have been run; however, results from the planned runs are being published as they become available. Currently, results for the RCM-AOGCM pairings in Table 5 are available for use in this project.

\section{Table 5 - Regional Climate Model \& Atmosphere-Ocean General Circulation Models Pairings}

\begin{tabular}{|l|l|}
\hline Model Run & Pairing Definition \\
\hline CRCM_ccsm & Canadian Regional Climate Model-Community Climate System Model \\
\hline CRCM_cgcm3 & Canadian Regional Climate Model -Coupled Global Climate Model 3 \\
\hline HRM3_hadcm3 & Hadley Regional Model 3-Hadley Climate Model 3 \\
\hline WRF_ccsm & Weather Research and Forecasting-Community Climate System Model \\
\hline RCM3_cgcm3 & Regional Climate Model 3-Coupled Global Climate Model 3 \\
\hline
\end{tabular}

NARCCAP model runs include both the current (i.e., historical period) of 19712000 and the future period of 2041-2070. Due to resource limitations, NARCCAP runs use only one IPCC emissions scenario: A2. The A2 scenario was chosen because, as mentioned above, it is considered a "marker" scenario and is commonly used in scenario development. The current trajectory of actual greenhouse gas emissions validates the choice of this scenario as a likely realization (Le Quere et al., 2009). 


\section{METHODS}

The domain for the NARCCAP project is almost all of North America (a small percentage of the most northerly latitudes is not included). Subdomains were created out of this overall domain in order to provide insight into the effects of climate change on a scale more meaningful to the PNW and Alaska regions. Each subdomain was chosen so as to contain a relatively consistent topography. The subdomains are listed below:

- Coastal (Oregon and Washington)

- Cascades (Oregon and Washington)

- Desert (Eastern Oregon/Washington/Southern Idaho)

- Rockies (Northern and Central Idaho)

- Alaska (Yukon Flats)

Each subdomain is a polygon defined by the following $\mathrm{N}$ latitude/E longitude points. For a visual depiction of the subdomains see figures 13 and 14 . 


\section{NARCCAP SUBDOMAINS LATITUDE AND LONGITUDE:}

\begin{tabular}{|l|l|}
\hline Subdomain & Lat/Long \\
\hline Coast & $(49.00,237.80),(47.82,238.28),(46.52,237.36),(45.50,238.00)$, \\
& $(42.00,236.40),(42.00,235.72),(46.20,236.00),(48.33,235.35)$ \\
\hline Cascades & $(49.00,240.49),(48.37,240.49),(47.84,239.66),(42.00,237.90)$, \\
& $(42.00,236.40),(45.50,238.00),(46.52,237.36),(47.82,238.38)$, \\
& $(49.00,237.80)$
\end{tabular}

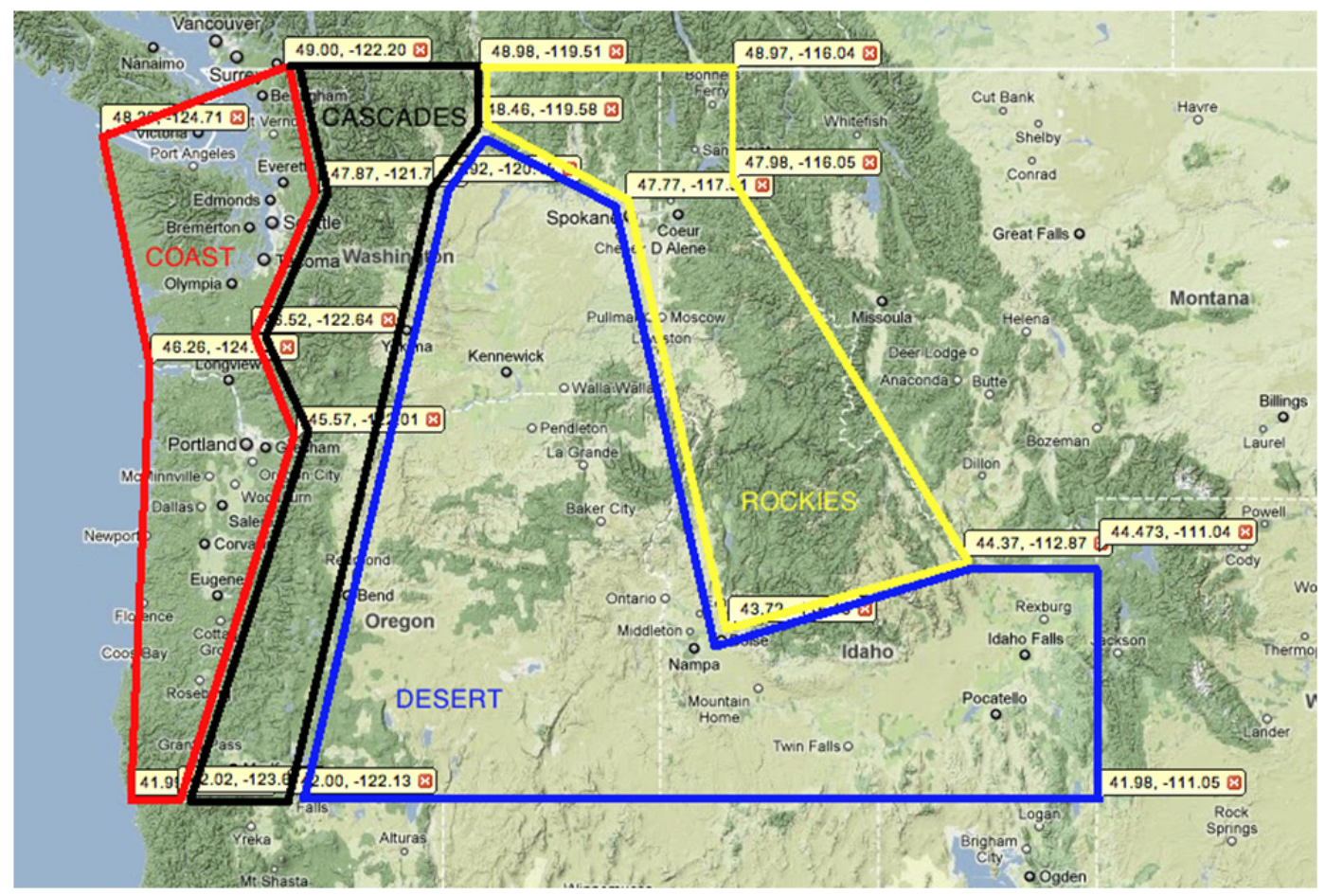

Figure 13 - Pacific Northwest subdomains. 


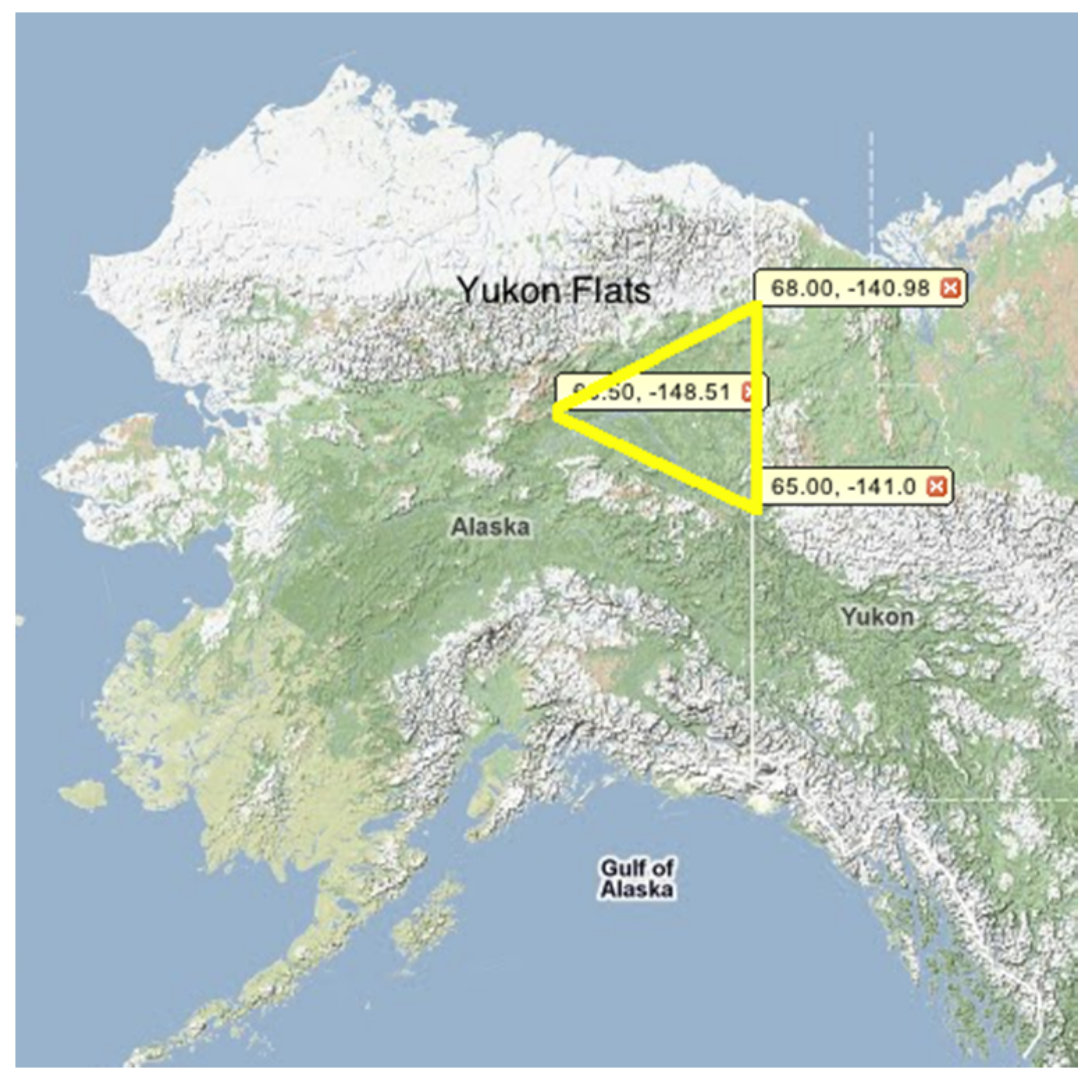

Figure 14 - Yukon Flats subdomain.

The Yukon Flats domain is considerably smaller than the other domains due to the limited coverage of Alaska by NARCCAP. It was chosen to maximize NARCCAP coverage. Data was available from all model pairings for all subdomains, except for Yukon Flats. The RCM3_cgcm3 model pairings domain did not intersect with Yukon Flats. As a result there is no data for RCM3_cgcm3 for Yukon Flats in any of the included plots.

NARCCAP climate parameters are reported as either a maximum or minimum daily value (for temperature); or as a three-hourly value in the case of precipitation or instantaneous temperature. For this project, each subdomain was "clipped" out of the NARCCAP North American domain. This produced a subdomain containing several 
dozen NARCCAP points. Then, the value of the parameter of interest was averaged across all the points in the domain. For example, if a subdomain contained 30 NARCCAP points, the 30 parameter values would be summed and then divided by 30 . This is the value that would then be reported.

Four NARCCAP climate parameters were utilized for this report and are detailed below in Table 6 . Table 7 describes the quantities derived from these parameters.

Table 6 - NARCCAP Climate Parameters

\begin{tabular}{|c|c|}
\hline $\begin{array}{l}\text { Climate } \\
\text { Parameter }\end{array}$ & Description \\
\hline tasmax & Maximum daily surface $(2 \mathrm{~m})$ air temperature, in degrees $C$ \\
\hline tasmin & Minimum daily surface $(2 \mathrm{~m})$ air temperature, in degrees $C$ \\
\hline tas & Instantaneous 3 hourly surface $(2 \mathrm{~m})$ air temperature, in degrees $\mathrm{C}$ \\
\hline$p r$ & $\begin{array}{l}\text { Average precipitation flux ( } \mathrm{mm} / \mathrm{s} \text { ) for a } 3 \text { hourly period (i.e. average flux for } \\
\text { the preceding } 3 \text { hour period) }\end{array}$ \\
\hline
\end{tabular}

\section{Table 7 - Climate Data Parameters Studied}

Climate Data Projected for this Study

Change in Average Temperature (degrees C), FHWA and CIG vs. NARCCAP (5 subdomains), annual and seasonal (Figure 13)

Change in Average Precipitation (percent), FHWA and CIG vs. NARCCAP (5 subdomains), annual and seasonal (Figure 13)

Change in the Average Number of Days/Year when the Temperature equals or exceeds 90F/32C (i.e., tmax >= 90/32), 5 NARCCAP subdomains (Figure 14)

Change in the Average Number of Days/Year when the Temperature equals or dips below 32F/0C (i.e., tmin<= 32/0), 5 NARCCAP subdomains (Figure 14)

Change in the Average Number of Heat Waves/Year, 5 NARCCAP subdomains (Figure 15)

Change in the Average Duration of a Heat Wave, 5 NARCCAP subdomains (Figure 15)

Change in the Average Number of Days/Year when the Total Precipitation equals or exceeds $1 \mathrm{in} / 25 \mathrm{~mm}, 5$ NARCCAP subdomains (Figure 16)

Modeled Historical Average Daily Temperature vs. Projected Future Average Daily Temperature, 5 NARCCAP subdomains (Figure 17)

Modeled Historical Average Daily Maximum Temperature vs. Projected Future Average Daily Maximum Temperature, 5 NARCCAP subdomains (Figure 18) Modeled Historical Average Daily Minimum Temperature vs. Projected Future Average Daily Minimum Temperature, 5 NARCCAP subdomains (Figure 18) Modeled Historical Average Precipitation of 10 Wettest Days vs. Modeled Projected Future Average Precipitation of 10 Wettest Days, 5 NARCCAP subdomains (Figure 19) Modeled Historical Average Number of Freeze/Thaw Cycles per Year vs. Modeled Projected Future Average Number of Freeze/Thaw Cycles per Year, 5 NARCCAP subdomains (Figure 20) 


\section{NARCCAP RESULTS SUMMARY}

NARCCAP temperature and precipitation results (both annual and seasonal) for four of the five subdomains examined (Coast, Cascades, Desert, Rockies) are broadly consistent with previous AOGCM based regional studies (FHWA and CIG). The fifth subdomain (Yukon Flats) exhibits large differences in annual and seasonal temperature and precipitation compared to FHWA and CIG (and the other four NARCCAP subdomains).

All methodologies for all subdomains project an increase in temperature. Precipitation is not so monolithic; projections span the range from an 80 percent increase to a 20 percent decrease, depending on the domain and model. For the Yukon Flats subdomain, however, all models project an increase in precipitation (both annually and seasonally), albeit with a considerable amount of uncertainty in the form of model spread. This result is consistent with the results of the Scenarios Network for Alaska Planning (SNAP) downscaled AOGCM analysis.

For the four subdomains within the contiguous United States, NARCCAP models generally project an increase in extreme warm days. However, the spread of model projections is high, indicating considerable uncertainty. NARCCAP models project a decrease across all domains for extreme cold days, with a moderate spread between the different models.

For the most part, NARCCAP projects an increase in the number of heat waves/year and an increase in the duration of heat waves (where a heat wave is defined as three or more consecutive days when the high temperature exceeds $32^{\circ} \mathrm{C} / 90^{\circ} \mathrm{F}$ ). However this is not consistent across all domains and all models. Some subdomain/model 
combinations project fewer heat waves and shorter durations. The variability in the heat wave results may be due in part to the small number of data points (as a result of very few events that met the requirements for a heat wave as defined here).

NARCCAP projects essentially no change in the number of extreme wet days to a slight increase, depending on the model and domain considered. Again, the very few data points involved may be adding to the variability and uncertainty.

These results above are summarized in Table 8, 9 and 10 below.

\section{Table 8 - Changes in Average Temperature and Precipitation}

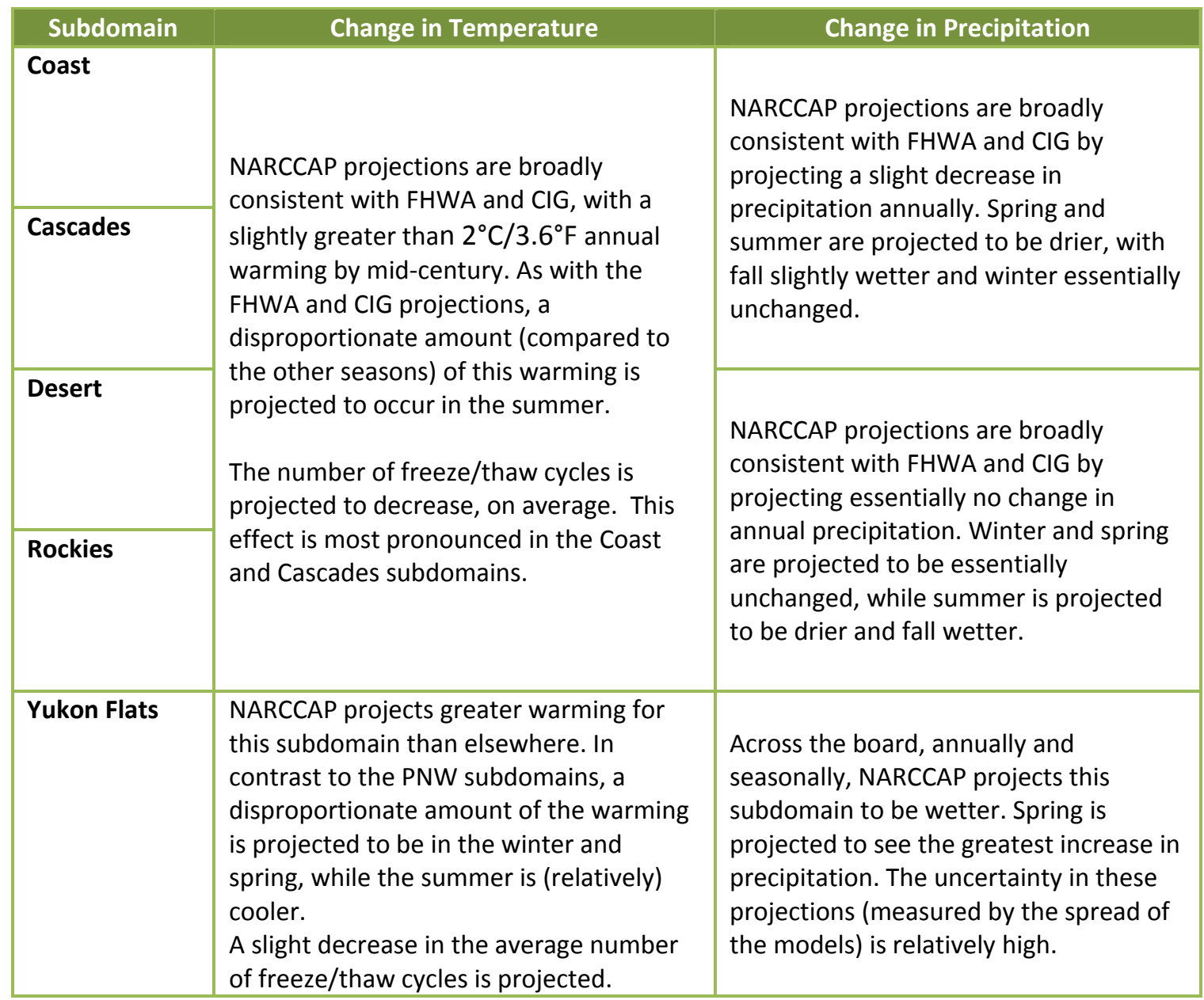


Table 9 - Extreme Warm and Cold Days

\begin{tabular}{|c|c|c|}
\hline Subdomain & $\begin{array}{c}\text { Change in Number of Extreme Warm } \\
\text { Days }\end{array}$ & $\begin{array}{c}\text { Change in Number of Extreme Cold } \\
\text { Days }\end{array}$ \\
\hline Coast & \multirow{4}{*}{$\begin{array}{l}\text { NARCCAP projections suggest an increase } \\
\text { in the number of extreme warm } \\
\text { days/year. However, there is broad } \\
\text { disagreement among the models. For any } \\
\text { of these subdomains, projections run the } \\
\text { gamut from essentially no increase to an } \\
\text { additional 20+ days/year. }\end{array}$} & \multirow{5}{*}{$\begin{array}{l}\text { NARCCAP projects a large decrease in } \\
\text { the number of extreme cold days/year } \\
\text { for all subdomains. The data suggests } \\
\text { that the Cascades subdomain may see } \\
\text { the largest decrease. However there is } \\
\text { some disagreement between models for } \\
\text { all subdomains. }\end{array}$} \\
\hline Cascades & & \\
\hline Desert & & \\
\hline Rockies & & \\
\hline Yukon Flats & $\begin{array}{l}\text { All the NARCCAP models are in } \\
\text { agreement in projecting no increase in } \\
\text { extreme warm days/year. It is unusual to } \\
\text { have even one extreme warm day } \\
\text { (historical or future)/year in this } \\
\text { subdomain. }\end{array}$ & \\
\hline
\end{tabular}

Table 10 - Number of Heat Waves/Year and Duration of Heat Waves

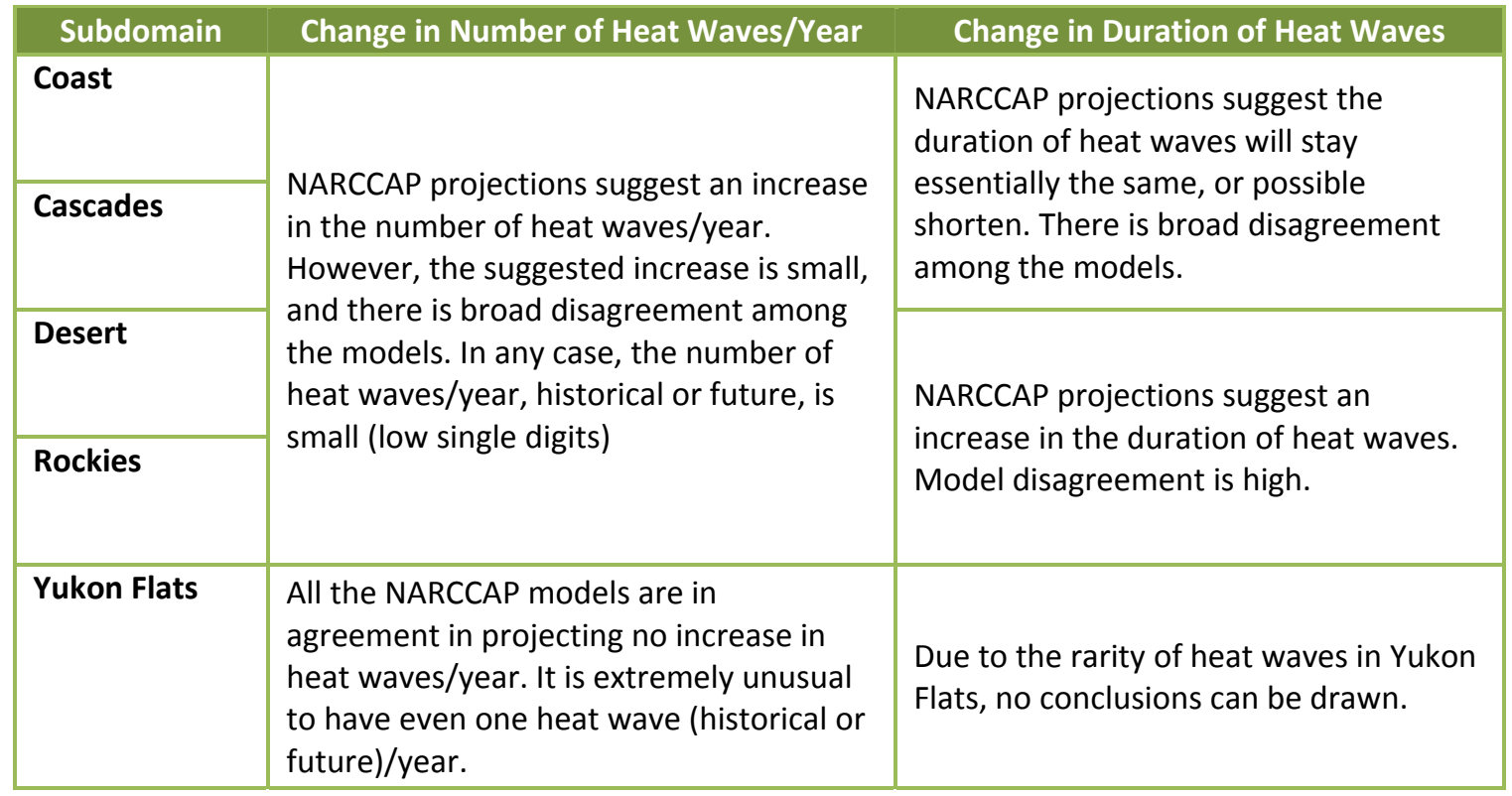




\section{NARCCAP SUBDOMAIN DETAILED RESULTS AND PROJECTIONS}

For each of the following plots, the change (or difference) is always the modeled future value minus the modeled historical value. Note that NARCCAP historical runs are not an attempt to exactly duplicate observed climate for that time period. Rather, they strive to approximate the average climate over the period in question. Likewise, future simulations are not an attempt to "predict" the future weather, but rather an attempt to simulate one possible realization of future climate.

Each plot illustrates the results for each of the RCM-AOGCM pairings examined, as well as the mean result for all the pairings (i.e., the ensemble mean). As mentioned above, NARCCAP modeling runs assume A2 emissions. In all plots, the ensemble mean is represented by the column, while the scatter points represent the individual model pairing results. For plots using error bars instead of individual model pairing results (i.e., scatter points), the range of the error bars indicates the range of the modeled results. The spread of the individual results (or the magnitude of the error bars) gives an indication of the uncertainty of the estimate. All changes are for the "mid-century" time period (20412070) unless otherwise noted.

For all plots, the following abbreviations for the seasons are used: Winter (DJF $=$ December, January, February); Spring (MAM = March, April, May); Summer (JJA = June, July, August); and Fall (SON = September, October, November.)

Figures $15(a-j)$ illustrate the change in temperature and precipitation on an annual and seasonal basis. The FHWA and CIG values used were obtained from the published reports cited above. Note that the FHWA report assumed A2 emissions, while the CIG report assumes A1B. Also, the FHWA "mid-century" time period is considered to be 
2040-2070, while the CIG time period illustrated is the 2040s. The base (or reference) period for FHWA is 1961-1979. The base period for CIG is 1970-1999. The base period for NARCCAP is 1971-2000. In Figures 15 (a-j), a positive temperature value indicates a warmer future. A positive precipitation percentage change indicates a wetter future.

Figures $16(\mathrm{a} \& \mathrm{~b})$ illustrate the average changes in extreme temperatures. Figure 16a illustrates the change in the average number of days/year that the daily maximum temperature (tmax) is greater than or equal to $32^{\circ} \mathrm{C} / 90^{\circ} \mathrm{F}$. Conversely, Figure $16 \mathrm{~b}$ illustrates the change in the average number of days/year that the daily minimum temperature (tmin) is less than or equal to $0^{\circ} \mathrm{C} / 32^{\circ} \mathrm{F}$. For Figure $16 \mathrm{a}$, positive values indicate an increase in the number of warm days. For Figure 16b, negative values (note the reversed scale) indicate a reduction in the number of cold days.

Figures $17(\mathrm{a} \& \mathrm{~b})$ illustrate the projected changes in the average number of heat waves/year, and the duration of the average heat wave. For both figures, positive values indicate more (or longer) heat waves, while negative values indicate fewer (or shorter) heat waves. A "heat wave" in this instance is defined as a period of three or more consecutive days when the high temperature (tmax) equals or exceeds $32^{\circ} \mathrm{C} / 90^{\circ} \mathrm{F}$.

Figure 18 illustrates the change in the average number of days/year when the total daily precipitation equals or exceeds $25 \mathrm{~mm} / 1 \mathrm{in}$. A positive value projects more extreme wet days/year in the future.

Figures 19 (a-e) depict the average daily temperature, by month, for the historical and future periods for each of the five subdomains. The error bars indicate the range of modeled results. 
Figure 20 (a-e) illustrate the average daily maximum and minimum temperature, by month, for the historical and future periods for each of the five subdomains. The daily maximum temperature is the highest temperature reached during the day, while the daily minimum temperature is the lowest. The error bars indicate the range of modeled results.

Figure 21 depicts the average precipitation for the 10 wettest days in each of the historical and future periods for each of the five subdomains. In other words, the 10 wettest days in each (30-year) period were identified, and their average was computed. This average was then plotted. The error bars indicate the range of the modeled results.

Figure 22 illustrates the average number of freeze/thaw cycles per year for the historical and future periods for each of the five subdomains. A "freeze/thaw cycle" was defined as a day that had both a maximum temperature $>0^{\circ} \mathrm{C} / 32^{\circ} \mathrm{F}$ and a minimum temperature $<=0^{\circ} \mathrm{C} / 32^{\circ} \mathrm{F}$. The error bars indicate the range of modeled results. 
Figures 15(a-j) - Annual and Seasonal Temperature and Precipitation Changes

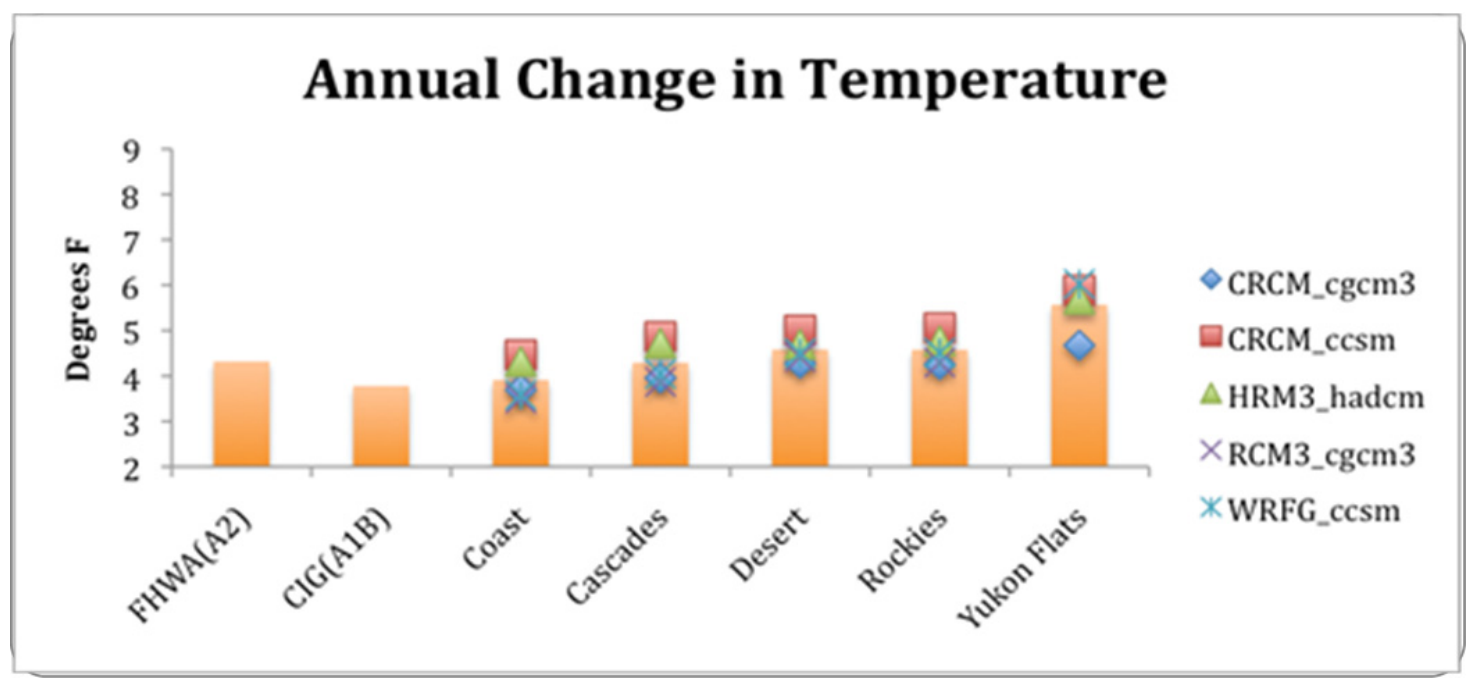

Figure 15a - Annual Change in Temperature

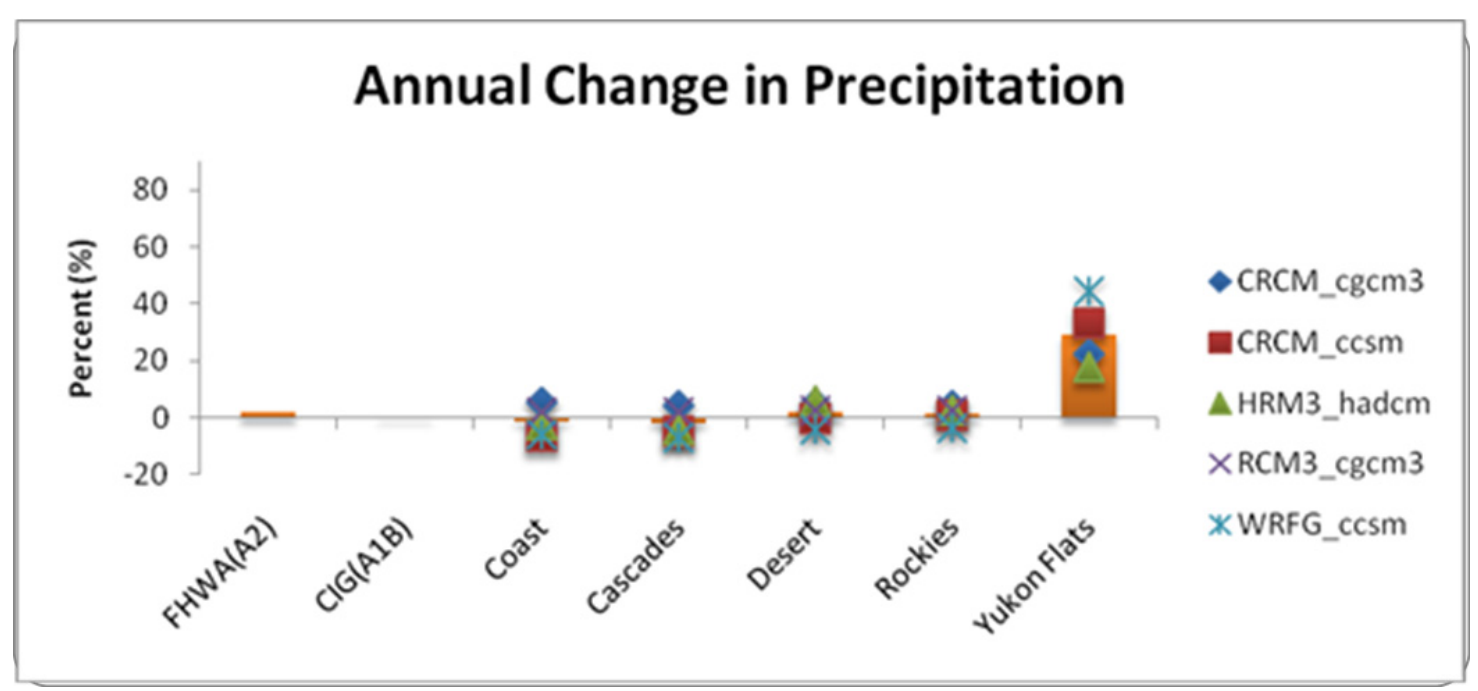

Figure 15b - Annual Change in Precipitation 
Figures 15(a-j) - Annual and Seasonal Temperature and Precipitation Changes

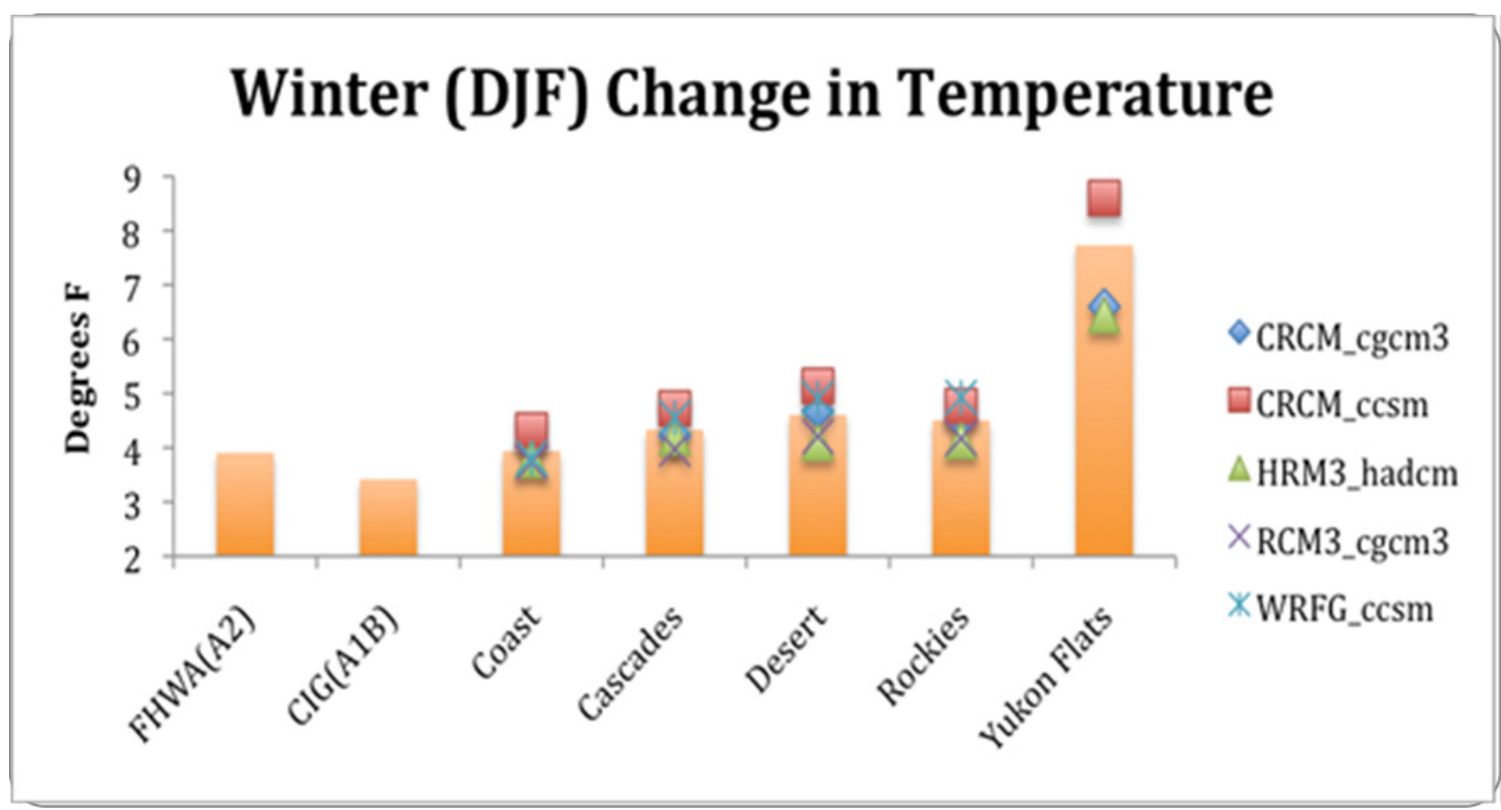

Figure 15c - Winter (December/January/February) Change in Temperature

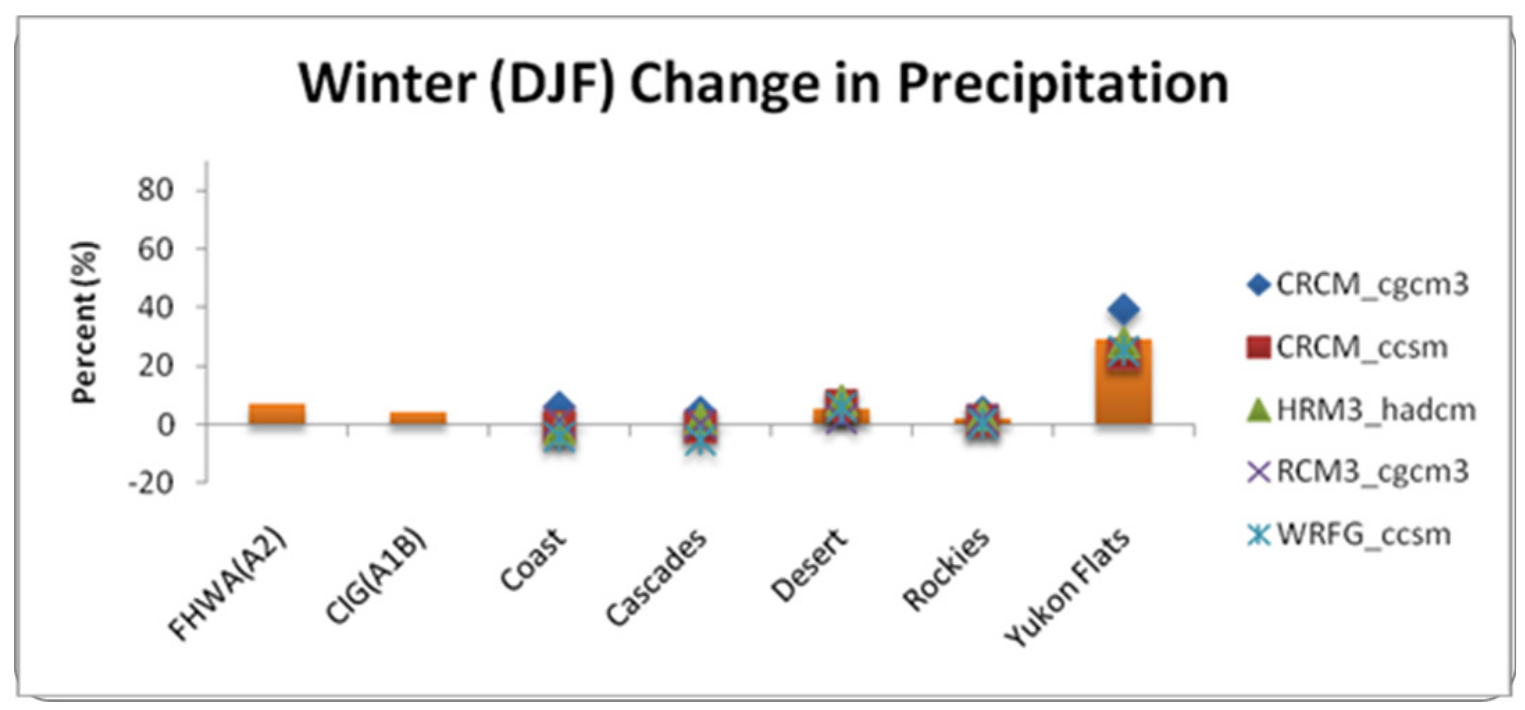

Figure 15d - Winter (December/January/February) Change in Precipitation 
Figures 15(a-j) - Annual and Seasonal Temperature and Precipitation Changes

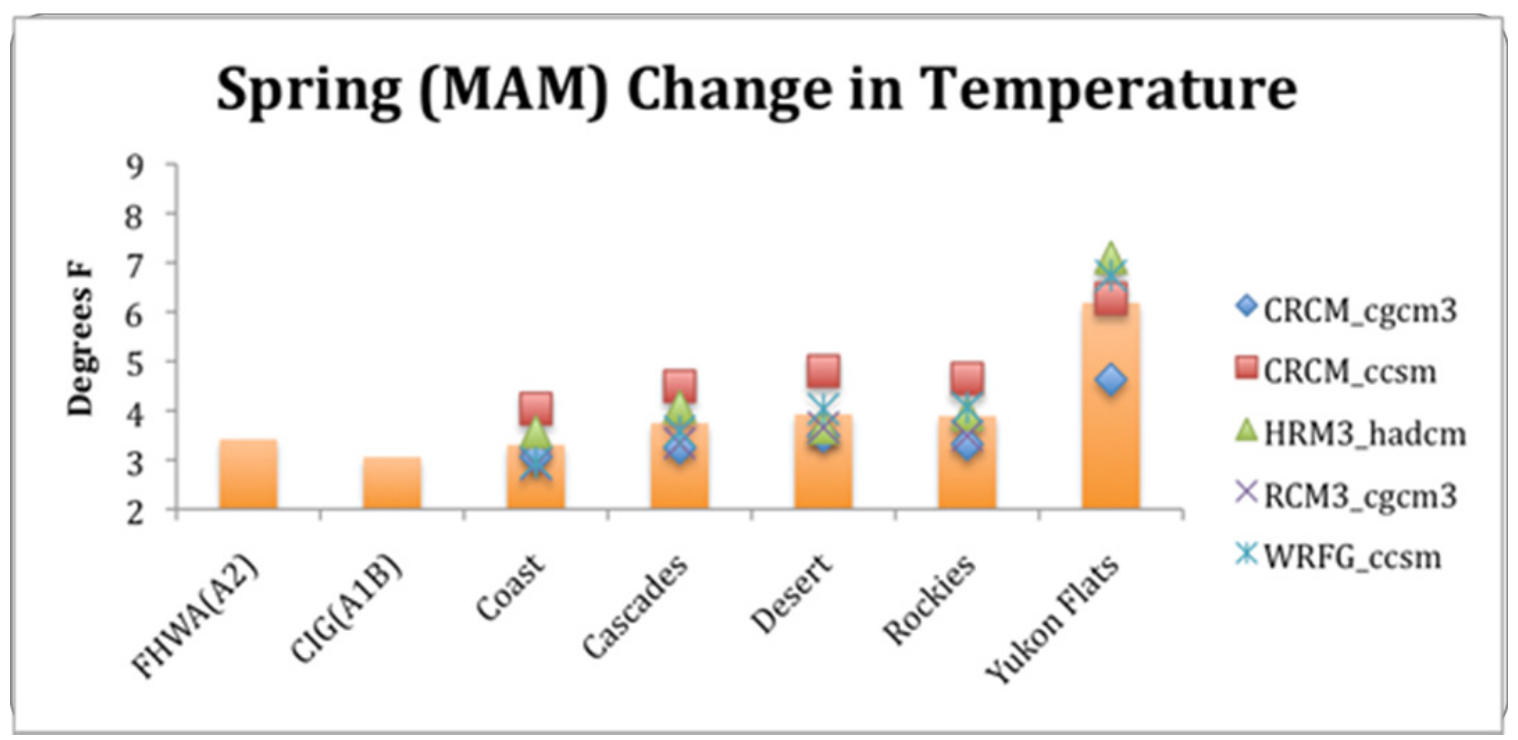

Figures 15e - Spring (March/April/May) Change in Temperature

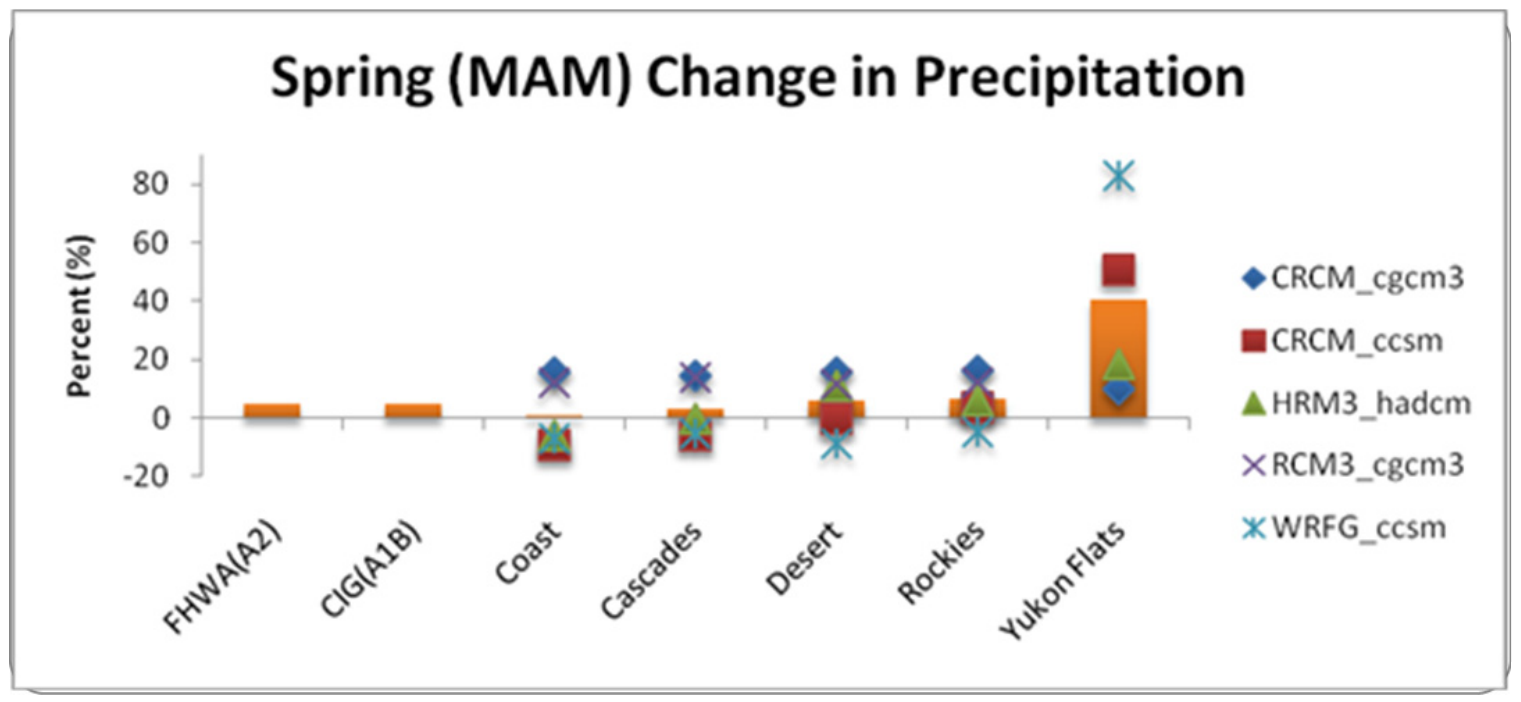

Figure 15f - Spring (March/April/May) Change in Precipitation 
Figures 15(a-j) - Annual and Seasonal Temperature and Precipitation Changes

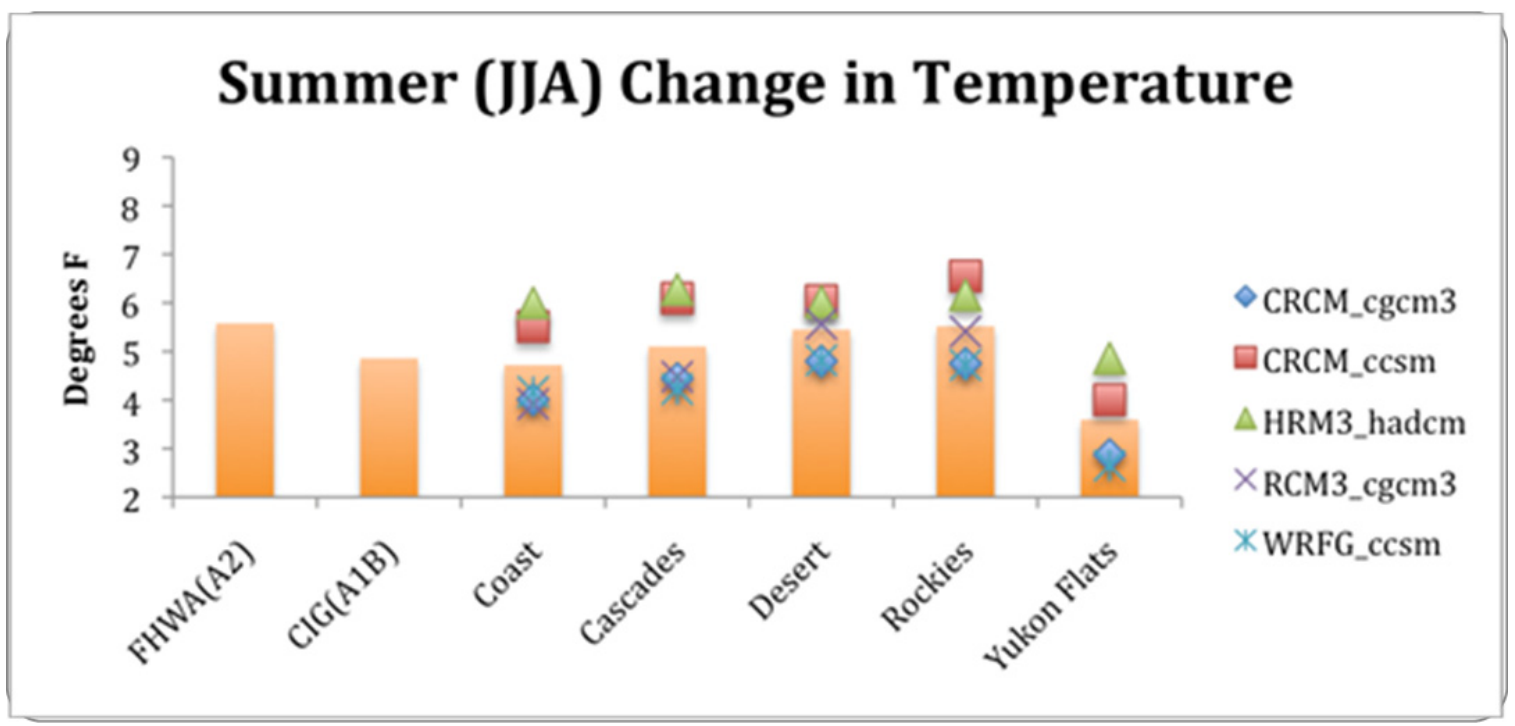

Figure 15g - Summer (June/July/August) Change in Temperature

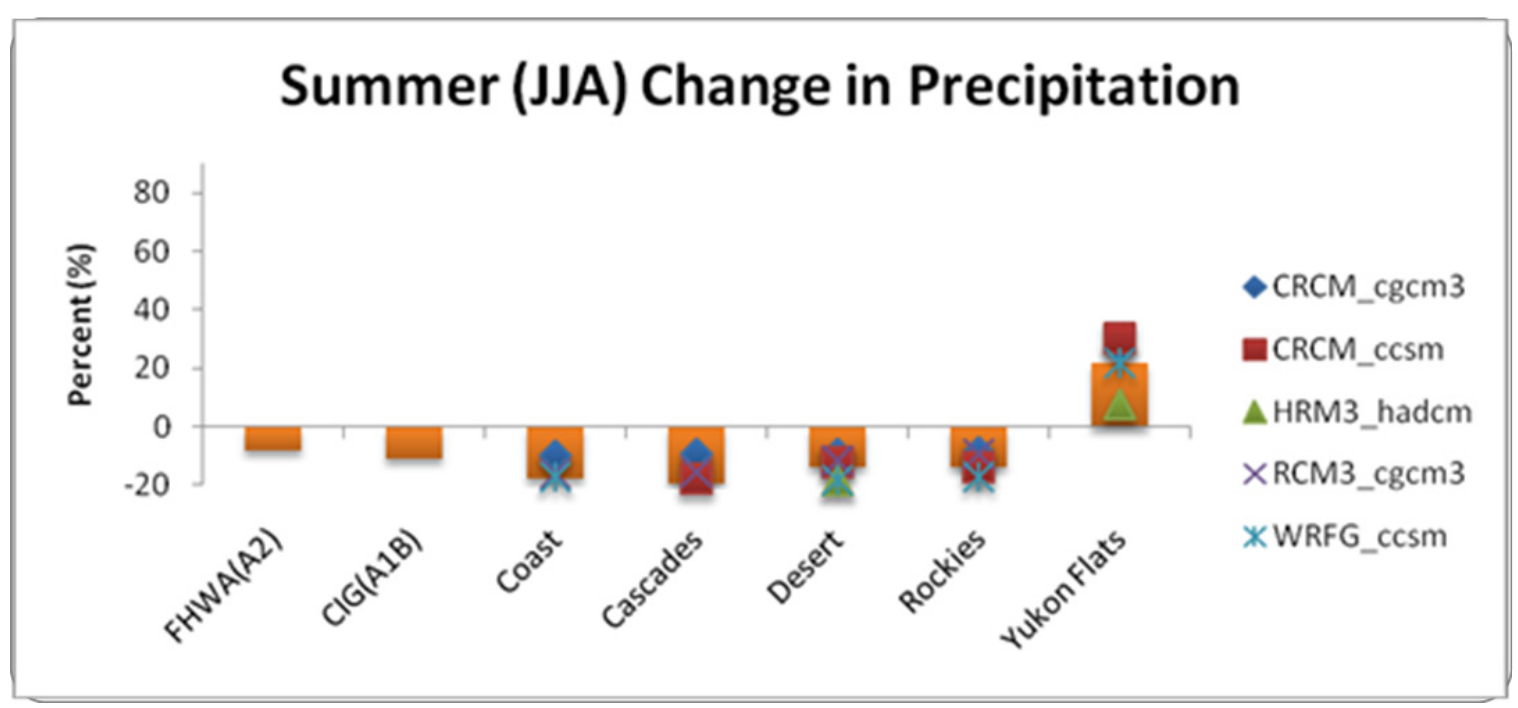

Figure 15h - Summer (June/July/August) Change in Precipitation 
Figures 15(a-j) - Annual and Seasonal Temperature and Precipitation Changes

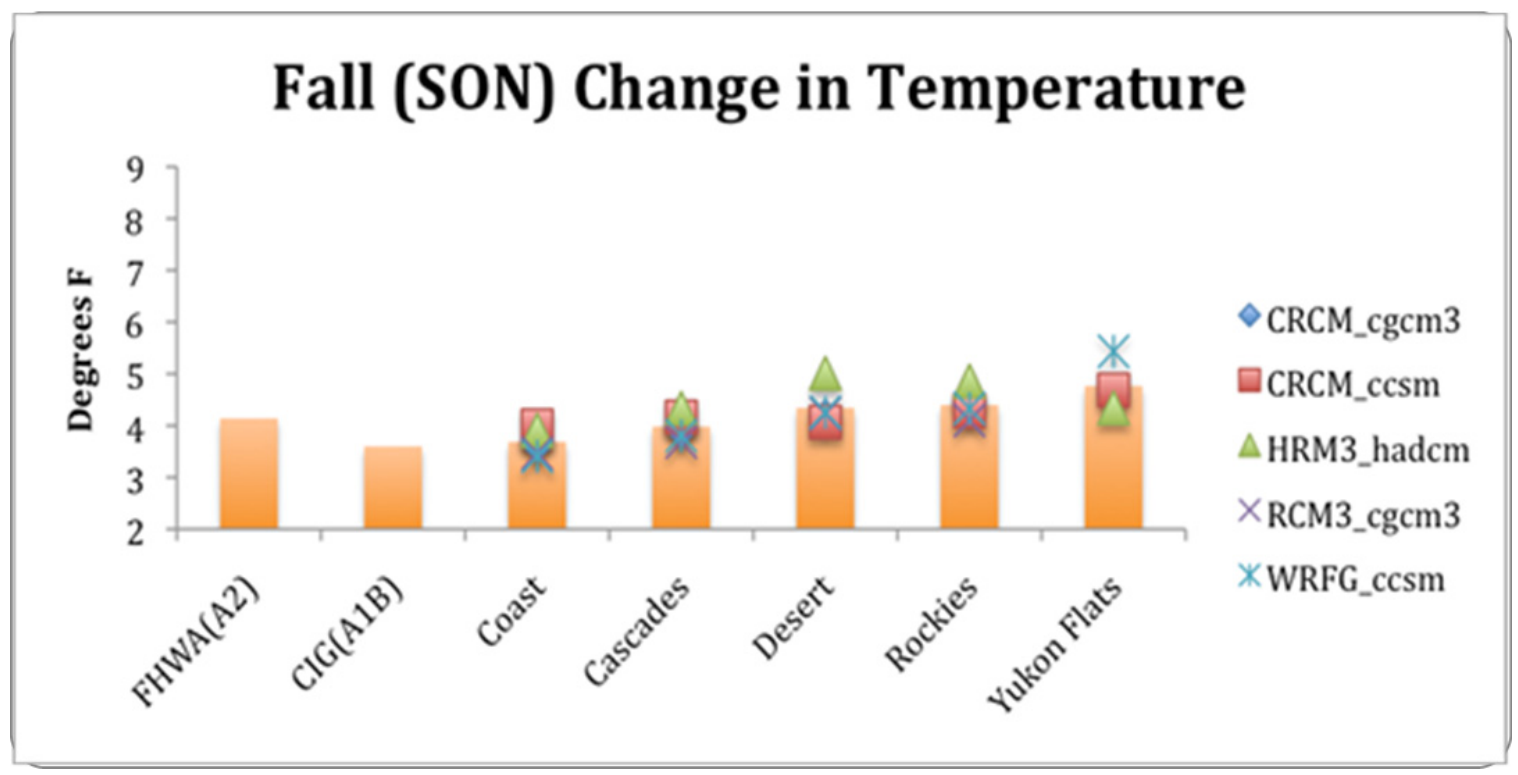

Figure 15i - Fall (September/October/November) Change in Temperature

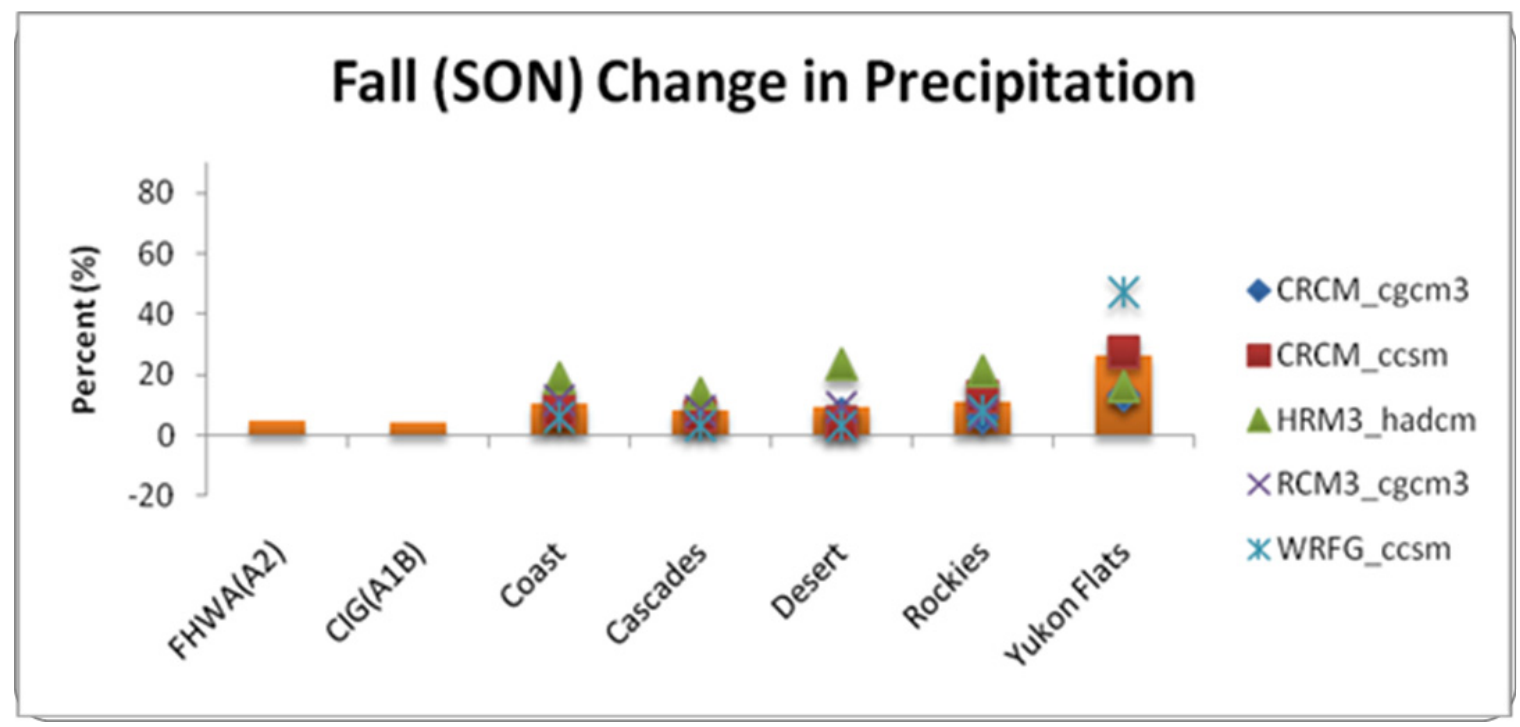

Figure 15j - Fall (September/October/November) Change in Precipitation 
Figure 16(a \& b) - Changes in Extreme Temperatures

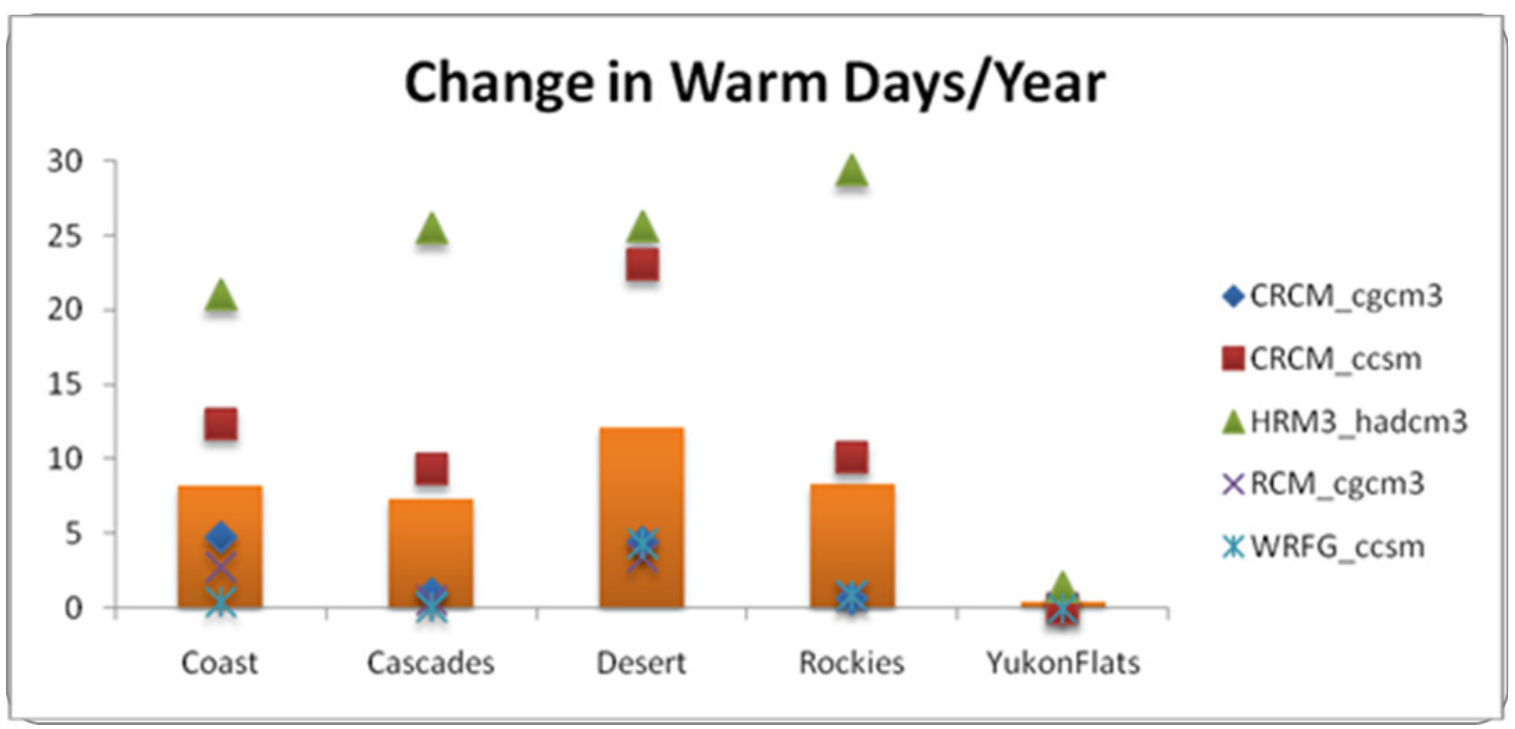

Figure $16 \mathrm{a}-$ Change in the Average Number of Days $/$ Year $>=90^{\circ} \mathrm{F} / 32^{\circ} \mathrm{C}$

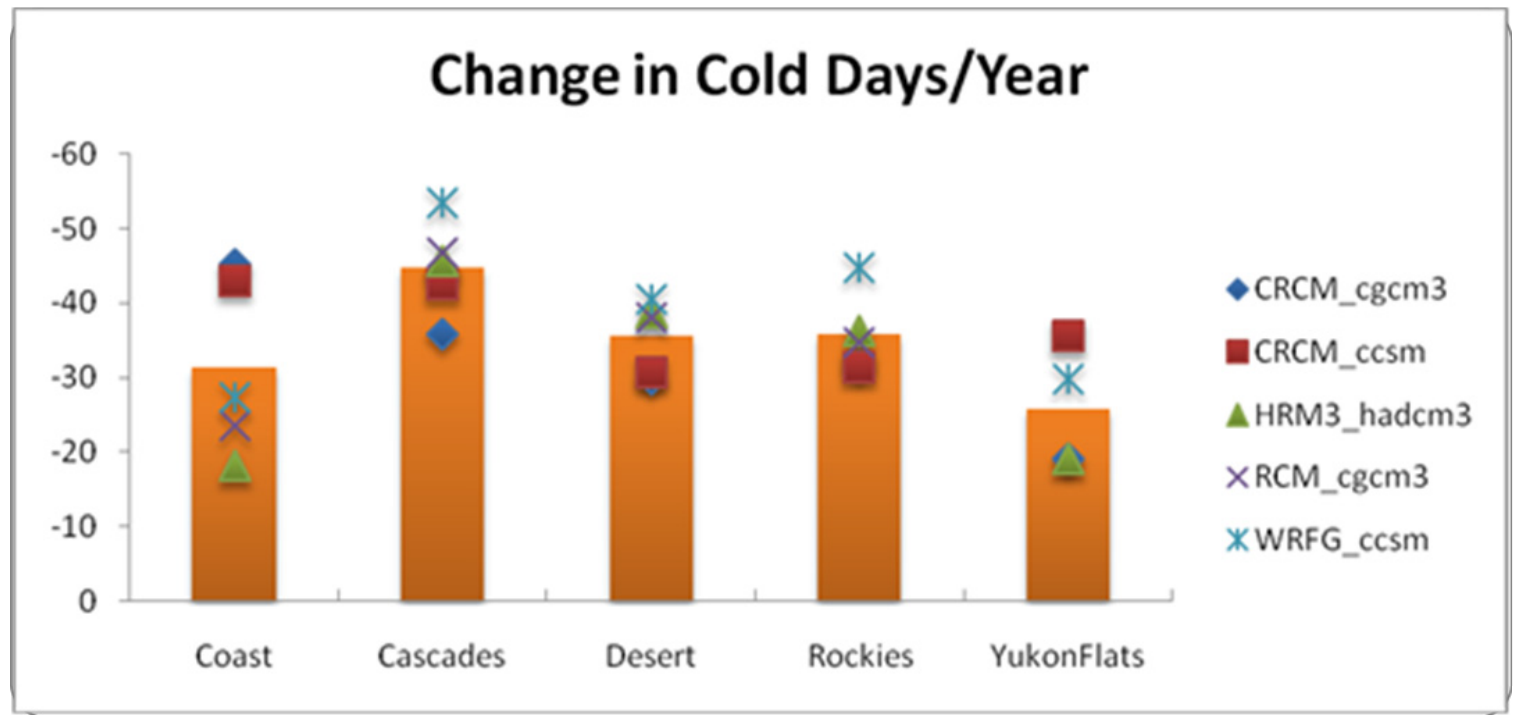

Figure $16 \mathrm{~b}-$ Change in the Average Numver of Days $/$ Year $<=32^{\circ} \mathrm{F} / 0^{\circ} \mathrm{C}$ 
Figure 17(a \& b) - Changes in Extreme Heat Events

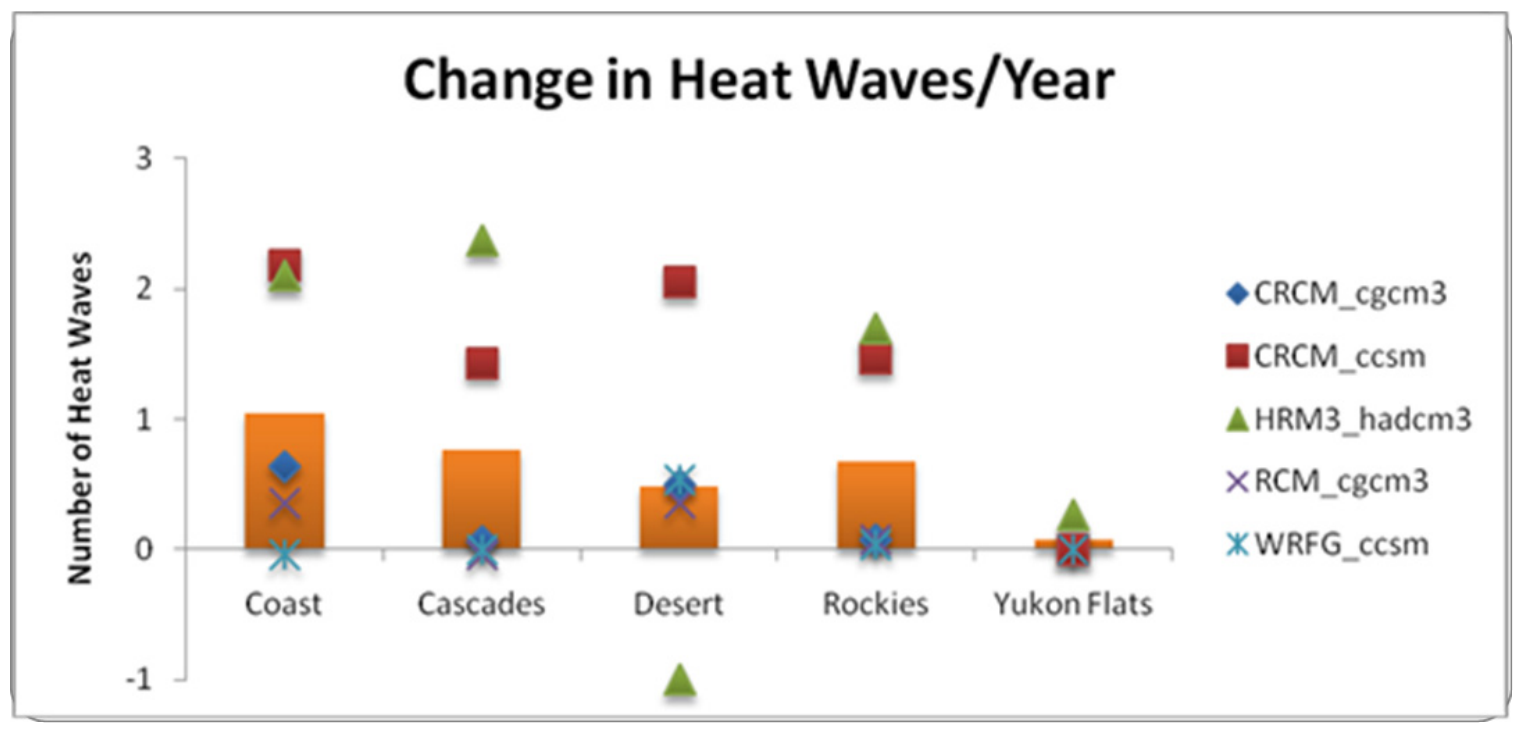

Figure $17 \mathrm{a}-$ Change in the Average Number of Heat Waves/Year

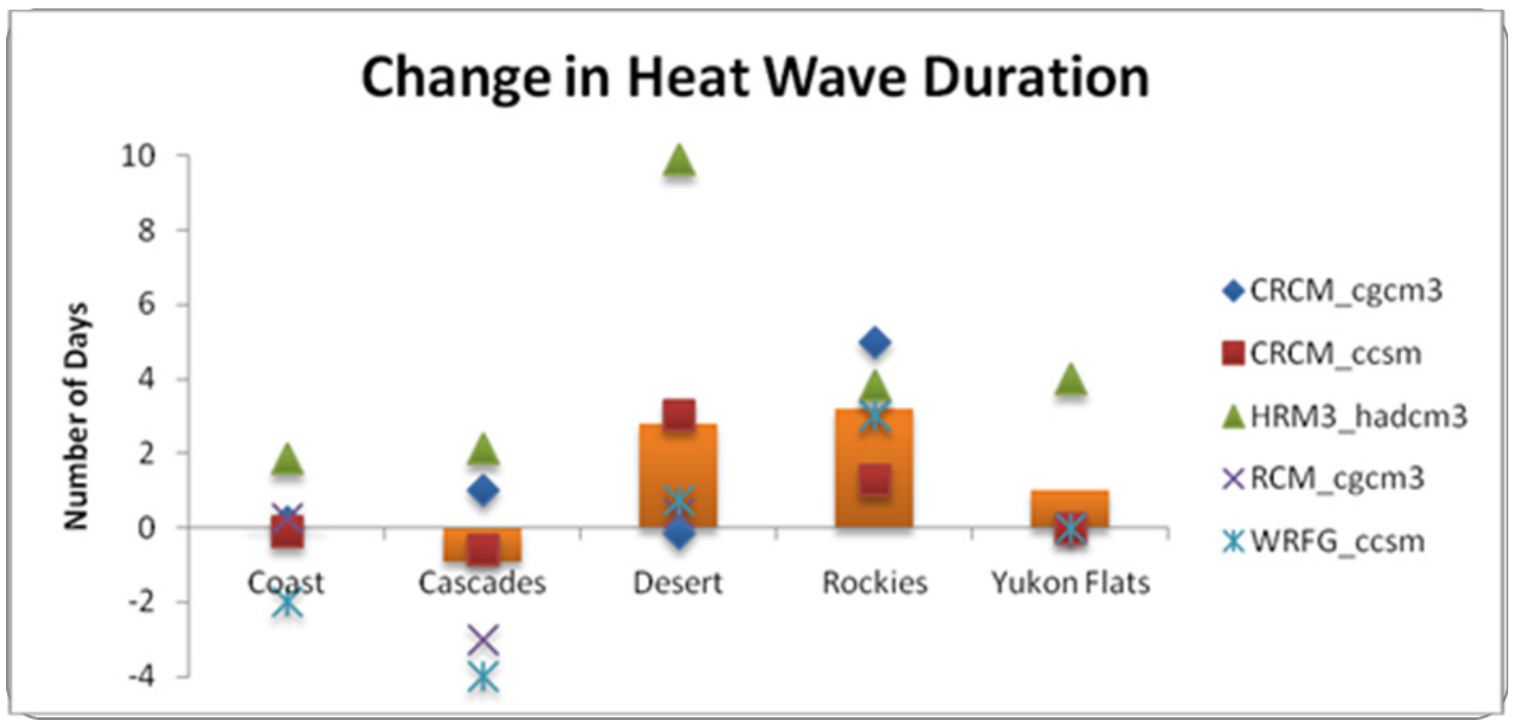

Figure $17 b-$ Change in Average Heat Wave Duration 
Figure 18 - Change in Extreme Precipitation Events

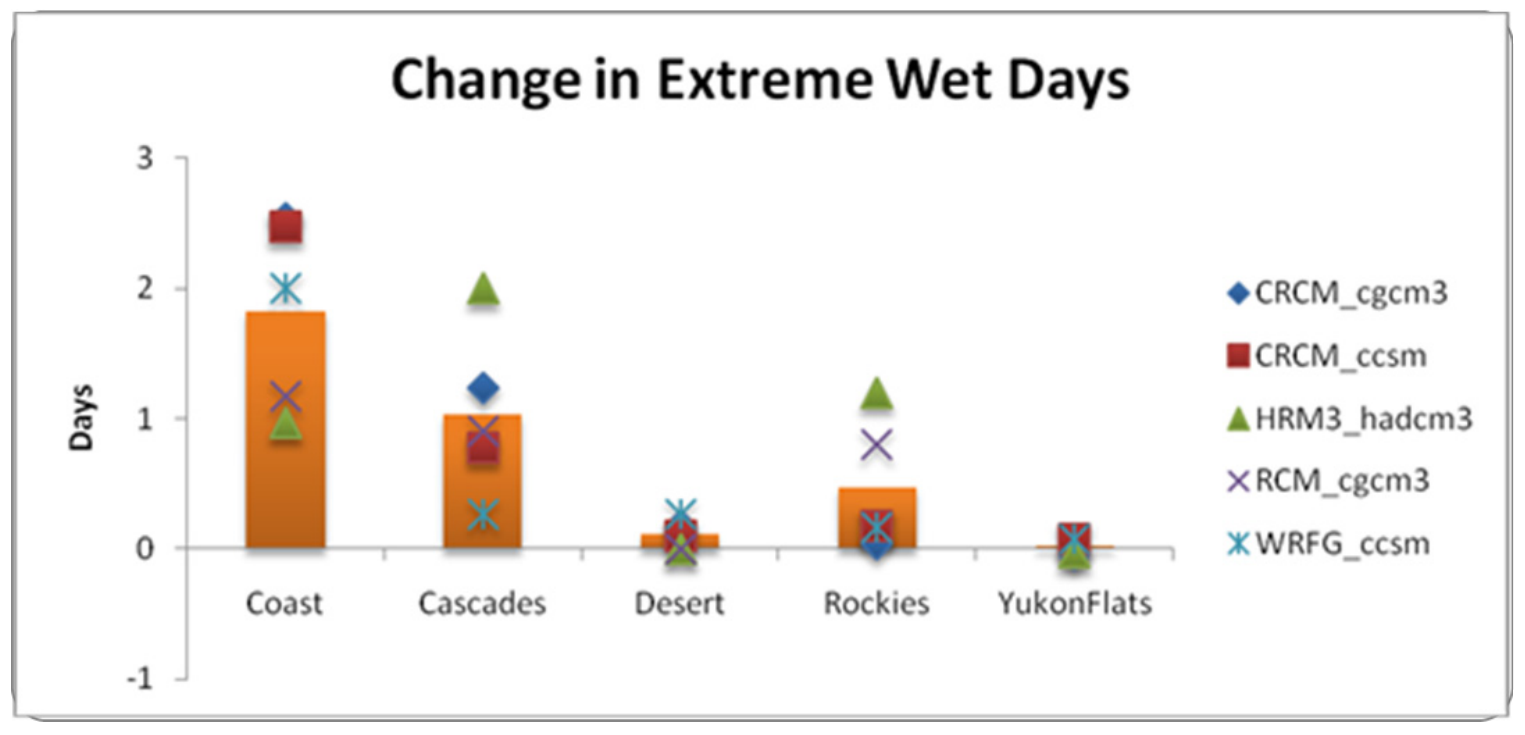

Figure 18 - Change in the Average Number of Days/Year with Total Precipitation $>=$ $1 \mathrm{in} / 25 \mathrm{~mm}$ 
Figures 19(a-e) - Average Daily Temperatures

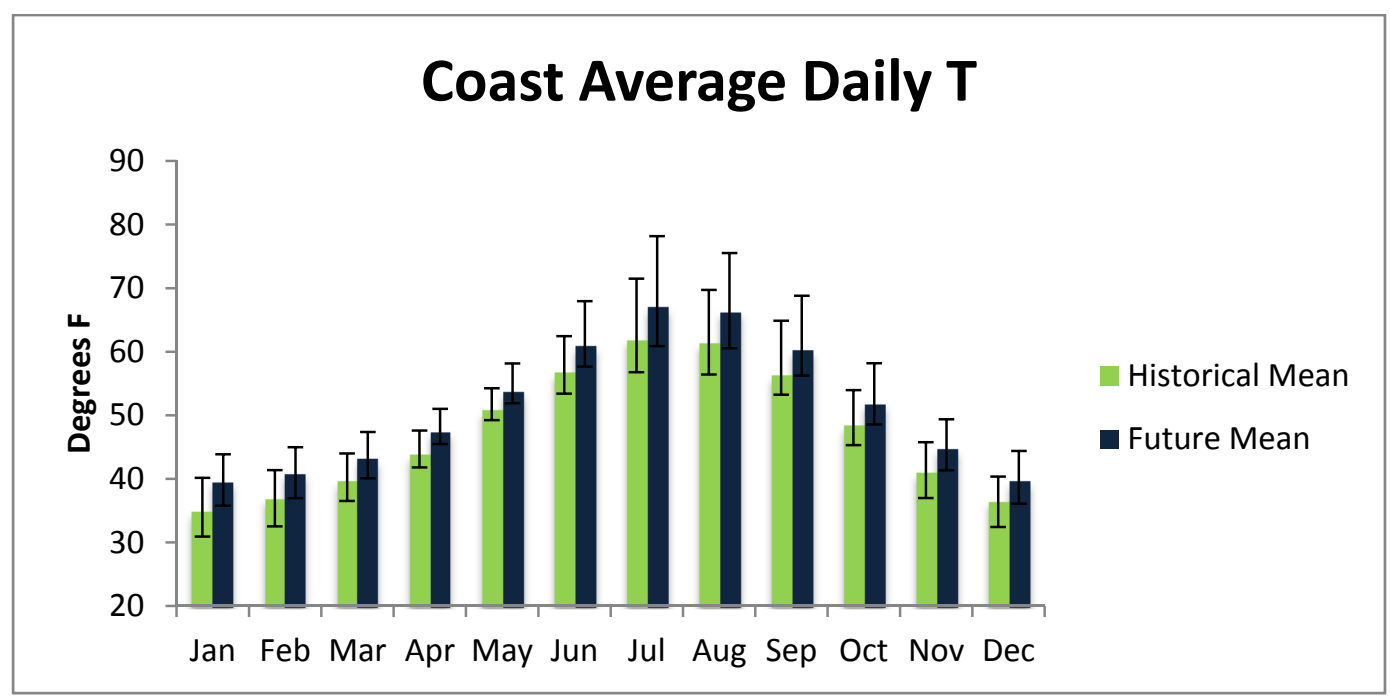

Figure 19a - Modeled Historical Average Daily Temperature vs. Projected Future Average Daily Temperature, Coast subdomain. Error bars indicate the range of modeled results.

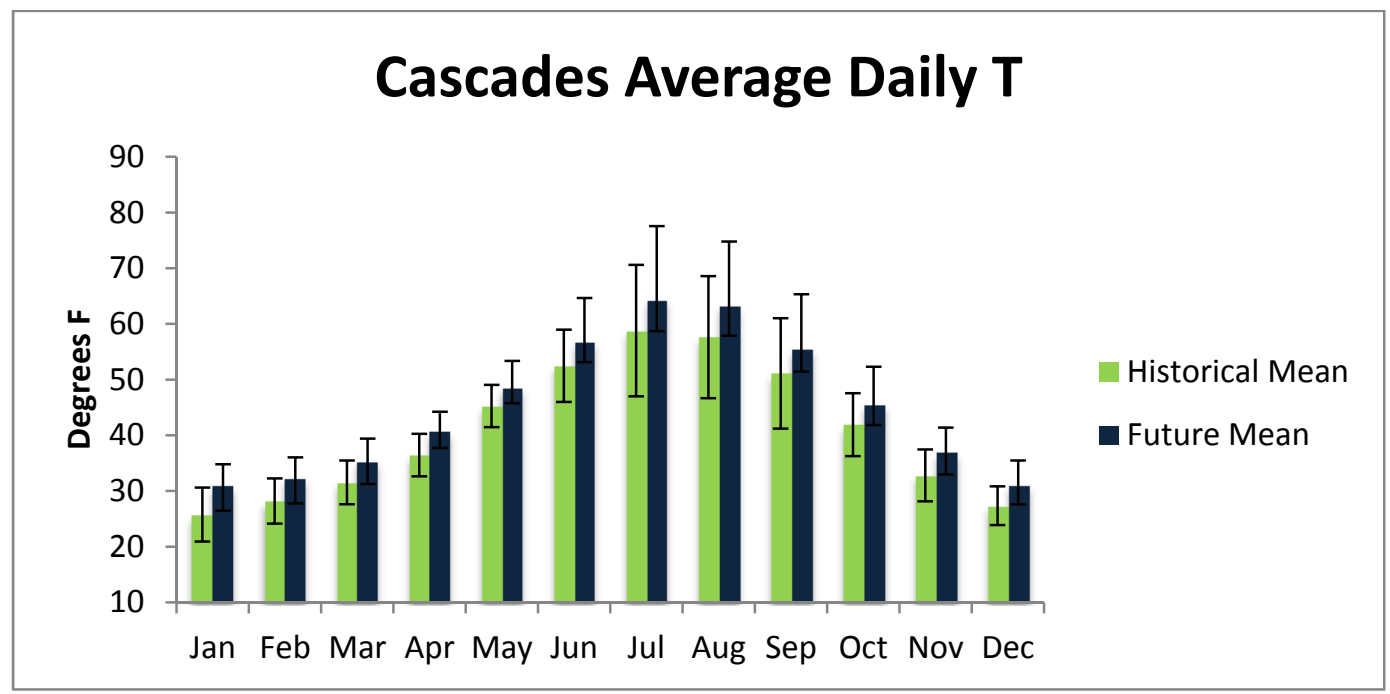

Figure 19b - Modeled Historical Average Daily Temperature vs. Projected Future Average Daily Temperature, Cascades subdomain. Error bars indicate the range of modeled results. 
Figures 19(a-e) - Average Daily Temperatures

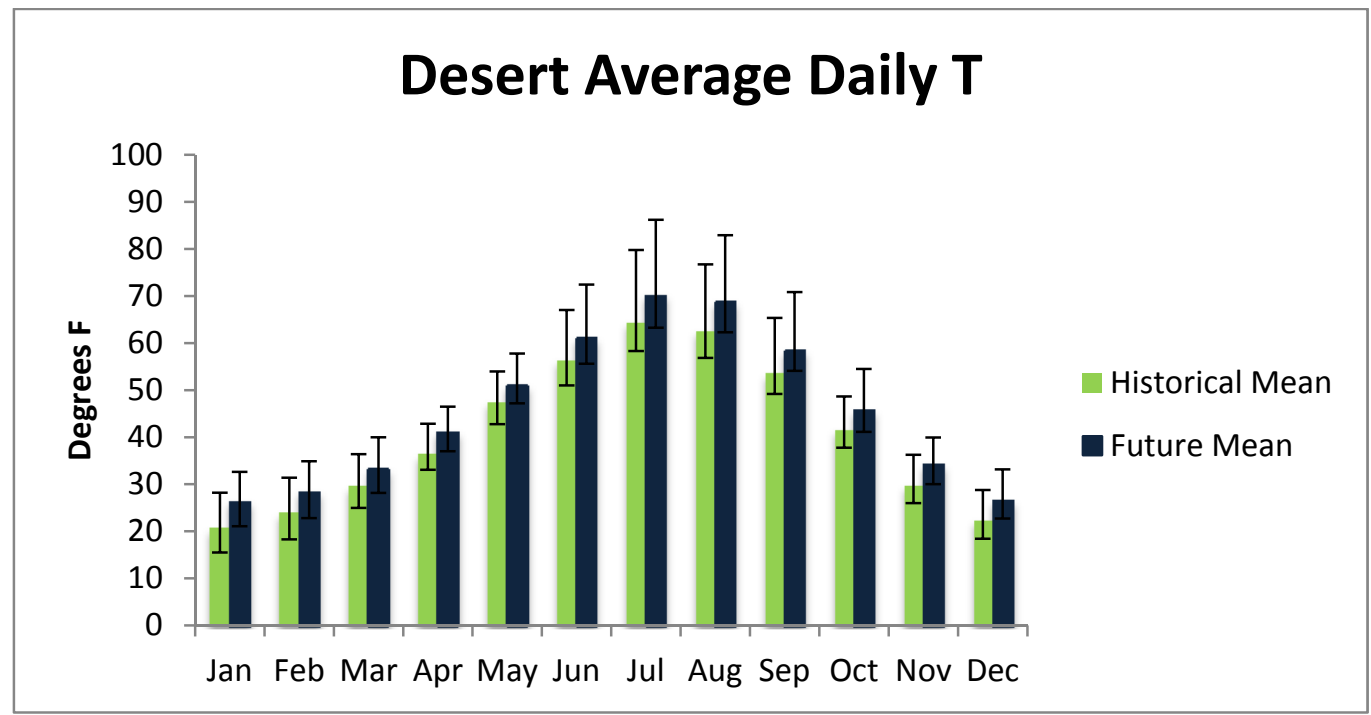

Figure 19c - Modeled Historical Average Daily Temperature vs. Projected Future Average Daily Temperature, Desert subdomain. Error bars indicate the range of modeled results.

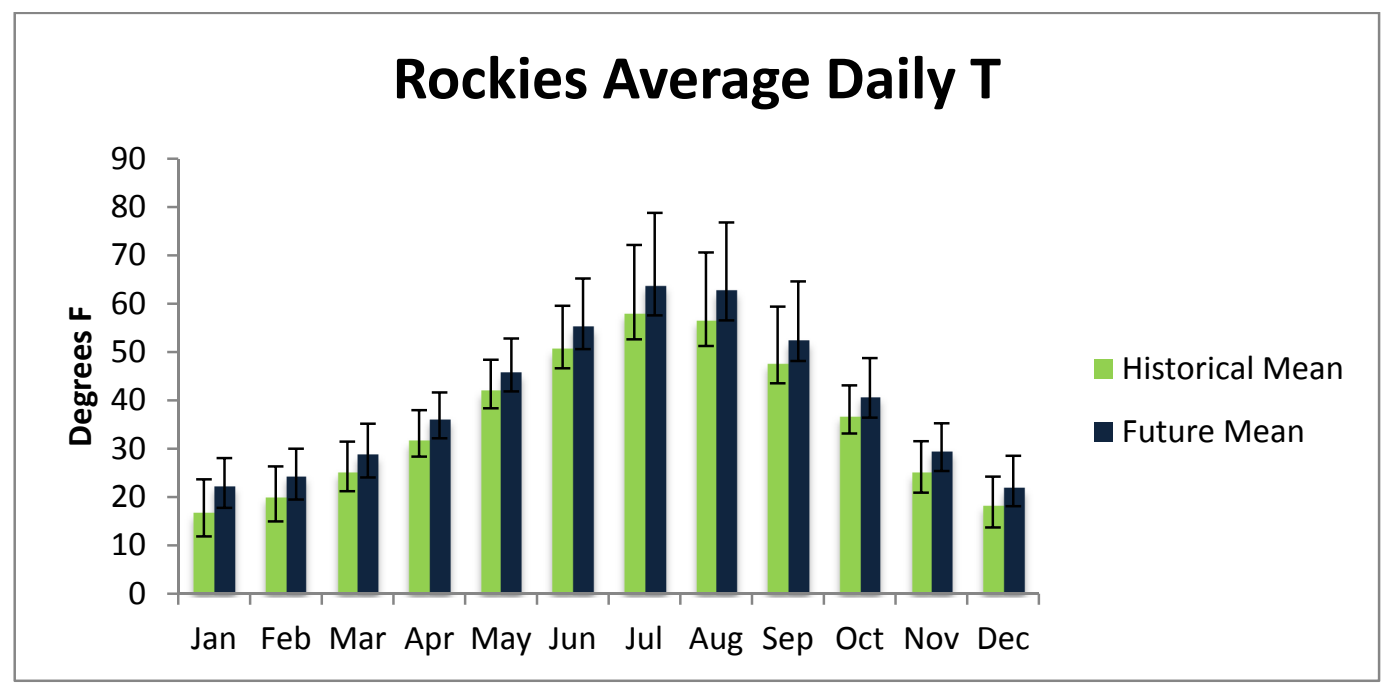

Figure 19d - Modeled Historical Average Daily Temperature vs. Projected Future Average Daily Temperature, Rockies subdomain. Error bars indicate the range of modeled results. 
Figures 19(a-e) - Average Daily Temperatures

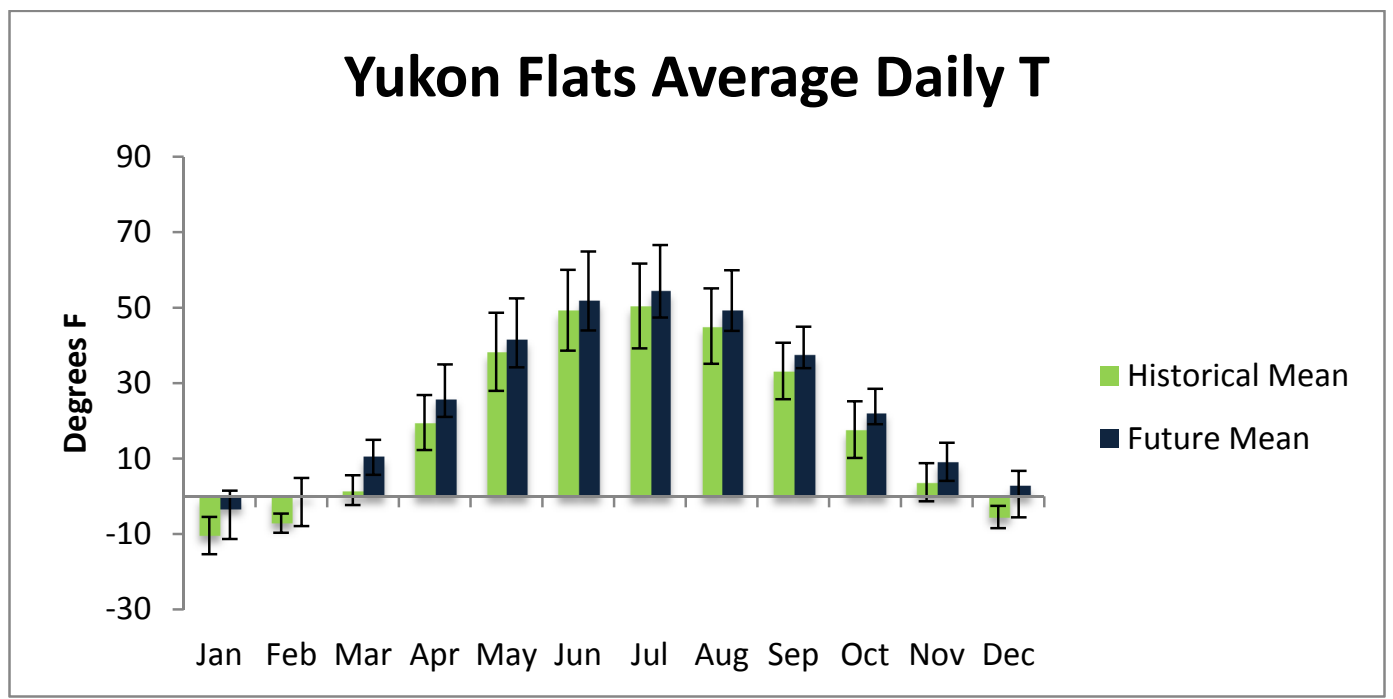

Figure 19e - Modeled Historical Average Daily Temperature vs. Projected Future Average Daily Temperature, Yukon Flats subdomain. Error bars indicate the range of modeled results. 
Figures 20(a-e) - Average Monthly Maximum/Minimum Temperatures
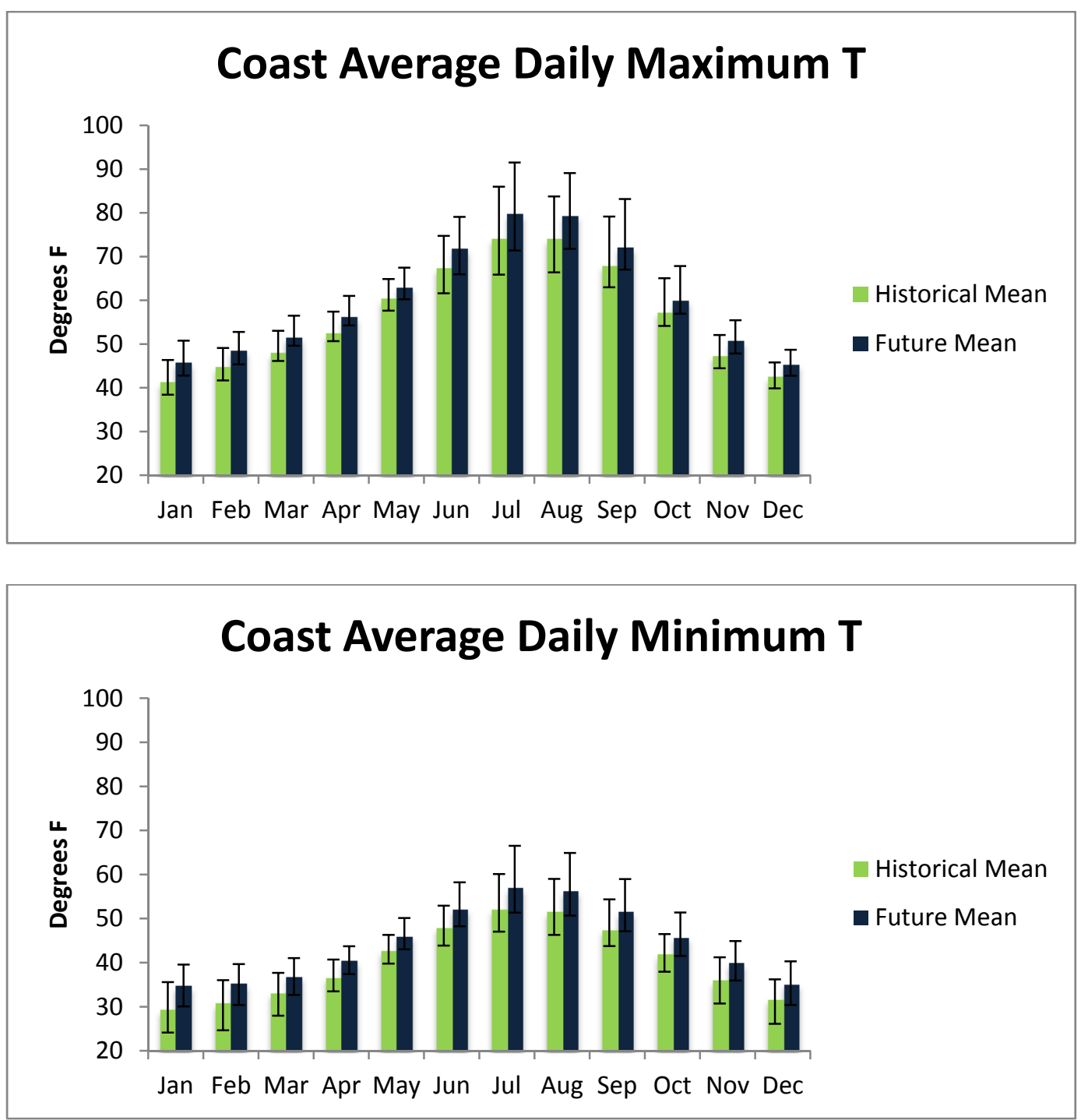

Figures 20a-Modeled Historical Average Monthly Maximum and Minimum Temperatures vs. Projected Future Average Monthly Maximum and Minimum Temperatures, Coast subdomain. Error bars indicate the range of modeled results. 
Figures 20(a-e) - Average Monthly Maximum/Minimum Temperatures
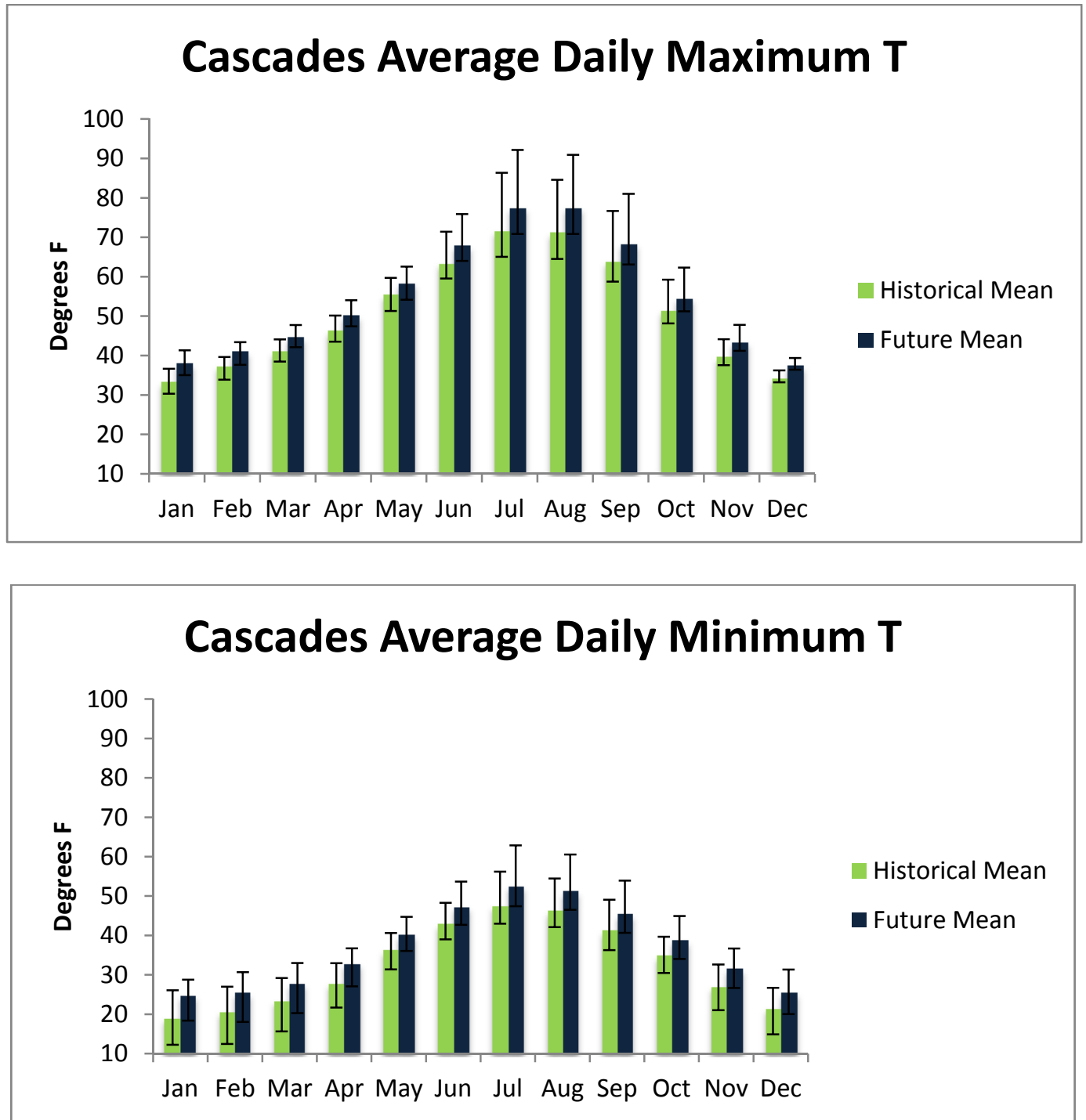

Figures 20b - Modeled Historical Average Monthly Maximum and Minimum Temperatures vs. Projected Future Average Monthly Maximum and Minimum Temperatures, Cascades subdomain. Error bars indicate the range of modeled results. 
Figures 20(a-e) - Average Monthly Maximum/Minimum Temperatures
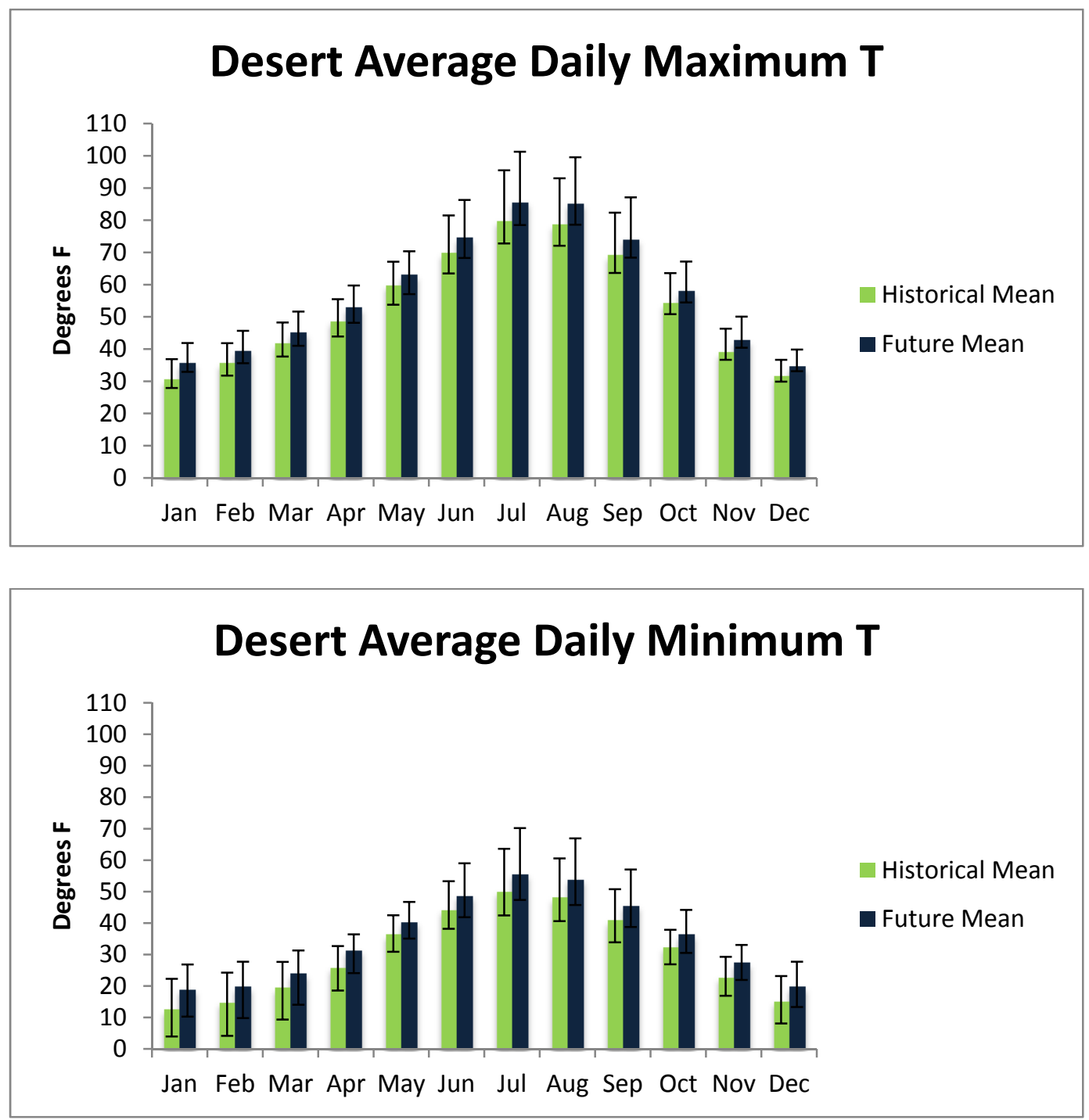

Figures 20c - Modeled Historical Average Monthly Maximum and Minimum Temperatures vs. Projected Future Average Monthly Maximum and Minimum Temperatures, Desert subdomain. Error bars indicate the range of modeled results. 
Figures 20(a-e) - Average Monthly Maximum/Minimum Temperatures
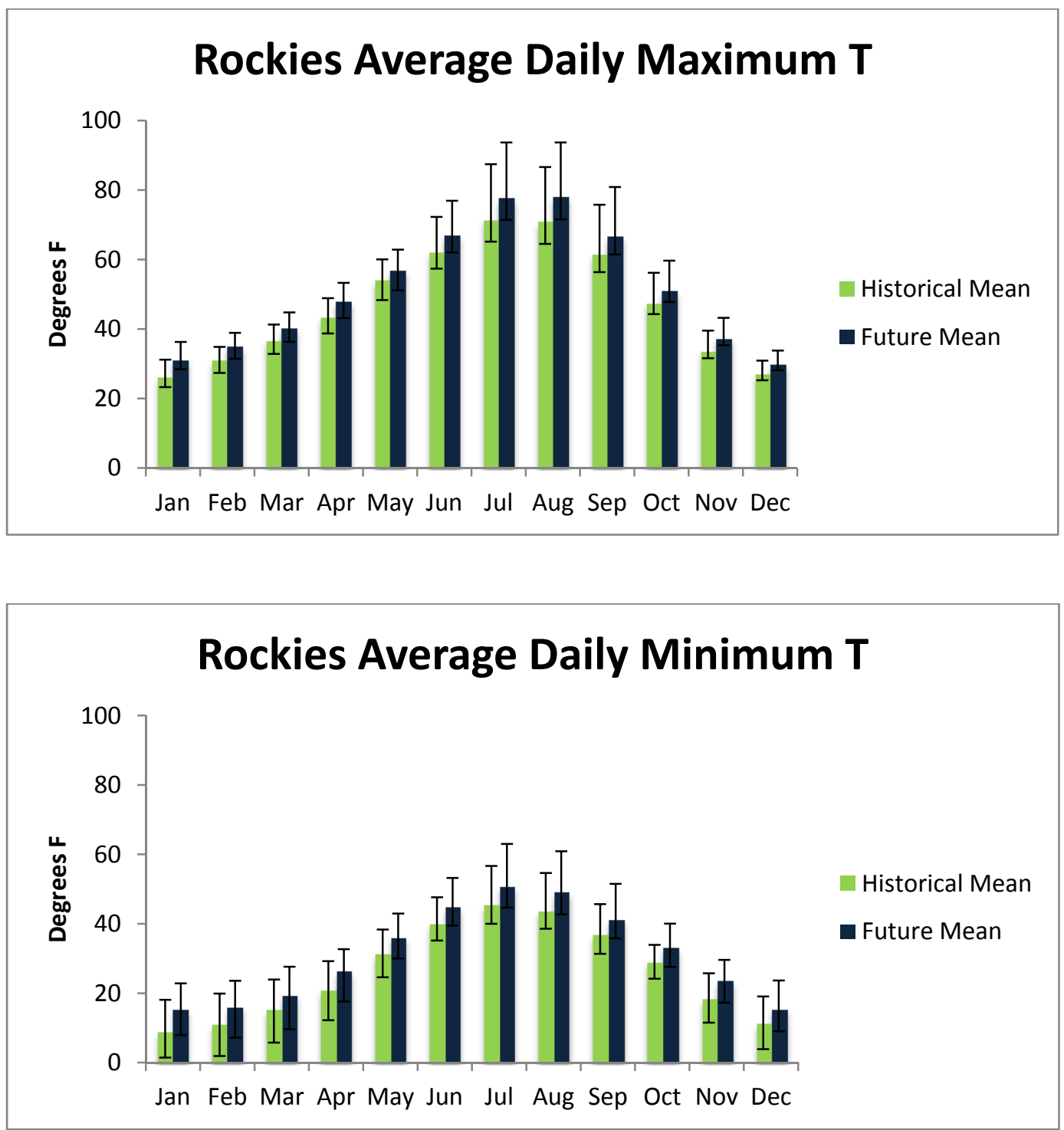

Figures 20d - Modeled Historical Average Monthly Maximum and Minimum Temperatures vs. Projected Future Average Monthly Maximum and Minimum Temperatures, Rockies subdomain. Error bars indicate the range of modeled results. 
Figures 20(a-e) - Average Monthly Maximum/Minimum Temperatures
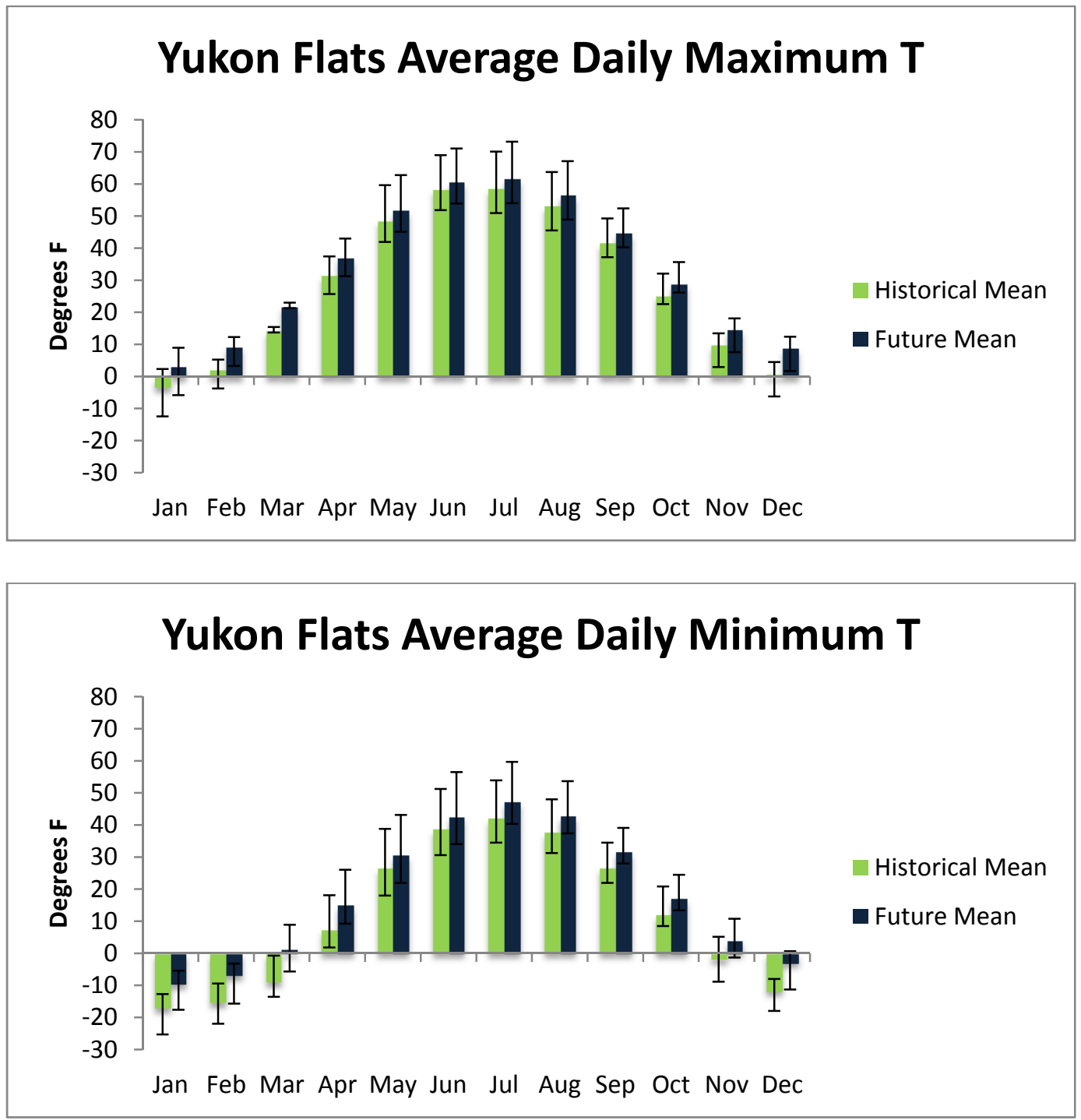

Figures 20e - Modeled Historical Average Monthly Maximum and Minimum Temperatures vs. Projected Future Average Monthly Maximum and Minimum Temperatures, Yukon Flats subdomain. Error bars indicate the range of modeled results. 
Figure 21 - Average Precipitations for the 10 Wettest Days

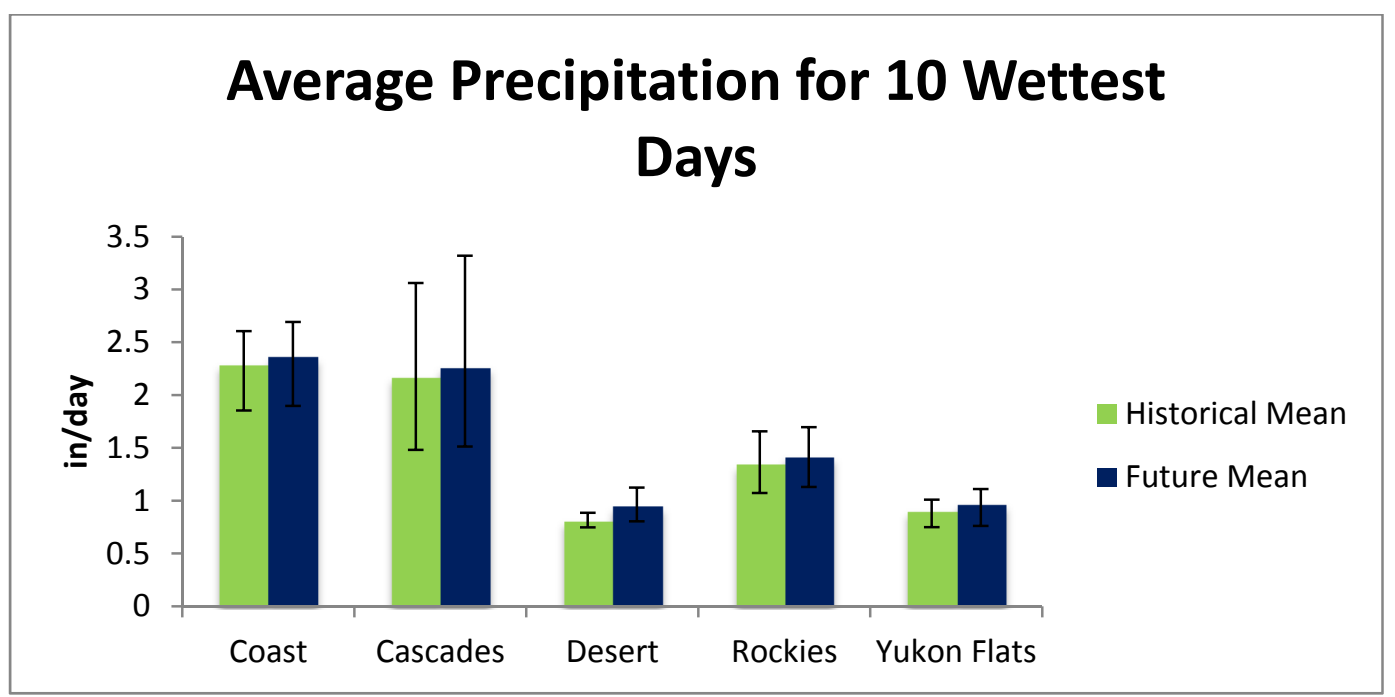

Figure 21 - Modeled Average Precipitation for the 10 Wettest Days in the Historical Period vs. Projected Average Precipitation for the 10 Wettest Days in the Future Period. Error bars indicate the range of modeled results.

Figure 22 - Average Number of Freeze/Thaw Cycles per Year

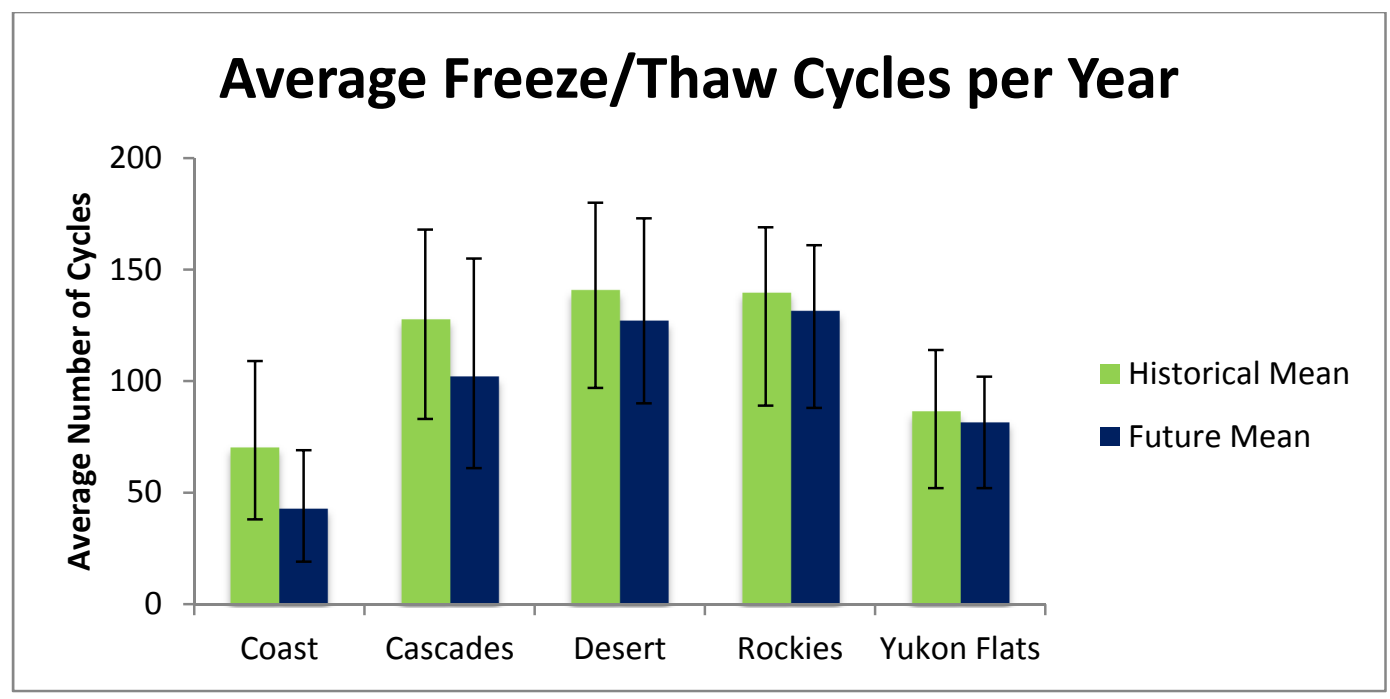

Figure 22 - Modeled Average Number of Freeze/Thaw Cycles per Year in the Historical Period vs. Projected Average Number of Freeze/Thaw Cycles per Year in the Future Period. Error bars indicate the range of modeled results. 


\section{IMPACTS OF PROJECTED CLIMATE CHANGE ON SURFACE TRANSPORTATION IN THE PACIFIC NORTHWEST AND ALASKA}

The existing surface transportation infrastructure represents billions of dollars of investment in capital improvements and maintenance. Each year, additional billions of dollars are invested in expanding, improving and maintaining this system. In his 2012 budget proposal, President Obama requested $\$ 128$ billion for transportation for the fiscal year 2012 (a \$51 billion increase over the enacted 2010 transportation budget), and a sixyear target of $\$ 556$ billion in transportation spending (Jaffe, 2011). In order to protect such costly transportation investments, minimize transportation disruptions and delay, and protect human life and property, transportation departments plan, design and maintain infrastructure appropriate to the local environment and the historic prevailing climate. However, the effects of climate change are expected to increase the costs of operating and maintaining transportation infrastructure (NRC, 2008). In Alaska alone climate change will incur an estimated additional cost of between $\$ 5.6-7.6$ billion dollars over the next 70 years to projects replacing public infrastructure as it wears out, over a third of which is tied specifically to roadways and harbors (Alaska Center for Climate Assessment and Policy, 2011).

Extreme events such as flooding and landslides can be difficult to predict, particularly when one event is responsible for triggering another, such as when long periods of heavy precipitation may result in landslides as soils become oversaturated. As a standard, engineers in transportation departments try to accommodate for occasional extreme events in their design of roadways, rail lines and bridges, but there is a probability level where it is no longer feasible to add design factors of safety. For 
example, culverts installed to prevent roadway flooding are generally designed to withstand an extreme peak precipitation event (such as a 50- or 100-year flood) specific to the local climate and hydrology.

But what happens when the climate for which our transportation system is built begins to change? How will a system designed for $20^{\text {th }}$ century climate patterns and extremes be impacted when what is now is considered an "extreme event" begins to occur more frequently or with greater intensity than previously encountered? What impacts could this have on the surface transportation system and how might the transportation industry prepare, respond and recover?

In the previous section, climate projections for individual subregions in the PNW and Alaska were presented. In this section, climate change projections are linked to their likely impacts on the surface transportation operations and infrastructure, including discussion of impacts by mode and location where possible (see Table 11).

\section{Table 11 - Examples of Potential Regional Climate Change Impacts on Transport}

\begin{tabular}{|c|c|c|}
\hline Climate Change & Impact on Operations & Impact on Infrastructure \\
\hline $\begin{array}{l}\text { Increases in very hot } \\
\text { days and heat waves }\end{array}$ & $\begin{array}{l}\text { - Limited rail operating speeds } \\
\text { - Delays due to wildfire }\end{array}$ & $\begin{array}{l}\text { - Railroad track deformities } \\
\text { - Reduced pavement } \\
\text { performance and life, } \\
\text { increased maintenance }\end{array}$ \\
\hline $\begin{array}{l}\text { Increases in Arctic } \\
\text { temperatures }\end{array}$ & $\begin{array}{l}\text { - Shortened seasonal access to ice } \\
\text { roads } \\
\text { - Longer marine transport seasons } \\
\text { and new routes }\end{array}$ & $\begin{array}{l}\text { - Damage to roadway } \\
\text { integrity due to thawing of } \\
\text { permafrost }\end{array}$ \\
\hline Rising sea levels & $\begin{array}{l}\text { - Increased travel interruptions due } \\
\text { to more frequent flooding }\end{array}$ & $\begin{array}{l}\text { - Damage to coastal } \\
\text { facilities due to erosion and } \\
\text { inundation }\end{array}$ \\
\hline $\begin{array}{l}\text { Increases in intense } \\
\text { precipitation events }\end{array}$ & $\begin{array}{l}\text { - Increased travel delays and } \\
\text { closures caused by flooding and } \\
\text { severe storms }\end{array}$ & $\begin{array}{l}\text { - Increased risk of landslide } \\
\text { and roadway washouts } \\
\text { - Bridge support scour }\end{array}$ \\
\hline
\end{tabular}




\section{CLIMATE CHANGE EFFECTS}

Based on work by Instanes (2006) and McKenzie (2003), climate change effects can be categorized as physical, engineering and socio-economic. Physical effects pertain to features of land and water. For example, sea level rise may impact physical aspects of coastal areas such as coastal circulation, sediment distribution, shoreline slope stability, and salinity of water bodies. Engineering effects are those affecting infrastructure, including maintenance and repair costs, the environmental loads on structures, and the impacts of geohazards and extreme weather events. Socio-economic effects pertain to human activity. Examples of socio-economic effects are changes in emergency preparedness, property development and legal concerns. Instanes suggests that due to the need for political solutions, socio-economic effects are the most complicated. Discussion of socio-economic effects is beyond the scope of this paper.

\section{Changes in Temperature}

Increases in temperature can affect transportation directly and indirectly. Direct impacts of temperature increases include increased pavement maintenance, railroad track deformities and/or reduced rail speeds due to deformity risk. While increased periods of extreme temperature (both increases in the number of extreme hot days and an extended duration of heat waves) may limit roadway construction periods in order to protect worker health, ensure quality construction practices, and maintain material performance, a benefit may accrue from general temperature increases by extending the construction season overall. 
Indirect impacts of temperature increases include shifts in the timing of seasonal thaw and freeze cycles, changes in freight movement and routing, transit operations, construction scheduling and increased exposure of workers to harsh conditions.

There may be positive impacts realized by increasing temperatures, such as less winter maintenance needed to maintain passes and potentially safer road conditions during winter months. In most cases, it will be hard to determine if these impacts will cause a positive net benefit to the system and to agencies. What might be a net benefit for maintenance may be an additional or new impact to the system in another region or the same location. An area might experience a decrease in freeze/thaw impacts on pavements but the temperatures and weather might cause more sleet or freezing rain. Agencies should be extremely cautious of weighing these cost/benefits of the changing climate.

\section{Roadways and Bridges}

The PNW is not likely to experience dramatic impacts to roadways as a direct result of the relatively small temperature increases projected under climate change. However, increases in extreme heat days can affect the longevity of pavements, particularly in the subregions that may be more sensitive to increases in temperature (Meyer et al., 2010). Increased temperatures may require changes in materials, construction and operations. For example, certain roadway construction materials, such as rigid pavements, are also prone to slab buckling as a result of excessive expansion in hot weather. So, as the number of hot days increases, different materials and/or additional maintenance may be required. Based upon research in southern Canadian communities, 
temperature increases may modestly increase roadway rutting ( $\mathrm{AC}$ and total) and cracking (longitudinal and alligator), and reduce transverse cracking (Tighe et al., 2008).

Issues with asphalt could include reduced durability as a result of increasing temperatures, which may cause the asphalt binder to deform to a greater extent resulting in increased rutting and shoving of the asphalt (increasing the movement of the pavement) and thereby increasing the associated maintenance frequency. In some areas, the freeze/thaw cycle will be reduced. In addition, regions where typically cooler temperatures prevail, infrastructure may become more prone to thermal (low-temperature of greater concern) cracking and fatigue cracking (typically occurs at intermediate temperatures). The Enhanced Integrated Climatic Model (EICM) and the MechanisticEmpirical Pavement Design Guide (MEPDG), which incorporates the EICM, can be useful tools to help planners/practitioners determine impacts of project climate change on asphalt paving projects. The MEPDG predicts performance of both asphalt and concrete pavements considering weather conditions. The model takes historical climate data and uses the monthly averages in the EICM. These historical climate records could be easily updated with projected climate change models to allow for computer simulation and provide additional decision-making tools to assess future risk. The MEPDG8 is available for download at http://onlinepubs.trb.org/onlinepubs/archive/mepdg/software.htm (NCHRP, 2006.) PNW transportation departments have been implementing MEPDG for flexible pavements, but have not used it to incorporate future climate scenarios into the model. Recently, researchers at the University of Delaware developed a framework to

\footnotetext{
${ }^{8}$ The next generation of this software is DARWin-ME, AASHTOWare ${ }^{\circledR}$ pavement design software http://www.aashtoware.org/Pages/DARWin-ME.aspx
} 
incorporate climate change effects into MEPDG (Li et al., 2011). Later in this section a case study is presented using Texas Concreteworks to model the impacts of temperature on concrete construction in the PNW.

A recent FHWA Regional Climate Change Effects report (FHWA, 2010) defined an extreme heat day as one where temperatures are at or in excess of $90^{\circ} \mathrm{F}$. It should be pointed out that the FHWA report and other reports defining "extreme heat" and "heat waves" use temperatures that are based on human health effects. These definitions and temperature levels are not necessarily linked to established material performance criteria. The report however also cites that "it is important to consider a range of future climate scenarios," owing to the importance to consider extreme events especially in locations subject to extreme heat events and events that may last for consecutive days. In these scenarios a more conservative value of $100^{\circ} \mathrm{F}$ may provide a more conservative approach to better facilitate decisions in regard to constructability, materials and worker health considerations. In the event that modeling is available (e.g., models that predict temperature performance of materials, worker health impacts and construction maximums), this represents an opportunity to provide greater information for improved decision making with relatively small additional cost/time deviations for project management decisions. This could be a very important factor to include in risk assessments where a range of scenarios may affect outcomes.

In Alaska, temperature changes have already produced significant impacts that are expected to increase in both intensity and range over the course of this century. Impacts include a reduced Arctic ice thickness and extent as well as thawing of the permafrost upon which roadways are constructed, causing extreme damage to roadway and bridge 
foundations as well as reduced seasonal access to ice roads and damage to pipeline structures. Ice road seasons are predicted to shorten and become less certain. Adaptations to this shortened season may include increased dependence on barge transportation during summer, more expensive maintenance of ice roads and construction of all-season routes. Canadian studies point to experimental methods to lighten truck loads on "delicate" ice roads such as the use of balloons when transporting oilfield equipment.

Permafrost thaw introduces two major concerns: thaw settlement and drainage (Beaulac, 2006). Because the physical properties of soil are temperature dependent, thawing permafrost causes excess foundation creep deformations, thaw settlement and frost heave, increased slide activity and surface slumping. No immediate threat has been found to infrastructure designed under current standards, but maintenance costs are expected to increase (Instanes, 2006). Figure 23 below shows how permafrost thaw affects geometry and cracking of roadways.

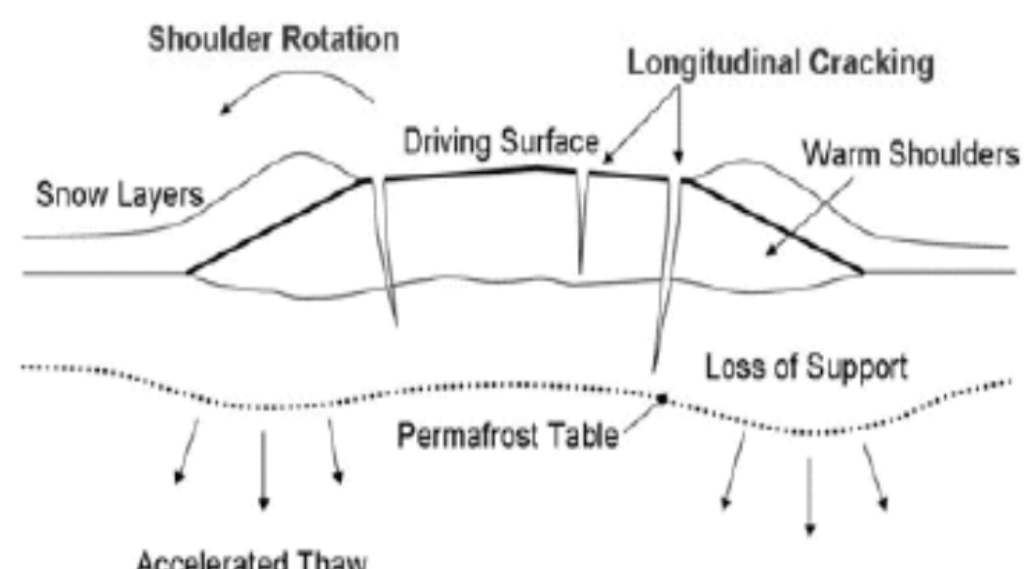

Accelerated Thaw

Accelerated Thaw

Figure 23 - Transportation infrastructure degradation mechanisms related to the embankment geometry (Beaulac, 2006). 
As mentioned above, most climate changes are associated with negative impacts, but temperature increases may in some instances offer positive impacts. For example, a shortened seasonal thaw/freeze period may reduce costs associated with snow removal. Figure 24 shows an example of a permafrost-damaged road in Alaska. As the melted water from the underlying permafrost layer seeps away, air voids are created. This compromises the structural integrity of the sub-base to a point where it can no longer support the roadbed above.

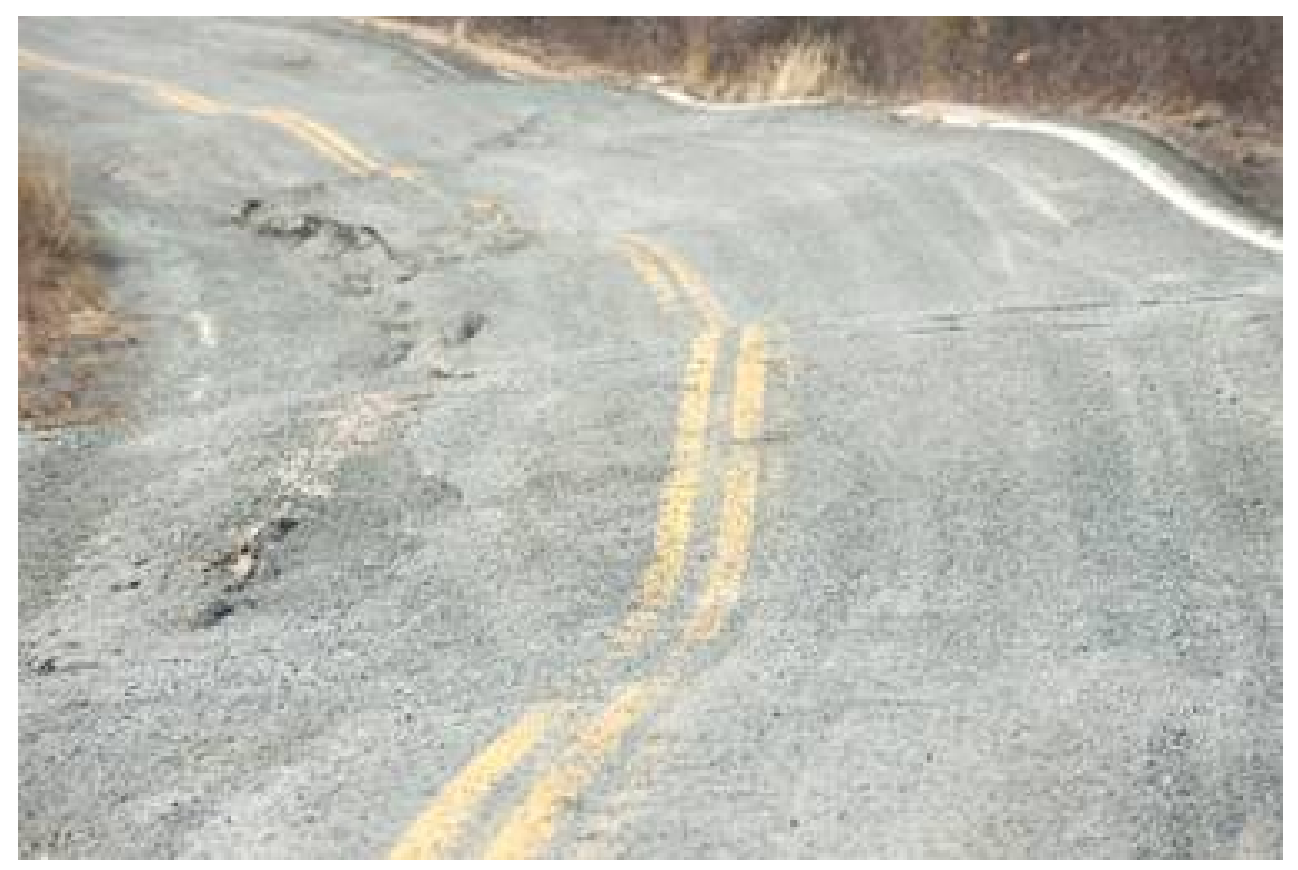

Figure 24 - Example of a permafrost-damaged road in Alaska.

By definition, permafrost is a frozen layer of soil or rock that remains below $0^{\circ} \mathrm{C}$ throughout the year. This is possible when the ground cools sufficiently in the winter to produce a frozen layer that persists through the following summer. In terms of roadway construction, permafrost makes a suitable sub-base layer because it is very strong. A major portion of the soil strength at the permafrost layer is due to ice bonding. This bond 
strength is compromised significantly by the melting of the ice crystals (Burgess and Smith, 2007).

The two main symptoms of permafrost degradation include lateral spreading and differential settlement of road embankments. Lateral spreading happens when ice melts, allowing shear failure in the soil (Alfaro, 2009). This causes longitudinal cracking on the surface. Differential settlement happens when the melted water is drained through dissipation, causing very dangerous, sharp dips in the roadway surface.

Quantitative information regarding the melting of permafrost under a roadway layer for an area is not possible without a specific case study. This is due to the wide variety of field conditions, including specific types of soil, current and projected temperature, roadway construction materials, etc. A case study done by Alfaro et al. (2009) on the degrading of permafrost beneath a road embankment in Northern Manitoba, Canada, demonstrated the potential impact of climate change on the melting of permafrost. Figures 25-27 show the projected melting of the underlain frozen (permafrost) layer in the month of July for this case study. The unfrozen layer is encroaching on the everthinning permafrost layer. This type of melting of the permafrost layer can be detrimental to the integrity of the surface transportation such as roadways being carried over these types of soils. Certainly this is an area for further research, both for adaptation strategies and monitoring of existing pavements in Alaska for such degradation. 


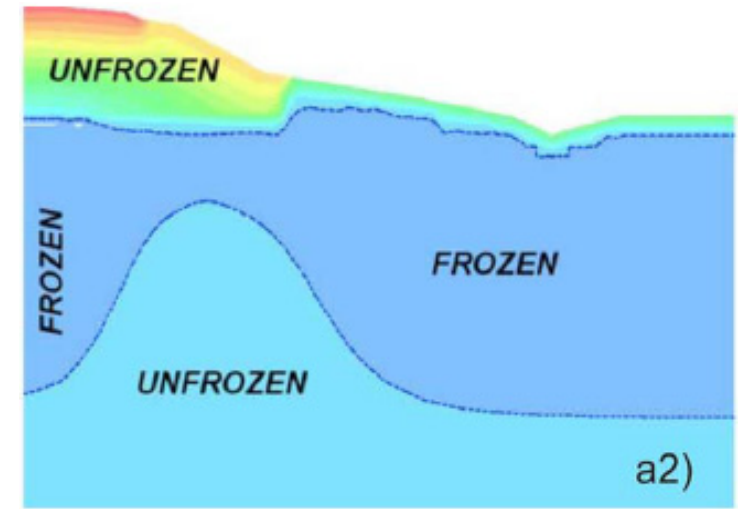

Figure 25 - Ground Condition in 2010 (Northern Manitoba, Canada] (Alfaro et al. 2009)

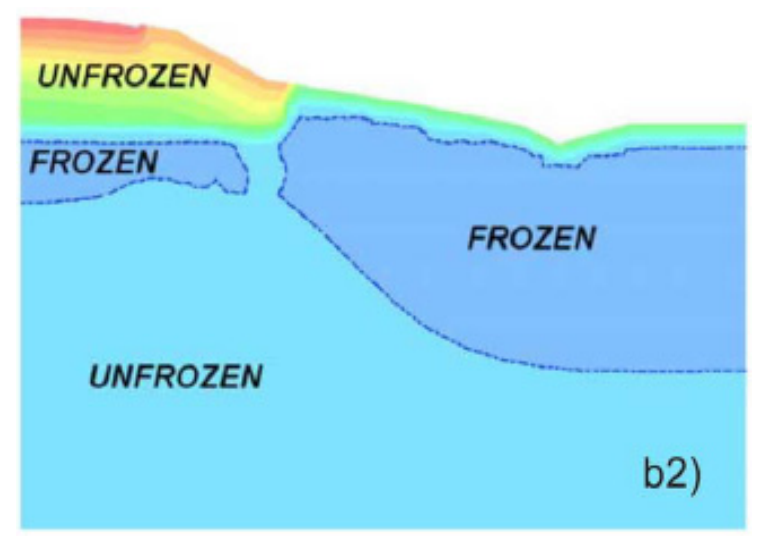

Figure 26 - Projected Ground Condition in 2030 (Northern Manitoba, Canada) (Alfaro et al. 2009)

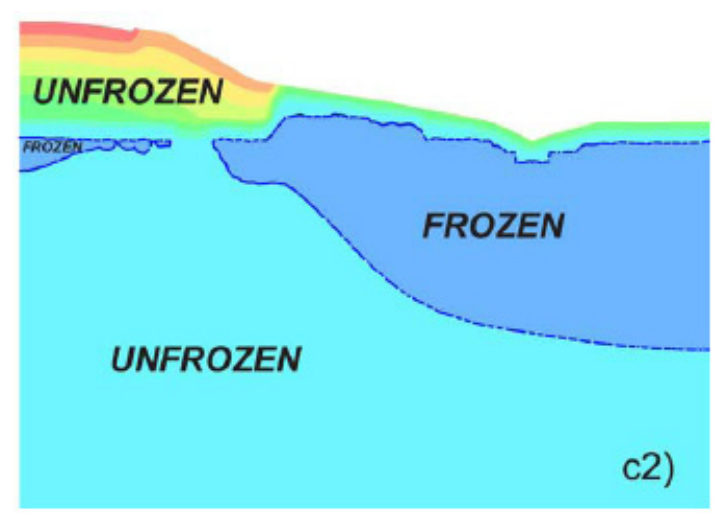

Figure 27 - Projected Ground Condition in 2040 (Northern Manitoba, Canada) (Alfaro et al. 2009) 
Similar to roadways, rail in the PNW will not likely be significantly impacted directly by increases in temperature. However, greater increases in temperature are projected for Alaska and the expansion joints currently in use may not be sufficient. As with Alaskan roadways, further complications arise in areas where rail lines have been constructed upon diminishing permafrost. Increases in the number of very hot days can impact rail maintenance and decrease operations of light and heavy rail. Extended periods of extreme heat can cause expansion of rails and potentially deform rails if the gaps between rail lengths are not sufficient to accommodate such expansion. Railroad engineers generally respond to expansion threats by reducing train speeds during high heat events to reduce the risk of "buckling." For instance, TriMet's (Portland, OR. transit agency) standard operating procedures calls for the reduction of train speeds by $10 \mathrm{mph}$ for all areas with speed limits of $35 \mathrm{mph}$ or more when temperatures are above $90^{\circ} \mathrm{F}$ (TriMet, 2010). Slow-orders, however, cause longer transit times, higher operating costs, delays, and reduced track capacity.

\section{Water Transport}

Shifts in seasonal thawing and freezing (in addition to changes in seasonal precipitation) are likely to affect water-based transportation in the PNW. Earlier spring snowmelt and increased winter precipitation (falling as rain rather than snow) may create higher river flows during cooler months. This may create river-transport access issues where high flows reduce bridge clearance. It may also affect navigation within waterways as large and/or changing flow patterns alter river-transport channels, possibly 
necessitating increased dredging. Conversely, lower-than-average summer precipitation and reduced snowmelt may reduce summer river flows. The reduced water depths would also affect navigation channels.

In Alaska, reductions in sea ice are likely to extend ocean shipping seasons as well as create new opportunities for shipping routes. Projected ice-free areas and lower ice concentrations could improve ocean transportation conditions, although a more dynamic ice cover is likely to increase demand for long-range forecasting and icebreaker support. Improvements to sea travel are likely to benefit the oil and mining industries (Instanes, 2006). This positive impact may be offset, however, by negative impacts to ports due to erosion, storm damage and SLR.

Ports

Ports are not likely to be impacted directly by temperature changes in the PNW. Sea level rise and increase in storm activities and intensity will have the most direct impact. Reductions in sea ice in Alaska may create new opportunities for port development and/or extend the season ports are available for use. However, loss of sea ice is also likely to contribute to increased erosion in some locations.

\section{Case Study: Impact of Temperature on Concrete Construction}

Texas Concreteworks is a computer modeling tool developed to predict heat of hydration in mass concrete elements. It can also be used to aid in concrete mixture proportioning, predicting alkali-silica reactivity potential and, most recently, been combined with LIFE-365 (a corrosion-predictive modeling software for reinforced 
concrete). A case study follows showing how this program can be used as a tool for adapting to climate change in the face of increasing temperatures during construction. This case study is germane to the region because a significant number of bridges in the region are made out of concrete. Table 12 shows that 15,000-plus bridges (75 percent of all bridges) are made from concrete.

Table 12 - Bridge Material Type, by State (FHWA National Bridge Inventory, 2010)

\begin{tabular}{|lccc|}
\hline State & Concrete & Steel & Other \\
\hline Alaska & $415(37 \%)$ & $559(49 \%)$ & $160(14 \%)$ \\
\hline Idaho & $2,897(70 \%)$ & $805(19 \%)$ & $430(10 \%)$ \\
\hline Oregon & $5,561(77 \%)$ & $1,081(15 \%)$ & $613(8 \%)$ \\
\hline Washington & $6,241(80 \%)$ & $980(13 \%)$ & $534(7 \%)$ \\
\hline Total & $15,114(75 \%)$ & $3,425(17 \%)$ & $1,737(9 \%)$ \\
\hline
\end{tabular}

A base case model is provided for a simulation done commensurate with the timing of this report in 2011 using historical climate data. A case is presented for projected increases in temperature for years 2041 and 2065. For all cases presented the location is Pendleton, OR, and a concrete column six feet in diameter is the subject element. Mixture proportions (based on a standard high-performance concrete mixture) are provided in Table 13.

Table 13 - Mixture Proportions for Texas Concreteworks

\begin{tabular}{|lc|}
\hline Mixture Proportions & $\mathrm{lb} / \mathrm{yd}^{\mathbf{3}}$ \\
\hline Cement Content & 419 \\
\hline F Fly Ash Content & 189 \\
\hline Silica Fume Content & 25 \\
\hline Water Content & 234 \\
\hline Coarse Aggregate Content & 1,810 \\
\hline Fine Aggregate Content & 1,110 \\
\hline Air Content & $5 \%$ \\
\hline
\end{tabular}


A total cementitious materials content of $633 \mathrm{lb} / \mathrm{yd}^{3}$ is used. Class F fly ash is included at 30 percent replacement level of total cementitious and 4 percent silica fume is also included, again by replacement based on total cementitious. An air content of nominally 5 percent is used and a water content of 0.37 is provided. A siliceous river gravel and sand are used for the entire analysis of the base case, 2041 and 2065 projections. This represents a typically high-performance concrete mixture where a minimum strength of 5,000 psi would be expected at 28 days after curing. All of these parameters are easily adjusted in Concreteworks to allow for customization to a specific geographic location for both materials modifications and for climate change impact modifications and/or historical climate data.

\section{Base Case - 2011 Using Historical Data}

Figure 28 shows the ambient temperature, maximum and minimum temperatures in the column, and the ambient temperature predicted for this time range using historical data. 


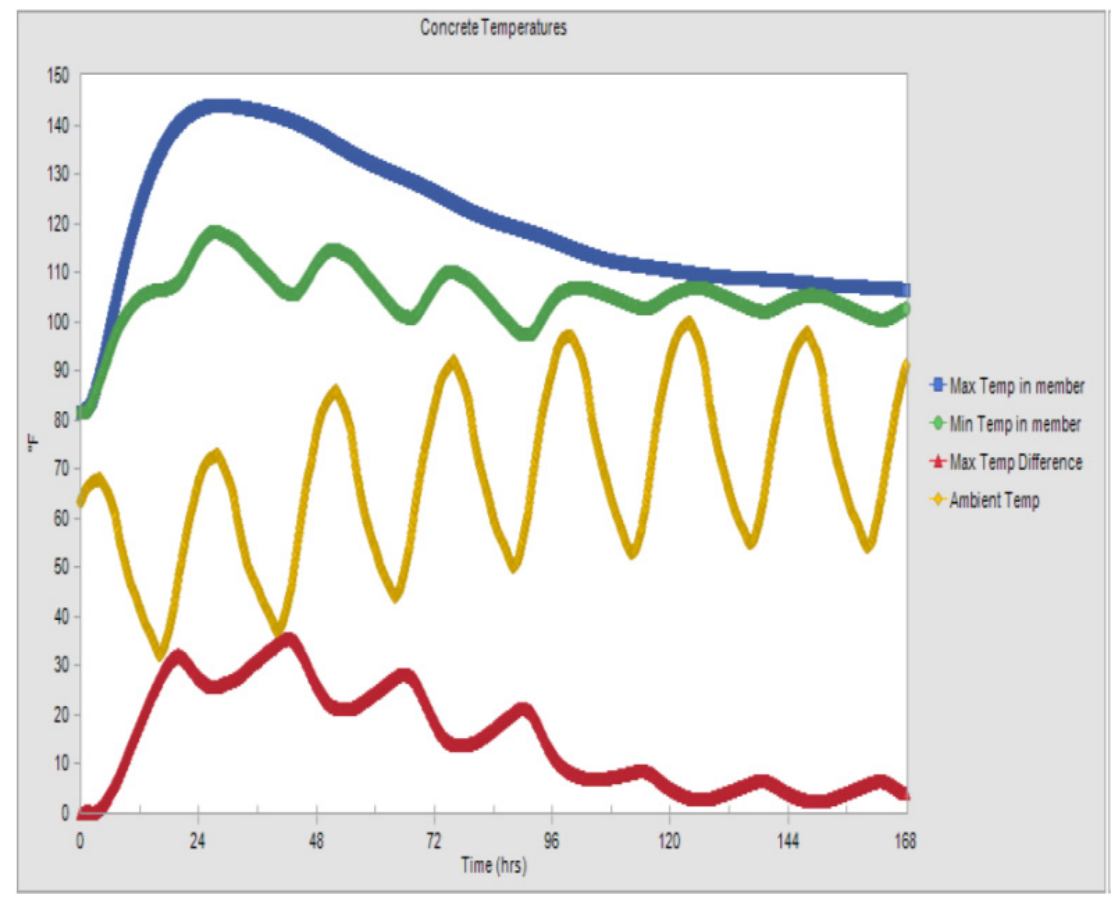

Figure 28 - In-Place Concrete Temperature for 7 day period, Pendleton, OR, based on 2011 Historical Climate data.

Figure 28 shows that the maximum in-place temperature during hydration for this concrete column would be expected to be nominally $143^{\circ} \mathrm{F}$, with a maximum in-place temperature differential of $35^{\circ} \mathrm{F}$. By 96 hours after pouring the column, the temperature differential between the center of the column and the exterior-most portion of the column is almost commensurate with fluctuations in ambient temperature. This indicates that the majority of the heat evolved during hydration has occurred prior to 96 hours. Local codes may govern at what point the formwork can be removed based on a maximum temperature differential to limit the possibility of thermal shock. Since the maximum inplace temperature does not exceed $158^{\circ} \mathrm{F}\left(70^{\circ} \mathrm{C}\right)$ there is no risk of delayed ettringite formation (DEF) and long-term durability issues from this specific type of deterioration. 


\section{Case - Using Climate Projections for 2041}

Figure 29 shows the ambient temperature, maximum and minimum temperatures in the column, and the ambient temperature predicted for this time range using projections of climate change for the year 2041.

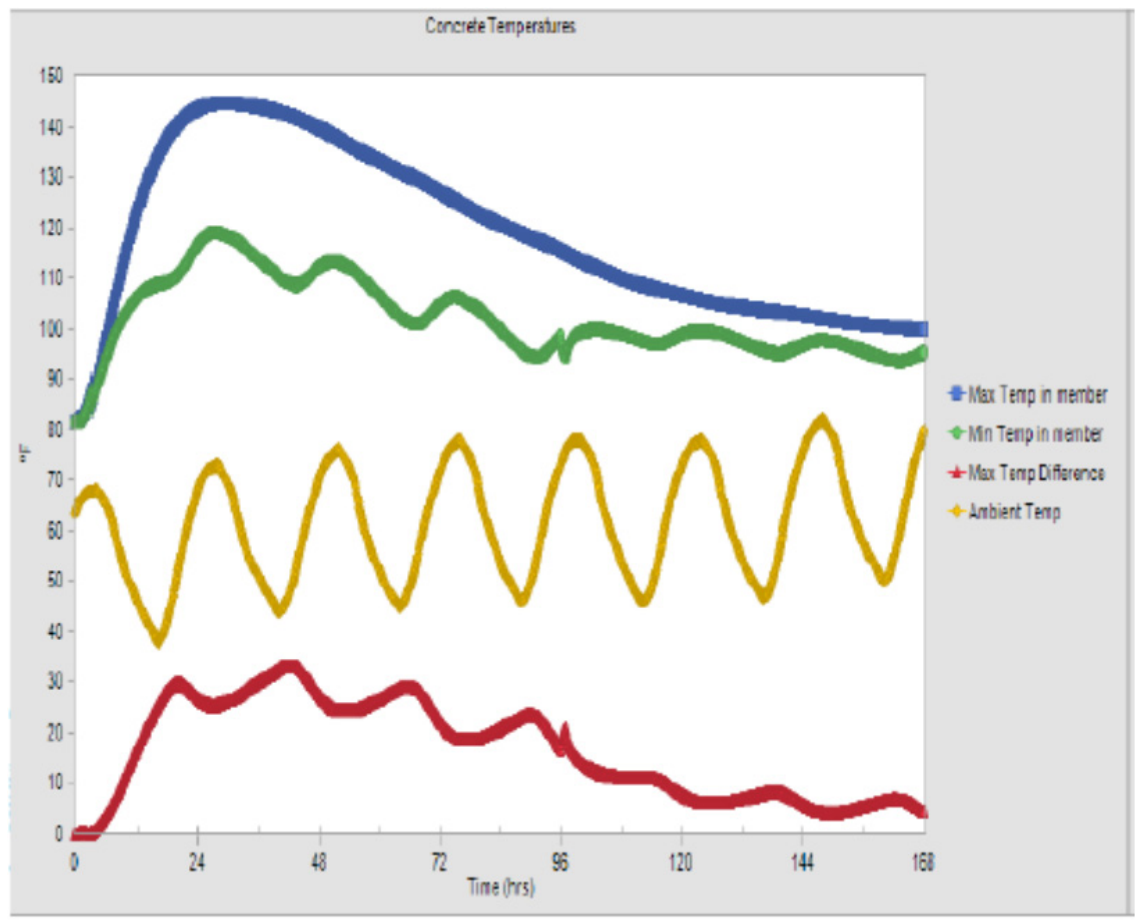

Figure 29 - In-Place Concrete Temperature for 7 day period, Pendleton, OR, based on 2041 Climate Projection.

The main item to notice in Figure 29 is that the maximum in-place temperature during hydration increases to $144^{\circ} \mathrm{F}$ however the maximum temperature differential decreases to $33^{\circ} \mathrm{F}$. The slight increase in temperature would be of little to no concern in this particular member. However, if a larger sized concrete element was investigated and the materials parameters were different (e.g. more cement) a higher maximum temperature may be observed pointing toward the risk of potential durability problems. It is interesting that 
due to the increase in ambient temperature, although slight, the maximum temperature differential decreases by $2^{\circ} \mathrm{F}$ compared to the base case presented in Figure 30 .

\section{Case - Using Climate Projections for 2065}

Figure 30 shows the ambient temperature, maximum and minimum temperatures in the column and the ambient temperature predicted for this time range using projections of climate change for the year 2065.

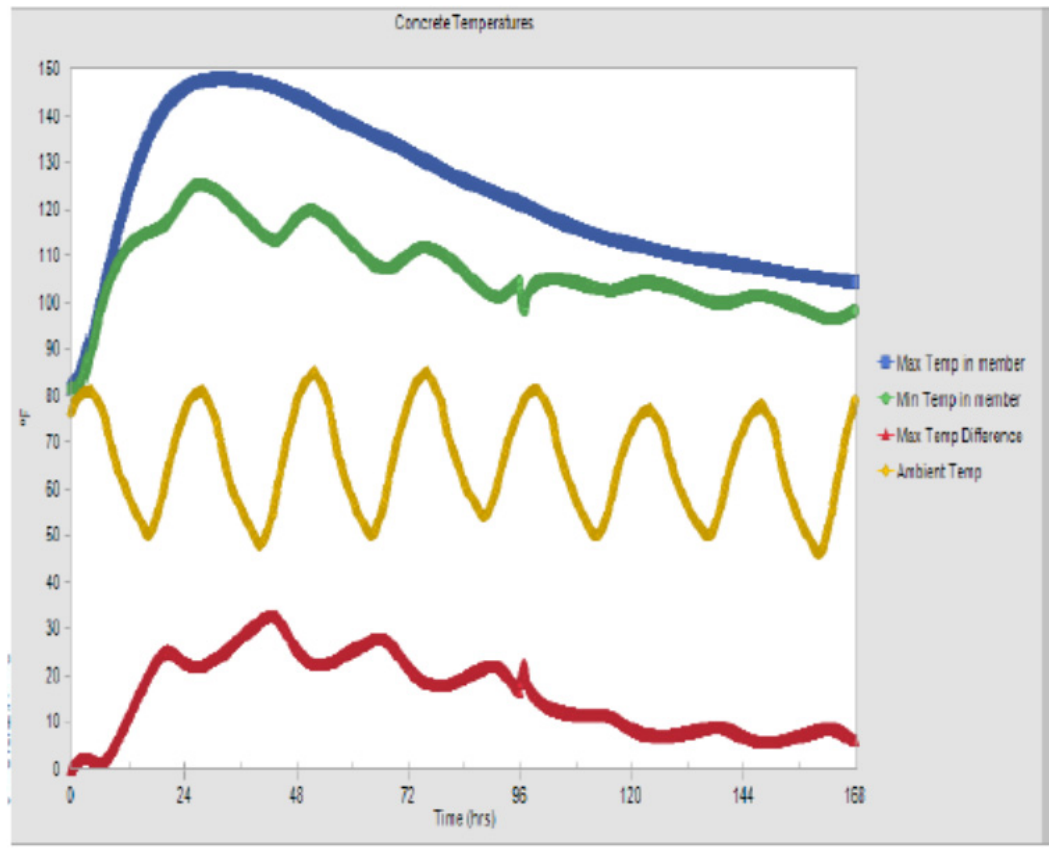

\section{Figure 30 - In-Place Concrete Temperature for 7 day period, Pendleton, OR, based on 2065 Climate Projection.}

In Figure 30 it can be seen that the maximum in-place temperature is $147^{\circ} \mathrm{F}$ and the maximum temperature differential is $32^{\circ} \mathrm{F}$. This represents a $4^{\circ} \mathrm{F}$ increase over the base case for 2011 using historical climate data, and a $3^{\circ} \mathrm{F}$ increase for climate projections using 2041 data. Again this is not of significant concern for this particular mixture design 
and element. However, if the overall ambient temperatures are increasing due to climate change, the maximum in-place temperature during concrete hydration will also be increasing. This may represent a concern in larger elements, elements where little to no supplementary cementitious materials are used (which lower overall heat of hydration) or in more aggressive environments.

A full study on many different factors, such as those mentioned above, is beyond the scope of this report. However, this is to be used as a demonstration that a program such as Concreteworks may be desirable as a predictive tool for determining climate impacts on concrete construction. Other such tools applicable to asphalt pavement and other materials may also be easily adaptable for such usage.

\section{Changes in Precipitation and Storms}

Increased flooding and landslides as a result of increased precipitation and increased intensity of storms are potential climate affects directly impacting roadway infrastructure. Transportation professionals have noted standing water due to flooding as a particularly damaging impact (Walker et al., 2010).

\section{Roadways/Rails}

Increases in winter rain precipitation and increased storm frequency and intensity in both Alaska and the PNW will likely affect roadway flooding. Existing culverts will more than likely be undersized to accommodate increased extreme precipitation and flow volumes. Consequent flooding is likely to result in direct damage to roadways from standing water and contribute to traveler delay as roadways become impassable. 
Roadways and bridges most susceptible to flooding include coastal routes, roadways bordering rivers and those constructed along valley bottoms.

Increased temperature and rain precipitation is likely to change the common avalanche type at low altitudes from dry to wet, affecting run-out distance and exposed traffic routes. Areas which may see intensity of heavy snowfall may also contribute to delay or closures on mountainous roadways. In addition to avalanches and snow slides, increased earth landslide activity is another threat related to increased precipitation and storm activity, particularly in areas with unstable slopes and/or disturbed vegetation. Areas previously burned by wildfire or disturbed by construction may exacerbate this risk. Extended periods of extreme rainfall in these locations may quickly saturate soils producing landslides on to roadway structures below. Both flooding and landslide activity associated with precipitation may impact evacuation and detour routes. Roadway embankments that come into direct contact with the sea or rivers can potentially have slope stability issues. The increased river flow from snowmelt and more violent sea activities can damage and/or wash away embankment fill materials.

\section{Bridges/Culverts}

Changes in precipitation could greatly change the hydrographs of many of the region's rivers as stated above. The changing flows can cause changes in river channels (avulsion) and changes in the deposition of sediment affecting the fluvial system. Higher river flows may increase the threat of bridge scour; a condition in which the sand and rock surrounding bridge abutment or piers is removed by swiftly moving water. As a result, extended precipitation and associated flooding can threaten structural stability of 
bridges and culverts. Bridge scour is a significant concern to engineers due to the sheer number of bridges potentially affected - approximately 20,000 in Alaska, Idaho, Oregon and Washington (FHWA NBI, 2010). The fact that concerns researchers the most about these bridges is their age. Most were designed and built before 1970. As these bridges continue to age, they become more susceptible to extreme weather events as they near the end of their design life. Culverts also play an equally important role in maintaining water flows under and around the road and rail systems. Like bridges, culverts are designed to meet flow volumes, but they must also meet fish passage requirements. Oregon has approximately 5,500 culverts and Washington has 3,200 fish-bearing, stream-crossing culverts (Oregon Department of Fish and Wildlife, 1999; Washington State Department of Fish and Wildlife, 2011). Increasing the water flow can cause flooding and damage of areas and infrastructure surrounding the culvert.

\section{Water Transport}

As discussed previously, in the PNW an increase in winter precipitation falling as rain rather than snow will create higher river and stream flows, potentially affecting river transport. Potential alterations in river channels may affect river navigation during periods of extreme precipitation and flows. According to Canadian research, it is typically easier to design new waterway locks than to retrofit existing ones. Therefore, it is suggested to design locks that are wider and deeper than currently needed in anticipation of climate change impacts (Natural Resource Canada, 2007). However, specific depths and widths are location-dependent and require local hydrological study. Decreases in summer precipitation, along with reduced snowpack, will lead to lower 
water levels, which may also impact river navigation due to decreased depths. This may create a need for increased dredging. Alternatively, shipping companies may invest in vessels with shallower drafts.

Bridge clearance issues may arise from higher-than-average seasonal river flows, restricting river traffic. Another item to note is that engineers cannot simply "raise a bridge by two feet" to accommodate potential future water levels. Any change in elevation carries slope and roadway consequences, which might impact the bridge's viability and cost. If pedestrian slope requirements are to be maintained at proper levels and a higher vertical clearance is provided to allow for proper river navigation, a cost increase will occur. As part of the Final Environmental Impact Study for the design of the Willamette River Bridge, TriMet conducted a climate-change impact analysis on the bridge's vertical clearance. The analysis looked at different climate scenarios and how they would influence the river levels. Based on the results of the study, the additional vertical clearance allowance of 3.4 feet was added to meet future river navigational needs (TriMet, 2010).

Increased coastal and river erosion could pose a threat to exposed buildings and harbors due to slope failure. Accelerated erosion rates are "one of the biggest threats to Arctic coastal communities" and have in some locations lead to abandonment or relocation of entire villages. It is important that new infrastructure planning should address coastal erosion (Instanes, 2006). There is potential for increased coastal erosion from increased wave heights, warranting concern for slope stability. It is also possible for ports and water travel to be affected by increased wave heights. 


\section{Coastal Impacts and Sea Level Rise}

Coastal and river-based ports are economically significant in the PNW and Alaska. The PNW's ports serve major shipping routes for various goods to/from Asia. In 2009, the Port of Portland handled 501 vessels with over 10 million tons of goods (Marine Terminal Statistics, 2010). In the same year, the Port of Seattle handled 1,226 vessels with 12.5 million tons of goods (Seaport Statistics, 2010). According to the Port of Portland, every ton of goods going through marine terminals generates a local economic impact of $\$ 70$ (Port of Portland, 2010). In a catastrophic event that could knock the Port of Portland offline for as little as a month, \$58 million dollars is removed from the Oregon economy. A similar event in Seattle could cost the state of Washington $\$ 72$ million dollars. These statistics demonstrate the importance of the marine terminal system to the economic prosperity of the PNW.

The Oregon coast is prone to severe winter storms, which are the dominant factor in coastal flooding and erosion. The intensity of storms has been increasing, and consequently the frequency and magnitude of these coastal flooding events will probably continue to increase (OCCRI, 2010). Significant wave heights measured during the winter have been increasing at a rate of $23 \mathrm{~mm}(.9$ in)/year, but extreme waves generated by the strongest storms are increasing at higher rates than the winter averages $(95 \mathrm{~mm} / 3.7$ in)/year). The annual maximum wave height has increased from about $9 \mathrm{~m} / 29.5 \mathrm{ft}$ in the late $1970 \mathrm{~s}$ to $12 \mathrm{~m} / 39 \mathrm{ft}$ in 2005 . This is a significant increase, though it is not yet understood if this is related primarily to climate change or to natural variability. Therefore, researchers have a limited ability to predict future trends in wave heights or coastal storms, but if the trend continues impacts will likely be substantial. As the 
intensity and frequency of extreme storm events has increased rapidly, unarmored coastal areas are increasingly vulnerable to flooding and erosion.

SLR is primarily driven by two factors: an increasing amount of water in the sea from melting sea ice and glaciers, and thermal expansion of water due to increases in ocean temperatures. Coastal upwelling, driven by wind, circulates cool water from the bottom of the ocean to the surface and can affect average ocean heights by 19 inches (OCCRI, 2010).

As discussed in a previous section, in several locations in the PNW and the Gulf of Alaska, SLR is offset by tectonic or isostatic vertical land movement. For example, as glaciers retreat in the Gulf of Alaska, land rises vertically. However, some locations may become permanently inundated as a result of SLR, reducing the availability of coastal travel and evacuation routes.

SLR combined with increased storm activity (e.g., storm surges, increased wave heights) may accelerate erosion along coasts and increase maintenance demands. However, coastal impacts depend on a variety of factors including the geology of the shoreline, natural or manmade protection from wave action (e.g., natural harbors, sea walls), and the intensity and type of development/land use along the coast. Erosion and inundation effects are likely to be exacerbated in locations where rivers meet open water. Alaska has seen several coastal villages relocated due to shoreline erosion caused by SLR. Segments of the Pacific Coast Highway (US 101) and railroads along the Oregon and Washington coasts are also threatened by shoreline erosion and inundation. 


\section{Roadways/Bridges/Rails}

Coastal routes may experience inundation and accelerated erosion as a result of SLR. This may undercut road bases and bridge supports. During storms, storm surges may reach further inland. Later in the report, an analysis on the extent and magnitude of SLR on Pacific Northwest roads will be presented. Rail and roadways along Puget Sound and coastal locations in Alaska are at particular risk given higher SLR projections.

\section{Water Transport}

Harbors and ports may be affected by SLR and increased erosion. Climate change can also affect surface water transportation systems. Washington has a very extensive ferry system, connecting the greater Seattle area to Canada (Figure 31). The rising sea level and increased storm risks from climate change pose a direct threat to this important system. These threats include increased maintenance costs, reduced rider comfort and potential disruption to service. There is a potential for higher engine strains and hull damage from more violent water. With an outdated fleet, the vessels' ability to smooth out choppy water is also compromised. The combination of these events can cause breakdowns of vehicles, increase maintenance costs and even disrupt service. Some of these effects could be realized along the Columbia River and into Idaho, especially disruptions to shipping vessels. 


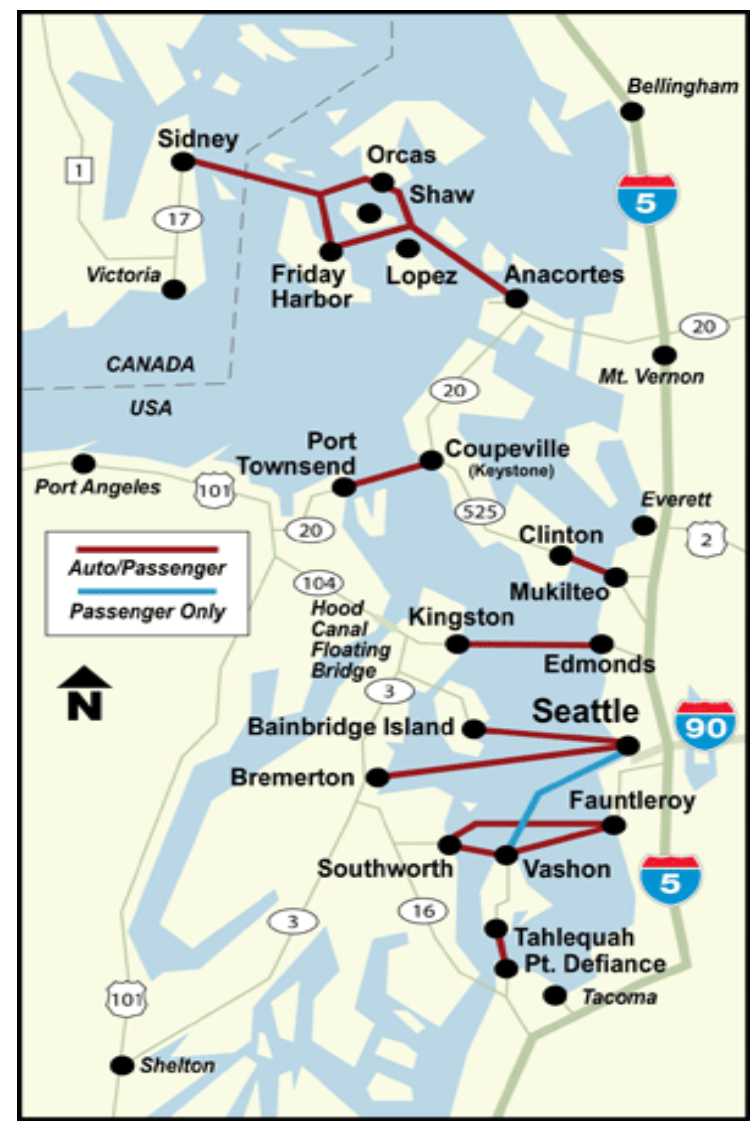

Figure 31 - Washington State Ferries System (Washington Ferries 2009)

\section{$\underline{\text { Indirect Climate Impacts on Surface Transportation }}$}

In addition to the direct impacts described above, the surface transportation system is also likely to be affected by indirect impacts such as increases in wildfire range and frequency, adjustments in wildlife corridors, changes in agriculture, and changes in land use as the population increases/relocates. Climate change could also impact and damage environmental enhancements to the transportation infrastructure such as biomaterial, biofilters, swales, surface water retention, wetlands, fish passage systems, landscaping, and roadside vegetation. 


\section{Wildfire}

Reduced summer precipitation and increased temperatures both impact wildfire risk. Increased droughts and generally drier conditions will extend the range of annual wildfire in both Alaska and the PNW. The Washington Climate Impacts Group anticipates a doubling or tripling of seasonally burned forest through 2080 (CIG, 2009). Similarly, the intensity and frequency of wildfires will likely increase in all Oregon forest types in the coming decades. Warmer and drier summers leave forests more vulnerable to the stresses from fire danger west of the Cascades. Increases in regional forest area burned are estimated between 180 percent and 300 percent by the end of the century, depending on the climate scenario and estimation method examined. The increased possibility of extreme temperature events and drought contributes to these increased fire risks. Areas previously burned are also typically more susceptible to landslide activity during storms (OCCRI, 2010).

Although increased wildfire activity is not likely to directly impact roadways or structures, it may impact operations in terms of delays and detours associated with wildfire response and potentially, subsequent landslide activity. Smoke from wildfires may also negatively impact road and rail operations due to temporary road closures. In extreme cases of excessive heat, wildfires can directly impact transportation structures, causing material damage to roadway, bridge structures, guardrails and signs, and impacts of slope stability near infrastructure. Risk to surface transportation from wildfires is greatest in suburban and rural areas removed from water bodies and covered with vegetation; however, wildfires occurring at the urban-rural interface may be more costly in terms of economic loss. 


\section{Pests and Infestations}

Warmer temperatures may also allow introduction of and/or an expanded range for destructive insect species, such as the spruce and mountain pine beetle. Generally, insects and diseases will expand northward in latitude, toward the coast and upward in elevation in a warming climate. Mountain pine beetle occurrence has been increasing over the last eight years and will likely continue to increase in a warmer climate. Drought also acts as an additional stressor in increasing vulnerability to the pest. Other pests and diseases, including sudden oak death, have been spreading northward from California into southwestern Oregon since the beginning of the century. In the case of sudden oak death, extreme precipitation events facilitate the infection of more trees, which then become vulnerable during droughts and even increase fuel for wildfires (Mote et al., 2010). In addition to the direct losses caused by infestation, infestations can also kill or weaken healthy timber stands making them more susceptible to wildfire.

\section{Effects on Wildlife Corridors}

Transportation departments currently must preserve wildlife corridors as part of their system development processes and protected habitats of endangered species. However, climate change is expected to alter the availability and location of wildlife habitat. This may cause wildlife corridors to change, causing additional design considerations by state DOTs or city planners and engineers. Further study is required to identify changes in wildlife corridors, especially in case of endangered species, and to understand the effect this would have on agency project designs and processes. 


\section{Invasive Species/Vegetation Management}

The projected climate changes in the region are likely to lead to the spread and dispersal of invasive species, such as noxious weeds (Sutherst, 2000). As climate changes, plant species that are not native to the Pacific Northwest may be able to expand into the region, or expand their ranges if they already occur in the region. Many exotic and weedy species already in the region, such as non-native blackberry and scotch broom, are better colonizers than most native species, making them more likely than native species to become established and spread in areas when native species decline. Exotic species like kudzu are likely to invade the region as the climate warms and join the abundance of weeds already disrupting the landscape. Some native species also could become invasive under climate-changed conditions as they shift their ranges to new areas with fewer competitors. Warmer temperatures and drought-stressed vegetation are likely to provide more favorable conditions for disease, insect pests and invasive species that will negatively impact wildlife and wildlife habitat (OCCRI, 2010).

For many areas in the Pacific Northwest, the increase in vegetation and invasive species will impact transportation agencies and city governments. The rights-of-way that border the region's roads will be affected by the increase in vegetation growth and the influx of invasive species and noxious weeds. Maintenance departments will need to budget for managing the land and responding to and preventing invasive species infestations. 


\section{ASSESSING CLIMATE CHANGE VULNERABILITY ON SURFACE TRANSPORT AND BUILDING AN ADAPTATION RESPONSE}

Greenhouse gases (GHG) and climate projections derived from modeling, along with exploration of the potential impacts of climate change, have prompted agencies to address global and regional climate change. Thus far, the overwhelming focus of government and non-governmental organizations has been on climate change mitigation through reduction of GHGs (Wheeler, 2008). Cities, counties, regions and states have developed climate action plans identifying major sources of climate change gases and initiating efforts to reduce GHGs in both the private and public realms. Activities within surface transport include purchases of hybrid and electric vehicles to replace less efficient vehicle pool fleets; an enhanced focus by transportation planners towards reducing the number and distance of vehicle trips; promotion of non-motorized transportation and transit alternatives; and efforts to increase the efficiency of traffic control systems to reduce vehicle idling, congestion, and frequent stops and starts. In some cases, entrepreneurs established carbon offset programs allowing private individuals and corporations to compensate for emissions created through their activities by purchasing credits towards programs that eliminate or capture emissions elsewhere. Meanwhile, states began developing their own carbon capping and trading programs for major industries (Barringer, 2010).

More recently, climate change response has expanded beyond mitigation of GHGs to include planning efforts that strategize how to adapt to climate changes that have already occurred as well as the projected changes described in the previous sections. Adaptation planning for climate change impacts is still in its infancy. Agencies and 
organizations are just beginning to develop methods for identifying the hazards associated with their particular regions and transportation systems under climate change, assessing the infrastructure likely to be impacted, and developing plans to avoid or mitigate these impacts. Table 14 below provides a timeline of U.S. and Canadian adaptation efforts to date. Development of adaptive strategies is an area of growing concern in the engineering community (Burton, 2005). In addition, strategies are also being developed in order to incorporate climate adaptation into standard planning processes. 
Table 14 - Summary of Canadian and U.S. Climate Change Adaptation Milestones (Haire, 2010).

\begin{tabular}{|c|c|c|}
\hline Canad & & \\
\hline Year & & Significance \\
\hline & 1990 & Initial assessment of climate change impacts on transportation in Canada \\
\hline & 1998 & $\begin{array}{l}\text { Cross-disciplinary evaluation of climate change and adaptation issues and } \\
\text { costs }\end{array}$ \\
\hline & 2001 & $\begin{array}{l}\text { Establishment of Canadian Climate Impacts and Adaptation Research Network } \\
\text { (C-CIARN) }\end{array}$ \\
\hline & 2004 & Federal document highlighting multi-disciplinary climate change challenges \\
\hline & 2005 & $\begin{array}{l}\text { Climate change adaptation and risk management within the context of public } \\
\text { infrastructure }\end{array}$ \\
\hline & 2006 & Guidelines for reducing climate change vulnerability at the municipal level \\
\hline & 2006 & $\begin{array}{l}\text { Introduced municipal decision-makers to adaptation; guidelines for } \\
\text { conducting vulnerability assessments and incorporating vulnerability into } \\
\text { municipal risk management decision making }\end{array}$ \\
\hline & 2006 & $\begin{array}{l}\text { Review of Canadian infrastructure adaptation literature including } \\
\text { transportation systems }\end{array}$ \\
\hline & 2006 & $\begin{array}{l}\text { Canadian design, construction, and maintenance standards addressing climate } \\
\text { change adaptation }\end{array}$ \\
\hline & 2007 & Adaptation issues in Arctic Canada with respect to culture, health, and safety \\
\hline & 2008 & $\begin{array}{l}\text { Federal document evaluating the vulnerabilities and adaptive capacities of } \\
\text { natural and built environments in Canada }\end{array}$ \\
\hline & 2008 & $\begin{array}{l}\text { Engineering assessment of specific climate vulnerabilities of public } \\
\text { infrastructure including road and bridge facilities }\end{array}$ \\
\hline United & tes & \\
\hline Year & & Significance \\
\hline & 2004 & Identifies adaptation as a needed strategy in addressing climate change \\
\hline & 2007 & $\begin{array}{l}\text { Produced in Washington State; guidance for federal, state, and local } \\
\text { governments in carrying out adaptation efforts }\end{array}$ \\
\hline & 2008 & Outlines the specific climate challenges facing transportation infrastructure \\
\hline & 2008 & Detailed assessment of transportation vulnerabilities in the Gulf Coast region \\
\hline & 2008 & Approaches adaptation from a business perspective \\
\hline & 2009 & $\begin{array}{l}\text { Advised Congress that federal guidance is needed to hasten adaptation efforts } \\
\text { at the federal, state, and local levels }\end{array}$ \\
\hline & 2009 & $\begin{array}{l}\text { Recommendations for research in transportation system adaptation and risk } \\
\text { management }\end{array}$ \\
\hline & & d municipal documents mentioning adaptation have been produced since \\
\hline
\end{tabular}




\section{What is Adaptation Response?}

Adaptation to climate change within the transportation sector encompasses a variety of activities that build capacity to appropriately adjust to climate changes and minimize negative impacts on the system (or take advantage of positive impacts). In order to begin climate change adaptation, planners must develop an understanding of how the different transportation modes are likely to be impacted by climate change in their geographical location. The planners will need to identify where potential vulnerabilities to these impacts lie within their system, assess the risk to the system should impacts occur, develop alternatives to address these impacts, and lastly, incorporate these findings into their plans and projects (Figure 32). An additional step, often overlooked, will be evaluating the effectiveness of the climate change adaptation process and making changes as needed. For example, did impacts occur when and where as expected? And were alternative responses adequate? Though this diagram is depicting a linear process, the actual process of adaptation includes many feedback loops, especially as improved models, data and other tools are developed.

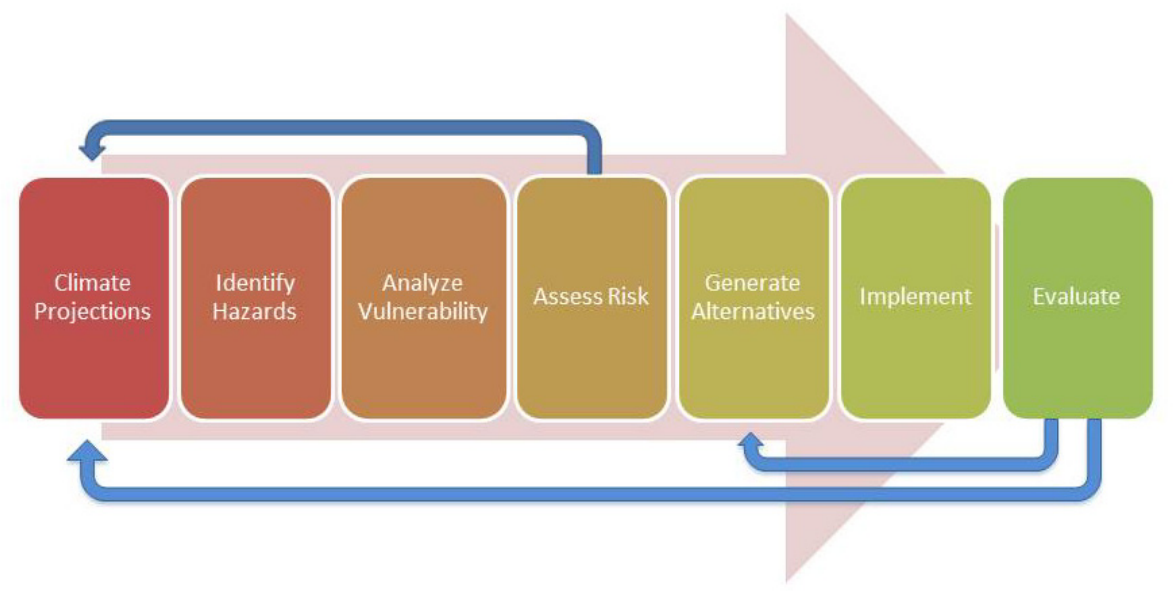

Figure 32 - General adaptation process. 


\section{$\underline{\text { Risk Management: Hazards, Vulnerability and Risk }}$}

Adaptation planning generally includes three processes that fall under the umbrella of risk management: hazard identification, vulnerability analysis and risk assessment (Figure ) (Kutz, 2004). Hazard identification involves identifying the potential threats for a particular location and its infrastructure. In coastal locations, sea level rise is a known hazard, as is erosion and increased storm activity. Vulnerability analysis involves identifying the susceptibility to loss or reduction in service from identified hazards. For example, identifying which roadways may be impacted by wildfire and the relative importance of each segment within the system. Risk analysis involves estimating the likelihood of an event along with the magnitude of consequences should impacts incur.

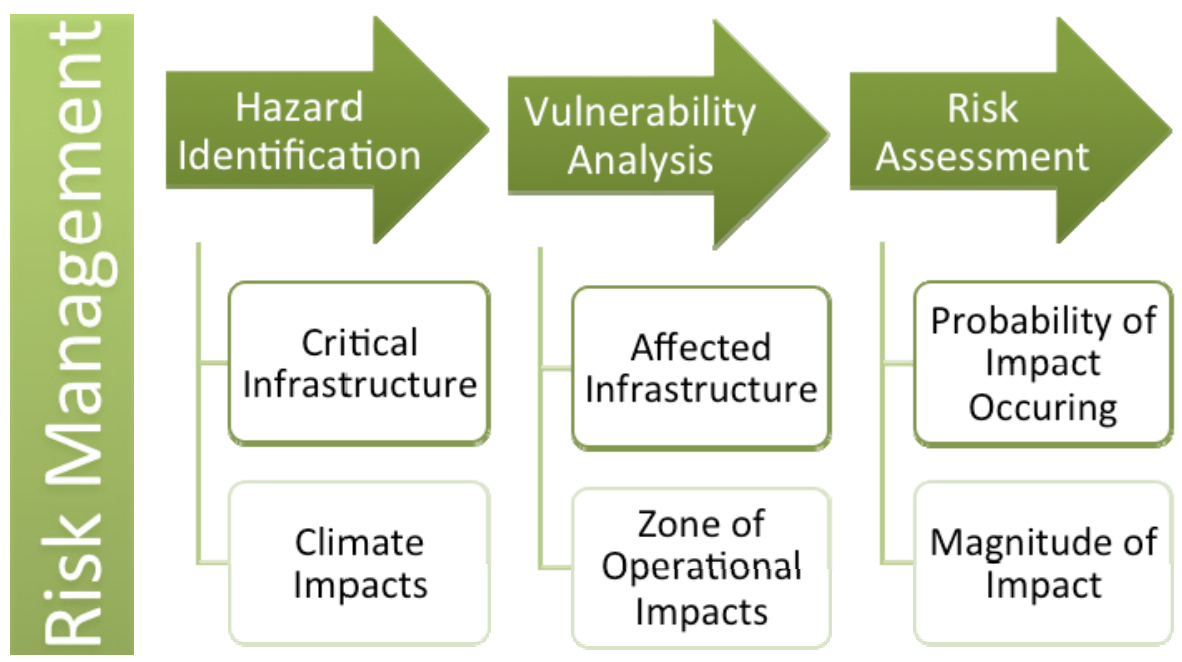

Figure 33 - Risk management processes.

Risk management is a decision-making process that has traditionally been associated with insurance and financial institutions, but its use has extended beyond 
these fields and can be applied to climate change risks to transportation. According to Noble et al., "the risk management process offers a framework for identifying, assessing and prioritizing climate related risks, and developing appropriate adaptation responses" (Noble, 2005). It is particularly appropriate in the context of climate change because it allows for decisions under uncertainty.

Risk management approaches generally include the following elements, described below in Table 15 within the context of climate adaptation:

\section{Table 15 - Risk Management Activities in the Context of Climate Change (Adapted from Walker et al., 2010)}

\begin{tabular}{|c|c|}
\hline Risk Management Activities & Climate Change and Transportation Context \\
\hline Preliminary Evaluation & $\begin{array}{l}\text { Define the scope of the analysis, including the hazards that } \\
\text { will be examined and the study limits. Both the geographic } \\
\text { field of study and the transportation modes should be } \\
\text { defined. }\end{array}$ \\
\hline Hazard Identification & $\begin{array}{l}\text { Identify potential risks, based upon a record of historical } \\
\text { vulnerabilities as well as projected future scenarios. }\end{array}$ \\
\hline $\begin{array}{l}\text { Vulnerability Analysis and } \\
\text { Risk Estimation }\end{array}$ & $\begin{array}{l}\text { Determine the costs associated with a particular risk should } \\
\text { it occur (magnitude), and assess the likelihood of the event } \\
\text { occurring over a specified time span (probability). }\end{array}$ \\
\hline Adaptation Response & $\begin{array}{l}\text { Develop strategies for addressing identified risk(s) - } \\
\text { protection, accommodation or retreat - based within the } \\
\text { context of other competing risks on the system and } \\
\text { prioritize. }\end{array}$ \\
\hline Action and Monitoring & Develop an implementation plan and evaluate effectiveness. \\
\hline
\end{tabular}

\section{Hazards and Impacts}

One of the most significant barriers to adaptation planning is a lack of information on what impacts can be expected as a result of climate change, and where and when (as well as within what time frames) impacts are likely to occur. In order to begin answering these key questions, planning staff should begin a systematic hazard analysis in their jurisdiction. 
Hazard analysis, such as hazard mapping, can be developed based on data collected from observed hazards like historic flooding as well as an inferential approach based on characteristics, such as the soil type and slope which may contribute to increased landslide activity. These maps can be further detailed by including a time horizon; for example, hazards such as wildfire are most likely a seasonal hazard and can be noted as such.

Geographic information system (GIS) technology has frequently been used in climate change hazard studies to identify locations of potential hazards. GIS offers several advantages for modeling hazards, including the ability to model multiple data sets simultaneously; the relative ease of adapting new or revised data sets to the model; the range of analysis options from simple to highly advanced; the ability to export data for analysis in other programs or for other uses (such as traffic modeling programs or identifying wildlife corridors); and the ability to visually present spatial data to stakeholders and other interested parties. GIS data commonly exist for transportation infrastructure such as roadways, bridges, ports, etc. Oftentimes, GIS data is also already available for certain known hazards in a region, as well as other parameters such as elevations and vegetative cover or flood zones. For example, the Federal Emergency Management Agency (FEMA) has prepared 100-year flood maps throughout the entire U.S. These may be readily obtained online at no cost through several reputable data clearinghouses such as Geodata.gov, the United States Geological Survey (USGS) and the Economic and Social Research Institute (ESRI) for direct mapping in a GIS.

However, existing sources of data may contain drawbacks, such as inadequate resolution or lack of currency, which may present issues for planning staff depending 
on the nature of their analysis. For example, the aforementioned FEMA 100-year flood maps are largely considered in need of update, a process which itself may be contentious due to hazard identification effects on property values and insurance rates (Congressional Natural Hazards Caucus, 2010; USGAO, 2004; USGAO, 2010; and FEMA, 2010.) Similarly, roadway network data may not be segmented in a way that allows a processor to select portions of the roadway for individual analysis. It is key that persons developing hazard maps understand the limits of the data they with which they are working as well as the potential for modification. In March 2010, FEMA began Phase II of reprograming the National Flood Insurance Program (NFIP), of which sustainability and resiliency are central goals. In addition to this effort, FEMA is continuing to complete the Flood Map Modernization program, with the goal to deliver reliable digital flood hazard data and maps in GIS format for 92 percent of the nation's population and to address gaps in flood hazard data (FEMA, 2010). Figure 34 shows the modernization of maps by county in the PNW and Alaska. The update to these flood maps is still based on historical data and assumes climate stability at late $20^{\text {th }}$ century conditions. States and local jurisdictions will need assistance and guidance to integrate climate science to develop scenarios for the flood maps. 


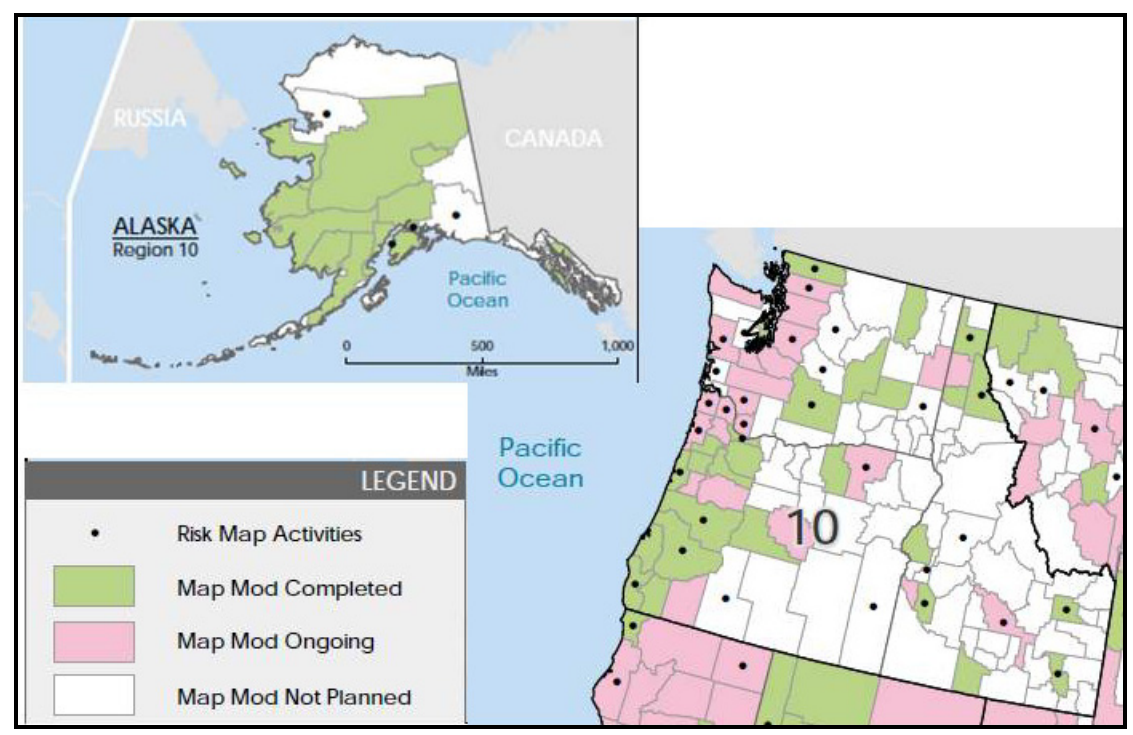

Figure 34 - Risk map activities relative to map mod counties in Region 10 through FY10 (FEMA, 2010).

As part of this research, simple hazard identification was conducted in the city of Portland using GIS (Walker et al., 2010). Based upon regional climate projections from the IPCC Physical Science Basis report and input from regional transportation planners on climate impacts of greatest concern, hazard maps were created to identify surface transportation vulnerable to flooding and landslide (Figure 35). Additional maps created for this case study and details on methodology may be found in Appendix B: Portland, Oregon Case Study. Intersection analysis was conducted to identify segments of major roadway, rail, transit (light rail and streetcar), and non-motorized routes that were likely to be affected by these two impacts. City transportation staff reviewed and validated the results and provided additional insights. Although vulnerability analysis, risk assessment and development of adaptation responses are not carried out for this case study, potential next steps to estimate vulnerability and risk 
(such as modeling traffic delay as a result of flooded roadway connections) were explored.

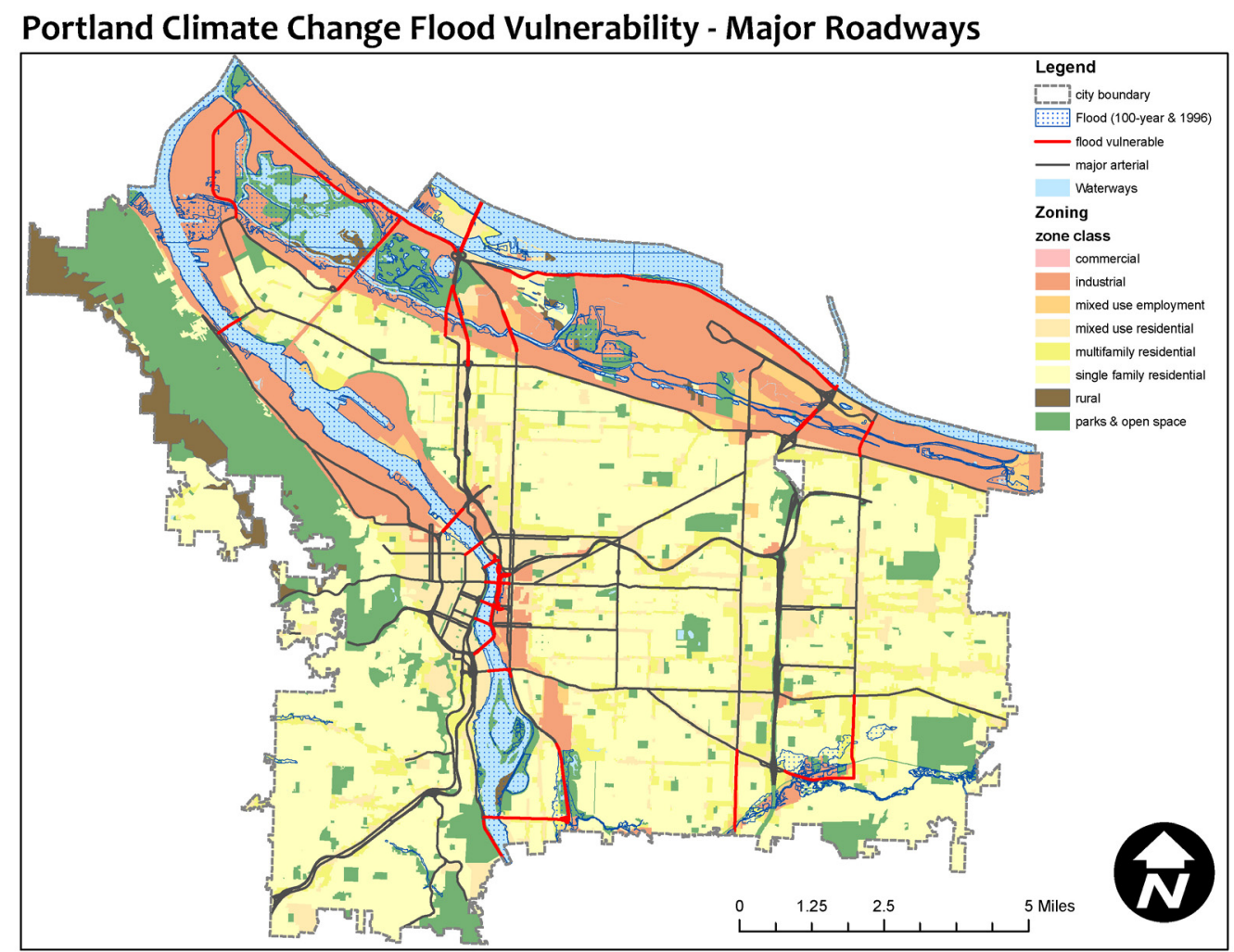

Figure 35 - A flood hazard map created for major roadways in Portland, OR., Using GIS.

Another method of identifying potential hazards extrapolates data from regional or localized climate projections and models impacts based on local conditions, such as hydrology. This is typically a resource-intensive task and, depending on resources, may only be feasibly completed for small portions of an entire jurisdiction. However, an increasing number of tools are being created to streamline hazard modeling and reduce costs associated with both visualizing and analyzing hazard data.

For example, the National Oceanic and Atmospheric Administration's (NOAA) Coastal Services Center has compiled a variety of digital hazard analysis tools that can 
assist planners to assemble, manage and analyze hazard data for their location and is particularly suited to coastal areas (NOAA, 2010). Such tools have been used for a variety of hazard identification-related studies, including potential inundation from SLR in Florida's Miami-Dade region and Transportation Research Board Special Report 290: Impacts of Climate Change and Variability on Transportation Systems and Infrastructure - Gulf Coast Study, Phase I. Models such as these allow planners to use both existing data and test a variety of scenarios, such as varying increases in SLR for a given location.

\section{$\underline{\text { Vulnerability Analysis }}$}

Vulnerability analysis includes an examination of weaknesses (or strengths) of infrastructure and systems under existing or current conditions as well as under projected conditions brought on by climate change. Vulnerability is based upon the sensitivity of infrastructure or systems to climate change as well as its resilience, or adaptive capacity for sustaining climate impacts with minimal cost or disruption in service (FHWA, 2009). According to England Highway's Climate Adaptaton Plan (UK Highways, 2008), criteria for evaluating vulnerability often includes the projected extent and severity of transportation disruptions, the estimated rate of climate change, and the level of uncertainty surrounding the climate projection (Meyer, 2010). Burton defines vulnerability as "the propensity for regional infrastructure to malfunction under

future forcing conditions" and proposes three categories of vulnerability. These are given in order of increasing severity below inTable 16. 


\section{Table 16 - Vulnerability Categories}

\begin{tabular}{|c|c|c|c|}
\hline Category & Impact & Description & Example \\
\hline Type I & $\begin{array}{l}\text { Reduced } \\
\text { Operational } \\
\text { Efficiency }\end{array}$ & $\begin{array}{l}\text { Vulnerabilities which cause a reduced } \\
\text { efficiency of infrastructure, but one } \\
\text { in which the reduction is relatively } \\
\text { mild and does not constitute a design } \\
\text { failure. They are a long-term } \\
\text { nuisance rather than a vulnerability } \\
\text { tied to a specific single event. An } \\
\text { indicator of Type I vulnerabilities is } \\
\text { increased maintenance. When } \\
\text { assessing this type of vulnerability, } \\
\text { one must also consider increasing } \\
\text { demands on infrastructure from the } \\
\text { population it serves (Burton, 2005). }\end{array}$ & $\begin{array}{l}\text { Increased rain causes } \\
\text { reduced visibility and } \\
\text { increased hydroplaning of } \\
\text { vehicles on freeways. This } \\
\text { reduces operational } \\
\text { capacity, but may be } \\
\text { mitigated with pavement } \\
\text { technologies (such as open } \\
\text { grade mix, porous pavement, } \\
\text { etc.) and driver warning } \\
\text { systems (such as changeable } \\
\text { message signs as part of an } \\
\text { Intelligent Transportation } \\
\text { System) }\end{array}$ \\
\hline Type 2 & Design Failure & $\begin{array}{l}\text { Vulnerabilities that reduce } \\
\text { operational efficiency significantly } \\
\text { enough to constitute a design failure. } \\
\text { Infrastructure is typically engineered } \\
\text { for a design event which exceeds } \\
\text { normal use, such as a storm with a } \\
\text { specified return period. A design } \\
\text { failure is indicated by extended and } \\
\text { unacceptable exceeding of } \\
\text { infrastructure capacity (Burton, } \\
\text { 2005). }\end{array}$ & $\begin{array}{l}\text { Closure of a highway due to } \\
\text { river flooding or ice due to a } \\
\text { major snowstorm. Once the } \\
\text { event dissipates the roadway } \\
\text { returns to normal, but may } \\
\text { require increased } \\
\text { maintenance. }\end{array}$ \\
\hline Type 3 & $\begin{array}{l}\text { Infrastructure } \\
\text { Failure }\end{array}$ & $\begin{array}{l}\text { Vulnerabilities that are catastrophic } \\
\text { infrastructure failures, not } \\
\text { operational failures. These are the } \\
\text { most serious and least likely. Type III } \\
\text { failure is usually clearly evidenced by } \\
\text { total or significant disruption to } \\
\text { normal function (Burton, 2005). }\end{array}$ & $\begin{array}{l}\text { Catastrophic failure such as } \\
\text { exposed bridge footings on a } \\
\text { critical bridge. }\end{array}$ \\
\hline
\end{tabular}

To conduct vulnerability analysis, planners must identify critical infrastructure.

In order to do this, one must explicitly define "infrastructure," and also determine the criteria that makes a given infrastructure "critical." In the context of this report, infrastructure includes roadways, bridges, railways, as well as sea and airports. Critical infrastructure can be identified by answering the question: "If this structure/route were affected (delay or closure), what would be the consequences?" 
After identifying what impacts are likely to occur and determining the likely location of affected infrastructure in hazard identification, planners must develop an estimate of the potential loss and/or impact to system operations caused by the hazard. Both existing hazards based on historical records and new hazards presented by climate change should be considered. Cost estimates of direct damages can likely be drawn from previously experienced impacts but may be adjusted to reflect a higher or lower magnitude as a result of climate changes or an increase in event frequency. The impact of a potential transportation disruption caused by hazards can be estimated in a number of ways. These include simple techniques based upon traffic volumes along the affected segments and/or the availability of alternative routes, or through more sophisticated analyses such as traffic modeling to estimate diversion, congestion and associated delay. For example, if a particular bridge is determined at risk of flood impacts, planners can utilize traffic modeling tools, such as VISSIM software, to model detour effects and extrapolate vehicle delay into an estimate of economic impact. This type of information can provide an indication of the impact a closure (detour and/or congestion) would have on the overall system and serve in later risk estimation and adaptive alternative prioritization.

Researchers at Portland State University have analyzed the potential impacts of climate change on transportation in terms of travel delay associated with flooding in Portland's Fanno and Johnson Creek watersheds and the resulting closure of two major roads (Chang et al., 2010). This study employed a variety of climate change scenarios, hydrologic modeling, roadway and stream channel surveys, and travel forecast models to estimate potential impacts in locations known to be susceptible to periodic flooding. 
Although vehicle miles traveled were not significantly affected in this particular model, vehicle delay was impacted. This conclusion suggests the need for detour and congestion response plans in areas at risk for disruption due to climate change in the short-term, as well as long-term physical improvements such as locating signal control electronics above flood level. Although a study as detailed as this is typically not feasible throughout the entire city, such an approach can be used to estimate impacts and weigh response in other vulnerable areas as they are identified. This is particularly true in locations where impacts and the associated adaptation improvements are likely to be very costly. Table 17 below, provides a list of the main factors that should be considered.

Table 17 - Climate Impact Factors to Consider

\begin{tabular}{|l|l|}
\hline Factors & Discussion \\
\hline Economic Impact & $\begin{array}{l}\text { Projected monetary impact on the surrounding economy from } \\
\text { discontinued operation }\end{array}$ \\
\hline Redundancy & $\begin{array}{l}\text { Availability and capability of redundant routes. For example, if a major } \\
\text { arterial was flooded or a bridge was to fail, how will the rest of the } \\
\text { system handle the sudden increase in traffic? }\end{array}$ \\
\hline Resilience & $\begin{array}{l}\text { Level of difficulty (time, resources, manpower) to restore to normal } \\
\text { operation. }\end{array}$ \\
\hline Human Impact & Number of citizens impacted (loss of life or \$) \\
\hline Quality of Life & $\begin{array}{l}\text { How is quality of life being impacted? What is the expected travel } \\
\text { delay? Impact on basic resources including power, water, sewer, food } \\
\text { accessibility, public safety and health (access to emergency services)? }\end{array}$ \\
\hline
\end{tabular}

It is possible, even expected, for any impacted infrastructure to have multiple factors described above. A quantified total impact can be captured through a numerical rating system. The vulnerability factors scale in Table 18 below provides a first approach to give a numerical rating to different level of impacts. An impact score of Level 1 denotes minimal to no impact, while a Level 5 impact is catastrophic. For example, a 
local collector might receive a score of Level 1, while the Glen Jackson Bridge on Interstate 205 might receive a score of Level 5.

Table 18 - Vulnerability Consequence Scale

\begin{tabular}{|cc|}
\hline Level & Impact \\
\hline $\mathbf{1}$ & Minimal / No Impact \\
\hline $\mathbf{2}$ & Easy to fix / Little impact \\
\hline $\mathbf{3}$ & Can be fixed / Moderate Impact \\
\hline $\mathbf{4}$ & Difficult to fix / Severe Impact \\
\hline $\mathbf{5}$ & Extremely Difficult to fix / Catastrophic Impact \\
\hline
\end{tabular}

It is up to local MPOs and/or DOTs to determine the exact definition of each level of potential impacts. It is neither practical nor possible to create a one-size-fits-all system due to the varying of size and scope of jurisdictions. Therefore, Table 18 is meant as a tool to enable planners to develop a framework in which local MPOs and/or DOTs can explicitly define impacts/consequences to better suit their individual needs.

After individual impacts are assessed and given a score, the next step is to aggregate those values to create a total impact score. Local DOTs and MPOs now have a preliminary list of critical infrastructure. This list can be used to create an action plan or, as demonstrated in the next section, to further analyze what critical infrastructure needs the most protection.

This additional layer of data will allow for better use of limited resources. For example, although an infrastructure item is deemed critical (e.g., the under-construction Sandy River Bridge on Interstate 84 in Oregon) it might carry a Level 1 risk because of modern design and new construction. While the Oregon Department of Transportation (ODOT) should still monitor the bridge's performance, fewer resources would be needed to monitor this bridge compared to a significantly older bridge. Alternatively, a less critical infrastructure component (e.g., the Van Buren St. Bridge connecting Corvallis, 
OR., and OR 34) can carry a higher risk rating of 2 or even 3, due to it being on an historic flood plain and of older construction date. However it is less critical because in the case of a weather-related event, such as flooding, the existing Highway 20/34 bypass and/or the parallel Harrison St. Bridge could be used as an alternate route to accommodate additional traffic (Wolcott et al., 2009).

The list of critical infrastructure and the risk assessment can be combined to create a Hazard-Vulnerability Impact Assessment matrix such as the one shown in Table 19 below. This combines the numerical critical infrastructure rating (column) with the risk assessment level (row) to create a matrix that can be used to create a recommended infrastructure priority list. For example, a structure with a critical infrastructure score of 1 that carries a risk rating of level 1 is of lowest priority (L); conversely, a structure with a critical infrastructure score of 5 that carries a risk rating of 5 carries a high $(\mathrm{H})$ priority. The recommended breakdown between low and high priorities is displayed below and can be modified to suit the needs of individual MPOs and DOTs, allowing them to efficiently use limited resources to develop more information that will better help them adapt to the impacts of climate change on critical infrastructures.

Table 19 - Hazard-Vulnerability Impact Assessment Matrix

\begin{tabular}{|l|cccccc|}
\hline \multirow{4}{*}{$\begin{array}{l}\text { Critical } \\
\text { Infrastructure }\end{array}$} & \multicolumn{1}{c}{ Severity } & $\mathbf{2}$ & $\mathbf{3}$ & $\mathbf{4}$ & $\mathbf{5}$ \\
\cline { 2 - 8 } & Level 3 & $\mathrm{M}$ & $\mathrm{M}$ & $\mathrm{H}$ & $\mathrm{H}$ & $\mathrm{H}$ \\
\cline { 2 - 8 } & Level 2 & $\mathrm{L}$ & $\mathrm{M}$ & $\mathrm{M}$ & $\mathrm{H}$ & $\mathrm{H}$ \\
\cline { 2 - 8 } & Level 1 & $\mathrm{L}$ & $\mathrm{L}$ & $\mathrm{L}$ & $\mathrm{M}$ & $\mathrm{H}$ \\
\hline
\end{tabular}




\section{$\underline{\text { Risk Assessment }}$}

Understanding the nature of potential climate change impacts, where they are likely to occur, and the prospective consequences when they occur is information necessary for risk assessment. However, to complete risk assessment, probability of impacts should be explored. As noted earlier, risk assessment involves estimating the likelihood or probablity of an event, such as a hazard occurring, along with the consequences discovered through vulnerability analysis (Figure 36). This type of analysis is generally described as a probabilistic risk assessment (PRA) and is a method that has been employed in other fields to address risk under uncertain conditions.
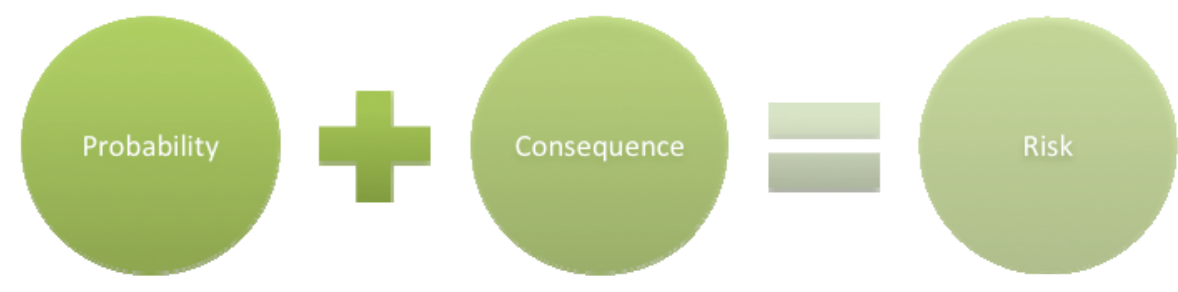

Figure 36 - Elements of probabilistic risk assessment.

A qualitative matrix of probability and magnitude of impact (or severity) is a common methodology used to assess risk under climate change. Such matrices rank risk for various vulnerabilities as high, medium or low. Table 20 below provides an example of such a matrix that also can be used to prioritize hazards/vulnerabilities requiring response and screen out those that are less significant. Hazards that are estimated to have catastrophic impacts and a high probability of occurring (or reoccurring) are assigned the high level of risk and could proceed to more detailed risk assessment and/or alternatives for adaptation may be developed and implemented. Likewise, hazards with minimal or no impact and that are unlikely to occur would be assigned a low level of risk. These lower- 
priority impacts may be addressed on an as-needed basis as they occur. This type of risk assessment can be completed with using a range of detail. For example, a Delphi approach using experts or knowledgeable individuals might provide a rough assessment, while a data- or model-driven approach may a more refined assessment.

Table 20 - Adaptation Priority Matrix (Adapted from Highways and Climate Change, 2009)

\begin{tabular}{|l|l|l|l|l|l|}
\hline \multicolumn{2}{|c|}{} & \multicolumn{4}{|c|}{ Impact } \\
\cline { 3 - 6 } \multicolumn{2}{|c|}{} & Catastrophic & \multicolumn{1}{|c|}{ Major } & \multicolumn{1}{|c|}{ Moderate } & Minor \\
\hline \multirow{4}{*}{ Likelihood } & Very Likely & High & High & Med & Med \\
\cline { 2 - 6 } & Likely & High & High & Med & Low \\
\cline { 2 - 6 } & Medium & High & Med & Med & Low \\
\cline { 2 - 6 } & Unlikely & Med & Med & Low & Low \\
\cline { 2 - 6 } & Very Unlikely & Med & Med & Low & Low \\
\hline
\end{tabular}

Quantitative risk assessments may also be conducted, but are generally less common due to the challenges presented by compounding uncertainties found under climate change. For impacts that have a historical record of occurring with an established frequency, an estimation of the likelihood of recurrence may be developed. For example, flooding risk as depicted in FEMA 100-year flood maps illustrate locations that have a 1 percent chance of flooding in a single year at a level expected to be equaled or exceeded every 100 years on average. However, for "new" hazards, probability becomes more challenging to estimate.

\section{$\underline{\text { Developing Alternative Adaptation Responses }}$}

Most adaptation strategies aim to make infrastructure more durable or sustainable on a system level. Very few strategies attempt to use innovative construction materials, although that is the subject of continuing research. Adaptation approaches to climate change impacts need to be region-specific. Various areas will 
experience different climate change effects, over different timeframes, and have different levels of associated risk. Some adaptation approaches include extending timeframes of the planning and design analysis and retrofitting existing structures to increase their resilience. In many regions, land use policies may need to be revisited in order to restrict development in higher-risk areas. Planners must also consider the likely cost of feasible adaptation alternatives. Each alternative has an associated cost that must be considered in comparing response options and prioritizing among competing risks located elsewhere within the system. Finally, the planning process might need to be more flexible to allow different outcomes and design life of infrastructure to be evaluated to ensure alternatives and solutions fit the context of the project.

There are three general adaptation alternatives (Parry et al., 2007):

1. Avoidance - Planning new facilities or rerouting existing facilities outside of hazard areas. An example includes construction of a bypass around a landslideprone area.

2. Protection - Improvements to existing facilities to increase their resilience or adaptive capacity to climate change impacts. Examples include increased height of sea walls, landslide fencing and monitoring, or bridge designs that are modified from current standards. Standards and criteria should be continually evaluated or modified based on the newest climate research.

3. Abandonment - Abandonment or closure of a facility may be the most costeffective solution if avoidance or protection alternatives are infeasible. Examples include closure of landslide-prone segments. 
A fourth adaptation response could include operational responses such as ongoing maintenance and incident response (including temporary or seasonal closure and messaging services to the traveling public). This alternative would factor in the ongoing cost of repair and incident response based on the projected frequency of events. For vulnerabilities with minimal impact and/or low likelihood of occurrence, or for assets with short lifespan (e.g., pavement) this approach may be an optimal response (Kinsella, 2005). Examples include a planned detour route in response to periodic flooding of a roadway. The City of Portland has such a plan established (including sandbag locations) for the Johnson Creek area, which is known to flood periodically.

In many cases, adaptation planning options are not unique to issues of climate change. For many agencies these are good business practices to emergency response, maintenance and asset management. Agencies need to integrate the issues, language and potential impacts of climate change into existing agency and business structures and practices.

\section{Adaptation Strategies: Planning}

The American Association of State Highway Transportation Officials (AASHTO) and Michael Meyer of Georgia Institute of Technology have published papers on the implications of climate change to the planning and design of infrastructure. Savonis and Kirshen also touch on the implications for planning. Climate change could have effects on planning, preliminary engineering, design, construction, and operations and maintenance. There is opportunity for inter-agency collaboration to develop solutions benefitting both transportation infrastructure and natural resources (AASHTO). The 
design stage is separated into subsurface conditions, materials specifications, standard cross sections and dimensions, drainage and erosion, and structures and location engineering (Meyer, 2008).

Climate change has varying effects in different regions. Therefore each region will need different adaptive strategies. Each form of climate change (increased temperature, sea level rise, etc.) also requires different adaptive strategies. For coastal areas the short-term concerns include SLR, changes in moisture/humidity, and storm frequency and severity. Long-term concerns include temperature changes and wind loads (AASHTO, 2008; Meyer, 2008).

Adaptation considerations in the design and planning processes should take into account the design life of the structure. Roads, which typically last 10-20 years, may not need as much adaptive capacity as bridges, which are designed to last much longer. The longer a structure lasts, the more concern it should merit for the evaluation of future climate impacts (Meyer, 2008). Similarly, structures with higher performance demands should merit more concern. It has been stated "as the importance of maintaining uninterrupted performance increases, the appropriate level of investment in adaptation for high-risk facilities should increase as well" (Savonis, 2009).

Federal transportation planning is generally done for investment planning, with a timeframe of 20 to 30 years. But because transportation structures have service lives as long as a century, agencies should incorporate longer-term considerations such as climate change as an additional evaluative criteria (Savonis, 2009). 


\section{$\underline{\text { Adaptation Strategies: Non-Design }}$}

There are other ways to adapt infrastructure other than modifying the design process. Meyer identifies such "non-design" strategies. The first is land use policy. If facilities are not built in areas susceptible to climate-induced changes in loads (storms, wind, etc.) then the existing design process may be adequate. Transportation infrastructure is integral to the way communities develop. Land use guidelines in areas with high vulnerabilities to climate change could help reduce or avoid associated risks. One of the difficulties with this approach is that local agencies develop land use policies through zoning laws and ordinances, but large-scale infrastructure projects are managed by state or regional agencies. There is need for inter-agency collaboration on infrastructure decisions (Meyer, 2008).

A second "non-design" strategy is to retrofit existing structures to give them higher adaptive capacity. This is a short-term but cost-effective solution. Retrofitting existing structures may only solve some of the problems occurring due to climate change. For example, connecting bridge decks to the piers would prevent them from being lifted off in high waters, as happened during Hurricane Katrina. But it is possible that not all effects may be resolved through retrofitting alone (Meyer, 2008). Adaptation strategies such as retrofitting may be suitable for individual structures, but a system-wide scale will require adaptation of planning and design standards (McKenzie, 2003).

A third strategy is to design more redundancy into the transportation system. When a major highway or line is disrupted there are economic losses due to loss of flow. A redundant system would provide alternate routes, thus minimizing the impacts of 
disruption on a single route. Finally, a fourth strategy is to incorporate new technology and construction in response to changing conditions (Meyer, 2008).

\section{Adaptation Strategies: Design}

Typically in the USA, ports are designed to withstand historic, 100-year return period storms (Becker et al., 2010). With climate change and potential for increased storm risk, this historic assumption may no longer be appropriate. Storms with historic 100 -year reoccurrences may return within 30 or 50 years. Thus, design-level storm intensities need be revisited by port authorities to accommodate for future events. This can be done using projected climate changes models that are accepted by the scientific community.

To further decrease the risk of damage from increasing storm events and rising sea levels, seaports may investigate the feasibility of building new storm protection structures. These include, but may not be limited to, dikes and jetties. Dikes protect port infrastructure from potential flood damage from major storm events by providing a buffer for storm surges. A jetty is intended to break up potentially violent waves and allow for smoother movement of ships.

"Design limits of existing infrastructure, such as bridges, causeways, dykes, breakwaters, jetties, seawalls, navigational aids, and port and harbor facilities, may not be suitable for responding to or effectively managing coastal impacts under conditions of future water level change, changing wave regime, or increased storm activity, and as such, engineering standards may have to be revised" (McKenzie, 2003). Design standards 
should be evaluated and, if needed, changed to reflect impacts of future climate scenarios and to allow the flexibility to address the uncertainties of future scenarios.

\section{$\underline{\text { Adaptation Strategies: Design - Smart Materials }}$}

There is ongoing research into the use of smart materials in civil infrastructure applications. One such application is the use of microsensors distributed throughout a structure as part of the aggregate in concrete. This is useful for ongoing monitoring of the structure's subsurface, or internal, condition and providing data on performance of materials under environmental conditions (Sackin, 2000). Robinson and Culshaw have also published work on the use of smart materials for infrastructure monitoring (Robinson, 2006; Culshaw, 2008). K. Dunn has published plans to incorporate smart technology into a pair of bridges at Savannah River, S.C.. The purpose of the upgrade is to evaluate the effectiveness of smart technology on large applications. Some of the materials planned are fiber reinforced polymeric (FRP) composite overlays for the deck and pilings, FRP rebar, and smart sensors (Dunn, 2010).

Other materials under research for structural applications are shape memory alloys (SMAs). These alloys are able to absorb large strains, with possibly a wide range of cycling, without permanent deformation. SMAs are suggested for passive use, such as frame bracing, and active use, such as seismic damping (Muthumani, 2010).

Although most of the research appears to be directed at structural applications, it is possible that new transportation structures designed with climate change effects in mind and with such technology incorporated internally could be monitored closely to initiate action as needed. Sensors could issue a warning as soon as conditions become 
abnormal, triggering remedial action before failure occurs. Technology may also actively protect a structure - for example, redirect highly turbulent flows away from bridge columns (Meyer, 2008). The use of SMAs may also be beneficial for areas where increased strains are expected to be problematic, such as from increased freeze/thaw cycling or wind loads. The FHWA is researching ways to improve transportation infrastructure's long-term performance and durability, including smart sensors in bridges and pavements and smart bridge systems (U.S. Department of Transportation, 2010).

Smart materials may also be used to mitigate or avoid permafrost melting. One recommendation to mitigate the effect of melting permafrost is to use highly reflective pavement instead of conventional asphalt materials. It is widely known that black asphalt absorbs a tremendous amount of heat from the sun. This accelerates the melting of the underlain permafrost layer, especially in the summer months. Highly reflective pavement deflects some of the heat away, reducing warming effects on the underlying soil layer. Different technologies for highly reflective pavement already exist, and some have been successfully used in urban environments to reduce "heat island" effect (Ting et al., 2001). Table 21 below describes different reflective pavement techniques that are being used or are under development in the U.S. Any one of the listed technologies can be used to reduce permafrost melting. The table also lists the pros and cons of different reflective pavement technologies to further assist Alaskan transportation officials in selecting the appropriate technology. 


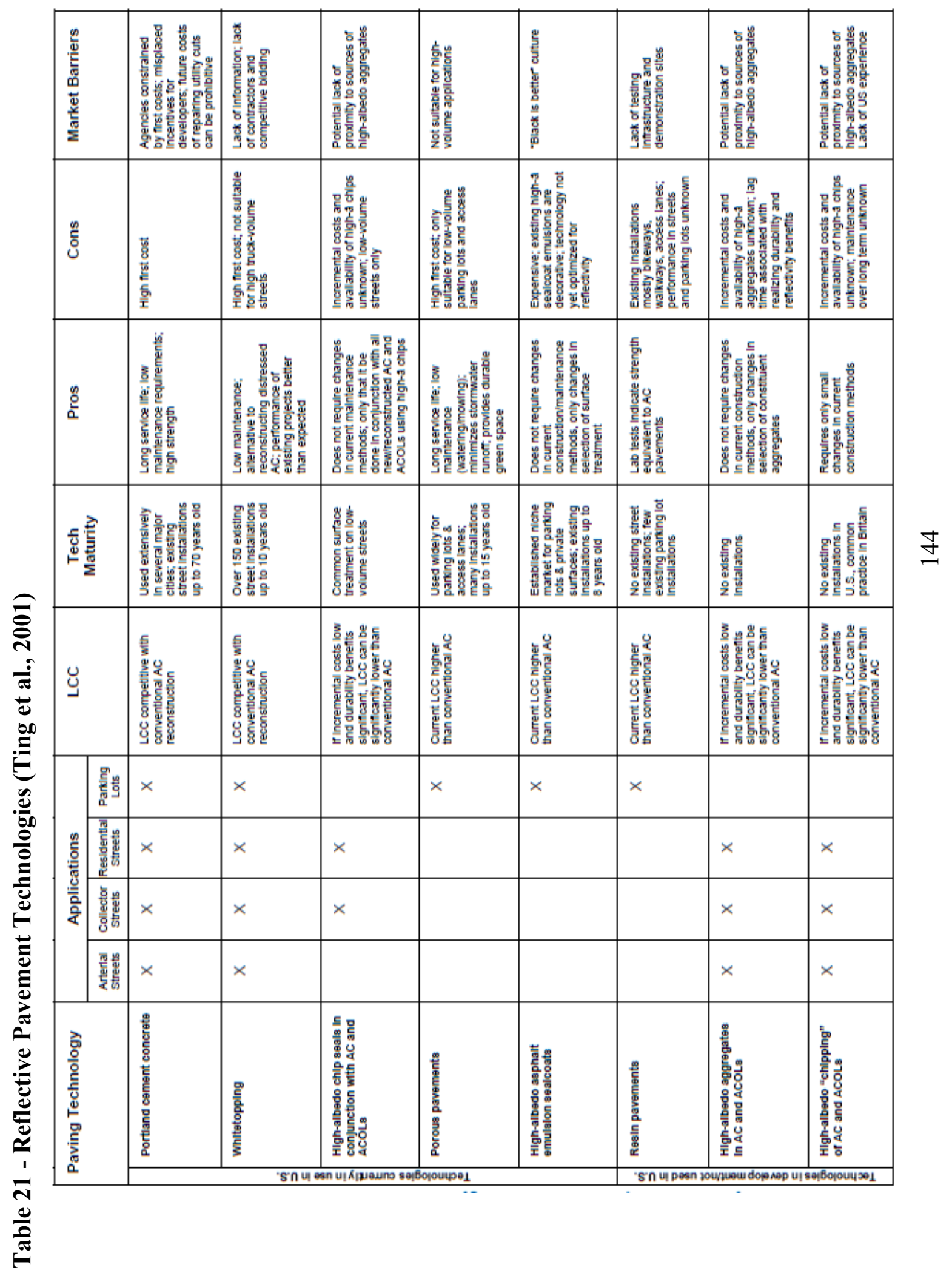




\section{Adaptation Strategies: Increased Monitoring}

Increased monitoring can help DOT staff identify and mitigate some climate change impacts. Weather-related impacts are occurring to the transportation system every day and agencies are dealing with the consequences. Agency maintenance staff is at the front line of managing and responding to the effects of weather impacts. By starting to monitor and gather weather-related impacts, an agency can start building a baseline and knowledge base around impacts. This data can help validate and inform climate modeling and projections of future impacts. It may also prove to be the most cost-effective strategy where impacts and their severity are very uncertain. Monitoring can be done by many methods, including but not limited to GPS, surface surveys, satellite altimetry, laser altimetry, road condition surveys, etc. (Forsberg et al., 2001) These methods vary in cost and accuracy, and should be investigated by local DOTs. One proven method used by DOTs is a road condition survey. Video-mounted and GPS-tracked vehicles are driven across the state once every two years to record the current highway conditions. A cross comparison can be done to assess any changes in highway conditions using a sophisticated rating system. A specific decrease in rating triggers a closer examination by engineers for possible solutions. A more frequent survey can also be conducted in areas where more rapid or immediate pavement deterioration is noted.

Bridge scour is an example of a climate change impact that is best detected through monitoring. DOTs should revisit their bridge inspection guidelines and scour monitoring procedures to make sure current procedures are adequate to identify potential scouring problems. Bridge inspection data should be compared to hydrologic data and flow projections of the river to provide early warning assessments. DOTs can also increase the 
use of passive energy dissipation systems at bridge peers and roadway embankments to further reduce hydraulic impact energy (i.e., utilize higher, projected flow values on hydraulic reports to increase riprap class recommendation). The FHWA conducted a study to demonstrate the flexibility of using rock riprap to guard against erosion and scouring of not just bridge peers, but also road embankments. There are many types of riprap that can be adapted to different situations. These include rubble riprap, handplaced riprap, broken concrete-block riprap, wire-enclosed rock, etc. (Brown and Clyde, 1989).

\section{CASE STUDY: ASSESSMENT OF CRITICAL INFRASTRUCTURE FOR THE PACIFIC NORTHWEST AND ALASKA}

The following provides a case study of critical infrastructure identification for the PNW and Alaska utilizing a conceptual model developed by the FHWA. The model was developed to provide a framework for agencies to inventory their transportation assets, gather climate information, and conduct a systems analysis of the likelihood and consequences of climate change impacts on transportation infrastructure and assets. With the conceptual model, agencies can develop a prioritized list of at-risk assets that allow them to plan for adaptation based on the level of risk.

The identification and analysis of the critical infrastructure in this case study are facilitated with GIS and geospatial data available for the four states examined in this report (Alaska, Idaho, Oregon and Washington). A comprehensive collection of geospatial data was assembled for the study. The database identifies the types (e.g., highways and railroads) and locations of the infrastructure in the states. Other supplemental data that identify natural and man-made features of the environment 
relevant to climate change impacts are also included in the database. Examples of such features include coastlines, rivers, water areas, topography (identified with digital elevation models), and National Ocean Services tide stations data (for SLR analysis).

After the necessary GIS data was assembled, the analysis proceeded by superimposing geographically areas at risk for particular climate change impact with the infrastructure. To identify the critical infrastructure that may be threatened by climate change impacts, well-studied consequences of climate changes in the four study states were first identified. Because each particular consequence can have different impact on infrastructure, different types of data are needed to identify the particular geographic regions and locations of infrastructure susceptible to each type of climate change consequence.

\section{Analysis Framework: FHWA conceptual model (FHWA, 2010)}

In 2009, FHWA initiated the development of a conceptual model to guide state DOTs and MPOs for the assessment of the vulnerability of their existing and planned transportation infrastructure to climate-related risks. In September 2010, FHWA started a pilot project to test the conceptual model. Five transportation agencies - the San Francisco Bay Metropolitan Transportation Commission, New Jersey DOT/North Jersey Transportation Planning Authority, Virginia DOT, Washington State DOT, and Oahu MPO - were selected to participate in the pilot. The selected agencies were expected to use the conceptual model and provide feedback to FHWA through November 2011. The FHWA expects each pilot agency to generate a final report detailing its activities, partners, lessons learned, and recommendations for future applications of the conceptual 
model. Based on input from these agencies, FHWA will revise and finalize the model for use nationwide.

For this case study the FHWA conceptual model is applied to the PNW and Alaska. However, this effort is independent of WSDOT's involvement in the FHWA pilot. With a significantly larger study area, it is not feasible to conduct analysis at the level of detail provided through the FHWA pilot projects. Rather, the focus here is instead on infrastructure and assets critical to the interconnectivity of the region. The resources developed can be used to perform a statewide risk and vulnerability assessment with more detailed analysis completed at the state (or regional, city, etc.) level.

The FHWA conceptual model consists of three primary components:

1. Develop inventory of assets;

2. Gather climate information; and

3. Assess the risk to assets and the transportation system as a whole from projected climate change.

The analysis process is illustrated below in Figure 37. 


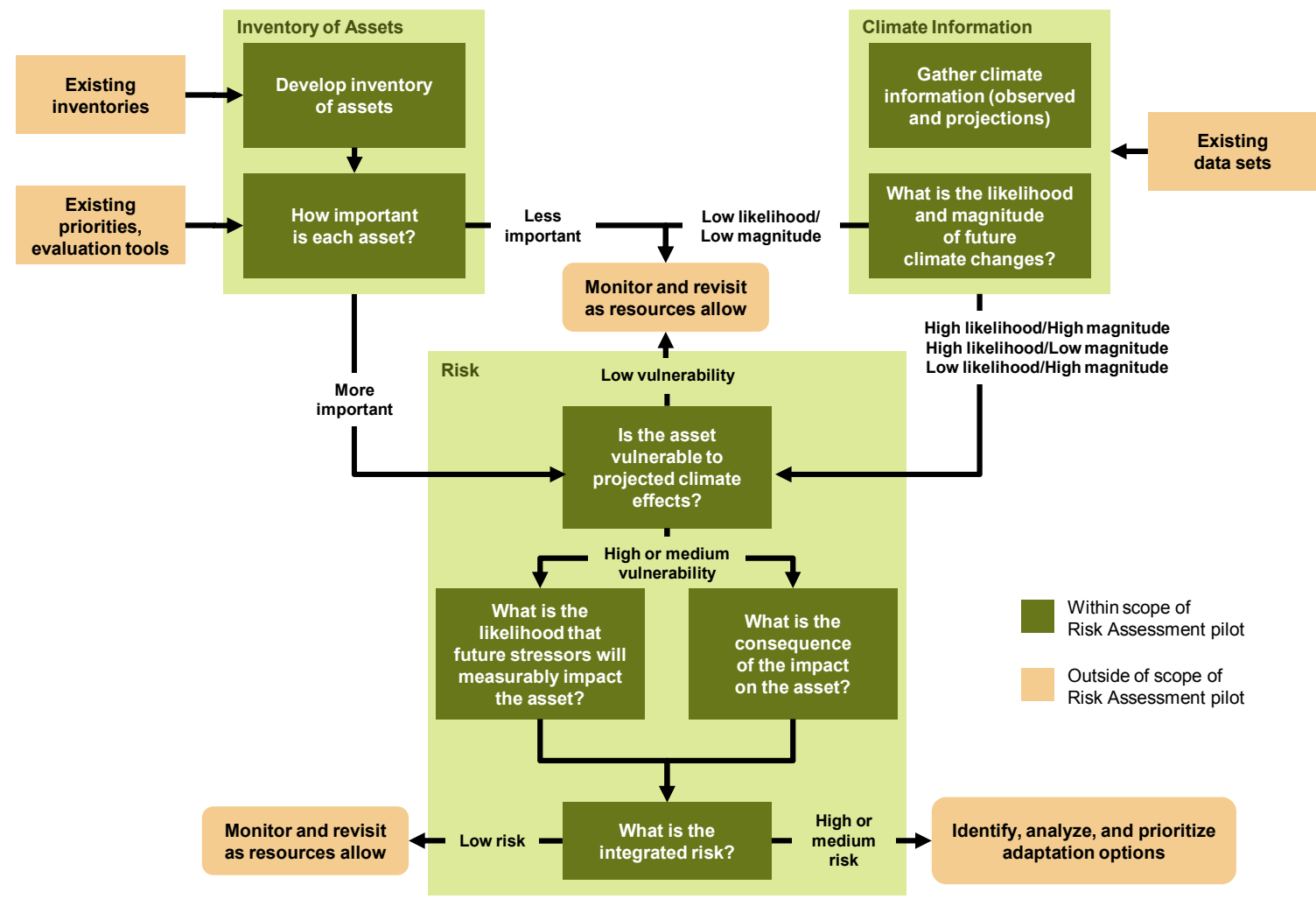

Figure 37 - Structure of FHWA's climate change risk assessment conceptual model (FHWA, 2010).

\section{Inventory of assets for the Pacific Northwest}

To implement FHWA's conceptual model, data representing both transportation assets and the climate information were assembled using GIS. The GIS database consists of data layers representing the locations and properties of natural and man-made features that may interact under the influence of climate change. For example, a highway bridge crossing a river sustains the impact of heavy water flows in the event of storms and heavy precipitation. With GIS, the data layer representing the infrastructure can be superimposed with the river layer. We can thus identify those sections of the highway that are most susceptible to impacts of heavy precipitation and floods. 
The GIS data compiled for this case study comes from several sources. For the inventory of transportation assets, state DOTs provided GIS data identifying assets. In addition, data files from the Caliper Corporation, the maker of the GIS software (e.g., TransCAD) used for the analysis, made up a majority of the database. The Caliper data include public GIS data such as the Bureau of Transportation Statistics' National Transportation Atlas Database (NTAD) and Census TIGER/Line files.

In this case study, three types of transportation infrastructures that are critical for the PNW region were examined: highways, railroads and airports. Sea and river ports' data are used with the tide station data for the analysis of the impacts of SLR on the three types of infrastructures. However, due to the lack of detailed data on the actual layout of the ports, no further analysis is performed for the impacts on the ports.

Information about the length and composition of roads was gathered from state DOTs and Hartgen's report on state highway systems (Hartgen, 2010). There is minor variation in reported mileages, but values are generally in agreement. The cause of variation is likely due to road classifications included or excluded in each report. The comparison of these data are intended only for general information and more uniform data should be sought from each state before performing more detailed comparisons.

The miles of roadway in Pacific Northwest states and Alaska are given below in Table 22. According to Hartgen, "state-controlled miles include the state highway systems, state-agency toll roads, some ferry services, and smaller systems serving universities and state-owned properties. In most states [the state highway agency mileage is] generally the Interstates and other major US-numbered and state-numbered roads, but 
a few states also manage major portions of the rural road system" (Hartgen, 2010). The state-controlled miles include the state highway agency miles.

Table 22 - State Highway Miles, to the Nearest 100 miles

\begin{tabular}{|c|c|c|}
\hline Oregon & $\begin{array}{c}\text { State-Controlled } \\
\text { miles }\end{array}$ & $\begin{array}{c}\text { State Highway } \\
\text { Agency miles }\end{array}$ \\
\hline Washington & 12,000 & 7,500 \\
\hline Idaho & 17,700 & 7,000 \\
\hline Alaska & 4900 & 4,900 \\
\hline
\end{tabular}

Data for the material composition of Oregon and Washington state highways is shown in Table 23. The total miles according to ODOT and WSDOT are consistent with Hartgen's reported state highway agency miles within a reasonable margin of error.

Table 23 - State Highway Miles by Material Composition, to the Nearest 10 Miles (ODOT, WSDOT, ITD)

\begin{tabular}{|cccc|}
\hline & Gravel & Asphalt* & Concrete \\
\hline Oregon & 20 & 7,170 & 220 \\
\hline Washington & 10 & 6,520 & 510 \\
\hline Idaho & 25 & 4,762 & 160 \\
\hline
\end{tabular}

*includes bitumen designated road composition

Similar composition data was not available for Alaska. However, it was determined that Alaska has about 3,700 centerline miles of paved and 1,900-2,400 miles of unpaved state agency highway (State of Alaska, 2008 (certified); State of Alaska, 2008 (public)). There is variation in the unpaved state agency mileage between the two Alaska reports, although the total mileage for roadways in the state (including local jurisdictions and Native American jurisdictions) is the same at approximately 15,300 centerline miles. 
Therefore the discrepancy appears to be a matter of which roads were considered state or local in each report.

\section{Highways}

The highway layer consists of roadways in the four states that are designated as state routes, U.S. routes and interstates. The data were created by the Caliper Corporation from multiple data sources including state DOTs and USGS. Before the choice of Caliper data was made, a comparison between the Caliper data and state route data obtained from the state DOTs was completed. It showed that all highway GIS data are essentially identical. With proper coordinate translation, all state DOT GIS networks superimpose on the Caliper network satisfactorily. Figure 38 shows the highway layer in the Puget Sound area that was formatted with route symbols. Ferry routes are also included in the highway layer. 


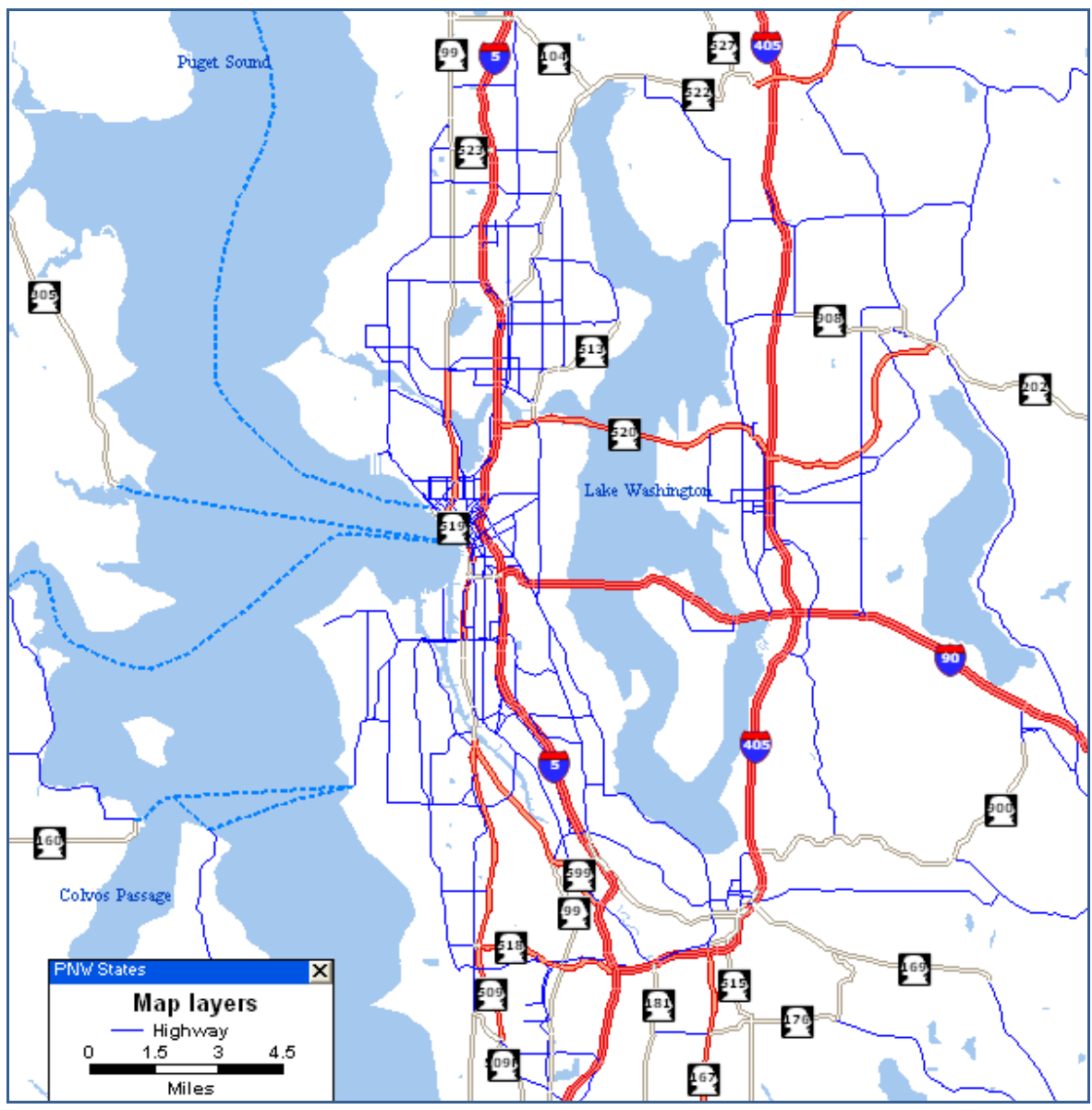

Figure 38 - Highway layer.

To determine the relative importance of highway links, functional classification was selected as the primary criterion. The functional classification data were obtained from the DOTs. Highways considered in this study include routes carrying interstate and state route numbers. These routes are classified from interstates down to major collectors. No minor collectors or local roads are considered in this case study.

For highways that are not classified as interstate or principal arterials, capacitybased criteria that are suggested by FHWA for the conceptual model were examined. The capacity-based criteria include Average Daily Traffic (ADT) and Truck ADT. ADT and 
Truck ADT data are obtained from state departments of transportation and entered into the highway database. Table 24 shows the distribution of highways in the Pacific Northwest by function classes and ADTs.

Table 24 - Distribution of Pacific Northwest Highway Functional Classes and ADTs

\begin{tabular}{|c|c|c|c|c|c|c|c|c|}
\hline Area & $\begin{array}{l}\text { Functional } \\
\text { Classes }\end{array}$ & $\begin{array}{l}\text { Total } \\
\text { Miles }\end{array}$ & $\begin{array}{l}\text { Miles } \\
\text { (\%) }\end{array}$ & $\begin{array}{l}\text { Average } \\
\text { ADT }\end{array}$ & Total VMT & $\begin{array}{l}\text { VMT } \\
\text { (\%) }\end{array}$ & $\begin{array}{l}\text { Total Truck } \\
\text { ADT }\end{array}$ & $\begin{array}{l}\text { Truck } \\
\text { VMT } \\
\text { (\%) }\end{array}$ \\
\hline \multirow[t]{5}{*}{ Rural } & Interstate & 1,770 & $8 \%$ & 19,995 & $33,805,744$ & $13 \%$ & $7,914,333$ & $27 \%$ \\
\hline & $\begin{array}{l}\text { Principal } \\
\text { Arterial }\end{array}$ & 4,060 & $19 \%$ & 6,614 & $19,119,233$ & $8 \%$ & $2,900,901$ & $10 \%$ \\
\hline & $\begin{array}{l}\text { Other } \\
\text { Principal } \\
\text { Arterial }\end{array}$ & 2,959 & $14 \%$ & 7,169 & $13,830,195$ & $5 \%$ & $2,118,154$ & $7 \%$ \\
\hline & $\begin{array}{l}\text { Minor } \\
\text { Arterial }\end{array}$ & 5,226 & $24 \%$ & 4,691 & $13,966,658$ & $6 \%$ & $1,871,304$ & $6 \%$ \\
\hline & $\begin{array}{l}\text { Major } \\
\text { Collector }\end{array}$ & 3,574 & $17 \%$ & 2,839 & $4,814,963$ & $2 \%$ & 723,041 & $2 \%$ \\
\hline \multirow[t]{5}{*}{ Urban } & Interstate & 1,355 & $6 \%$ & 72,613 & $98,277,649$ & $39 \%$ & $9,431,454$ & $32 \%$ \\
\hline & $\begin{array}{l}\text { Principal } \\
\text { Arterial }\end{array}$ & 964 & $4 \%$ & 36,121 & $33,575,797$ & $13 \%$ & $2,360,945$ & $8 \%$ \\
\hline & $\begin{array}{l}\text { Other } \\
\text { Principal } \\
\text { Arterial }\end{array}$ & 1,372 & $6 \%$ & 21,112 & $31,932,528$ & $13 \%$ & $2,080,723$ & $7 \%$ \\
\hline & $\begin{array}{l}\text { Minor } \\
\text { Arterial }\end{array}$ & 349 & $2 \%$ & 11,487 & $3,883,972$ & $2 \%$ & 304,507 & $1 \%$ \\
\hline & Collector & 22 & $0 \%$ & 6,353 & 197,384 & $0 \%$ & 33,973 & $0 \%$ \\
\hline Total & & 21,650 & & 188,995 & $253,404,122$ & & $29,739,337$ & \\
\hline
\end{tabular}

In this case study, interstate and principal arterials are deemed important for the region because these highways are critical to the mobility of the entire region, including from state to state. The decision is supported by the fact that interstate and principal arterials are carrying almost 90 percent of the region's VMT. Following the FHWA conceptual models, minor arterials and collectors are considered less important. These facilities can be re-evaluated for importance by incorporating other decision criteria such as the designation of emergency evacuation routes. 


\section{Railroads}

The railroad layer identifies the locations of railroad tracks. The railroad layer is also obtained from Caliper and formatted from NTAD. The railroad data identifies the usage of the railroad tracks and bridges. The data also marks abandoned tracks. Figure shows an example of passenger and abandoned railroad tracks in the vicinity of Portland, OR.

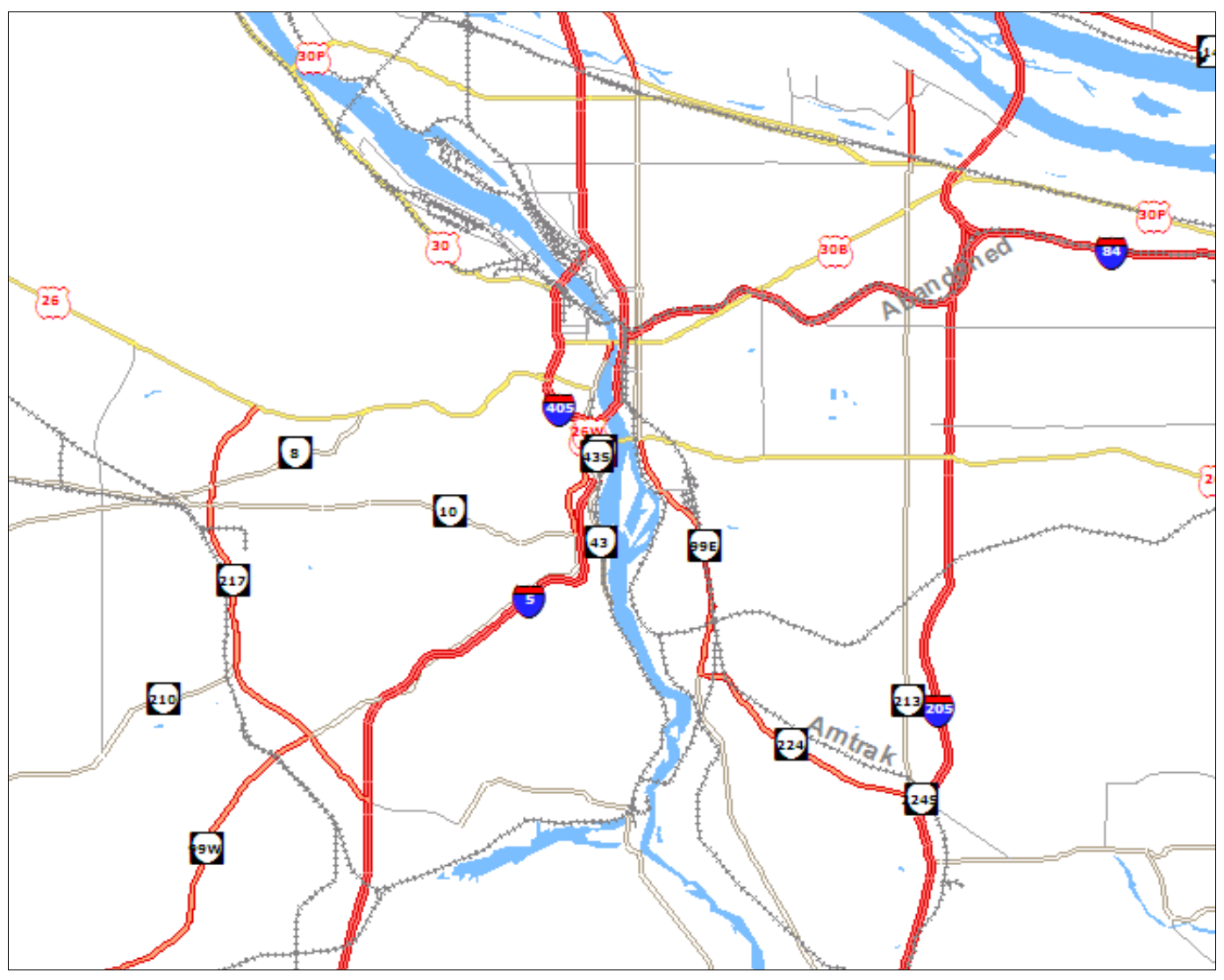

Figure 39 - Railroad tracks near Portland, OR.

For this report, railroad tracks carrying passengers are considered the most important asset in the rail category, followed by tracks for other uses (e.g., freight). The decision of placing the importance of passenger use over other uses is based on FHWA's 
document "Assessing Vulnerability and Risk of Climate Change Effects on Transportation Infrastructure: Pilot of the Conceptual Model" (FHWA, 2010a). The document lists example criteria for important assets and "loss of life" is on the top of the list, followed by economic costs. However, in many instances, both passenger and freight share the same rail. Abandoned tracks are placed in the less-important category. Table 25 shows the distribution of railroad usage in the Pacific Northwest.

\section{Table 25 - Railroad Usage ${ }^{9}$ Distribution in the Pacific Northwest}

\begin{tabular}{lcc}
\hline Railroad Usage & Total Miles & Percent Miles \\
\hline Abandoned & 933 & $7 \%$ \\
\hline Passenger & 1,597 & $12 \%$ \\
\hline Freight & 10,667 & $81 \%$ \\
\hline Total & 13,197 & $100 \%$ \\
\hline
\end{tabular}

Airports

Table 26 gives the number of airports (public use only), bridges, and ports by state. Airport data is by the Federal Aviation Administration. Functional bridge data was derived from the Bureau of Transportation Statistics. The major shipping ports are considered to be those with container liner service as listed on the World Port Source. The major shipping port in Oregon is in Portland (a river port). Those in Washington are Everett (a sea port); Longview (a river port); Seattle (a sea port); and Tacoma (a sea port). The 30 major Alaskan shipping ports, of which Anchorage, Ketchikan, and Valdez are the largest, can be found listed at World Port Source.

\footnotetext{
${ }^{9}$ The numbers in this table are usage distributions, not ownership.
} 
Table 26 - Public-use Airports, Bridges and Ports, by State (Federal Aviation Administration, Bureau of Transportation Statistics, World Port Source)

\begin{tabular}{|l|c|ccccc|}
\hline State & $\begin{array}{c}\text { Public Use } \\
\text { Airports }\end{array}$ & All Bridges & $\begin{array}{c}\text { \% Obsolete } \\
\text { or Deficient }\end{array}$ & $\begin{array}{c}\text { Functional } \\
\text { Bridges }\end{array}$ & $\begin{array}{c}\text { Total } \\
\text { Ports }\end{array}$ & $\begin{array}{c}\text { Major } \\
\text { Ports }\end{array}$ \\
\hline Oregon & 97 & 7,318 & 23 & 5,635 & 11 & 1 \\
\hline Washington & 137 & 7,651 & 27 & 5,585 & 42 & 4 \\
\hline Idaho & 125 & 4,155 & 18.8 & 3,374 & 1 & 0 \\
\hline Alaska & 408 & 1,229 & 28 & 885 & 55 & 30 \\
\hline
\end{tabular}

The locations of airports in the three PNW states are shown in Figure 40. Idaho, Oregon and Washington DOTs all provided the airport GIS data that the department maintains. It is noted that there may be some discrepancies between the airport data used and the most recently active airports. If more detailed analysis of the airports is to be conducted, the airport data needs to be updated.

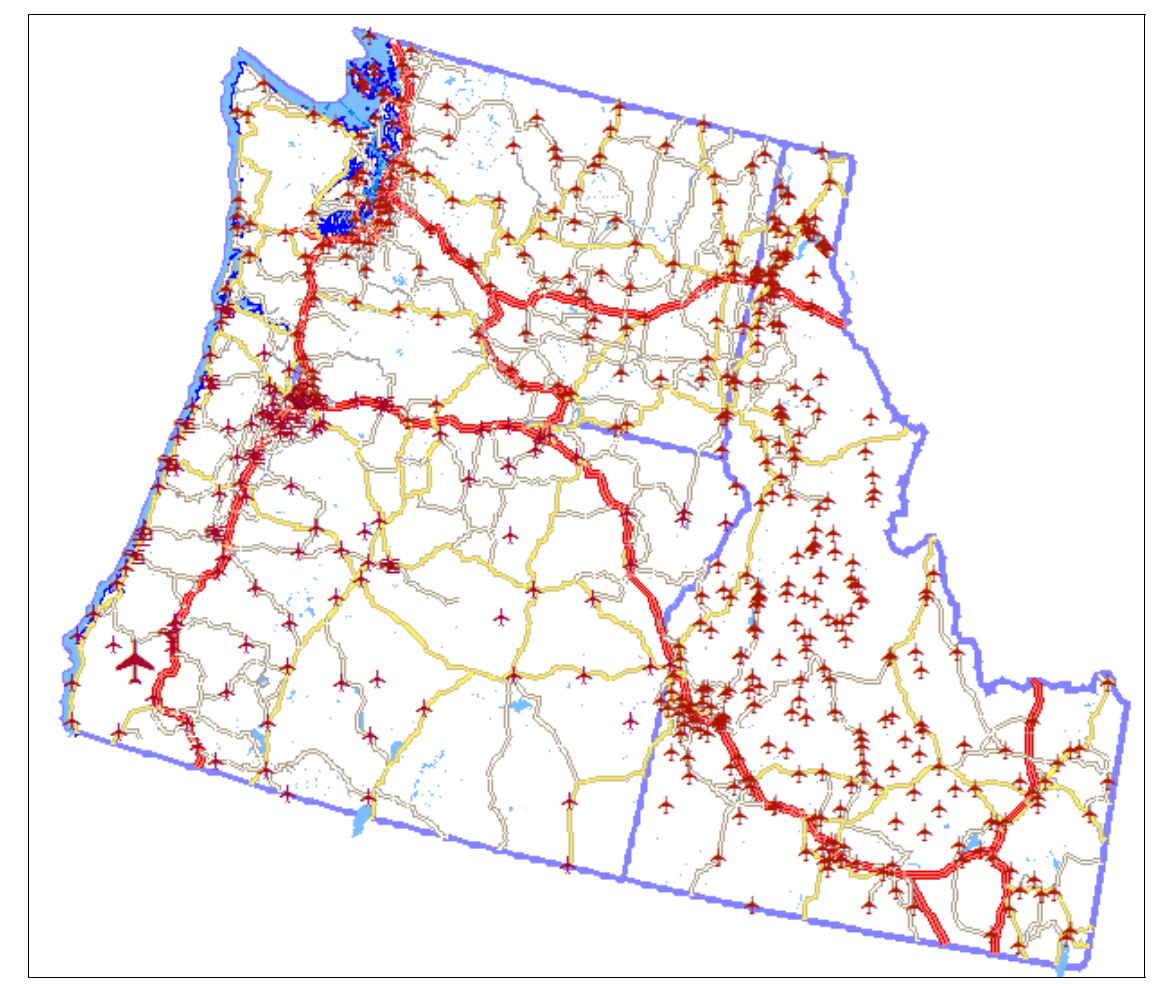

Figure 40 - Airports in the Pacific Northwest. 
Table 27 shows the ownership distribution of airports in the three states. Public airports are considered more important than private airports in this analysis.

\section{Table 27 - Airport Ownership Distribution}

\begin{tabular}{|lcc|}
\hline \multicolumn{1}{|c}{ State } & Owner & Total \\
\hline Washington & Private & 31 \\
\hline & Public & 106 \\
\hline & WA Total & 137 \\
\hline Idaho & Private & 159 \\
\hline & Public & 125 \\
\hline & ID Total & 284 \\
\hline Oregon $^{\mathbf{1 0}}$ & Public & 97 \\
\hline & OR Total & 97 \\
\hline
\end{tabular}

Sea and river ports

The NTAD contains port locations and attributes. Sixteen ports are located along the Washington and Oregon coast. Figure 41 shows the locations of the ports. However, we do not have data on the actual layout and the elevation of the port structure; thus, no further analysis is performed for the climate change impacts on the ports. The port data are only used in conjunction with tide station data for the analysis of the impacts of SLR on highways, railroads and airports. It is noted that, although the analysis included several ports in Oregon along the Columbia River, the analysis does not include the Port of Lewiston in Idaho. The rationale behind the exclusion of Lewiston in the analysis is that the Port of Lewiston is far from the coast and the Columbia River is highly controlled. It is not expected that SLR will create much impact on the Port of Lewiston.

\footnotetext{
${ }^{10}$ The ODOT airport data do not identify the ownership of the airports. All airports in the database are labeled as "Public Use."
} 


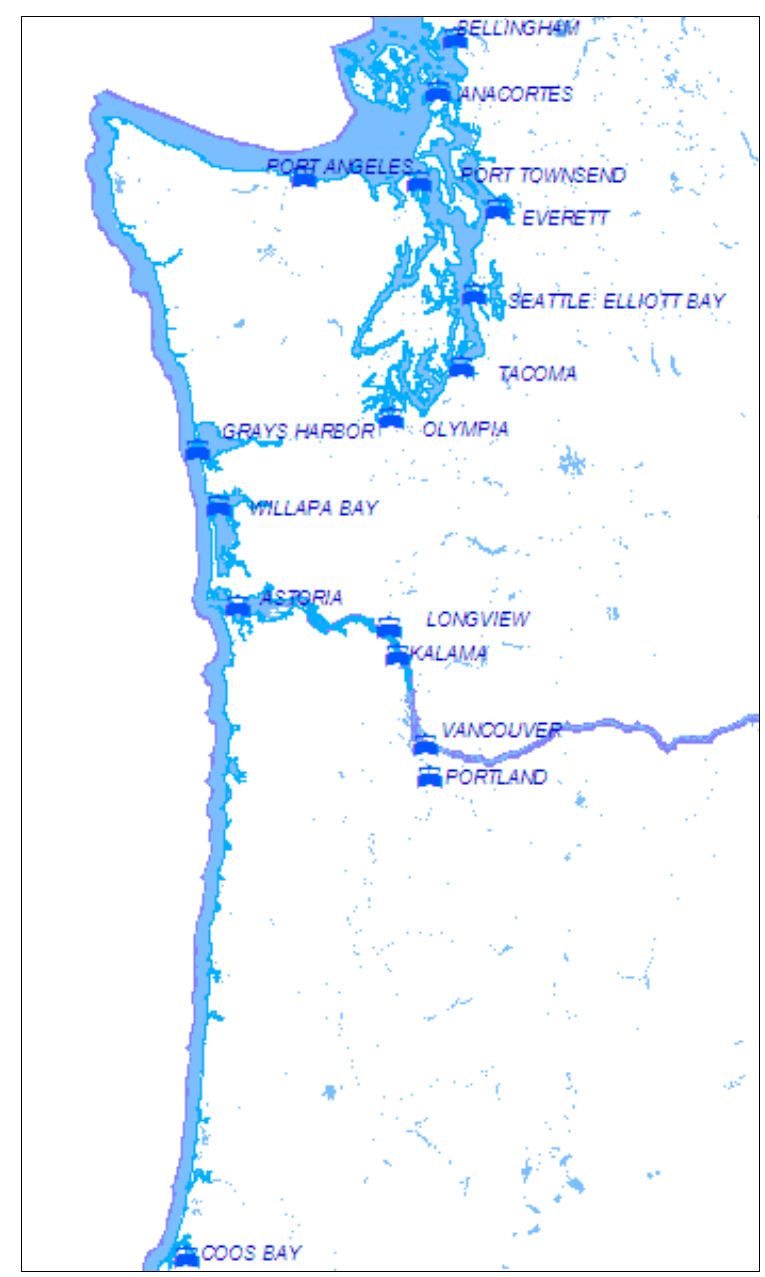

Figure 41 - Ports along the Washington and Oregon Coast.

\section{Climate data}

Climate data required for the analysis were downloaded from web sites of weather and climate agencies and taken from our analysis presented in the above section. For example, historic tide data are required to model the extent of SLR. Tide station data are downloaded from National Oceanic and Atmospheric Administration's (NOAA) National Ocean Services (NOS). In addition to climate data, GIS data of other natural features that interact with climate stressors are also examined. 


\section{NOS Tide Station Data}

Before impacts of future SLR can be assessed, a surface model that identifies the current coastal sea-water level along the Washington and Oregon coast was developed. NOS maintains tidal stations along the U.S. coast that are used to measure the daily variances of sea level. The main tidal data used for this study is the Mean Higher High Water (MHHW) that identifies the average high tide over various time periods. MHHW measurement is used in this study to determine areas that could be regularly inundated under different SLR projections. Figure shows the tide stations in the Puget Sound used for this study.

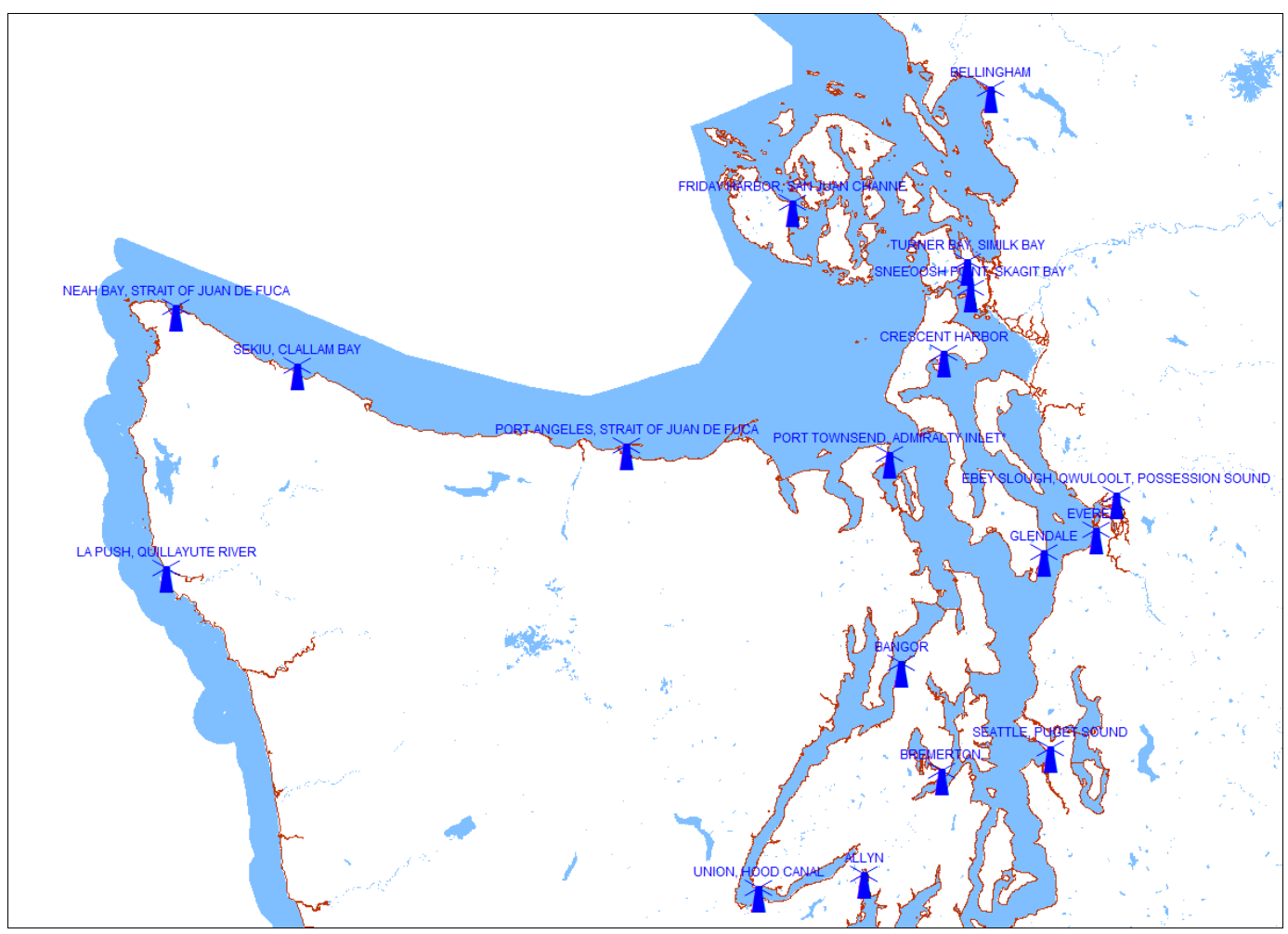

Figure 42 - NOS tide stations in the Puget Sound region. 
Figure 43 shows an example of the tidal station data collected from the NOS for Neah Bay in Washington's Olympic Peninsula. The data identify the National Tidal Datum Epoch (NTDE) for the tidal epoch of 1983-2001. The NOS defines a tidal epoch as the specific 19-year period that is the official time segment over which tide observations are taken and reduced to obtain mean values (e.g., mean higher high water) for tidal data.

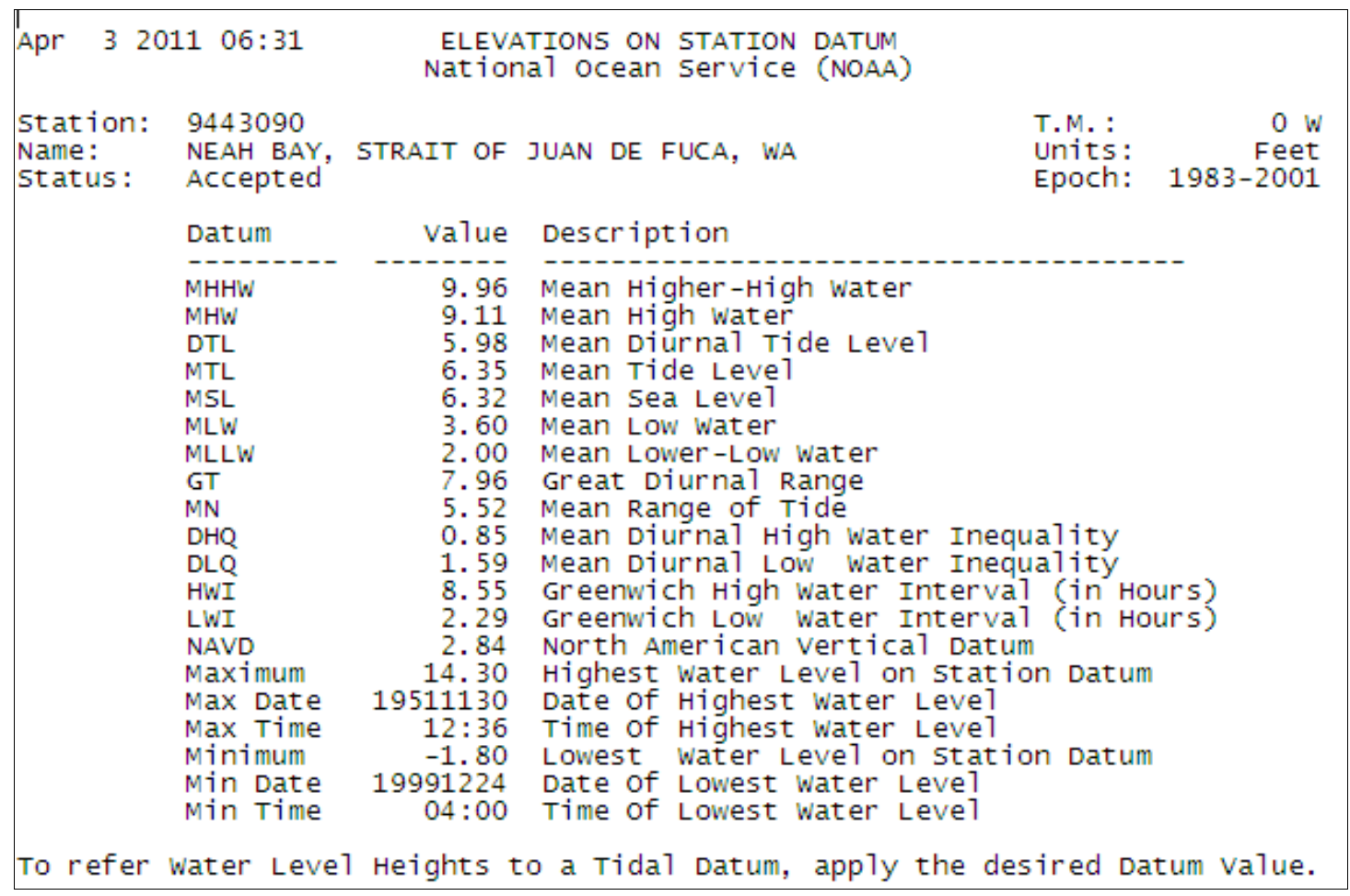

Figure 43 - 1983-2000 datum for Neah Bay tide station.

In Figure 44, the MHHW is the average of the higher-high water height of each tidal day observed over the National Tidal Datum Epoch ${ }^{11}$. For the tidal station data used in this analysis, the water-level heights are referenced to datum NAVD88 (North

\footnotetext{
${ }^{11}$ http://tidesandcurrents.noaa.gov/datum_options.html\#MHHW
} 
American Vertical Datum of 1988). To find out the elevation difference between the high tide and the ground, the value of NAVD needs to be deducted from MHHW number. The relationship between MHHW and NAVD is depicted in Figure 44.

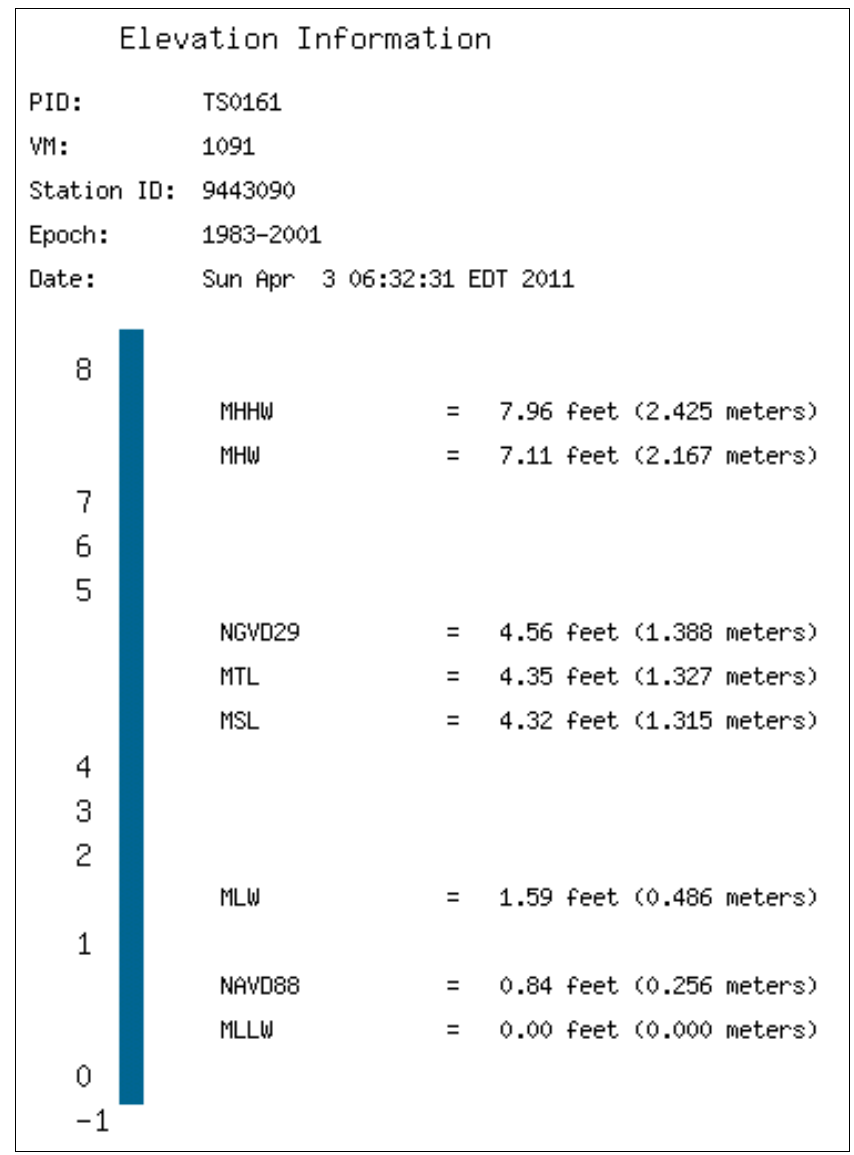

Figure 44 - Tide station water-level elevation graphics.

Only tide stations that contain both MHHW and NAVD data can be used for the identification of coastal sea-surface level. Of all tide stations along the Washington and Oregon coast, only 39 stations contain the required MHHW and NAVD data for this study. Details of coastal sea-level modeling using the data are described in SLR analysis. 


\section{Digital Elevation Model (DEM)}

The elevation at which an infrastructure is located is important for this analysis. For example, a highway at lower elevation near the coast or river banks is more susceptible to flooding and SLR inundation.

A DEM is a digital representation of ground surface topography or terrain. The three-second DEM data used for this study are obtained from the Caliper Corporation. The three-second DEM has a grid spacing of three arc-seconds in latitude and longitude (i.e., approximately 80 meters). Each value associated with a DEM grid represents the highest elevation for that grid. Figure shows Washington, Oregon and portions of Idaho superimposed with DEM data. The darker colored areas are lower in elevation while lighter colored areas are higher. 


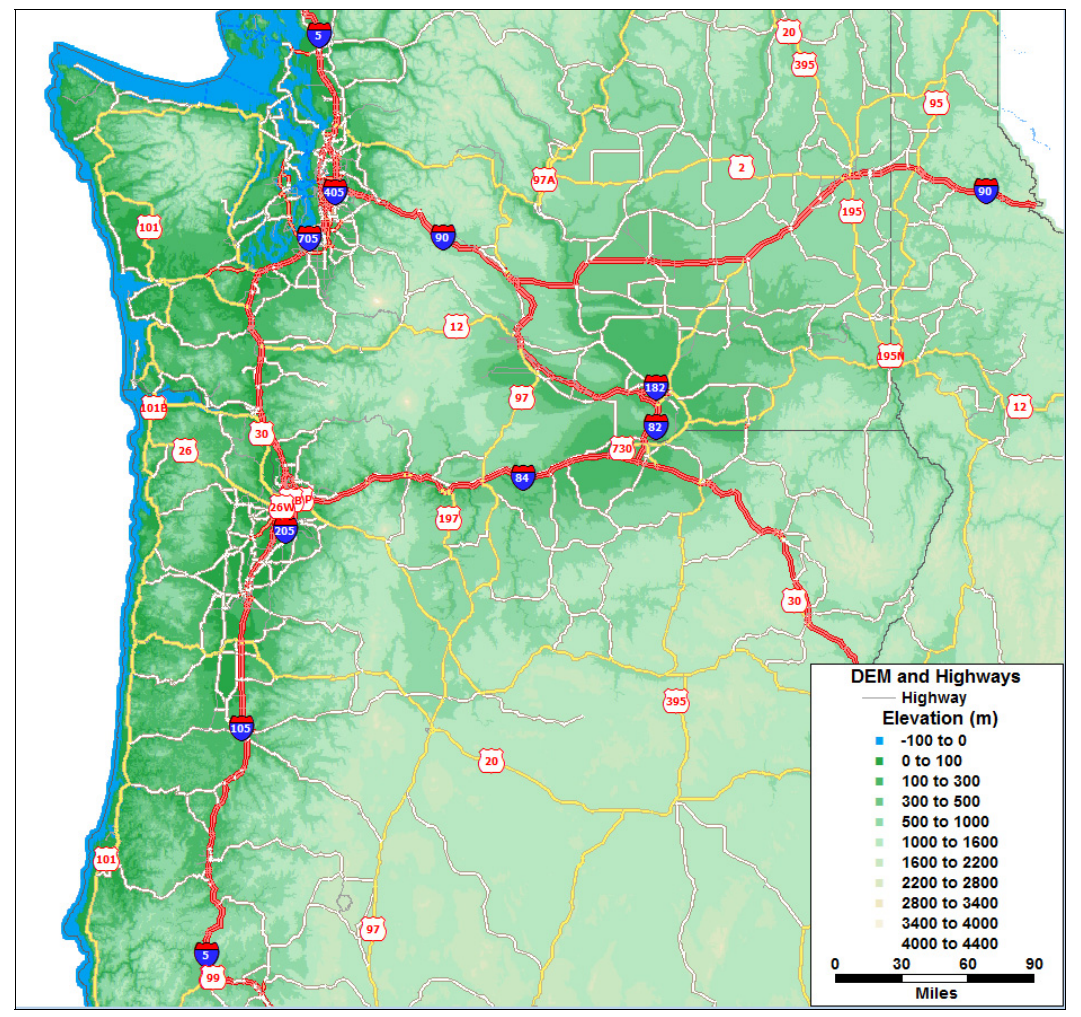

Figure 45 - The DEM layer superimposed with other data layer.

\section{FEMA Floodplain Q3 Data}

FEMA's Q3 Flood Data is a digital representation of certain features of FEMA's Flood Insurance Rate Maps (FIRM), intended for use with GIS mapping applications. Digital Q3 Flood Data has been developed by scanning the existing FIRM hardcopy and creating area coverage of flood risks.

The Q3 data used for this study are purchased from Caliper, which formatted the data published by FEMA for use with TransCAD. Figure 46 shows the Q3 data plotted for Washington. The red areas identify floodplains with return probability (i.e., 100 year and 500 year). The blue areas are where no data are available. The gray areas are areas outside the floodplains. 


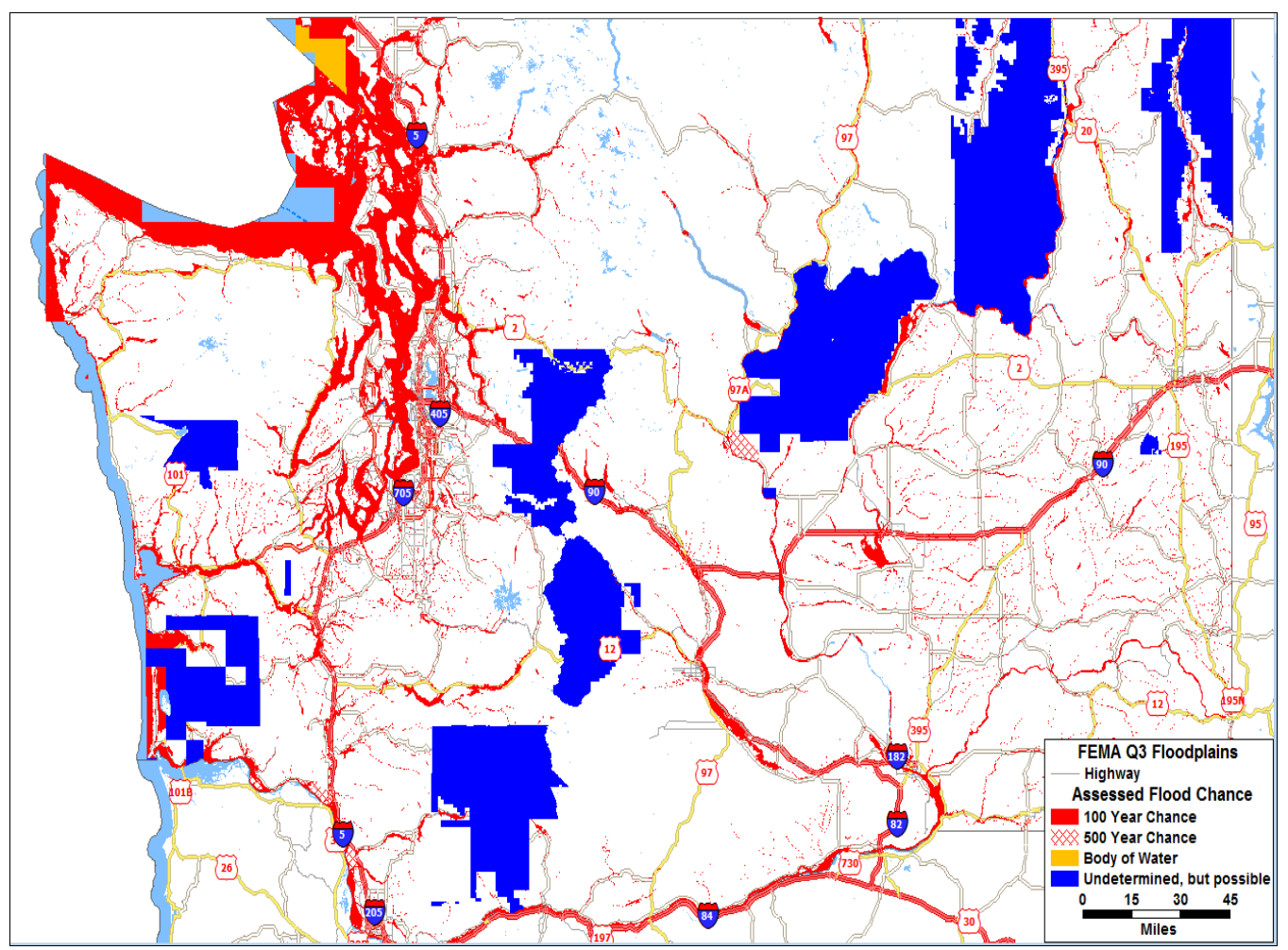

Figure 46 - FEMA Q3 Data for Washington state.

\section{Temperature and Precipitation Data}

Historic mean temperature and precipitation data are downloaded from the website of the PRISM Climate Group at Oregon State University. The PRISM data sets were developed through projects funded partly by the USDA Natural Resources Conservation Service, USDA Forest Service, and NOAA Office of Global Programs.

The average maximum temperature data (i.e., 1971-2000) downloaded are for the summer months of June, July (see Figure 47), and August, while the precipitation data are for the winter months of November, December and January, when the monthly average precipitation levels are the highest during the year. The temperature data are downloaded as TIF images, which are then superimposed on top of other GIS data with 
precise coordinate registration. Maps of temperature and precipitation zones are then created.

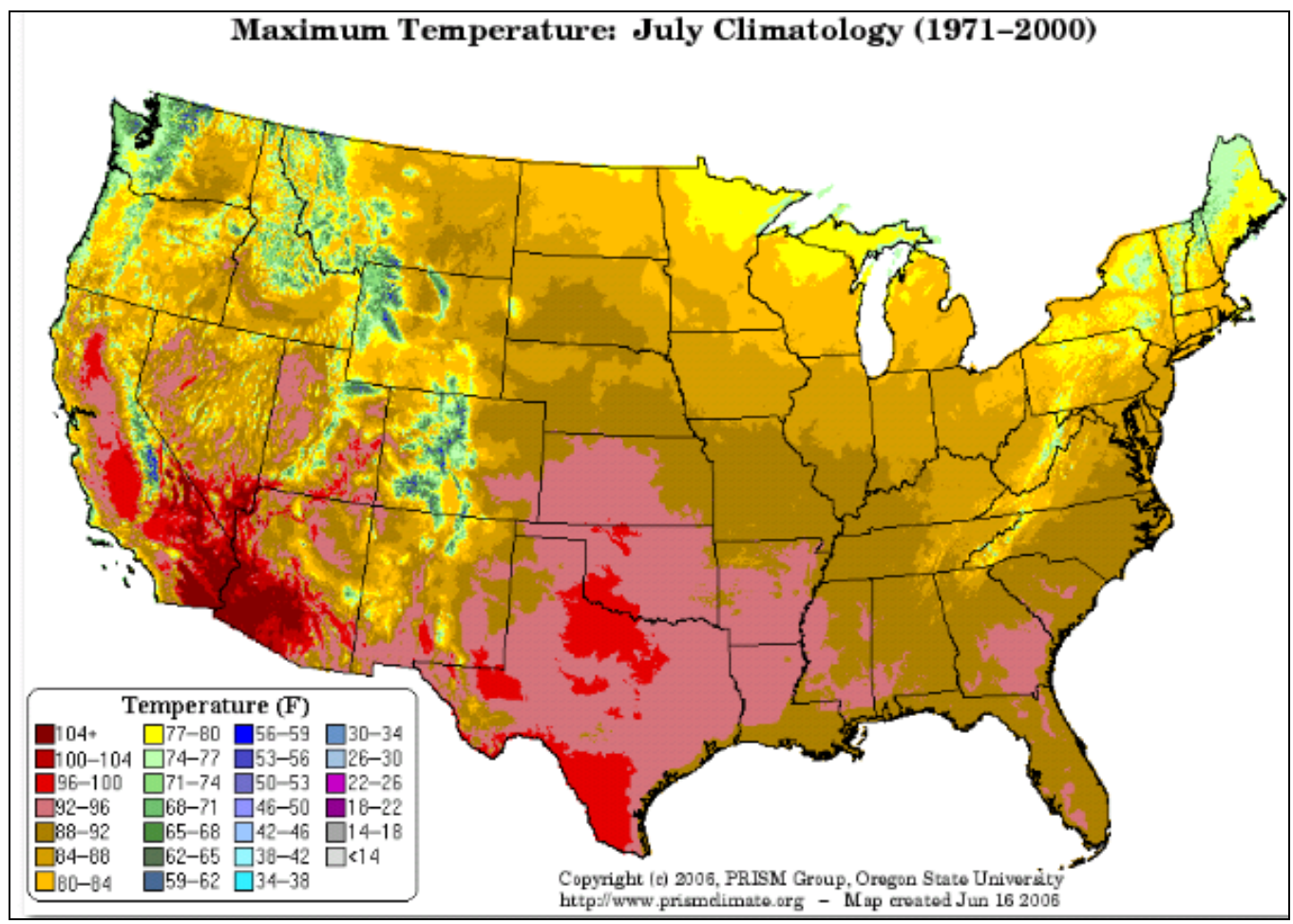

Figure 47 - Mean maximum temperature for July (1971-2000).

\section{Climate Change Risk Assessment}

Impacts of Sea Level Rise

Global SLR projections are typically provided in terms of the amount of rise in centimeters (or inches) from the existing sea level. The first step in projecting the areas at risk for inundation by risen seawater is to establish an existing sea-surface model for coastal water along Washington and Oregon. It is noted that the methodology of projecting the impacts of SLR follows the U.S. DOT report, the Potential Impacts of Global Sea Level Rise on Transportation Infrastructure (U.S. DOT, 2008). 
In order to model this, the actual ground elevation levels (i.e., MHHW minus NAVD) of the MHHW associated with the 39 tide stations in the study coast were used to create Triangulated Irregular Network (TIN) surfaces. A TIN essentially interpolates for the elevation in areas bounded by several control points.

Five TINs are created along the study coast. The five TINs cover the Puget Sound region, Olympic Peninsula, Washington Coast, Columbia River Gorge and the Oregon coast. The division of TINs allows for more precise and accurate interpolation for elevation between stations. The interpolated elevations along the edges of the TINs are then used to estimate the actual ground elevation of MHHW along the coastline.

With the interpolated ground elevation of high tide along the coast, future seawater levels are projected by adding the projected SLR to the existing elevation. The SLR projection follows the regional numbers shown above in Table 4 that was introduced in an earlier section of this report. It is noted that the same SLR projections for the southern Washington coast were also used along the Oregon coastline due to lack of established projection specific to Oregon.

The projected coastal water ground elevations are then compared to the elevation of the DEM grids. The areas at risk are those grids that have elevation between the ground elevation of existing MHHW and the projected MHHW with global SLR. The assembled transportation infrastructure layers are then superimposed on the at-risk grids to see what facilities are located in the at-risk area.

It is noted that projected risks are for regular inundation caused by increased high tide (i.e., MHHW). Potential increase in wave height is not factored into the analysis. It is mentioned earlier in the report that this is an area of active research and information for 
projection is still lacking. Cautions may need to be exercised to incorporate certain levels of wave height increase when preparing for SLR adaptation strategies.

\section{$\underline{\text { Results }}$}

2050 Projection

At the "very low" level projections (i.e., 1.2-3.2 in/3-8 cm along WA and OR coast) for 2050 , no critical coastline encroachment by rising sea water is projected.

At the "medium" SLR projected for 2050 (i.e., 4.9-5.9 in (12.5-15 cm) along WA and OR coast, see Table 4), the region will see minimal risk in terms of regular inundation due to SLR. Figure 46 shows the locations of the highways relative to the atrisk areas. Note that National Atlas ports in the map legend of Figure 48 are added as landmarks that help pinpoint the map features. 


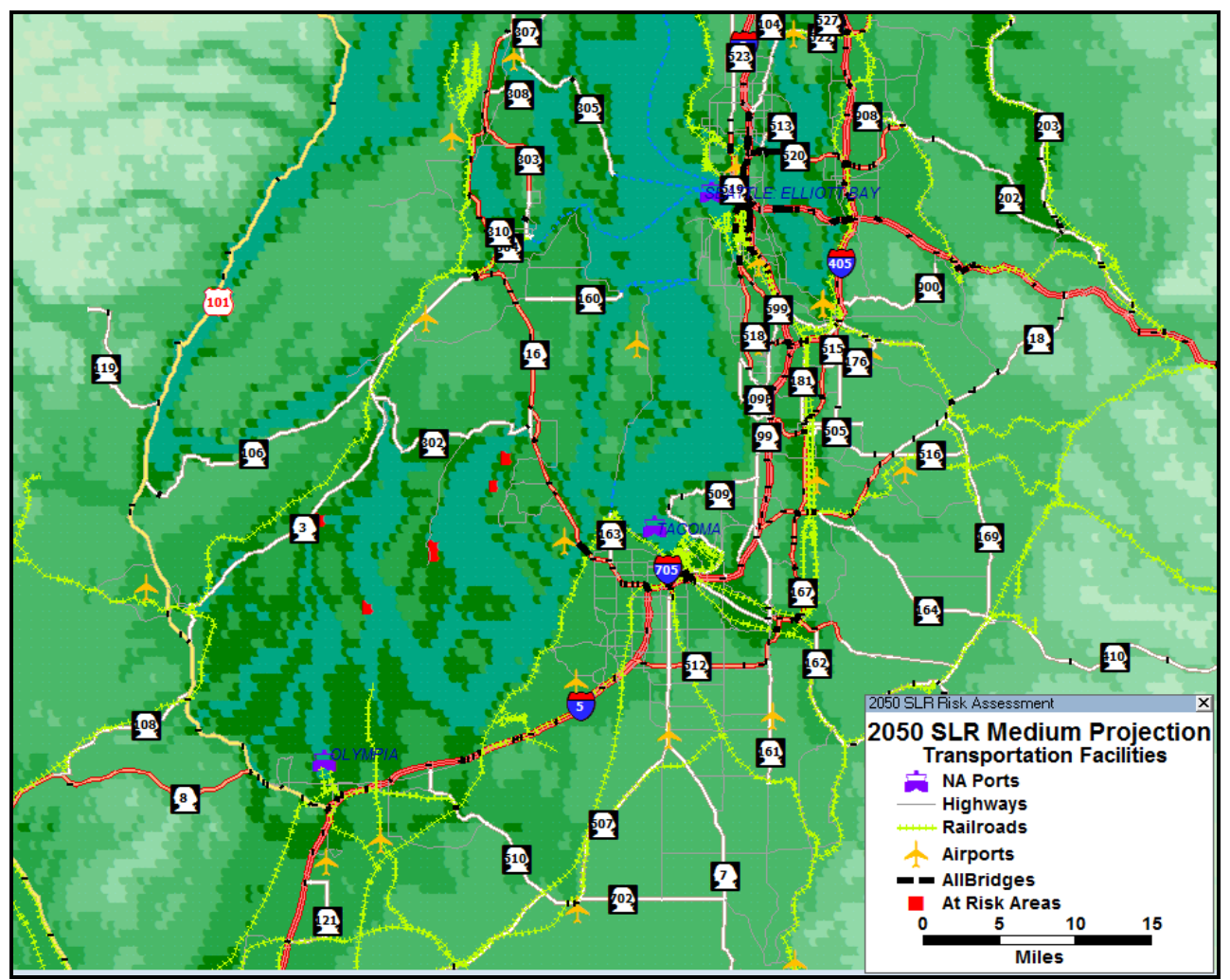

Figure 48 - 2050 SLR projections for at-risk areas (medium projection at $15 \mathrm{~cm}$ SLR).

Only a few small coastal areas in the Puget Sound near Olympia are at the elevation levels slightly less than the projected SLR. There are no transportation facilities that fall directly in the at-risk areas.

At the "very high" level projection for 2050, the analysis results show that the rising sea water (i.e., $21.7 \mathrm{in} / 55 \mathrm{~cm}$ for the Puget Sound) may reach spots on highways in close proximity to existing shorelines (Figure 48). Based on the 17.7 in/45 cm SLR projected for southern Washington and Oregon coast by 2050, no infrastructure is at risk. 


\section{Projections}

The "very low" level projections for 2100 are at the same scale as the "medium" level of 2050 (i.e., $6.3 \mathrm{in} / 16 \mathrm{~cm}$ projected at the "very low" level for the Puget Sound by 2010 and $5.9 \mathrm{in} / 15 \mathrm{~cm}$ at the "medium" level by 2050). Thus, Figure 48 also represents the at-risk areas for 2100 at the "very low" level projection.

The "medium" level projections for 2100 are all lower than the "very high" level projections for 2050. It is thus expected that the at-risk areas in Figure 49 cover for the 2100 "medium" level projection.

At the "very high" level of SLR projection for 2100, there could be many areas inundated by the increased high tide (see figures 49, 50 and 51), under the current infrastructure conditions. Most of these locations are in the Puget Sound area, but similar patterns can also be found in the mouth of the Columbia River. Calculations were performed in GIS to estimate the extent and proportion of transportation facilities that could be impacted by the increased high tide. It was determined that highways located within 500 feet of the SLR inundation areas to be at risk. The distance criterion is based on the observation that many existing roadways operate safely when they are away from tidal water boundaries by approximately 500 feet. It is noted that the 500 -feet criterion is arbitrarily chosen for this study in order to facilitate the risk assessment at a large scale (i.e., the entire coastline of Washington and Oregon). When detailed analysis of a subregion is called for, Oregon and Washington DOTs may incorporate their own criteria appropriate for operation and maintenance purposes in each state. 


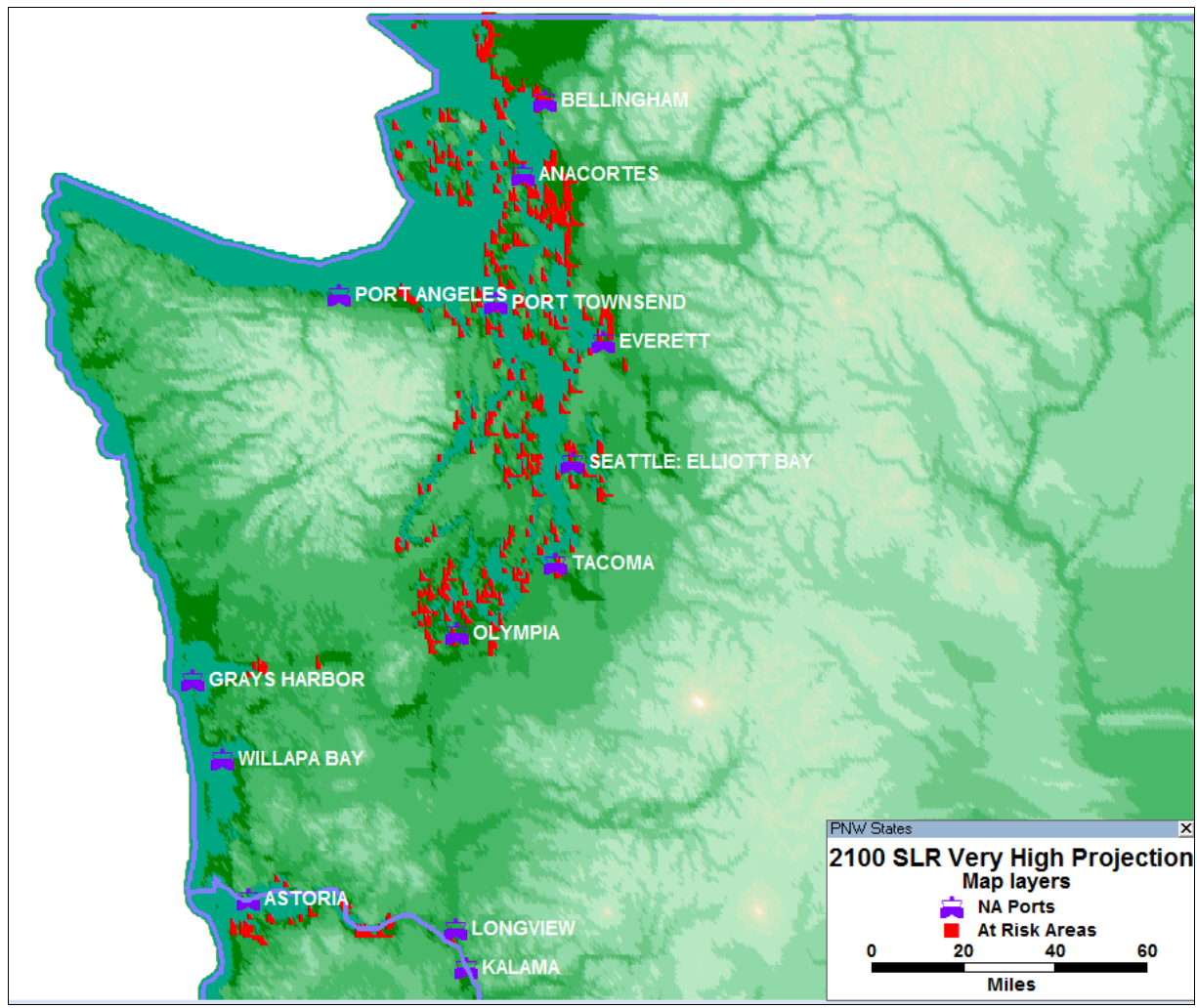

Figure 49 - Overview of 2100 SLR "very high" projection at-risk areas.

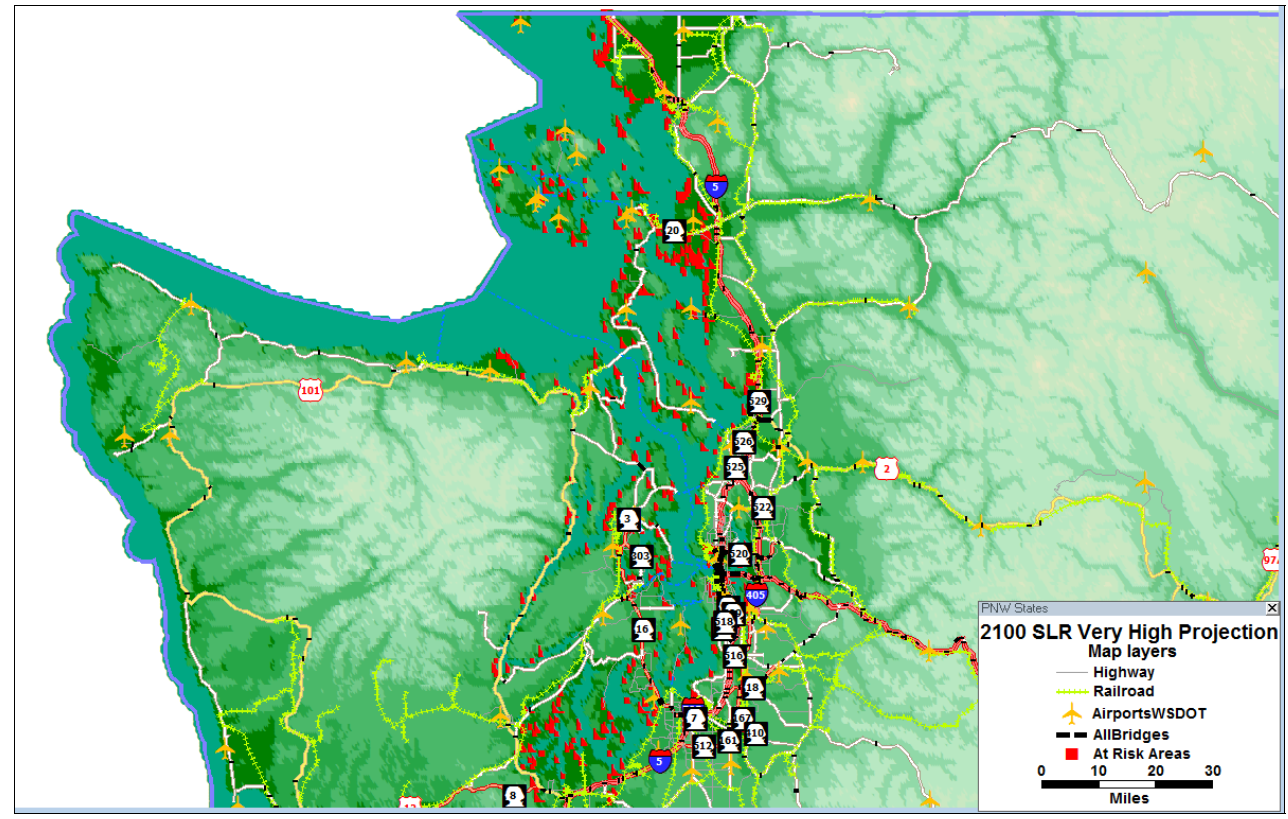

Figure 50 - 2100 SLR "very high" projection $(128 \mathrm{~cm} / 50.4 \mathrm{in})$ at-risk areas surrounding the Puget Sound. 


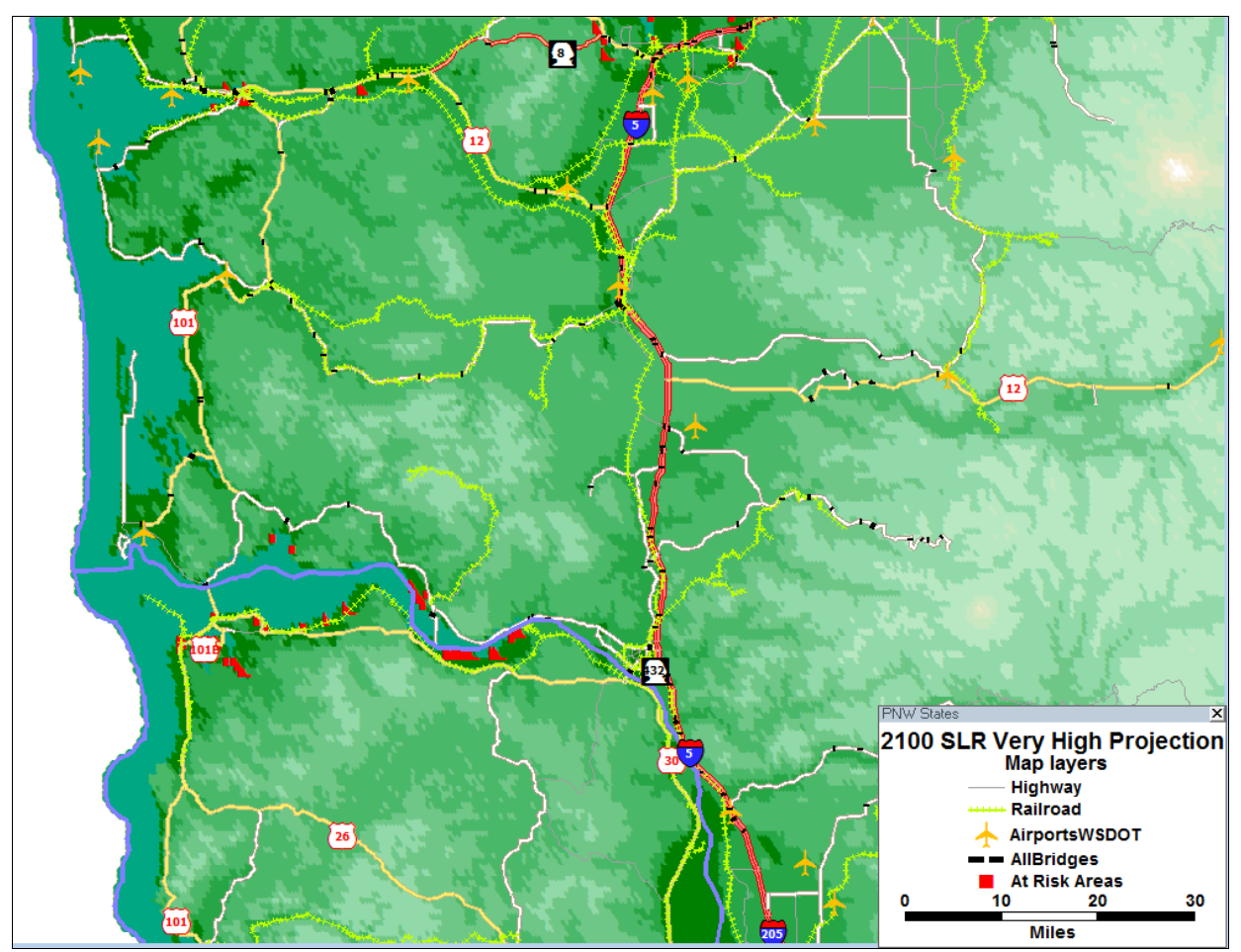

Figure 51 - 2100 SLR "very high" projection $(108 \mathrm{~cm} / 42.5$ in) at-risk areas near the mouth of the Columbia River.

Table 28 shows the distribution of highway length in miles that are near the high tide by 500 feet $(0.1$ mile). It is noted that approximately 35 percent of the at-risk roadways are in our category of less important facilities (i.e., minor arterials and collectors). Most of these highways are in the Puget Sound area. There are only approximately five miles of highways near Astoria, OR. 
Table 28 - At-risk Roadways for the 2100 "Very High" SLR Scenario

\begin{tabular}{|l|c|c|}
\hline Function & Total Miles & Percent Miles \\
\hline Urban-Principal-Arterial & 21.94 & $11 \%$ \\
\hline Urban-Other-Principal-Arterial & 1.25 & $1 \%$ \\
\hline Urban-Minor-Arterial & 9.51 & $5 \%$ \\
\hline Urban-Interstate & 10.23 & $5 \%$ \\
\hline Rural-Principal-Arterial & 114.96 & $60 \%$ \\
\hline Rural-Major-Collector & 27.69 & $14 \%$ \\
\hline Rural-Interstate & 0.21 & $0 \%$ \\
\hline Rural Other Principal Arterial & 6.88 & $4 \%$ \\
\hline Total & 192.69 & $100 \%$ \\
\hline
\end{tabular}

Table 29 shows the same analysis for at-risk railroads. Only a small portion of the at-risk railroads carry passengers. There are no airports within 500 feet of the projected high tide. Note that this assessment is made with point-based airport location data. There may actually be portions of the airport boundaries (i.e., including runways and all facilities) that are located in the projected SLR-inundation areas. In the future, the actual layouts of the airports should be incorporated into detailed analysis of individual airports that are located in vicinity of shorelines.

Table 29 - At-risk Railroads for the 2100 "Very High" SLR Scenario

\begin{tabular}{|c|c|c|}
\hline Rail Usage & Total Miles & Percent \\
\hline Passenger & 0.10 & $10 \%$ \\
\hline Freight & 0.89 & $90 \%$ \\
\hline Total & 0.99 & $100 \%$ \\
\hline
\end{tabular}




\section{Impacts of Increased Rainfall and Flood}

This study makes use of FEMA's floodplain data to assess the risk of flooding due to intensified rainfall events. Areas at risks for flooding are identified by the FEMAidentified floodplains. Figure 52-55 show the identified floodplains in the three states. The "Chance" variable (see the map legends in Figure 52-55) identifies the flood return probability of a floodplain. Note that FEMA's floodplains were originally created for estimation of flood insurance rates. Thus, areas with low population density may not have been mapped with flood risks. There are also areas where FEMA's flood-risk decisions were not made. These areas are labeled as "Undetermined, but possible." The areas that appear in the maps (Figure 52-55) with white background are either areas assessed by FEMA as "outside of flood plains" or areas not covered by FEMA assessment at all. The areas not covered by FEMA are those areas where population densities are low. 


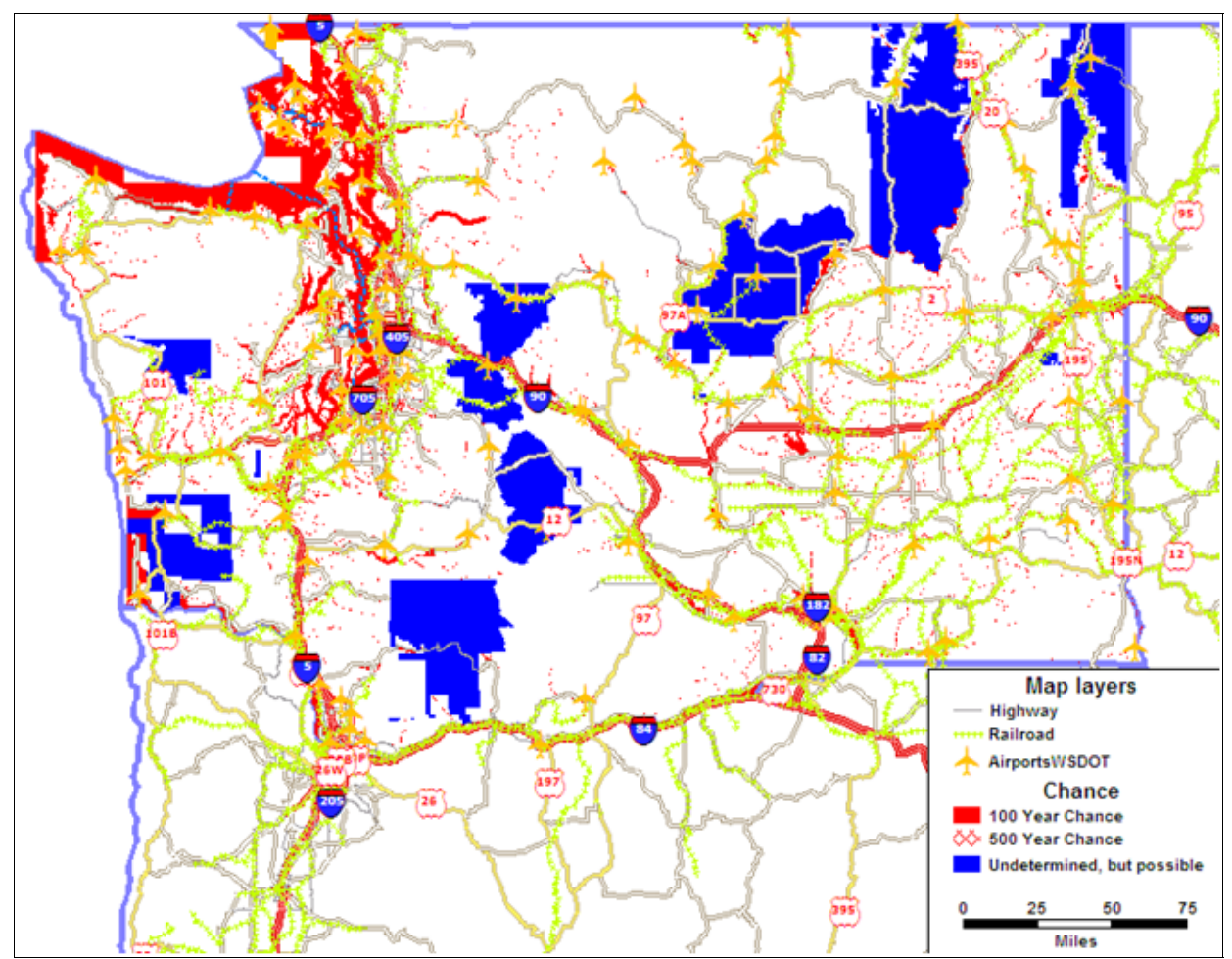

Figure 52 - FEMA Flood Q3 Data for Washington State

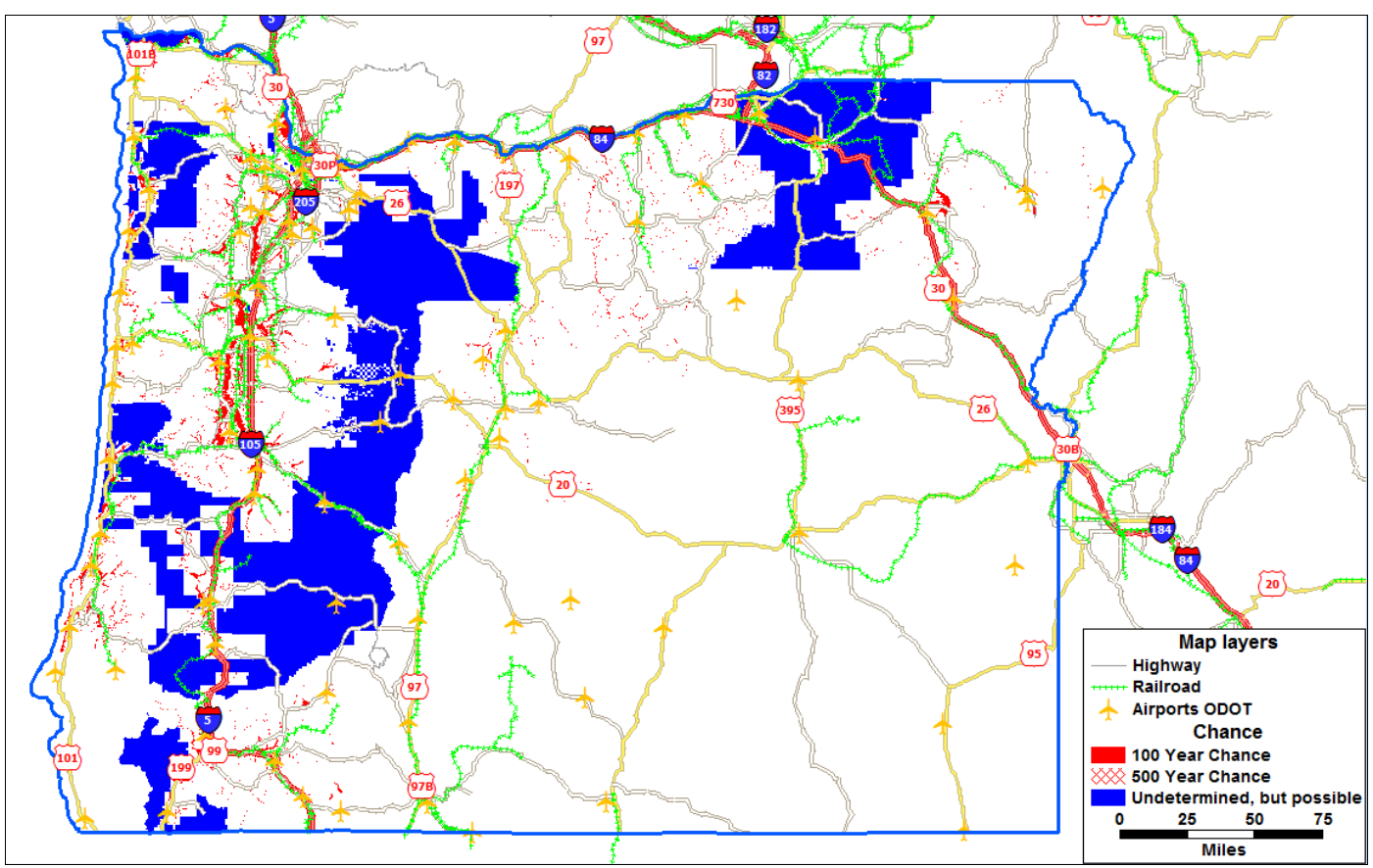

Figure 53 - FEMA Flood Q3 Data for Oregon 


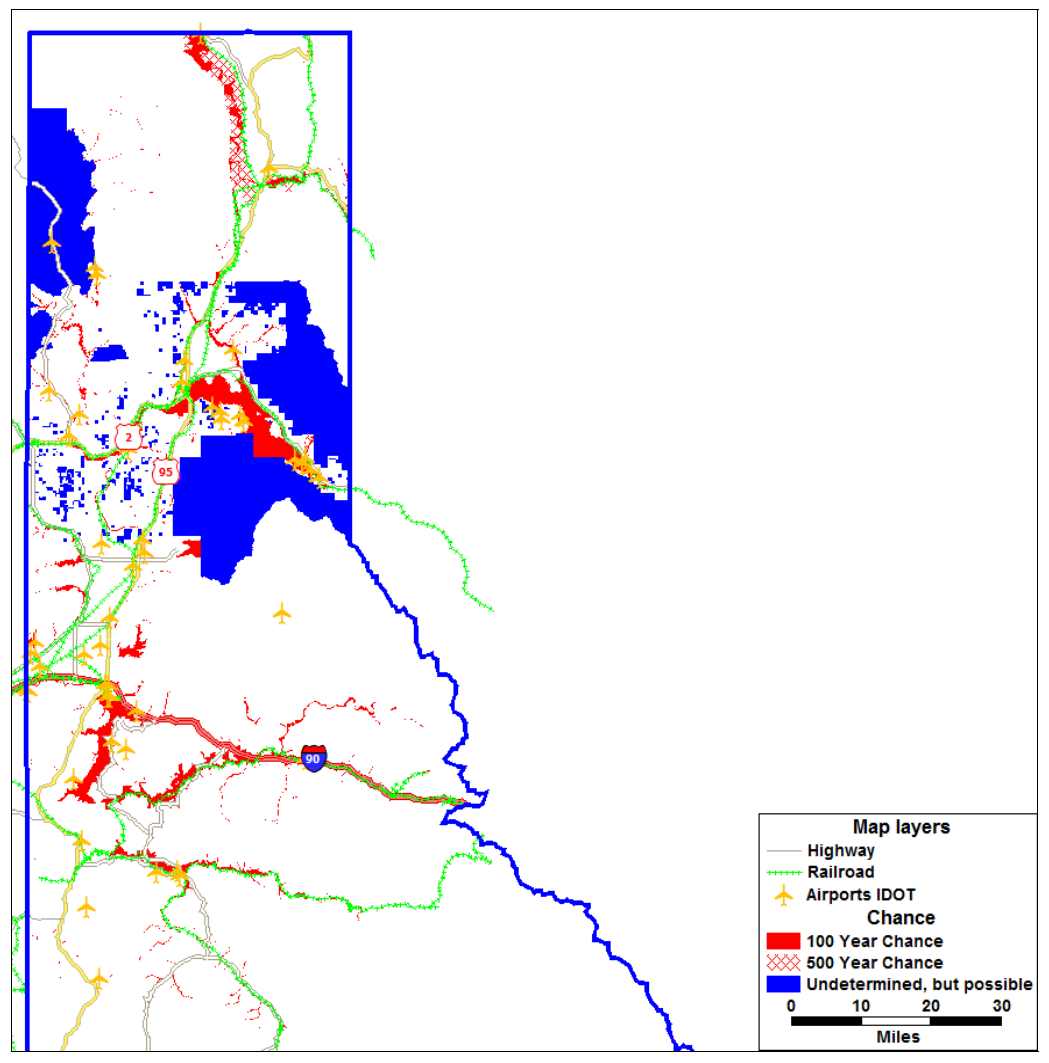

Figure 54 - FEMA Flood Q3 Data for Northern Idaho

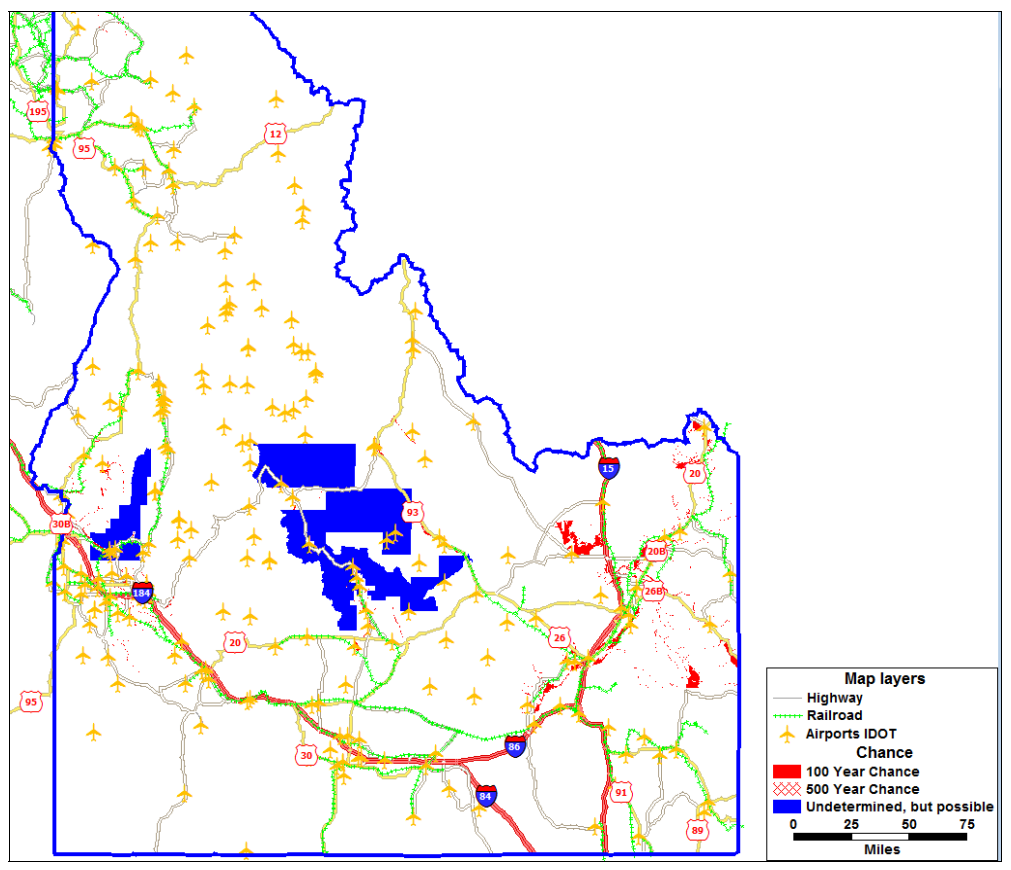

Figure 55 - FEMA Flood Q3 Data for Southern Idaho 
The highway and railroad layers were then superimposed on top of the FEMA floodplains. The highway and railroad alignments were "clipped" by the floodplains with flood chances (i.e., 100 year, 500 year, and probable but undetermined). "Clipping" essentially identified highway and railroad segments that are located in floodplains. The identification of airports was achieved by finding the airports located within the floodplains.

The results of the floodplain analysis are graphically presented in Figure 58. The highways and railroads in floodplains (i.e., those highlighted with different colors) are those that are located in areas with flood risk of 100 years, 500 years, and probable but not determined. Note that in Figures 57 and 58 there are areas (i.e., those in white background) in Oregon and Idaho that are not covered by FEMA floodplain data. These areas are also counted as "Not Mapped" and Table 31 summarize the highways, railroads and airports in floodplains of different risk levels in the tri-state region. Note that the highways included in the analysis are those in the analysis database (i.e., mostly interstate and state routes). In addition, abandoned railroad tracks are not included in the mileage calculations either. Railroads labeled as passenger use are mainly Amtrak tracks with a very small number of other tracks used for personal travel.

It is noted that FEMA is currently engaged in updating the floodplains to take into account climate changes and future scenarios. Our approach has the opportunity to be improved in the future as more resources become available. 


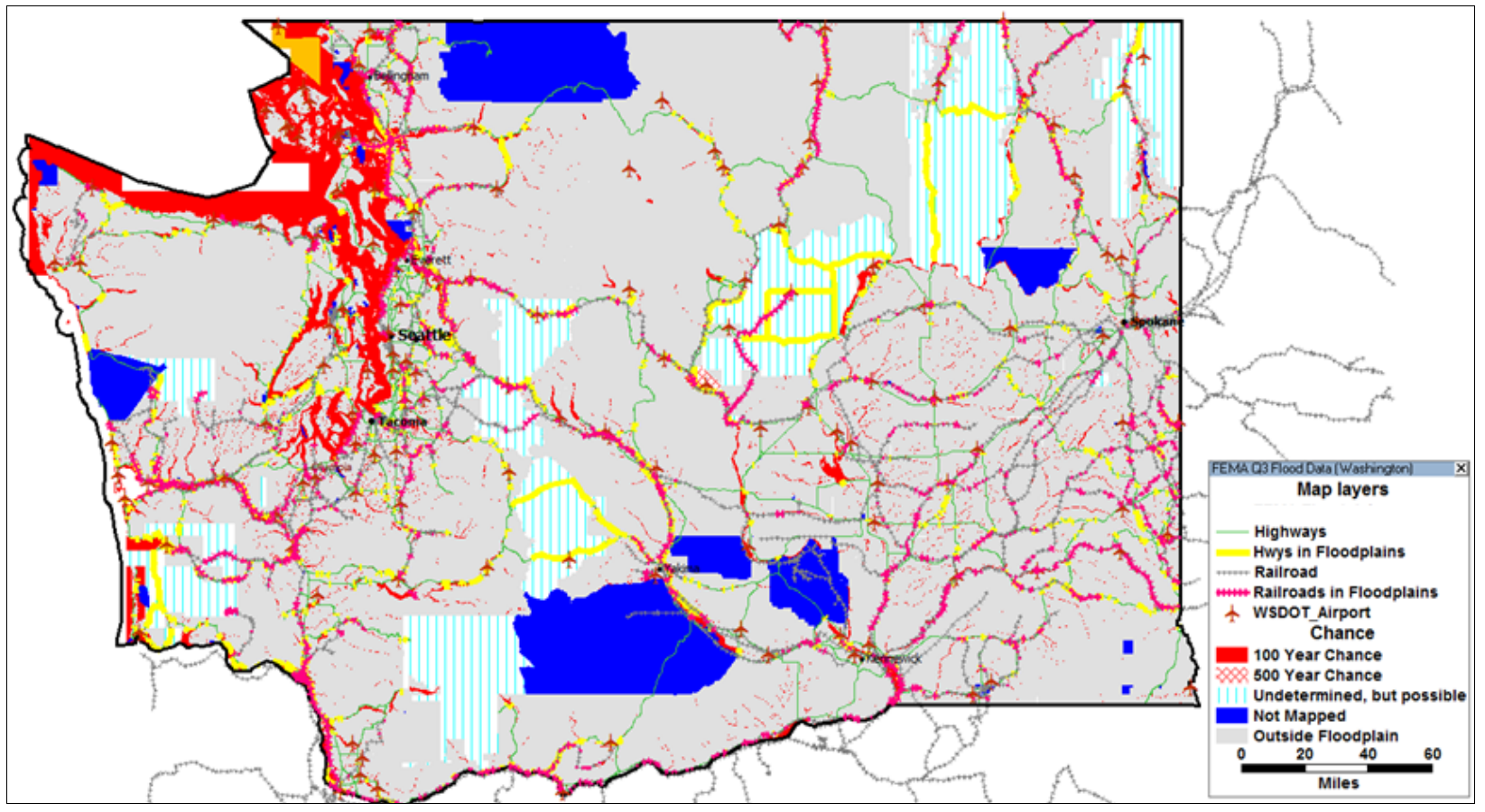

Figure 56 - Transportation facilities located in FEMA floodplains in Washington.

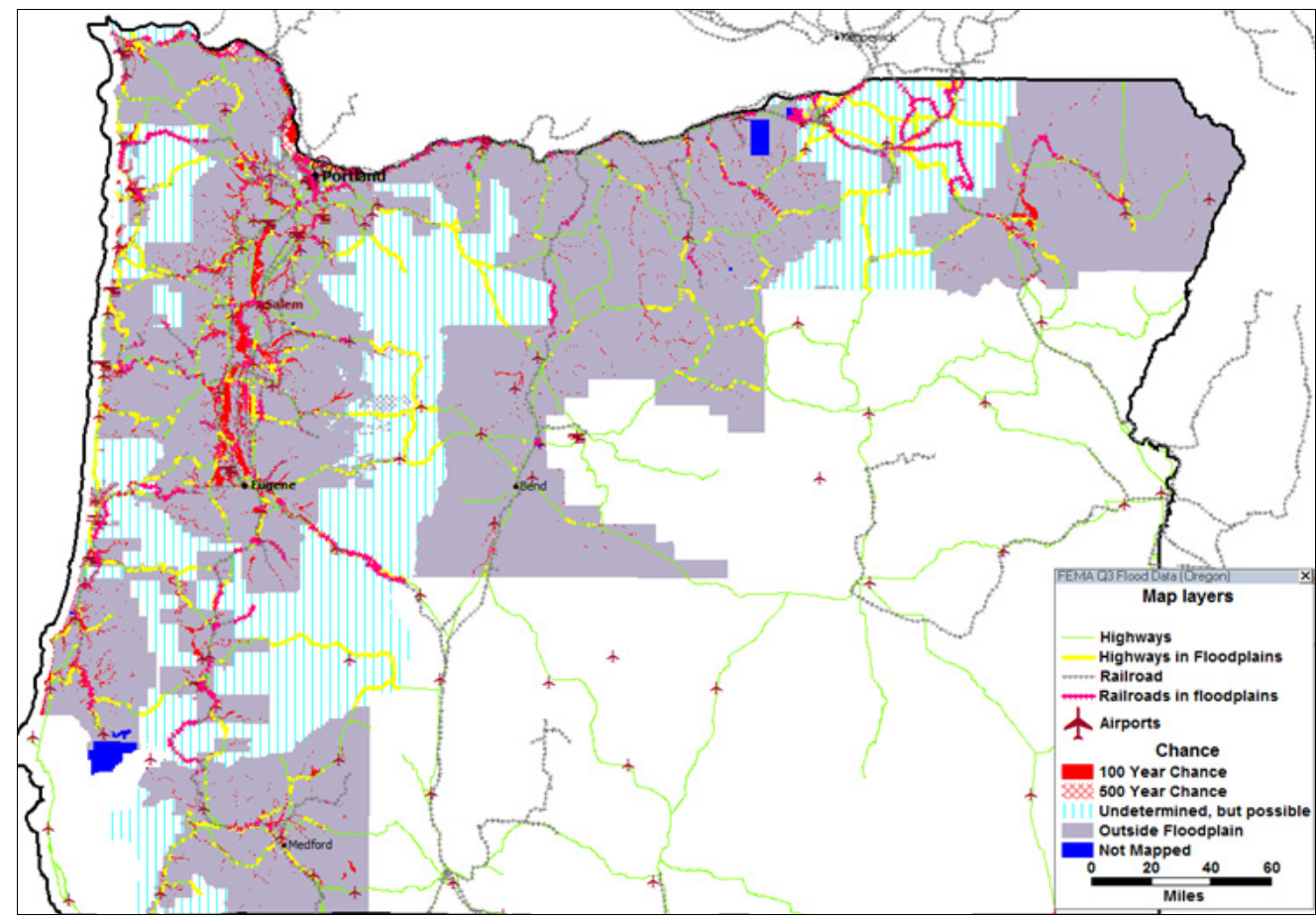

Figure 57 - Transportation facilities located in FEMA floodplains in Oregon. 


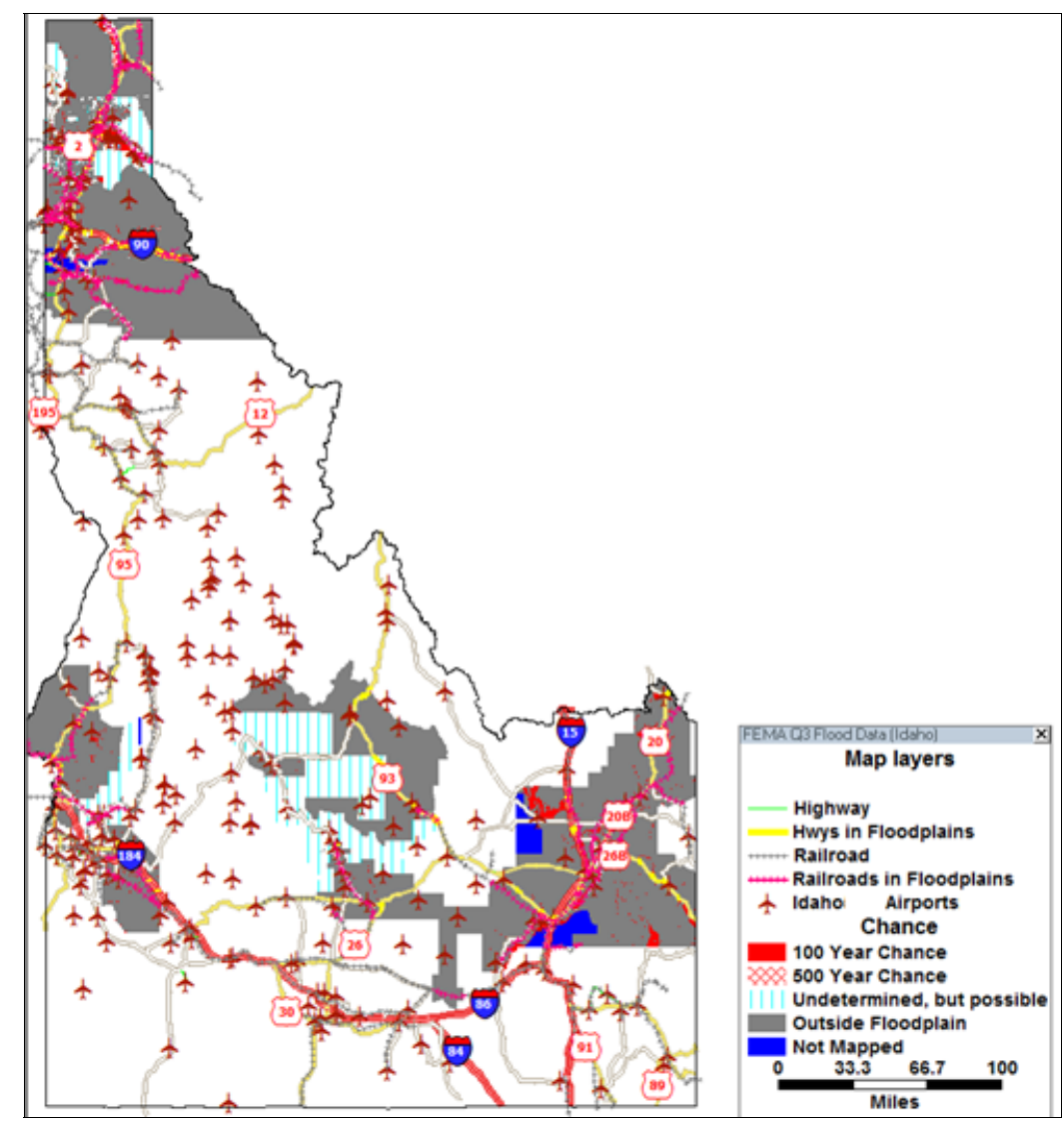

Figure 58 - Transportation facilities located in FEMA floodplains in Idaho. 
Table 30 - Highways and Railroads in FEMA Floodplains (ID, OR and WA)

\begin{tabular}{|c|c|c|c|c|c|c|c|}
\hline State & Facility & Risk Types & $\begin{array}{c}\text { Functional } \\
\text { Classes } \\
\text { /Usage }\end{array}$ & $\begin{array}{c}\text { Miles in } \\
100 \text { Year } \\
\text { Chance } \\
\text { Floodplains } \\
\end{array}$ & $\begin{array}{l}\text { Miles in } \\
500 \text { Year } \\
\text { Chance } \\
\text { Floodplains } \\
\end{array}$ & $\begin{array}{c}\text { Miles in } \\
\text { "Undetermined, } \\
\text { but possible" } \\
\text { zones } \\
\end{array}$ & $\begin{array}{l}\text { Total } \\
\text { Miles } \\
\end{array}$ \\
\hline \multirow[t]{18}{*}{ WA } & \multirow[t]{12}{*}{ Highways } & \multirow[t]{9}{*}{$\begin{array}{c}\text { Inside } \\
\text { Floodplains }\end{array}$} & Rural Interstate & 60 & 15 & 18 & 93 \\
\hline & & & Rural Major Collector & 199 & 13 & 127 & 339 \\
\hline & & & Rural Minor Arterial & 183 & 16 & 127 & 327 \\
\hline & & & $\begin{array}{c}\text { Rural Principal } \\
\text { Arterial }\end{array}$ & 224 & 10 & 149 & 382 \\
\hline & & & Urban Interstate & 75 & 12 & & 87 \\
\hline & & & Urban Minor Arterial & 31 & 5 & & 36 \\
\hline & & & $\begin{array}{c}\text { Urban Other Principal } \\
\text { Arterial }\end{array}$ & 49 & 33 & & 82 \\
\hline & & & $\begin{array}{c}\text { Urban Principal } \\
\text { Arterial }\end{array}$ & 56 & 21 & & 76 \\
\hline & & & Floodplain Total & 876 & 125 & 421 & 1422 \\
\hline & & $\begin{array}{c}\text { Outside } \\
\text { Floodplains }\end{array}$ & & & & & 6469 \\
\hline & & Not Mapped & & & & & 249 \\
\hline & & All Highways & & & & & 8140 \\
\hline & \multirow[t]{6}{*}{ Railroads } & \multirow[t]{3}{*}{$\begin{array}{c}\text { Inside } \\
\text { Floodplains }\end{array}$} & Passenger & 301 & 22 & 21 & 344 \\
\hline & & & Non-Passenger & 471 & 48 & 31 & 550 \\
\hline & & & Floodplain Total & 772 & 70 & 52 & 894 \\
\hline & & $\begin{array}{c}\text { Outside } \\
\text { Floodplains } \\
\end{array}$ & & & & & 2718 \\
\hline & & Not Mapped & & & & & 234 \\
\hline & & All Railroads & & & & & 3846 \\
\hline \multirow[t]{13}{*}{ OR } & \multirow[t]{13}{*}{ Highways } & \multirow[t]{10}{*}{$\begin{array}{c}\text { Inside } \\
\text { Floodplains }\end{array}$} & Rural Interstate & 99 & 13 & 150 & 261 \\
\hline & & & $\begin{array}{l}\text { Other Rural Principal } \\
\text { Arterial }\end{array}$ & 223 & 17 & 316 & 556 \\
\hline & & & Rural Minor Arterial & 194 & 28 & 218 & 440 \\
\hline & & & Rural Major Collector & 125 & 10 & 146 & 281 \\
\hline & & & Rural Minor Collector & 1 & 0 & 11 & 12 \\
\hline & & & Urban Interstate & 42 & 12 & 1 & 55 \\
\hline & & & $\begin{array}{l}\text { Other Urban } \\
\text { Freeways and } \\
\text { Expressways }\end{array}$ & 10 & 3 & 1 & 14 \\
\hline & & & $\begin{array}{l}\text { Other Urban Principal } \\
\text { Arterial }\end{array}$ & 48 & 21 & 7 & 76 \\
\hline & & & Urban Minor Arterial & 9 & 4 & 1 & 14 \\
\hline & & & Floodplain Total & 750 & 108 & 852 & 1710 \\
\hline & & $\begin{array}{c}\text { Outside } \\
\text { Floodplains }\end{array}$ & & & & & 4833 \\
\hline & & Not Mapped & & & & & 2022 \\
\hline & & All Highways & & & & & 8565 \\
\hline
\end{tabular}




\begin{tabular}{|c|c|c|c|c|c|c|c|}
\hline State & Facility & Risk Types & $\begin{array}{c}\text { Functional } \\
\text { Classes } \\
\text { /Usage }\end{array}$ & $\begin{array}{l}\text { Miles in } \\
100 \text { Year } \\
\text { Chance } \\
\text { Floodplains }\end{array}$ & $\begin{array}{c}\text { Miles in } \\
500 \text { Year } \\
\text { Chance } \\
\text { Floodplains }\end{array}$ & $\begin{array}{c}\text { Miles in } \\
\text { "Undetermined, } \\
\text { but possible" } \\
\text { zones }\end{array}$ & $\begin{array}{l}\text { Total } \\
\text { Miles }\end{array}$ \\
\hline & Railroads & $\begin{array}{l}\text { Inside } \\
\text { Floodplain }\end{array}$ & Passenger & 36 & 9 & 64 & 107 \\
\hline & & & Non-Passenger & 264 & 43 & 148 & 485 \\
\hline & & & Floodplain Total & 300 & 52 & 212 & 595 \\
\hline & & $\begin{array}{c}\text { Outside } \\
\text { Floodplains } \\
\end{array}$ & & & & & 1034 \\
\hline & & Not Mapped & & & & & 804 \\
\hline & & $\begin{array}{c}\text { Total } \\
\text { Railroads }\end{array}$ & & & & & 2433 \\
\hline \multirow[t]{16}{*}{ ID } & \multirow[t]{10}{*}{ Highways } & \multirow[t]{7}{*}{$\begin{array}{c}\text { Inside } \\
\text { Floodplains }\end{array}$} & Rural Interstate & 17 & 2 & & 19 \\
\hline & & & Rural Minor Arterial & 33 & 2 & 106 & 141 \\
\hline & & & $\begin{array}{c}\text { Rural Principal } \\
\text { Arterial }\end{array}$ & 28 & 4 & 16 & 49 \\
\hline & & & Unknown & 25 & 2 & 24 & 51 \\
\hline & & & Urban Interstate & 1 & & & 1 \\
\hline & & & $\begin{array}{c}\text { Urban Principal } \\
\text { Arterial }\end{array}$ & 8 & 16 & & 24 \\
\hline & & & Floodplain Total & 113 & 26 & 146 & 286 \\
\hline & & $\begin{array}{c}\text { Outside } \\
\text { Floodplains } \\
\end{array}$ & & & & & 1725 \\
\hline & & Not Mapped & & & & & 3174 \\
\hline & & All Highways & & & & & 5185 \\
\hline & \multirow[t]{6}{*}{ Railroads } & \multirow[t]{3}{*}{$\begin{array}{l}\text { Inside } \\
\text { Floodplain }\end{array}$} & Passenger & 11 & 2 & & 13 \\
\hline & & & Non-Passenger & 77 & 8 & 27 & 112 \\
\hline & & & Floodplain Total & 88 & 10 & 27 & 125 \\
\hline & & $\begin{array}{l}\text { Outside } \\
\text { Floodplain }\end{array}$ & & & & & 680 \\
\hline & & Not Mapped & & & & & 859 \\
\hline & & $\begin{array}{c}\text { Total } \\
\text { Railroads }\end{array}$ & & & & & 1664 \\
\hline
\end{tabular}

Table 31 - Airports in FEMA Floodplains (Idaho, Oregon, and Washington)

\begin{tabular}{|c|c|c|c|c|c|c|c|}
\hline \multirow[b]{2}{*}{ State } & \multirow[b]{2}{*}{ Airport Use } & \multicolumn{5}{|c|}{ Number of Airports in Floodplains } & \multirow[b]{2}{*}{ Total } \\
\hline & & $\begin{array}{l}100 \text { Year } \\
\text { Chance }\end{array}$ & $\begin{array}{l}500 \text { Year } \\
\text { Chance }\end{array}$ & $\begin{array}{l}\text { Outside } \\
\text { Floodplain }\end{array}$ & $\begin{array}{l}\text { Undetermined, } \\
\text { but possible }\end{array}$ & Not Mapped & \\
\hline \multirow[t]{3}{*}{ ID } & Private & 9 & 3 & 51 & 2 & 88 & 159 \\
\hline & Public & 5 & & 31 & 4 & 79 & 125 \\
\hline & State Total & 14 & 3 & 82 & 6 & 167 & 284 \\
\hline \multirow[t]{2}{*}{ OR } & Public & 11 & 4 & 58 & 2 & 22 & 97 \\
\hline & State Total & 11 & 4 & 58 & 2 & 22 & 97 \\
\hline \multirow[t]{3}{*}{ WA } & Private & 5 & & 26 & & & 31 \\
\hline & Public & 17 & 5 & 76 & 4 & 4 & 106 \\
\hline & State Total & 22 & 5 & 102 & 4 & 4 & 137 \\
\hline
\end{tabular}




\section{Impacts of Landslides}

In the three states of the Pacific Northwest, landslides are a typical threat to transportation infrastructures. The occurrence of landslides is highly associated to high precipitation intensity and rolling terrains. It can be expected that with potentially higher rainfall intensity of climate change effects transportation facilities in the region could suffer more damages due to increased number of landslides.

To identify the areas in the region where landslides are critical to the transportation infrastructure, GIS databases and other supporting documents on past landslide occurrences were obtained from the web sites of Oregon, Washington and Idaho state governments.

\section{Oregon}

The state of Oregon has established a comprehensive landslide GIS database SLIDO (The Statewide Landslide Information Database of Oregon) ${ }^{12}$ with the intention of improving the current understanding of the landslide hazards in Oregon and to create a statewide base level of landslide data. SLIDO is currently in Release 2 (R2).

SLIDO R2 database contains two major data groups: landslide deposit polygons and the historic locations of landslide occurrences. The database entries were identified from over 250 landslide studies with the earliest records dating back to the 1930s. The original studies vary in scale, scope and focus. The variation is reflected in the wide range in the accuracy, detail and completeness identified with the landslide entries. Note

\footnotetext{
${ }^{12}$ http://www.oregongeology.org/sub/slido/background.htm
} 
that field records from the Oregon Department of Transportation, Federal Highway Administration and local public works departments constitute a major portion of the SLIDO database.

Figure shows the SLIDO R2 features superimposed on 30 arc-sec DEM and the ODOT highways identified with functional classes (i.e., the functional_class_200 layer in the map).

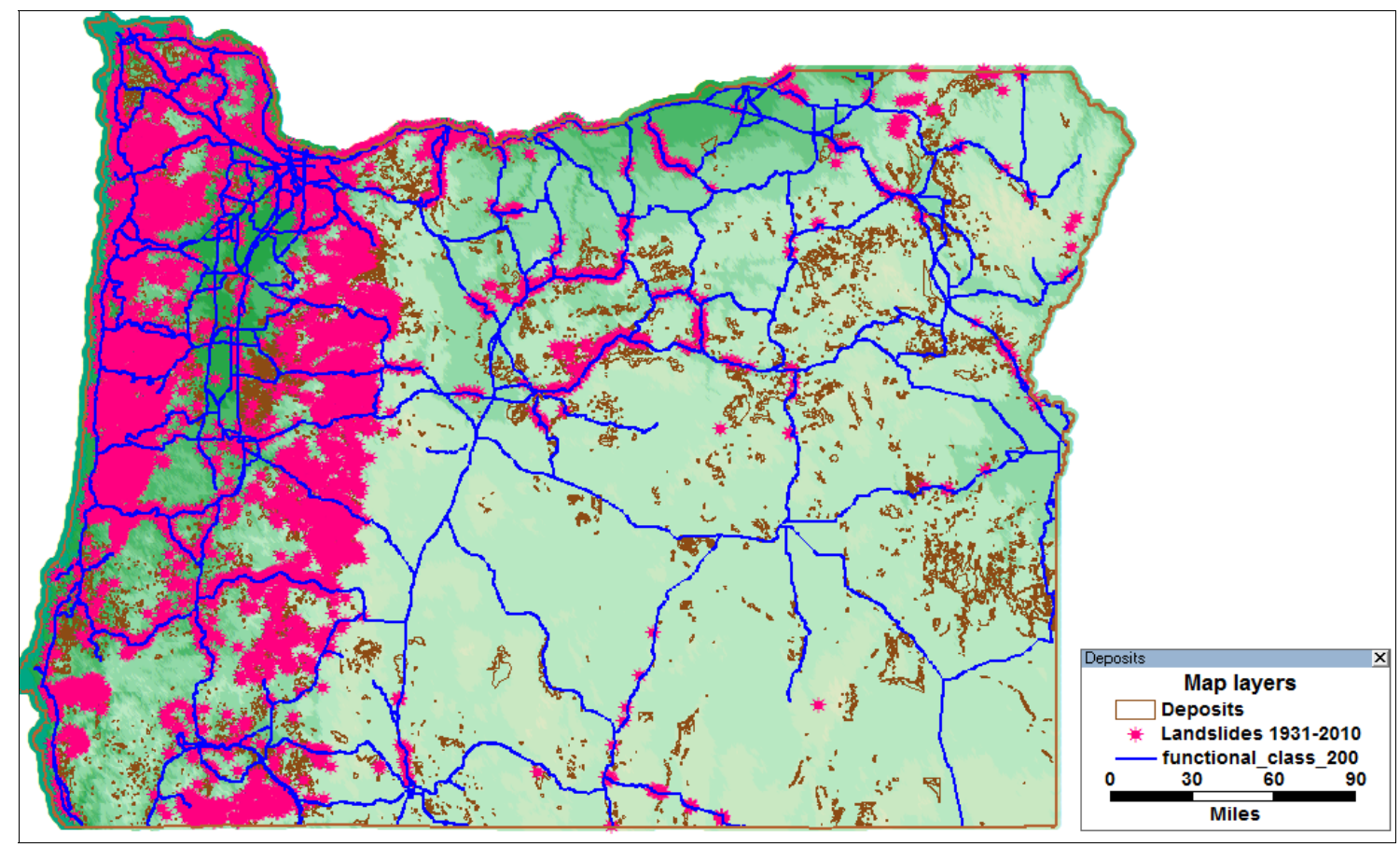

\section{Figure 59 - SLIDO R2 Data Features with DEM and ODOT Highway Functional Classes}

A total of 10,626 historic landslide entries were identified from SLIDO R2. The map in Figure 59 shows that most of the highways on the western part of Oregon have had landslide occurrences dating back to the 1930s. The patterns of DEM shadings underneath the landslides appear to show changes in elevations with darker shades depicting low elevations and pale shades high elevation. To better examine the terrain 
features where most landslides occurred, landslide locations were superimposed on the DEM with a legend showing color scheme for the corresponding elevation levels (see Figure 60).

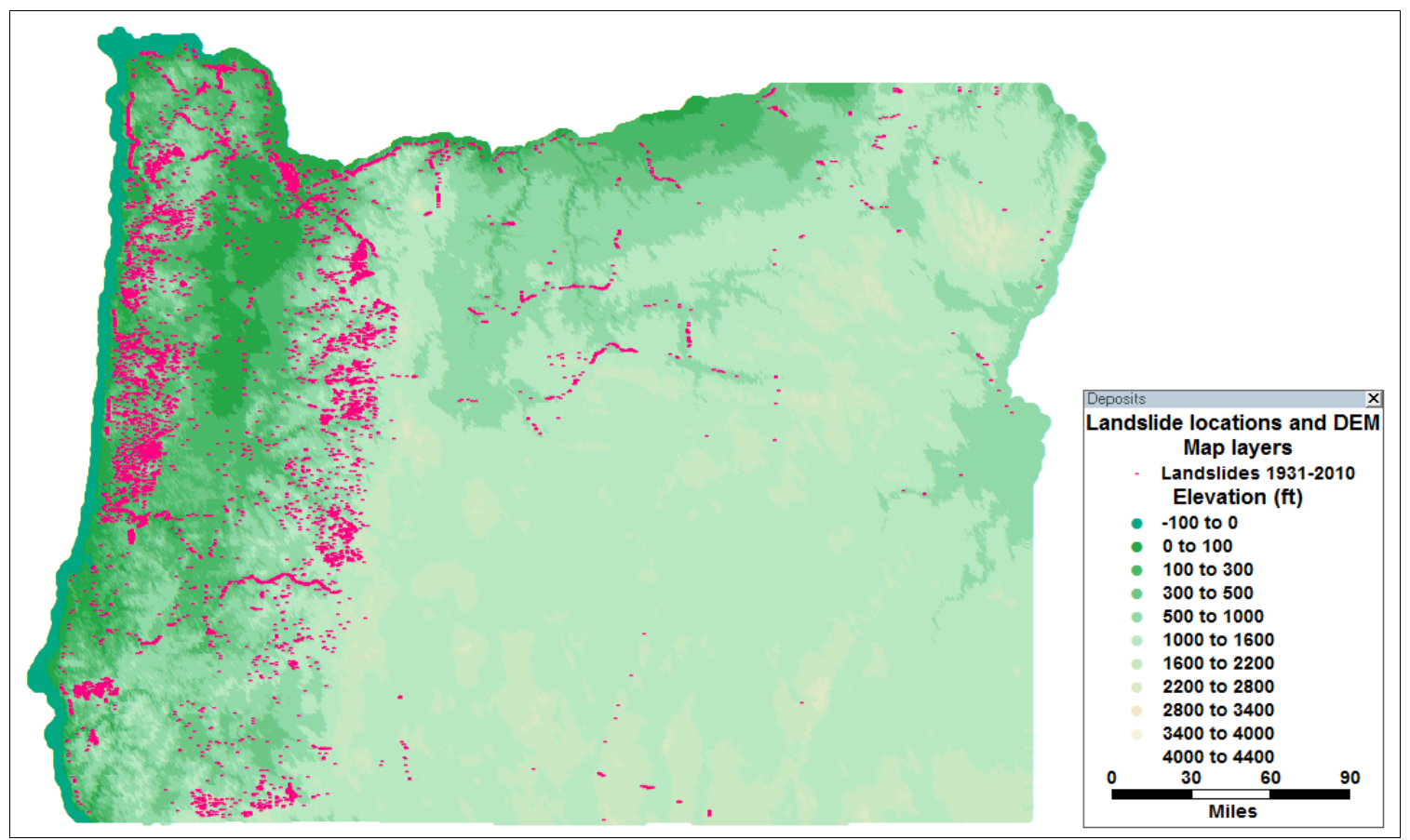

Figure 60 - OR Landslide Locations and 30 Arc-Sec DEM

Quantitative analyses were performed to examine factors related to the terrain that contributes to landslides. Figure 61 depicts a histogram showing landslide occurrence frequency by DEM elevations. A major portion of landslides in OR occurred under 500 feet in elevation. It is noted that the elevation levels that most of the landslides were records are associated with places where roads and other infrastructures are located. These elevations also happen to exist in the western part of the state where high rainfall intensity exists. 


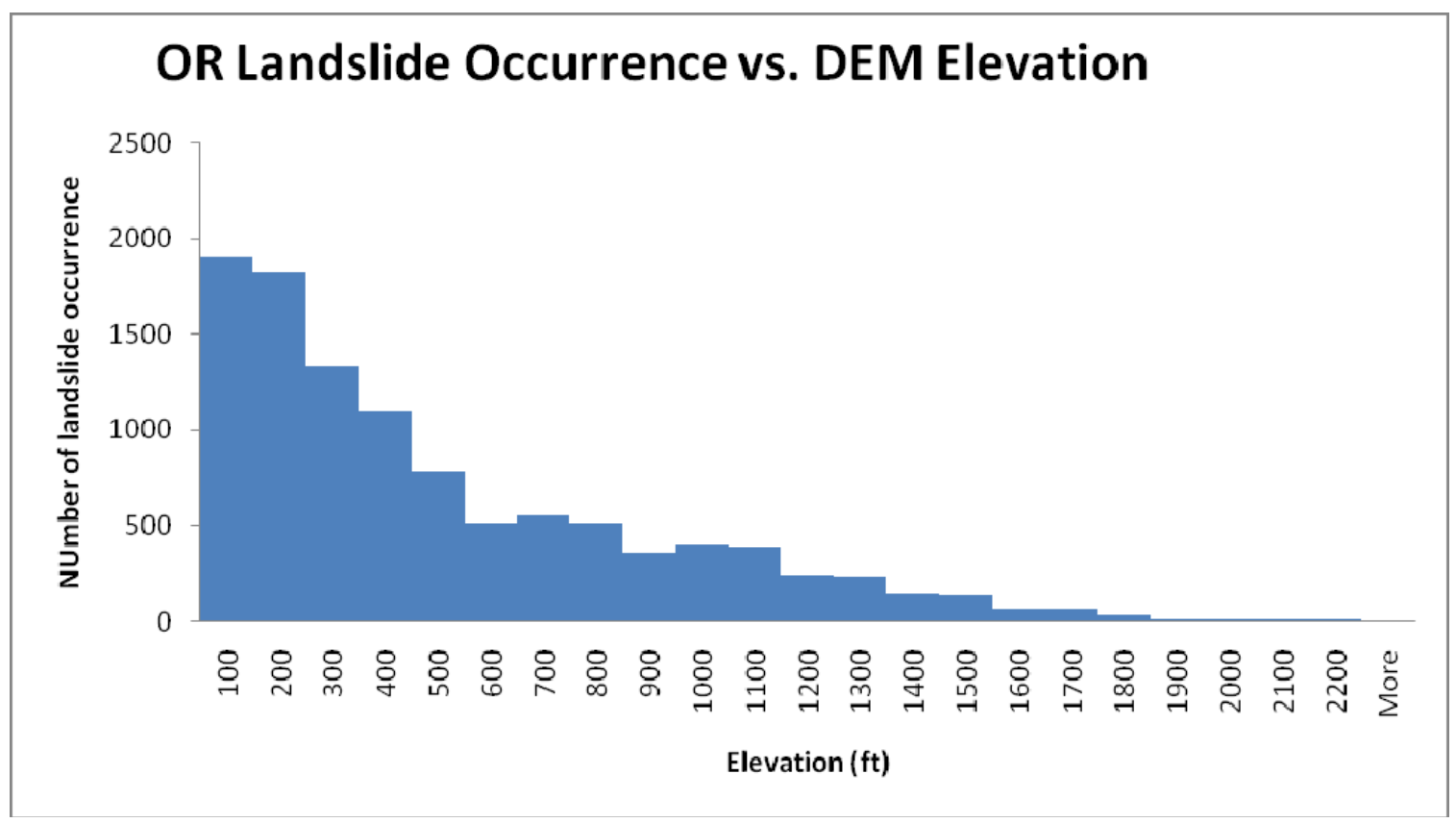

Figure 61 - Histogram of Landslide Occurrence by DEM Elevation in Oregon

Figure 62 shows the relationship between landslide locations and the average precipitation in December (i.e., a typical peak of raining season in the region). The precipitation data were obtained from the PRISM group of Oregon State University ${ }^{13}$. The precipitation numbers are the averages from 1971 to 2000.

${ }^{13} \mathrm{http}: / /$ prism.oregonstate.edu/index.phtml 


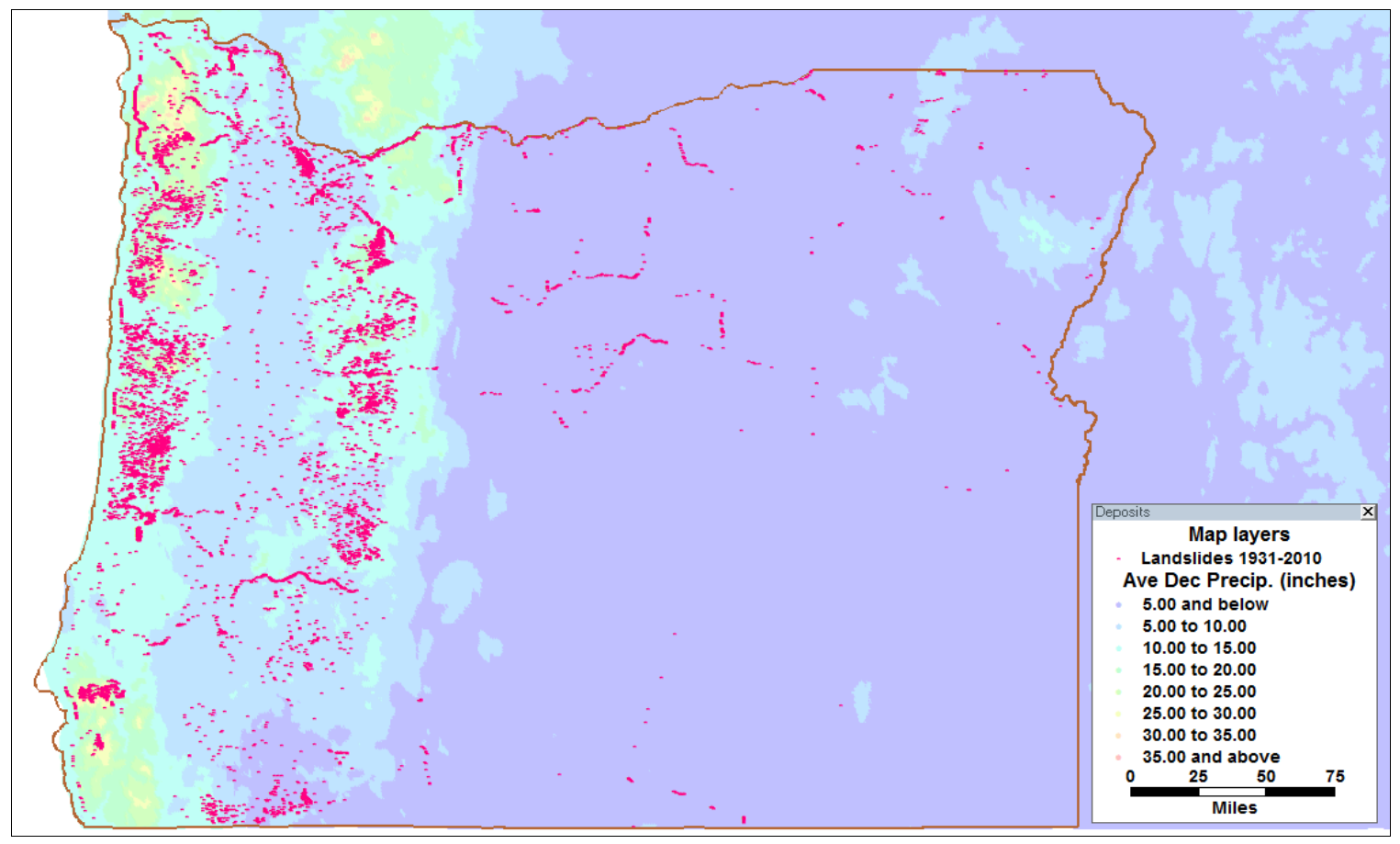

Figure 62 - OR Landslides and Average Precipitation in December

Figure 62 clearly identifies that most recorded landslides occurred in areas with average December precipitation of above 10 inches. After identifying the typical patterns of landslide occurrences in terms of elevations and precipitation intensity, the analysis proceeded with selection of landslide records that are road-related. Figure presents the elevations of only road-related landslides. When the elevations of road-related landslides were examined, it revealed a similar pattern as the one with all landslides (see Figure 63). Most of the road-related landslides are in elevations below $500 \mathrm{ft}$. 


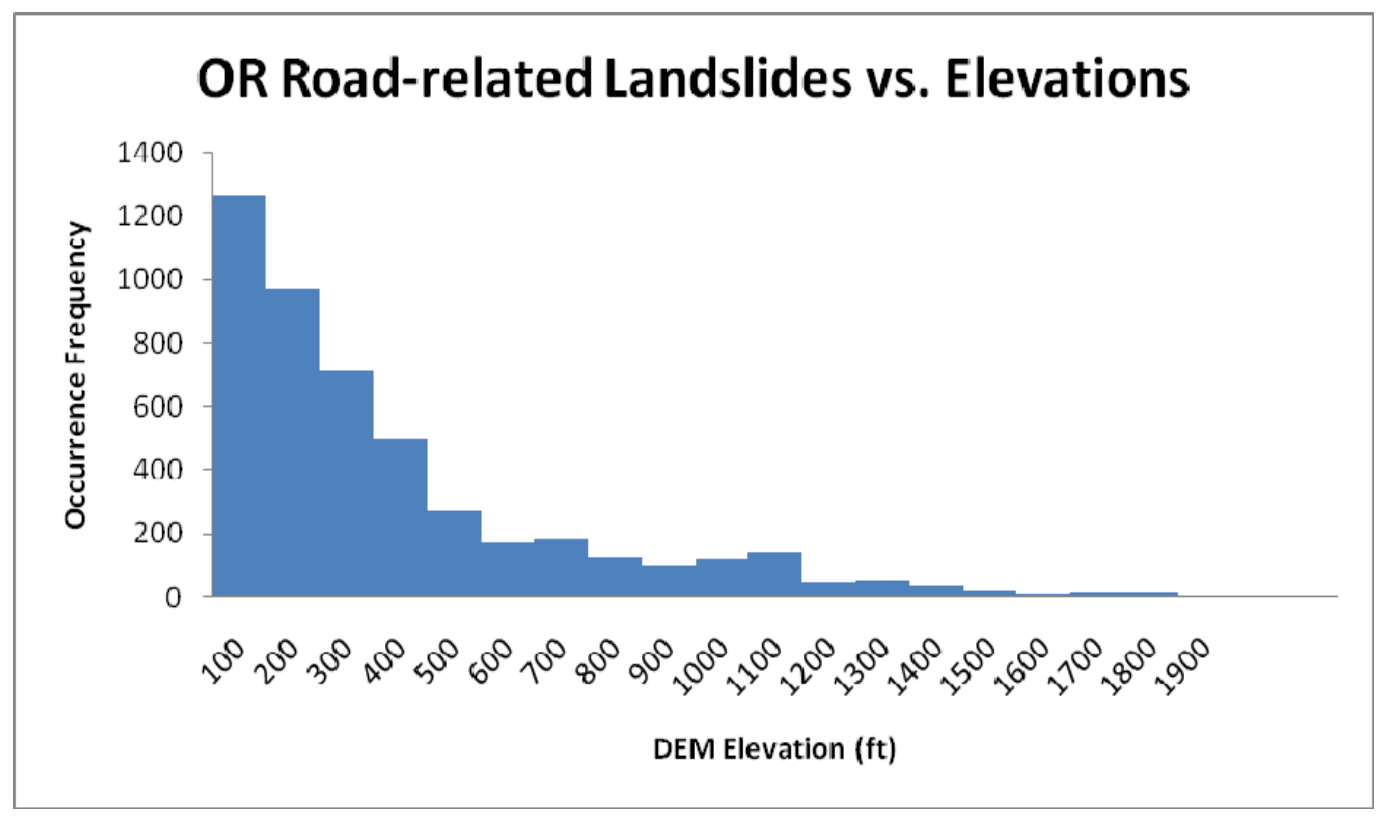

Figure 63 - Elevations of Road-Related Landslides in Oregon

Figure 63 shows how the degrees of slopes adjacent to the landsides relate to occurrence frequency. Note that the SLIDO R2 database contains many records with missing slope data that are coded as zero slope. These records were excluded from the records shown in Figure 64, which shows that roads with adjacent slopes in the degrees between 35 to 50 are most prone to landslides.

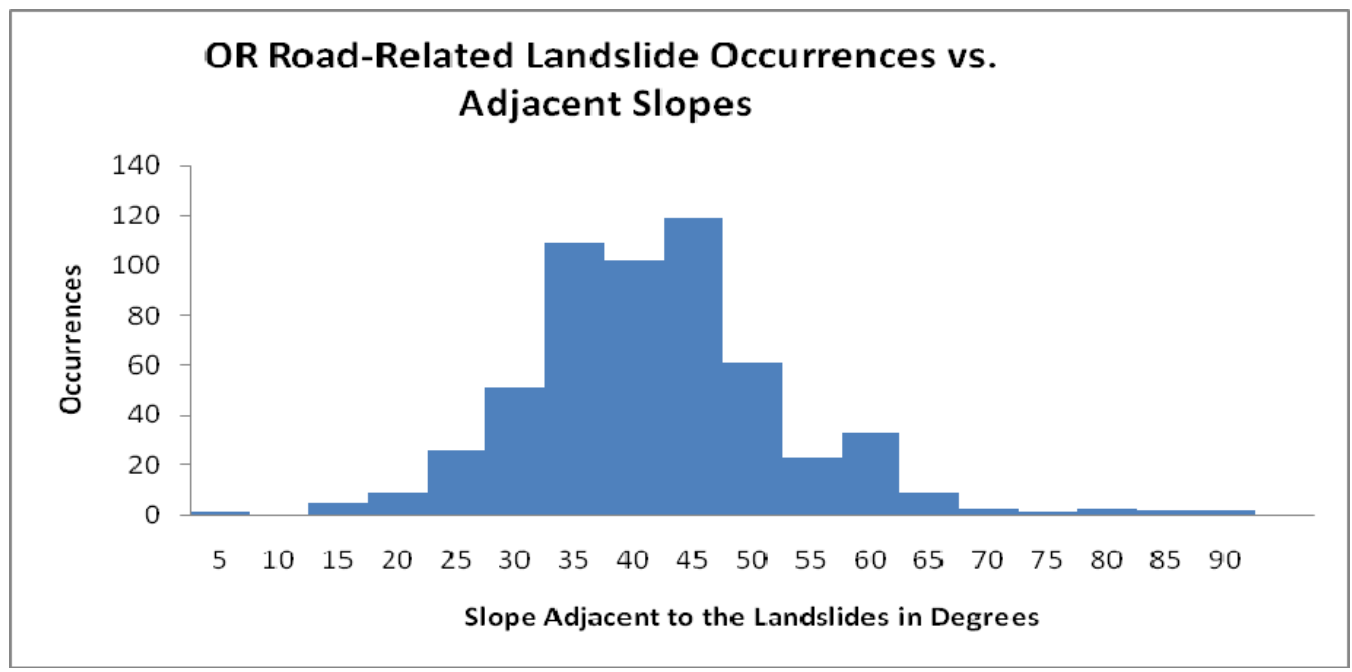

Figure 64 - Slopes Adjacent to Road-Related Landslide Sites in Oregon 
Table 32 shows the proportions of landslide occurrences by material types. Of the 611 road-related cases coded with landslide materials, majority of them were debris and earthen materials. However, approximately $8 \%$ of them actually involved rocks.

Table 32 - Type of Road-Related Landslide Materials in Oregon

\begin{tabular}{|lcc|}
\hline Type of Materials & Total Occurrences & Percent \\
\hline Debris & 122 & $19.97 \%$ \\
\hline Earth & 417 & $68.25 \%$ \\
\hline Earth/Debris & 11 & $1.80 \%$ \\
\hline Earth/Rock & 2 & $0.33 \%$ \\
\hline Fill & 8 & $1.31 \%$ \\
\hline Fill/Debris/Earth & 1 & $0.16 \%$ \\
\hline Rock & 47 & $7.69 \%$ \\
\hline Rock, Debris, Earth & 2 & $0.33 \%$ \\
\hline Rock/Earth & 1 & $0.16 \%$ \\
\hline Total & $\mathbf{6 1 1}$ & $\mathbf{1 0 0 . 0 0 \%}$ \\
\hline
\end{tabular}

Figure 65 shows the frequency of road-related landslides by average December precipitation. It appears that there are significantly less landslides in areas with average December precipitation below the 8 inch category.

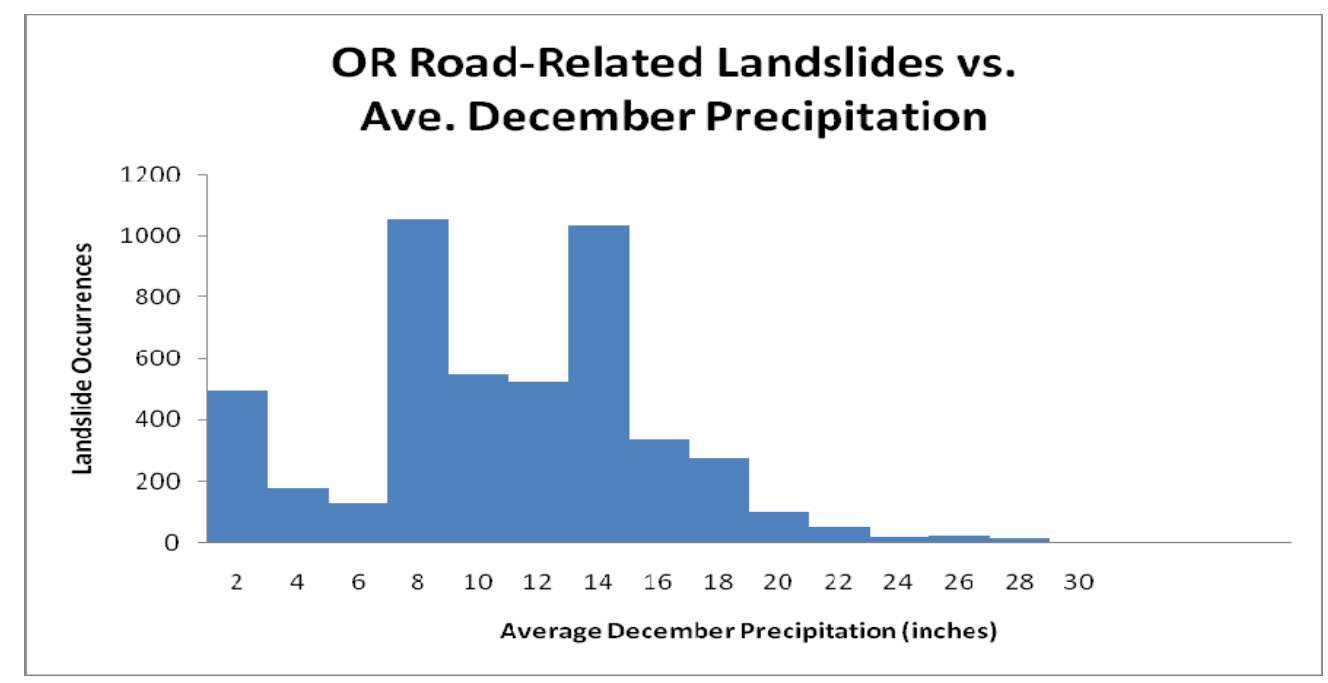

Figure 65 - Histogram of Landslide Frequency by Average December Precipitation in Oregon 
Figure 66 shows the map view of highways located in areas where the average December precipitation is above 7 inches. The map shows that the areas with precipitation above 7 inches cover most of the historic road-related landslide occurrences, with the exception of several interstate routes in the northeastern part of the state. Figure 66 shows a larger view of these landslides superimposed on top of DEM in northeastern Oregon. The figure shows that landslides in these areas are more likely due to highway cut slopes in the mountainous terrain as the DEM demonstrates patterns of elevation drops with many highways located in lower elevations.

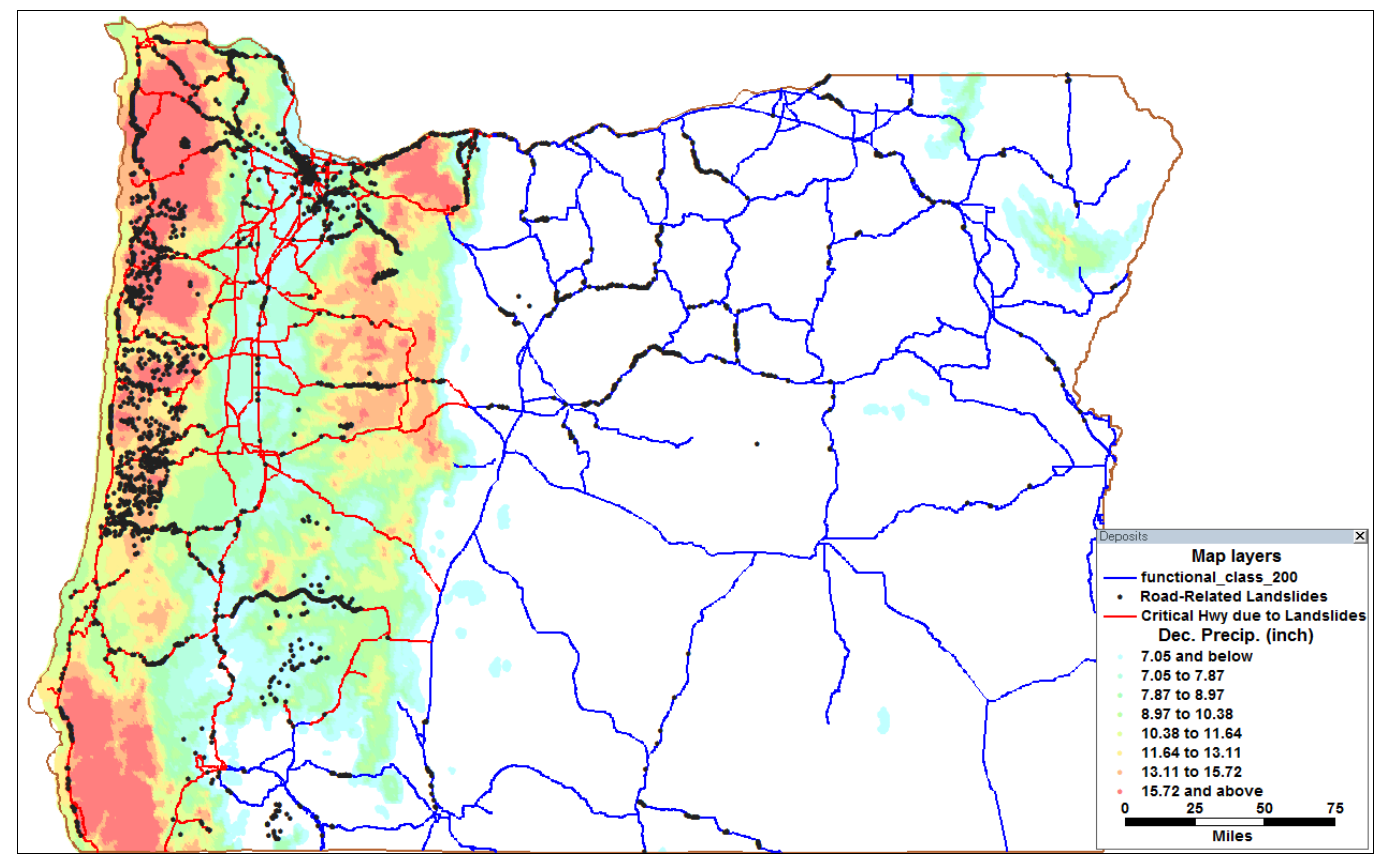

Figure 66 - Identification of Critical Highways subject to Landslides in Oregon ${ }^{14}$

\footnotetext{
${ }^{14}$ To preserve a clear view of precipitation intensity variations and landslide locations, railroads, and airports located in the areas with over 7 inch precipitation are not displayed.
} 


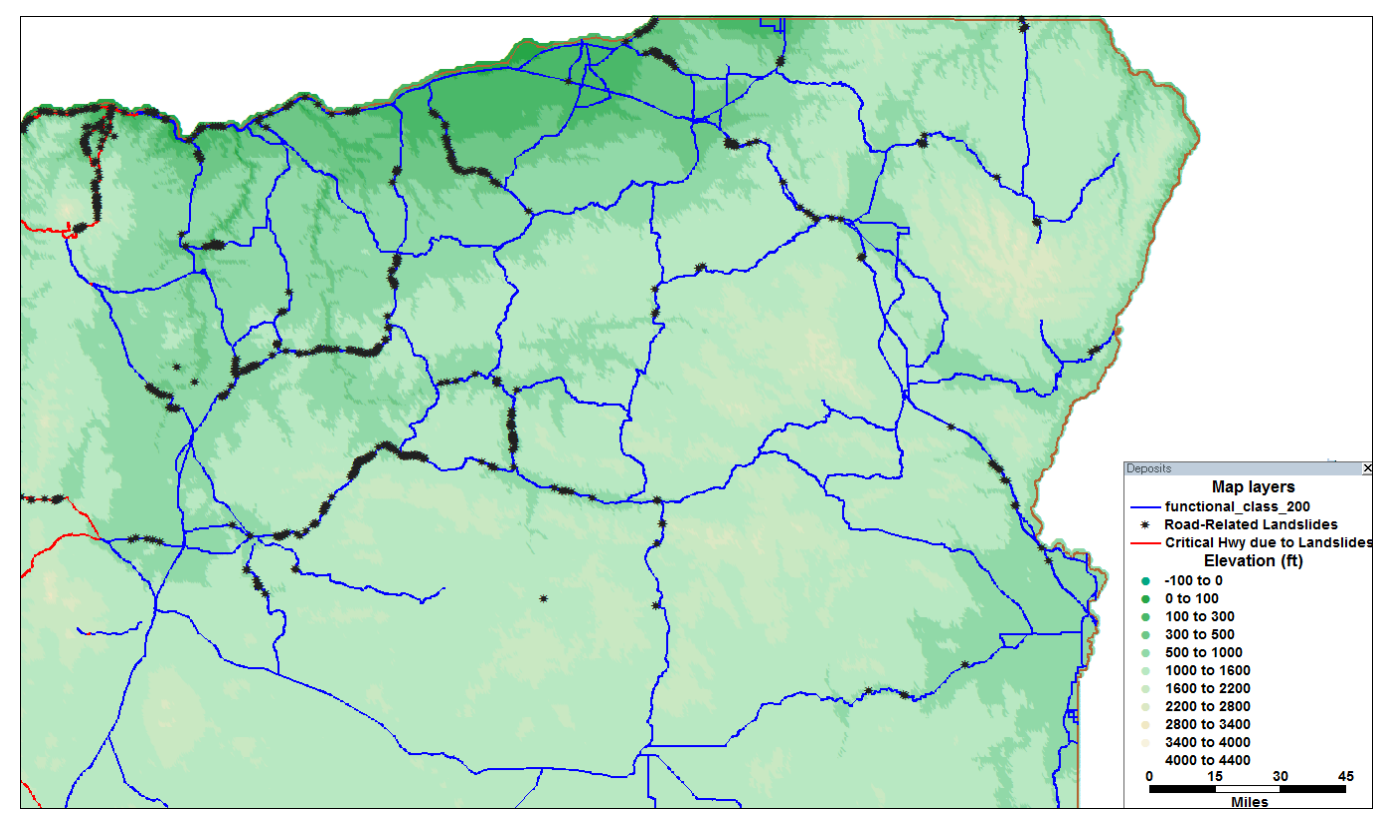

Figure 67 - Road-related landsides in northeastern Oregon

With the identification of above 7 inches, December precipitation as the critical factor for road-related landslide occurrence, highways critical to landslide damages due to climate change are identified (i.e., the red routes in Figure 66 and 67). Table 33 shows the distribution of transportation facilities by the importance criteria defined at the beginning of the study. It is noted that, unlike highways and railroads, airports are generally located in wide open space in relatively level terrain. Airports are not prone to damage of landslides as much as highways, which are often located directly adjacent to cut slopes. The numbers of airports listed in Table 33 are those located in areas where the average December precipitation is above 7 inches. 
Table 33 - Roadways, Railroads, and Airports Subject to Landslide Damages in Oregon

\begin{tabular}{|lcc|}
\hline Functional Classes & Total Miles & Percent \\
\hline Highway Usage & Total Miles & Percent \\
\hline Rural Interstate & 479 & $12 \%$ \\
\hline Rural Major Collector & 592 & $15 \%$ \\
\hline Rural Minor Arterial & 768 & $19 \%$ \\
\hline Rural Minor Collector & 18 & $0 \%$ \\
\hline Other Rural Principal Arterial & 1,235 & $31 \%$ \\
\hline Urban Collector & 13 & $0 \%$ \\
\hline Urban Interstate & 272 & $7 \%$ \\
\hline Urban Minor Arterial & 75 & $2 \%$ \\
\hline Other Urban Freeways and Expressways & 95 & $2 \%$ \\
\hline Other Urban Principal Arterial & 411 & $10 \%$ \\
\hline Highway Total & $\mathbf{3 , 9 5 7}$ & $\mathbf{1 0 0 \%}$ \\
\hline Railroad Usage & Total Miles & Percent \\
\hline Passenger & 309 & $20 \%$ \\
\hline Non Passenger & 1,200 & $80 \%$ \\
\hline Railroad Total & $\mathbf{1 , 5 0 9}$ & $\mathbf{1 0 0 \%}$ \\
\hline Airport Usage & Total \# & Percent \\
\hline Private & 15 & $20 \%$ \\
\hline Public & 59 & $80 \%$ \\
\hline Airport Total & $\mathbf{7 4}$ & $\mathbf{1 0 0 \%}$ \\
\hline
\end{tabular}

The total 3,957 miles of highways identified as critical constitute $46 \%$ of all highways at the functional classes of collectors and above (i.e., no local roads and roads with lower functional classes) in the state of Oregon. Railroads labeled as passenger use are mainly Amtrak tracks with a very small number of other tracks used for personal travel. Total railroad mileage in Oregon (excluding abandoned tracks) is approximately 2,433 miles. Railroads in the landslide risk zone account for $62 \%$ of all railroad mileage in Oregon. The number of airports in the 7 inches December precipitation area accounts for $13 \%$ of all airports in Oregon. 


\section{$\underline{\text { Washington }}$}

The Washington Geological Survey GIS Statewide Landslide Database ${ }^{15}$ was created by the Washington Department of Natural Resources, Geology and Earth Resources Division (DGER), also known as the Washington Geological Survey. A total number of 44,527 landslide records are in the database with each landslide record managed as a polygon that facilitates the identification of the actual site and extent of the landslide. Figure shows the landslide locations superimposed on 30-sec DEM in the state of Washington together with the highways classified as interstates and state routes (i.e., local roads not included).

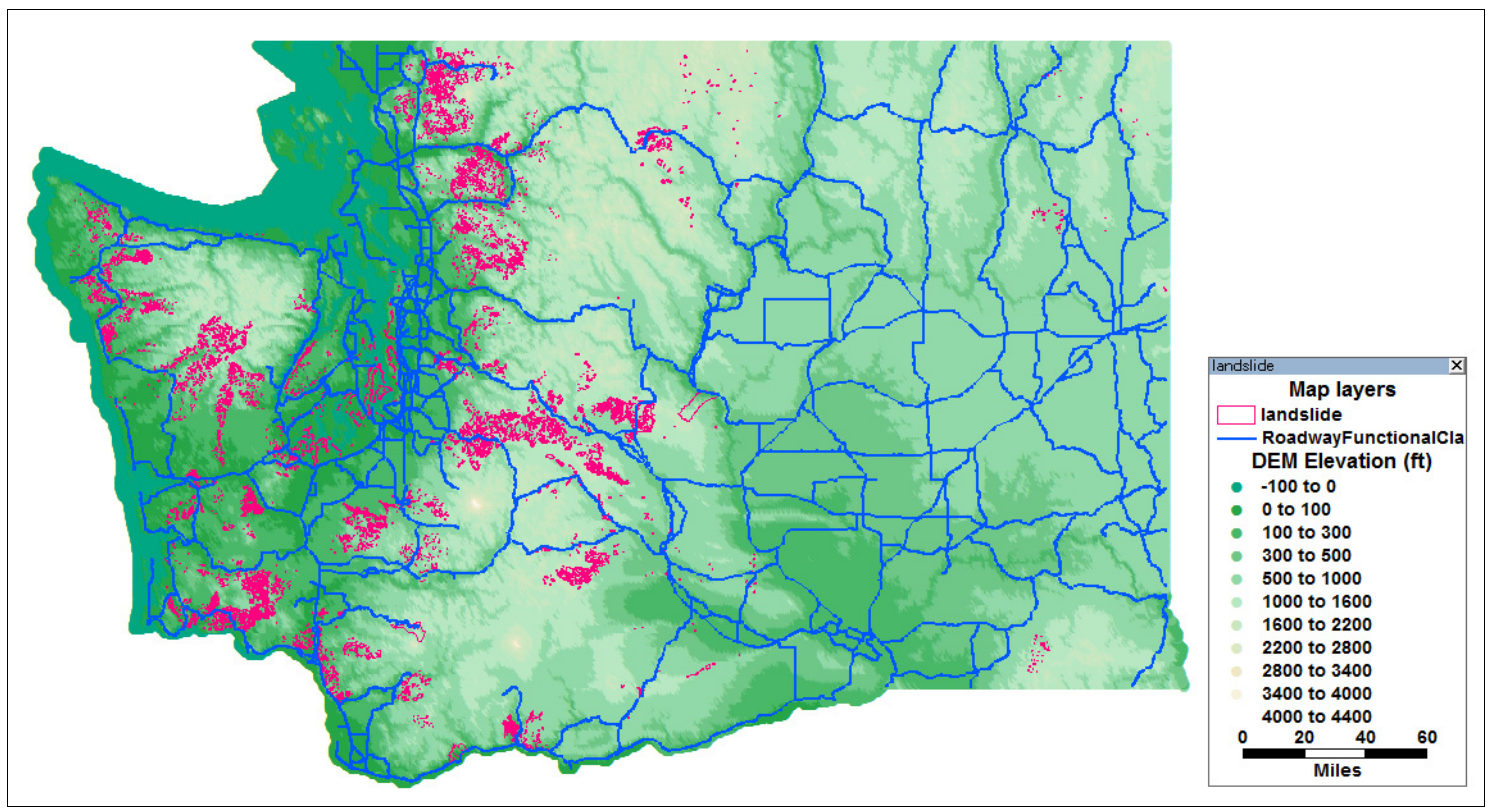

Figure 68 - Landslide locations in the state of Washington

15 (http://www.dnr.wa.gov/ResearchScience/Pages/PubData.aspx) 
Table 34 shows the distribution of land uses at the landslide sites. The variable Land Use is taken directly from the database. There are $22 \%$ of all landslides coded with transportation-related land use (i.e., road, railroad, trail). It is not clear if any of the landslides coded as Unknown is transportation-related.

Table 34 - Land Use Categorization of Landslide Locations in the Washington State

\begin{tabular}{|lrr|}
\hline LAND USE & \multicolumn{1}{c}{ Total } & \multicolumn{1}{c|}{ Percent } \\
\hline Agriculture and range land & 4 & $0.01 \%$ \\
\hline Forestry related activities & 13,438 & $30.18 \%$ \\
\hline Road, railroad, trail & 4915 & $11.04 \%$ \\
\hline Undisturbed & 561 & $1.26 \%$ \\
\hline Unknown & 23,935 & $53.75 \%$ \\
\hline Urban development & 1,674 & $3.76 \%$ \\
\hline Total & $\mathbf{4 4 , 5 2 7}$ & $\mathbf{1 0 0 . 0 0 \%}$ \\
\hline
\end{tabular}

Figure 69 shows the map of the landslide locations in spatial relation to the average December precipitation. It shows that most of the recorded landslides occurred in areas with over 6 inches of precipitation in December. This assertion is backed by the information in Figure 69. There is a significant increase in landslide frequency at the 6-8 inch category. 


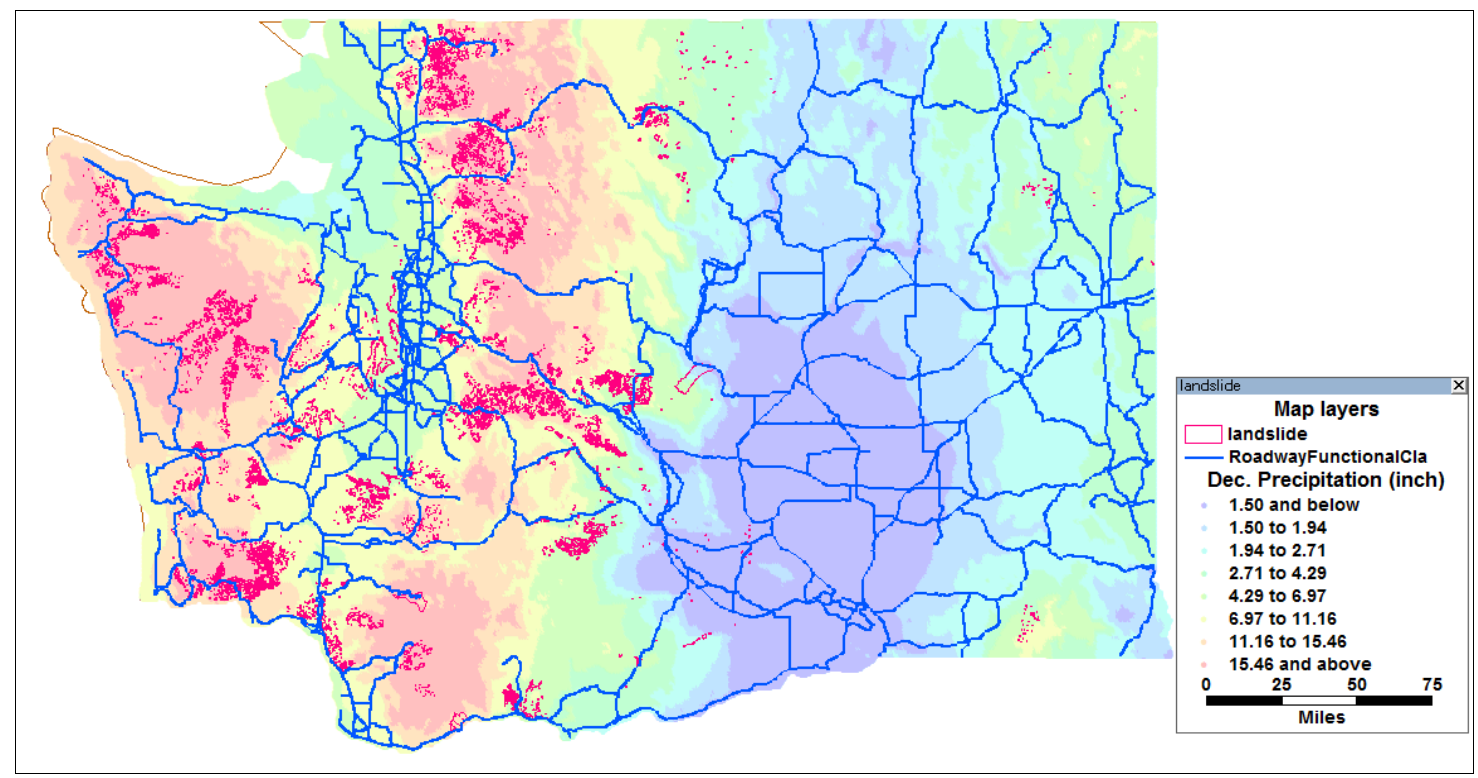

Figure 69 - Average December Precipitation Map of the Washington State

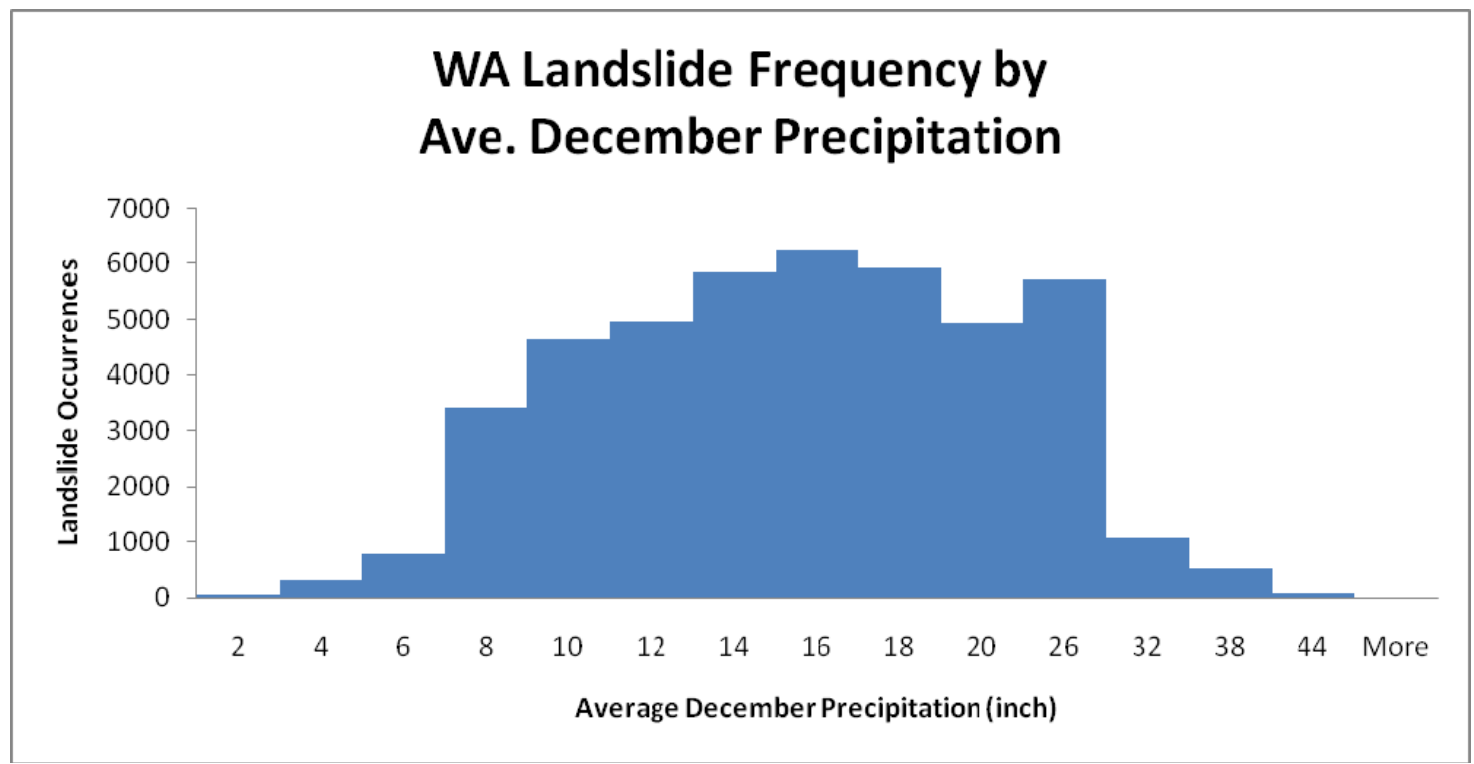

Figure 70 - WA Landslide Frequency by Average December Precipitation

Figure 71 shows the areas where the average December precipitation is over 7 inches and the highways located in these areas. Note that the areas in the center of the Puget Sound area do not have average December precipitation over 7 inches. Roadways located in this area are not identified as critical for landslide impacts. Figure 72 shows a 
local view of highways in the central Puget Sound area. There has been close to zero occurrence of past landslide in this area because most of this area is in relative level terrain with a urban landform mostly paved.

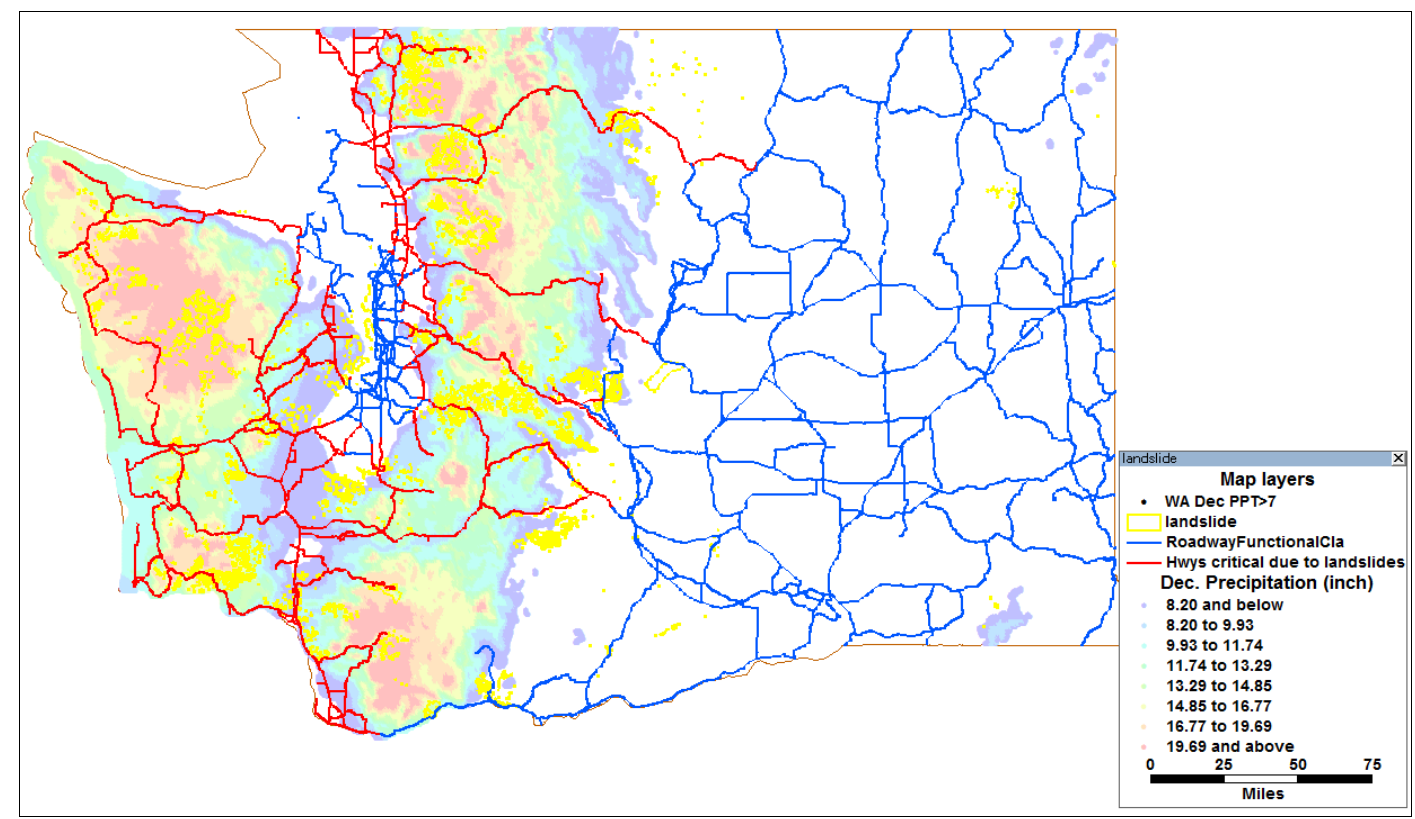

Figure 71 - Highways Located in Areas with Over 7 Inches of Average December Precipitation in WA 


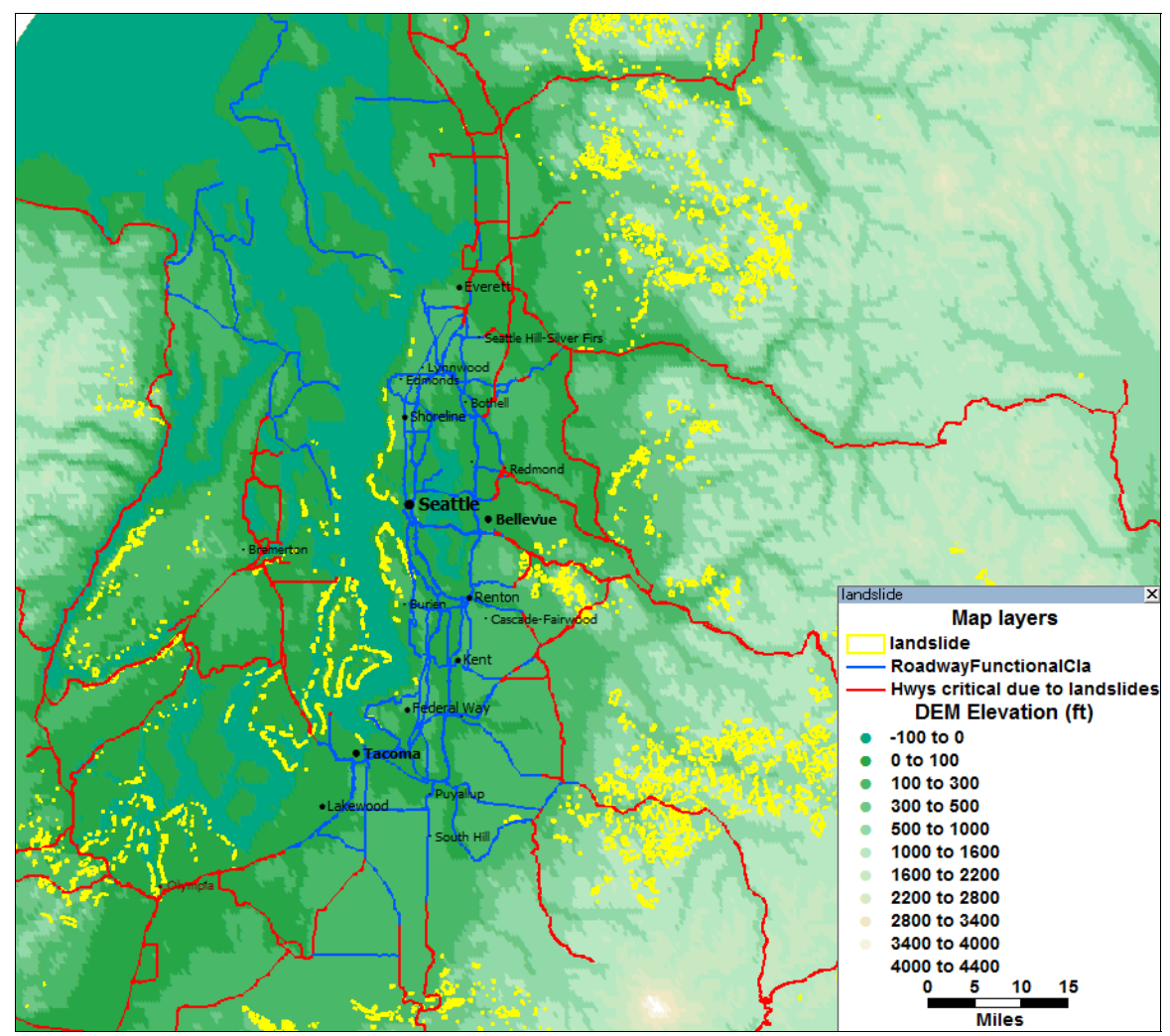

Figure 72 - Highways in the Puget Sound Area with Level Urban Landforms

Table 35 summarizes the distribution by the importance criteria of transportation facilities in the identified critical areas. These critical highways account for $38 \%$ of the total mileages of highways at these classes (i.e., approximately 8,000 miles) in Washington, railroad mileage $48 \%$ and number of airports $34 \%$. 
Table 35 - Roadways, Railroads, and Airports Subject to Landslide Damages in Washington

\begin{tabular}{|lcc|}
\hline Functional Classes & Total Miles & Percent \\
\hline Railroad Usage & Total Miles & Percent \\
\hline Rural-Interstate & 299 & $10 \%$ \\
\hline Rural-Major-Collector & 531 & $17 \%$ \\
\hline Rural-Minor-Arterial & 715 & $23 \%$ \\
\hline Rural-Principal-Arterial & 785 & $26 \%$ \\
\hline Urban-Interstate & 260 & $8 \%$ \\
\hline Urban-Minor-Arterial & 110 & $4 \%$ \\
\hline Urban-Other-Principal-Arterial & 146 & $5 \%$ \\
\hline Urban-Principal-Arterial & 225 & $7 \%$ \\
\hline Highway Total & $\mathbf{3 , 0 6 9}$ & $\mathbf{1 0 0 \%}$ \\
\hline Railroad Usage & Total Miles & Percent \\
\hline Passenger & 447 & $32 \%$ \\
\hline Non Passenger & 935 & $68 \%$ \\
\hline Railroad Total & $\mathbf{1 , 3 8 2}$ & $\mathbf{1 0 0 \%}$ \\
\hline Airport Usage & Total \# & Percent \\
\hline Private & 9 & $20 \%$ \\
\hline Public & 37 & $80 \%$ \\
\hline Airport Total & $\mathbf{4 6}$ & $\mathbf{1 0 0 \%}$ \\
\hline
\end{tabular}

$\underline{\text { Idaho }}$

No GIS database of landslides could be identified from various governmental web sites of Idaho. A PDF map, Landslides in Idaho, produced in 1991 by the Idaho Geological Survey ${ }^{16}$ was used as reference of Idaho landslide locations for this study. The map identifies locations and types of landslides in Idaho prior to 1991. Figure 73 show essential views and map legends of the map.

\footnotetext{
${ }^{16}$ W. Adams, R. Breckenridge, and K. Othberg, 1991, Landslides of Idaho: Idaho Geological Survey Geologic Map SGM-
} 


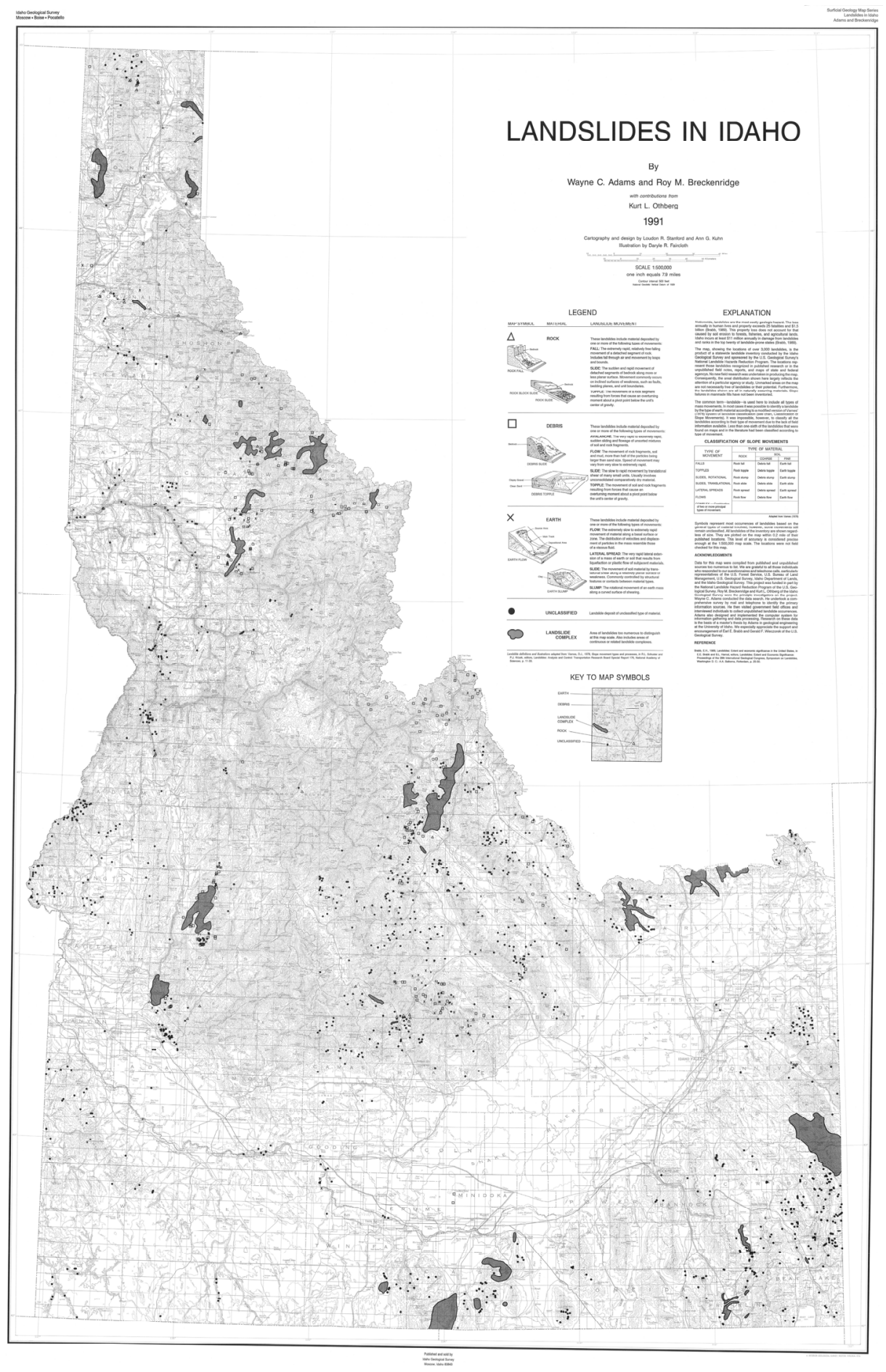

Figure 73 - State View of the Map of Landslides in Idaho 


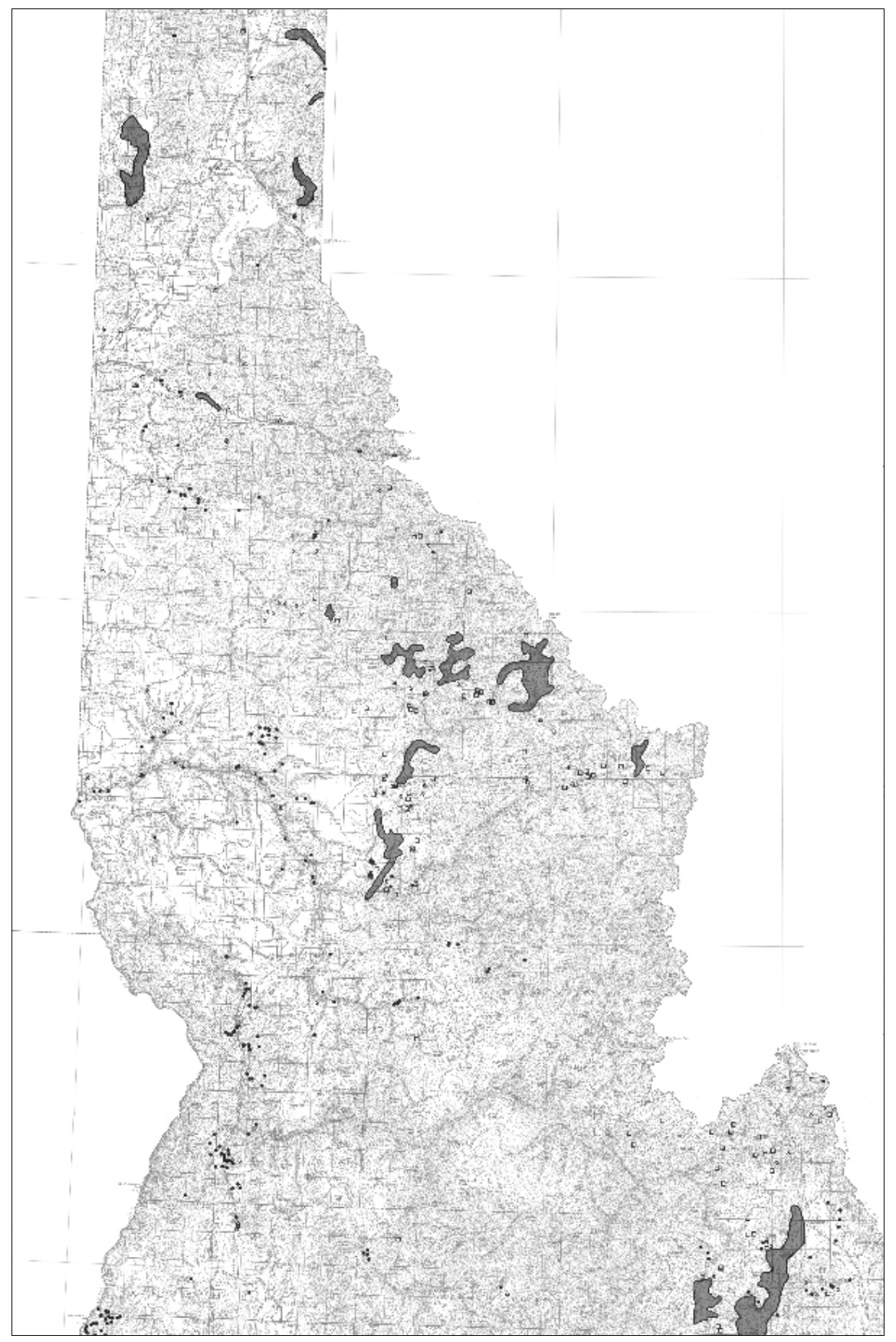

Figure 74 - Northern View of the Map of Landslides in Idaho 


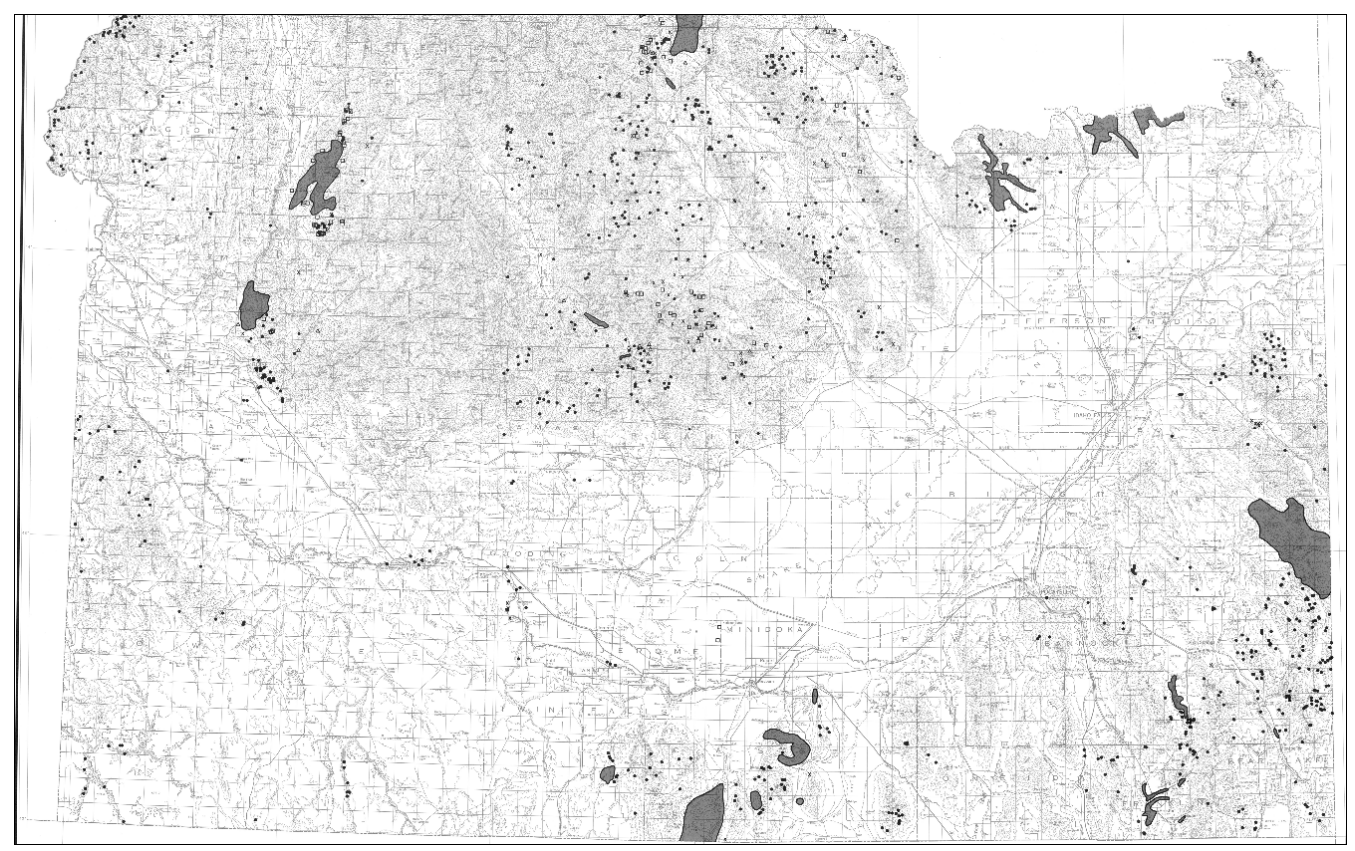

Figure 75 - Southern View of the Map of Landslides in Idaho

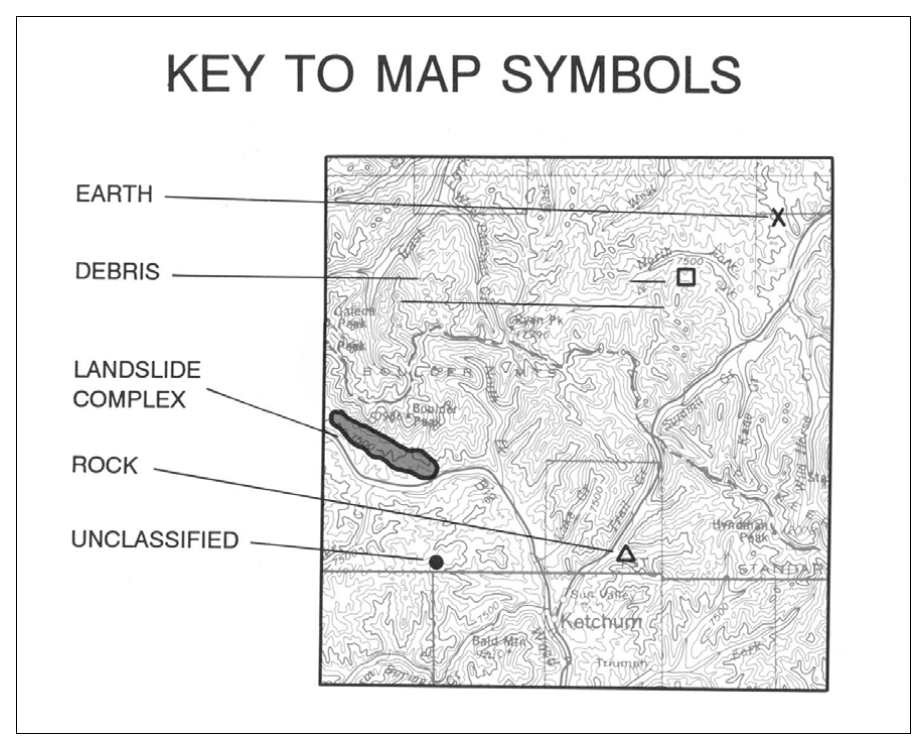

Figure 76 - Symbols for Landslides on the Map of Landslides in Idaho 
Figure 77 shows the locations of highways and 30 arc-sec DEM in the state of Idaho. Comparing with views from the map of Landslides in Idaho, the DEM grids in the three highlighted squares of Figure 77 show that many landslides in Idaho occurred in areas where substantial elevation changes exist.

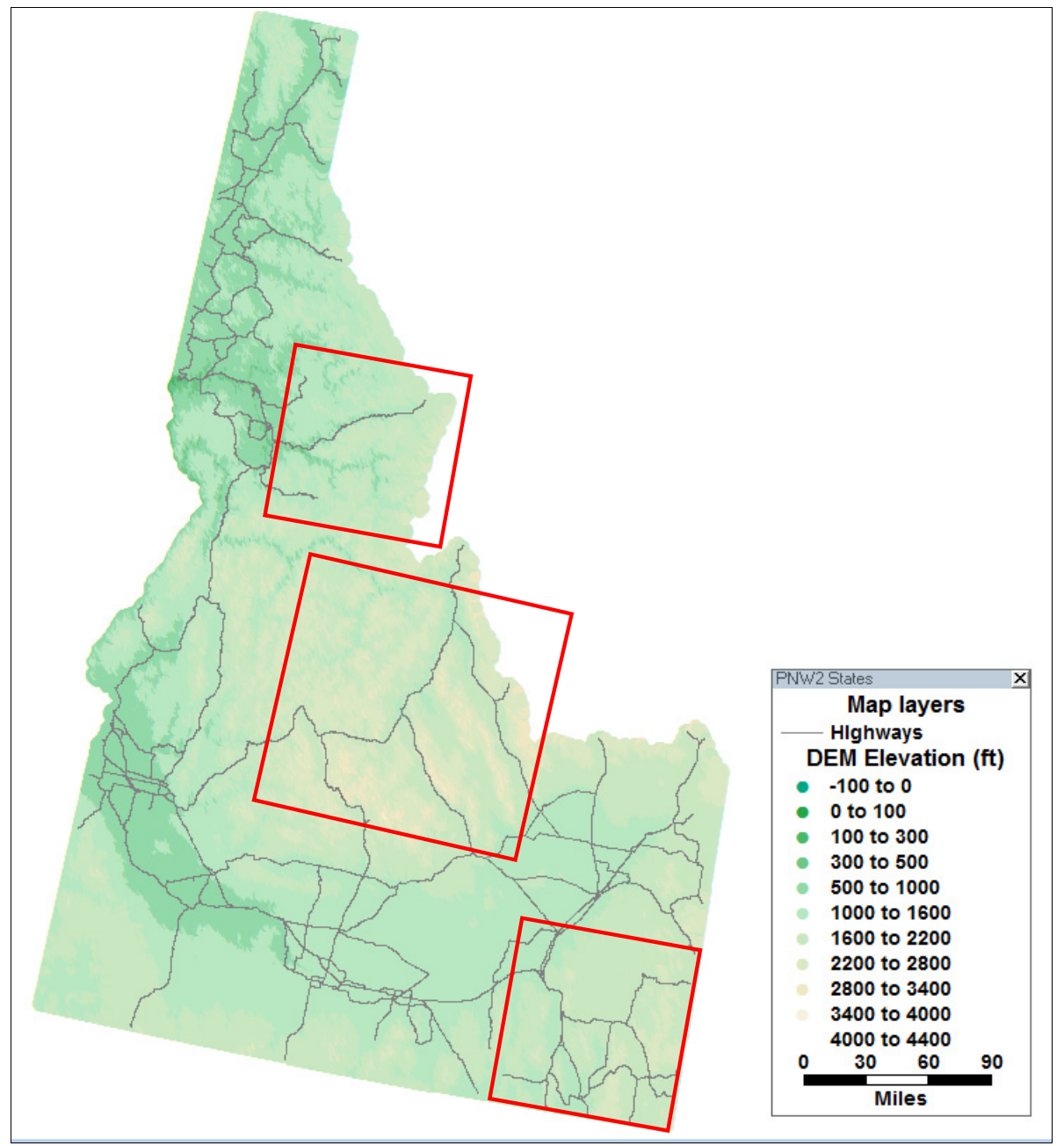

Figure 77 - DEM and Highways of Idaho 
Figure 78 shows the map of average December precipitation in Idaho. The three highlighted squares correspond to the locations with significant numbers of landslides identified in the map of Landslides in Idaho. Figure 78 shows that most landslides in Idaho occurred in areas with average December precipitation of 2 inches and above.

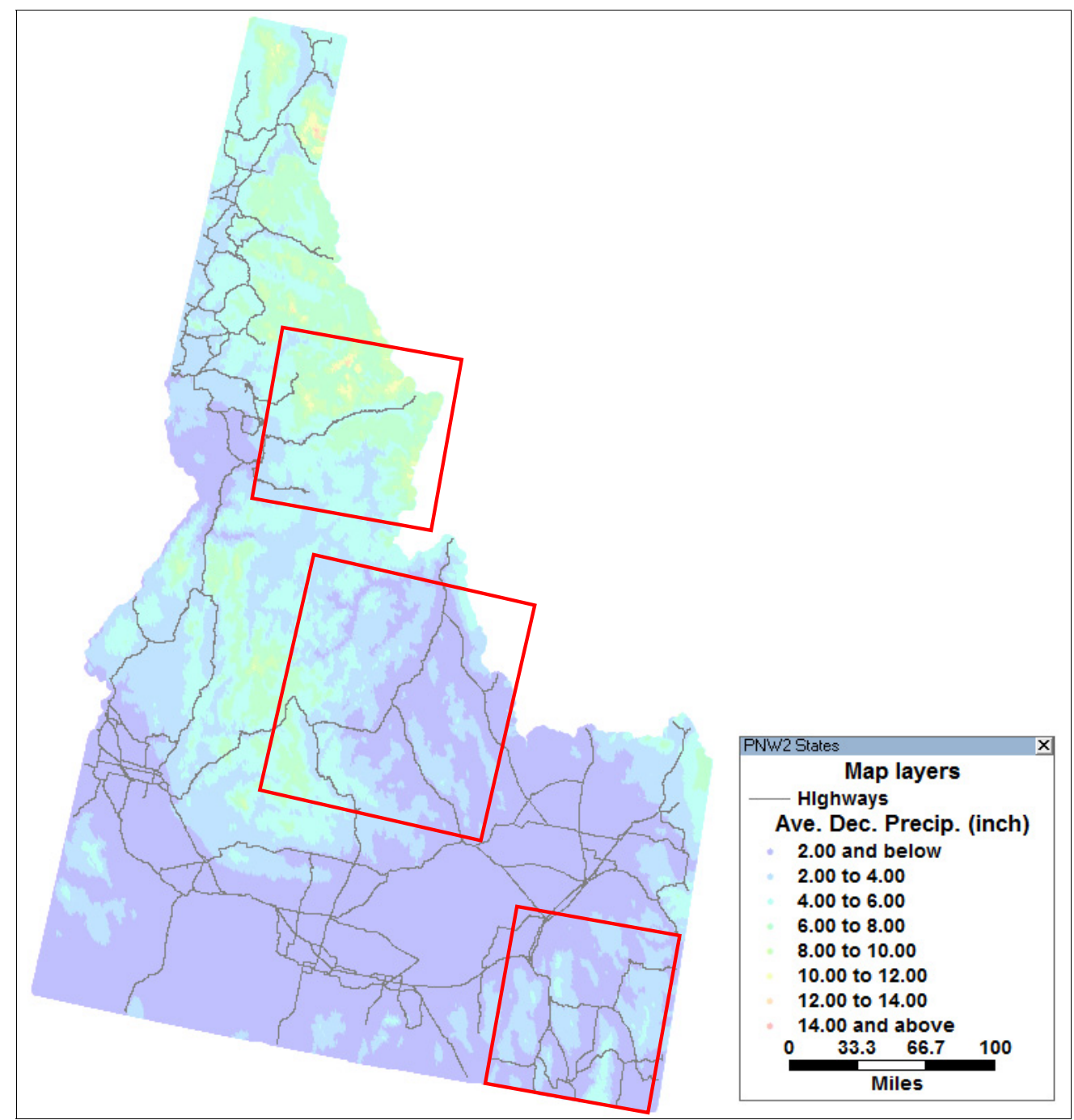

Figure 78 - Average December Precipitation and Highways in Idaho 
Figure 79 shows areas in Idaho where the average December Precipitation is over 2 inches. By comparing these areas with the map of Landslides in Idaho, it can be seen that the highlighted areas cover majority of the landslides in Idaho.

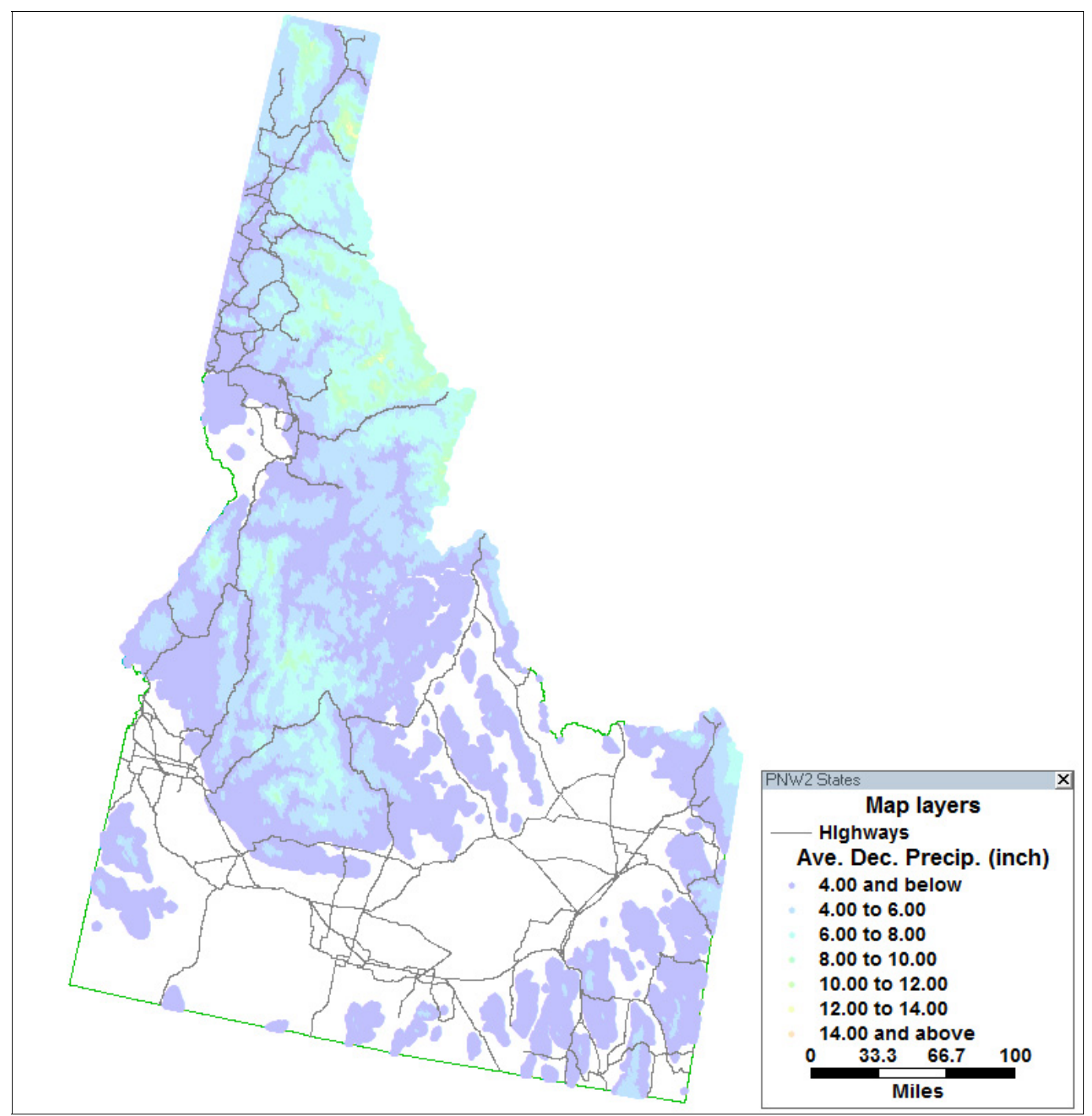

Figure 79 - Areas with Over 2 Inch Average December Precipitation in Idaho

Figure 80 shows the highways located in the areas with over 2 inches of average December precipitation. Table 36 shows the distribution by the importance criteria of transportation facilities in the identified critical areas to landslides. A small proportion of 
interstate highways are located in the landslide prone areas in Idaho. Note that the highways located in the critical areas account for $56 \%$ of total mileage of highways at these functional classes (i.e., approximately 5,185 miles) in Idaho. Railroads in these areas account for $58 \%$ of all railroad mileage in Idaho, while these airports represent $70 \%$ of all Idaho airports.

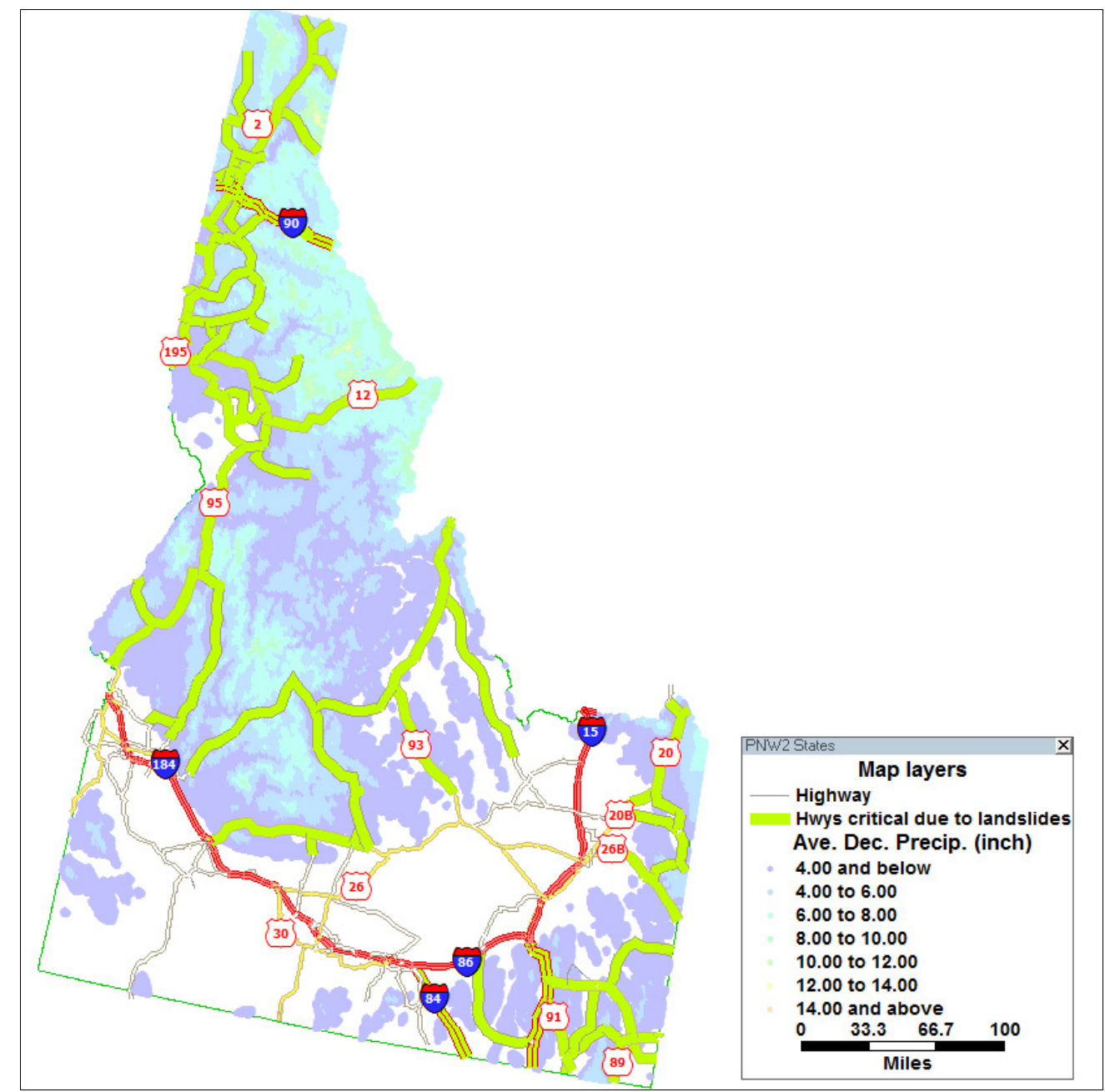

Figure 80 - Highways Located in Areas with Over 2 Inch Average December Precipitation in Idaho 
Table 36 - Roadways, Railroads, and Airports Subject to Landslide Damages in Idaho

\begin{tabular}{|lcc|}
\hline Functional Class & Total Miles & Percent \\
\hline Railroad Usage & Total Miles & Percent \\
\hline Rural Interstate & 172 & $5.94 \%$ \\
\hline Rural Minor Arterial & 791 & $27.26 \%$ \\
\hline Rural Principal Arterial & 1,214 & $41.81 \%$ \\
\hline Unknown & 682 & $23.51 \%$ \\
\hline Urban Interstate & 21 & $0.74 \%$ \\
\hline Urban Principal Arterial & 21 & $0.75 \%$ \\
\hline Highway Total & $\mathbf{2 , 9 0 5}$ & $\mathbf{1 0 0 . 0 0 \%}$ \\
\hline Railroad Usage & Total Miles & Percent \\
\hline Passenger & 120 & $12 \%$ \\
\hline Non Passenger & 853 & $88 \%$ \\
\hline Railroad Total & $\mathbf{9 7 3}$ & $\mathbf{1 0 0 \%}$ \\
\hline Airport Usage & Total \# & Percent \\
\hline Private & 108 & $57 \%$ \\
\hline Public & 81 & $43 \%$ \\
\hline Airport Total & $\mathbf{1 8 9}$ & $\mathbf{1 0 0 \%}$ \\
\hline
\end{tabular}

\section{Impacts of Increased Summer Temperature}

To identify critical infrastructure under the threat of increased temperature, the summer maximum temperature zones were overlaid on top of the infrastructure layers (Figure 81). Based on the aforementioned temperature and precipitation maps obtained from the PRISM group, the areas with high summer temperature are located in southeastern Oregon and southern Idaho, where summer precipitation also tends to be low. The infrastructure located within high temperature zones are likely to sustain higher risks of wildfire in the future. The maintenance cost for these facilities may also increase due to heat induced damages. 


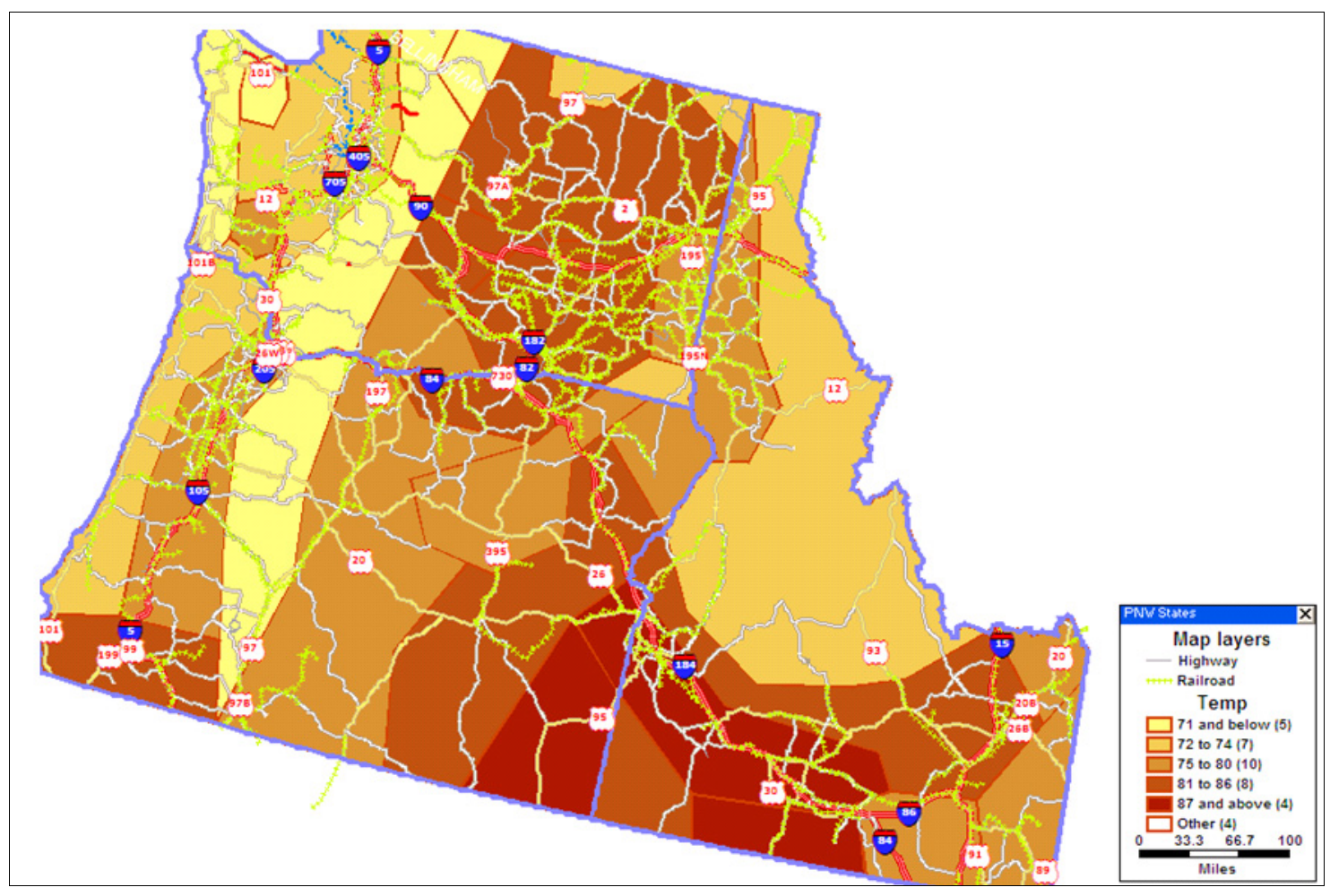

Figure 81 - July Mean Maximum Temperature (1971-2000) with the Highway Network of the Pacific Northwest

One potential way to predict impacts of future climate change, such as temperature fluctuations on construction practices, are to use existing models, such as the Mechanistic-Empirical Pavement Design Guide (MEPDG), that incorporate historical or current environmental conditions to predict certain engineering properties. Often, these programs rely on coded historical climate data such as temperature, rainfall, wind speed, relative humidity, etc. and these data files can be easily updated to include future climate change projects to allow for advanced risk management and asset management adaptation strategies. Another example is Texas Concreteworks that enables practitioners to predict when maximum temperature rise in a concrete element and temperature differential from the center of a hydrating element to the exterior will occur during the exothermic reaction of cement hydration. This process may be exacerbated by potential climate change, 206 
specifically an increase in temperature that could result in increasing concrete hydration temperatures and subsequently presenting the increased risk of cracking and/or durability problems. If these increases can be predicted, modifications to concrete placing/curing can be incorporated to reduce overall temperature increase and temperature differentials to safe levels.

\section{FHWA Conceptual Model Application for Alaska}

Due to Alaska's unique geography and climate challenges, the application of FHWA's conceptual model to the state requires different consideration than the other three states in the Pacific Northwest. The same analytical process performed for the three states in the Pacific Northwest cannot be repeated for Alaska with the same level of detail due to three following major differences:

\section{Presence of permafrost}

Much of Alaska's infrastructure is built on permafrost (i.e., permanently frozen ground). Increases in average temperature have caused thawing of permafrost in some areas of Alaska, which will continually cause the failing of roadways, infrastructure and foundations to fail.

2. Sparse surface network coverage

With a land area of over 586,400 square miles, Alaska only has approximately 3,700 miles of roads that carry the designation of interstates or state routes, excluding roads that primarily provide only local access. Although traffic volumes on these roads are much lower than similar roads in other PNW states, 
each link in Alaska's major roadway network is considered critical due to the lack of alternative routes.

\section{Data limitation}

Due to the extremely low ratio of human resources to natural resources, data available for our analysis of Alaska are limited. For example, most of tide station data maintained by National Ocean Services (NOS) along Alaska's coastline do not include the height of the tide stations according to the North American Vertical Datum of 1988 (NAVD 88). The lack of NAVD 88 numbers makes estimation of existing height of sea level relative to the elevation of coastal land difficult. It is also important to note that much the Alaskan coastline is tectonically very dynamic and thus a simple one time establishment of the NVD of a site would mean little. This also means that climate change related changes in relative sea-level will be augmented, or diminished, by tectonic changes in relative sea-level.

Inventory of Assets

Data used to identify transportation infrastructure in Alaska come from different sources. Alaska State Geo-spatial Data Clearinghouse (ASGDC), a service provided by the Alaska Department of Natural Resources, supplied most of the data. The data include:

- Highways, major and secondary roads

- Railroads

- Airports

- Ferry ports. 
Data obtained from ASGDC mostly identify the geographic shapes and locations of the infrastructure. GIS data from Caliper Corp. was also used to supplement the database. Caliper's data contain attributes of the infrastructure from sources such as FHWA, FAA, and the Bureau of Transportation Statistics.

\section{Interstate and State Routes}

Unlike the analysis performed for the three Pacific Northwest states, only functional classification was used as the criterion for assessing the importance of a road. Traffic volumes on the roads are not considered, due to limited traffic data in GIS format. Roads falling in the "Other" categories are mostly roads classified by Alaska Department of Transportation and Public Facilities as collector roads.

\section{Table 37 - Functional Class Distribution of Interstate and State Routes in Alaska}

\begin{tabular}{|lrr|}
\hline Functional Class & Total Mileage & Percent \\
\hline Rural Interstate & 1,020 & $28 \%$ \\
\hline Rural Minor Arterial & 1,120 & $30 \%$ \\
\hline Rural Principal Arterial & 307 & $8 \%$ \\
\hline Urban Interstate & 62 & $2 \%$ \\
\hline Urban Principal Arterial & 67 & $2 \%$ \\
\hline Other & 1,121 & $30 \%$ \\
\hline Total & 3,697 & $100 \%$ \\
\hline
\end{tabular}

\section{Railroads}

Table 38 shows the railroad data are from the ASGDC. There are approximately 800 miles of railroads in Alaska. The Alaska Railroad company operates close to 600 miles of railroads, which run between Anchorage and Fairbanks, providing freight and 
passenger services. The Alaska Railroad are considered more important following FHWA framework criteria.

Table 38 - Railroads in Alaska

\begin{tabular}{|l|r|r|}
\hline Railroad Names & Total Mileage & Percent \\
\hline ABANDONED & 54 & $7 \%$ \\
\hline N/A & 124 & $15 \%$ \\
\hline THE ALASKA RAILROAD & 591 & $74 \%$ \\
\hline WHITE PASS AND YUKON & 25 & $3 \%$ \\
\hline YAKUTAT AND SOUTHERN & 10 & $1 \%$ \\
\hline Total & 804 & $100 \%$ \\
\hline
\end{tabular}

Airports

To identify airport locations in Alaska, we use Caliper's Airport GIS data, because the same data from ASGDC have no information other than the locations of the airports. We consider public airports to be important (see Table 39), because these airports provide the only transportation for many Alaska villages.

\section{Table 39 - Airport Ownership in Alaska}

\begin{tabular}{|lr|}
\hline Owner & Total \\
\hline Air Force & 15 \\
\hline Army & 6 \\
\hline Navy & 1 \\
\hline Private & 49 \\
\hline Public & 365 \\
\hline Total & 436 \\
\hline
\end{tabular}

Ferry Ports

A total of 29 ferry ports (see Figure 82) and the routes among them are identified from ASGDC database. Due to the lack of North American Vertical Datum (NAVD 88) data for most of NOS tide stations along Alaska coastline, projection of SLR extent cannot be made for Alaska, except for a limited analysis along the western shore of Kenai Peninsula and Cook Inlet near Anchorage (see sea level analysis in Climate Information). 


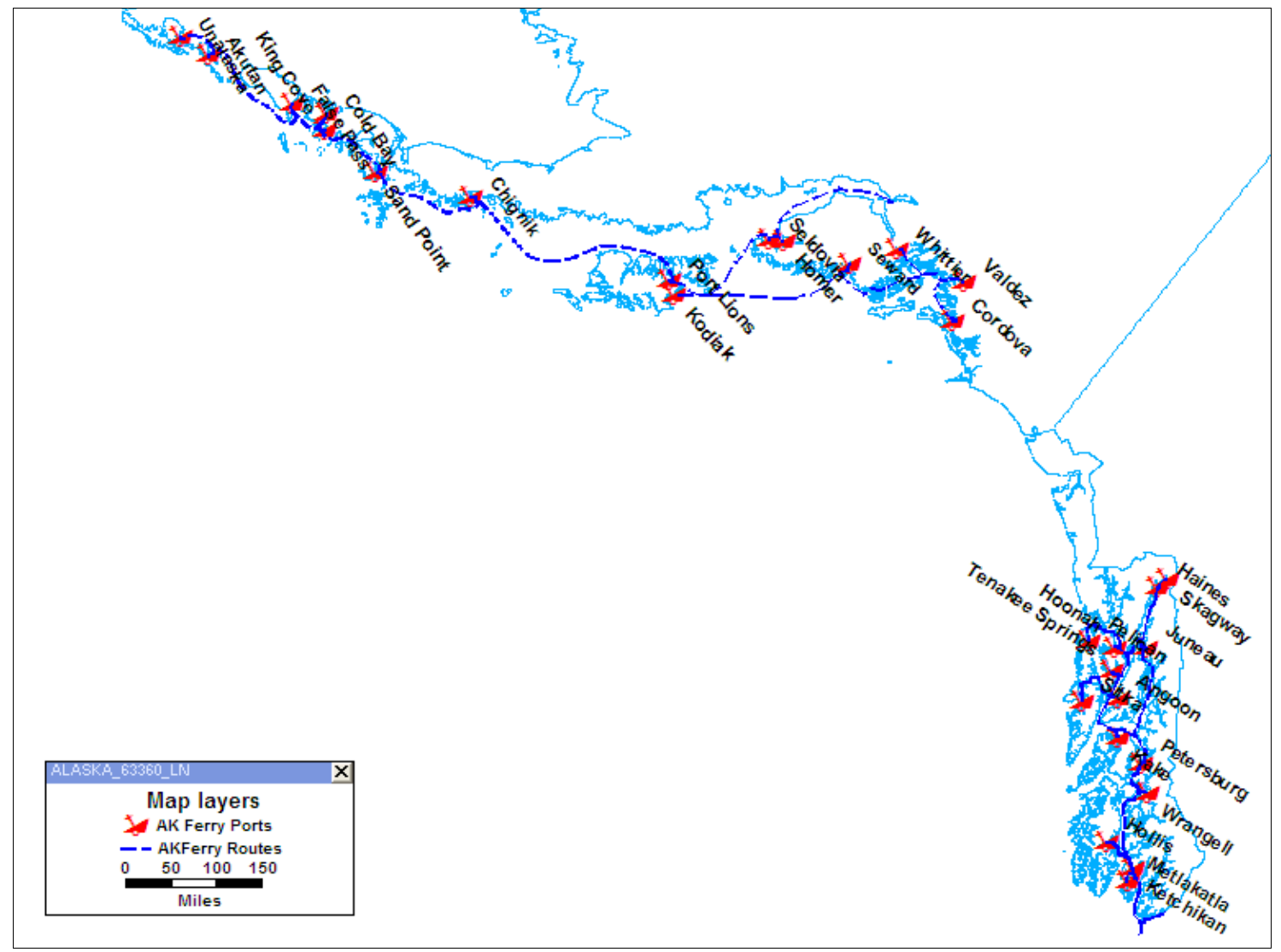

Figure 82 - Ferry Ports and Routes in Alaska

\section{Climate Information}

Permafrost

Figure 83 shows the locations of different types of permafrost in Alaska. The data are obtained from National Snow and Ice Data Center at the University of Colorado. Permafrost existence in the circum-arctic region of Alaska can be categorized as Continuous (90-100\% of the ground soil is permanently frozen), Discontinuous (5090\%), Sporadic (10-50\%), and Isolated Patches (0-10\%). The areas marked as "other" are those that no permafrost existence is identified. 


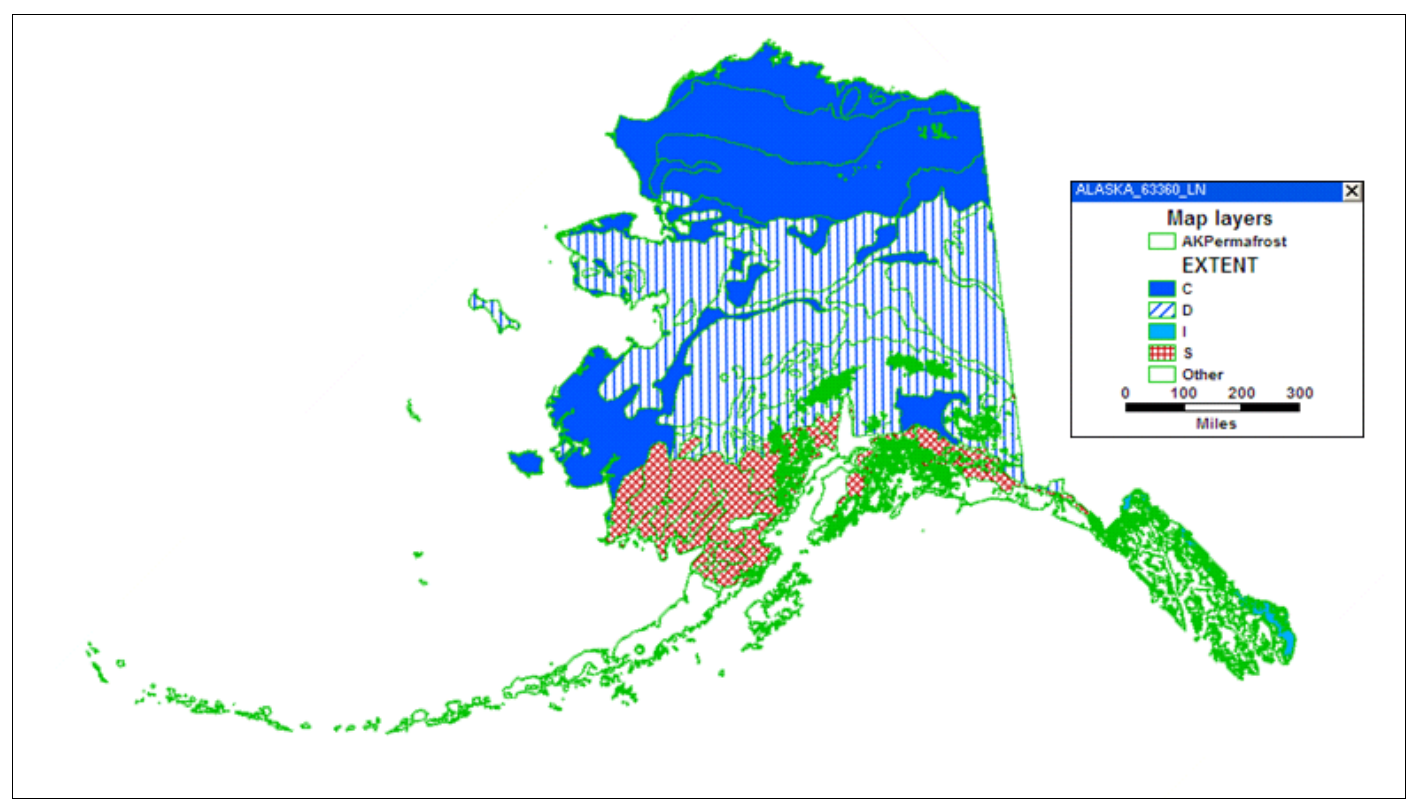

Figure 83 - Permafrost Locations in Alaska

\section{$\underline{\text { Sea Level Rise }}$}

To follow the same modeling approach performed for the coastal region in Pacific Northwest, NOS' tide stations along the Alaska coastline are identified. Originally, we intend to carry the analysis for the coastal regions of Cook Inlet and Southeast Alaska, because these two regions have transportation infrastructures near the coastlines. However, most of the tide stations in these waters do not have the NAVD 88 data. Without the vertical datum, the height of the high tide relative to the coastal land cannot be identified. We only managed to retrieve complete tidal data for four stations: Anchorage, Nikiski, Whittier, and Homer. Figure 84 shows the locations of the four stations and the heights (i.e., MHHW - NAVD 88 in feet) of the Mean Higher High Water (MHHW) relative to NAVD 88. 


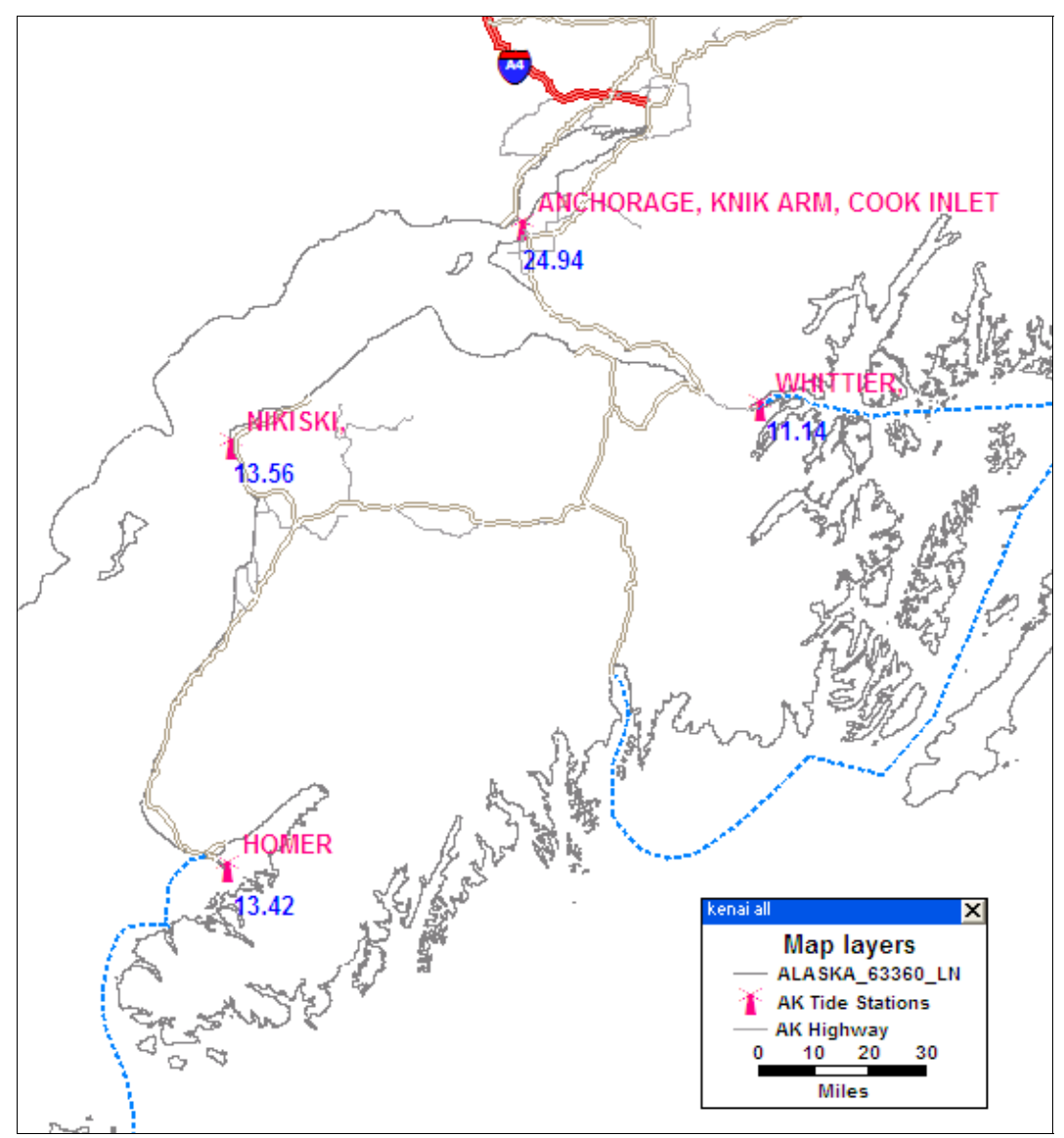

\section{Figure 84 - Four National Ocean Service Tide Stations with Complete Data Thawing Index}

Thawing index is the degree-days when temperature is above freezing $\left(32^{\circ} \mathrm{F}\right)$ for

one year. Thawing index is simply the yearly summation of the daily air temperatures over those days when temperature is over $32^{\circ} \mathrm{F}$ (Frauenfeld 2007). Thawing index is the most relevant climate variable determining the thawing of permafrost. The indices are calculated from temperature data obtained from the Alaska Climate Research Center, a research and service organization at the Geophysical Institute, University of Alaska Fairbanks. Figure 85 shows the weather stations providing data on average temperature and the number of days in a year when temperatures are above $32^{\circ} \mathrm{F}$. The data are the 
averages from 1971 to 2000 . The data layer Alaska_63360_Ln identifies the state boundary.

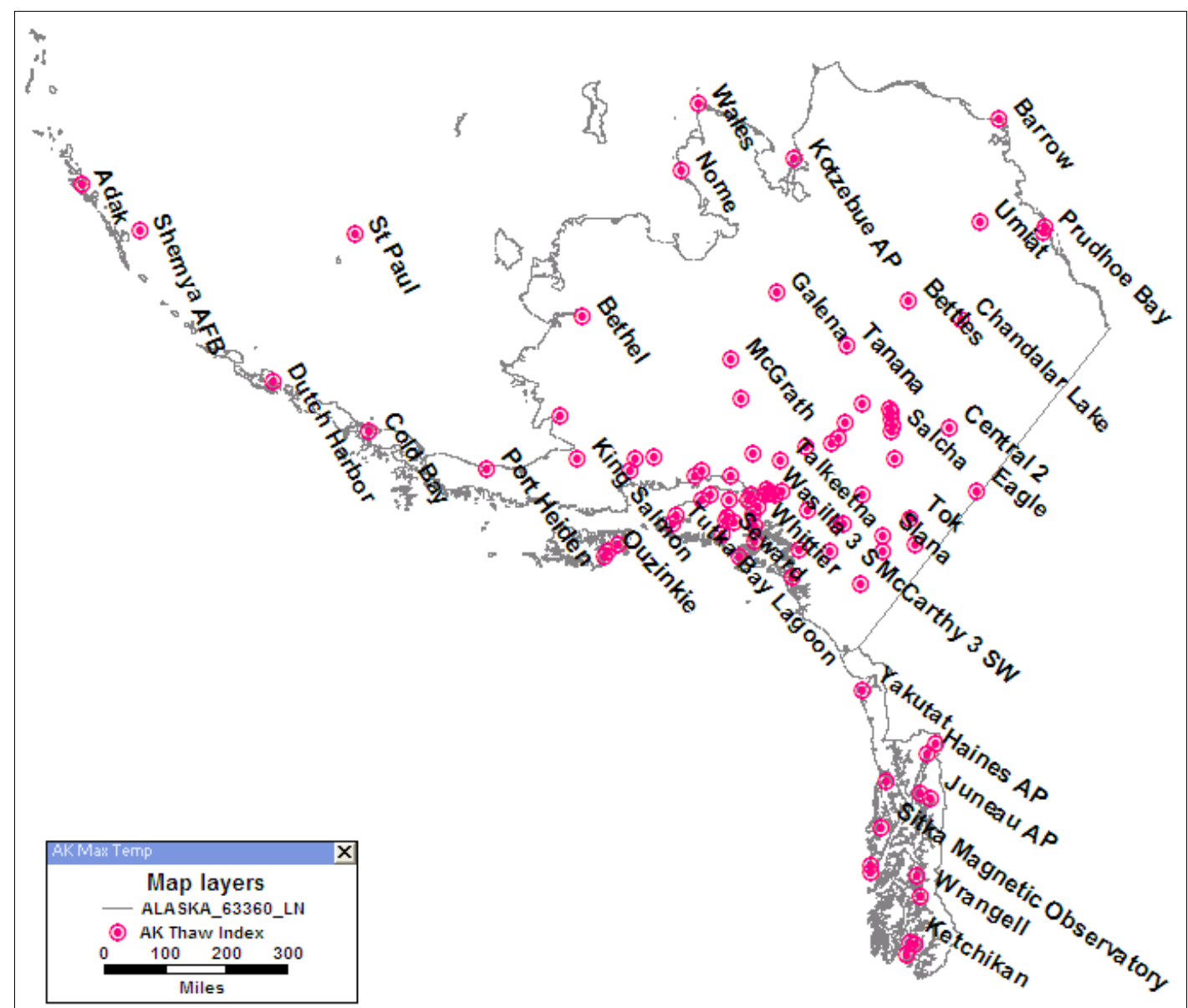

Figure 85 - Weather Stations Providing Thawing Index Data

The calculated thawing indices were used for all weather stations to create thawing index contours for the entire state of Alaska (see Figure 86). A comparison between the contours and the thawing index contours from the Environmental Atlas of Alaska of 1969 verifies that the contours in Figure 86 are reasonable. Fairbanks and Anchorage are in the $3000\left({ }^{\circ} \mathrm{F}\right.$-days) range, Barrow 500, Nome 2000, and Juneau 4000. 


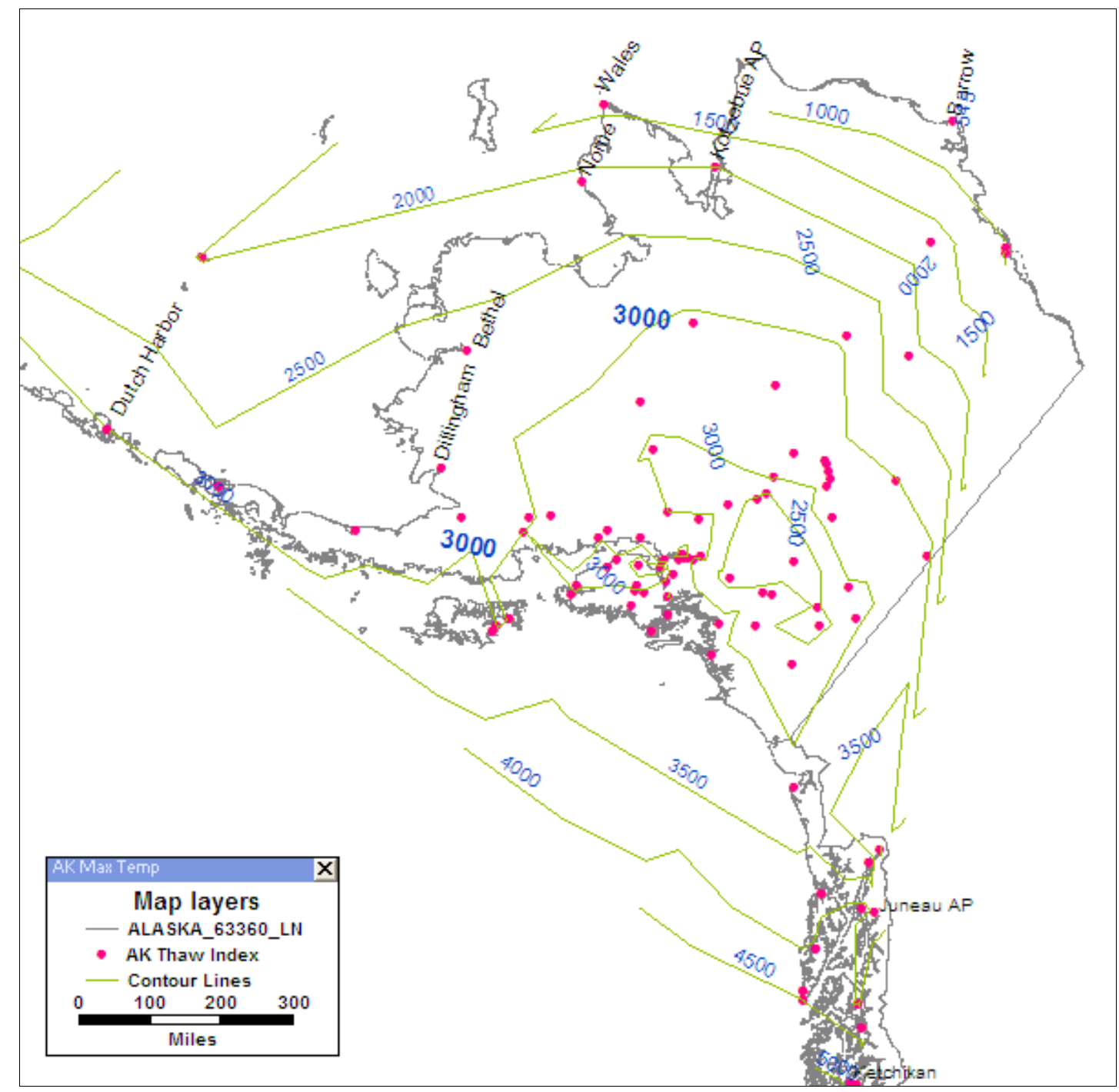

Figure 86 - Thawing Index Contours

\section{$\underline{\text { Mean Precipitation }}$}

Mean monthly precipitation data for the state of Alaska are also obtained from the Alaska Climate Research Center based on the same set of weather stations shown in Figure 87. Triangulated Irregular Network (TIN) surfaces are created from all the stations based on the maximum monthly precipitation. From the TINs, we identify contour areas with equal ranges of precipitation. 


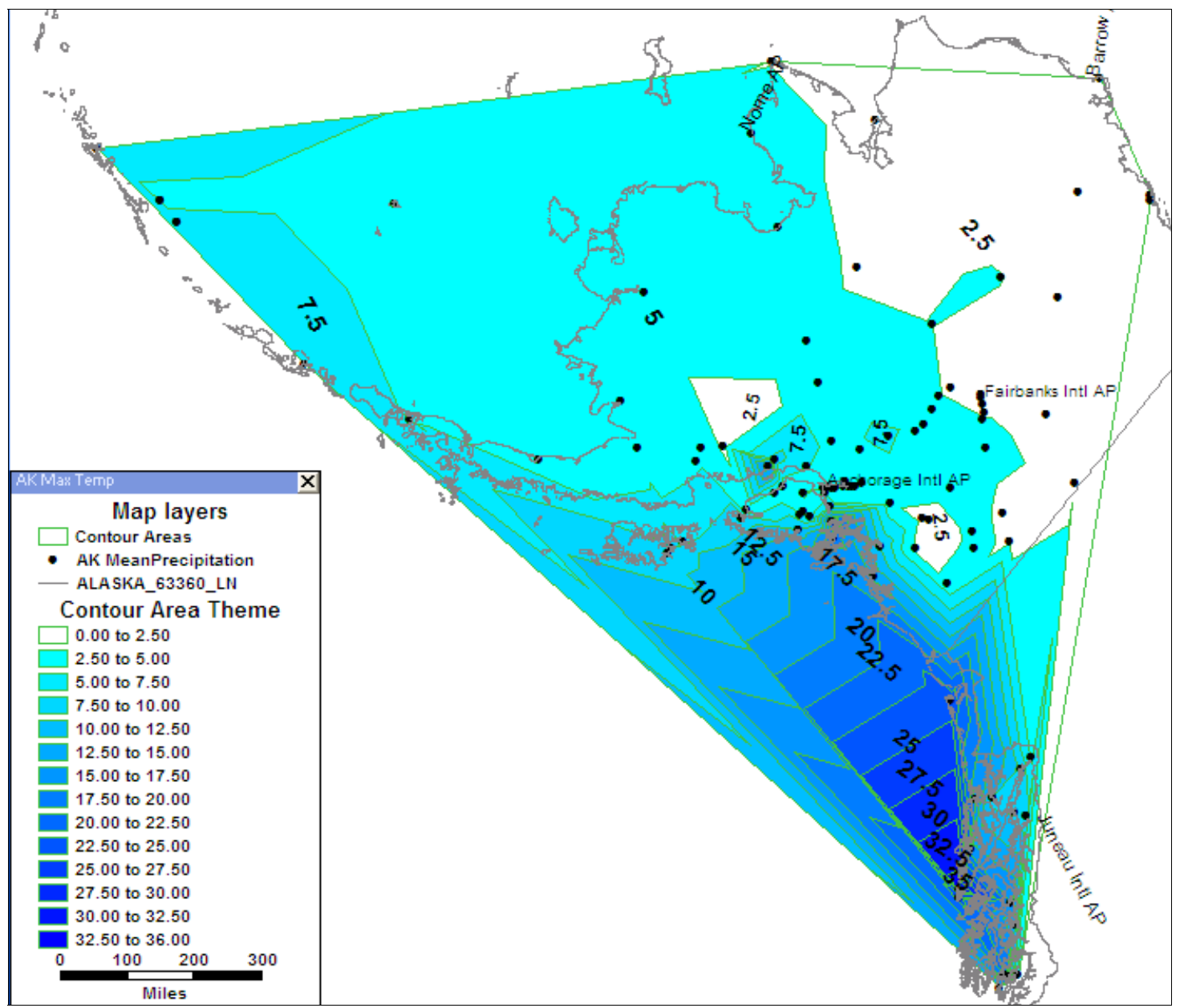

Figure 87 - Contour areas of Maximum Monthly Precipitation in Inches FEMA Q3 Data

Although the Municipality of Anchorage maintains a successful floodplain management program, Anchorage's floodplains data are still in scanned PDF format, which cannot facilitate a GIS analysis. The only municipality in Alaska with FEMA's digital flood Q3 data is the Fairbanks North Star Borough (FNSB). Figure 88 shows an overlay of the highway network on top of the floodplains. It appears that a portion of the Richardson Highway (Alaska State Route 2) is in close proximity of the 100 year floodplain, while George Parks Highway (Alaska State Route 3) runs through the 500 year floodplain. 


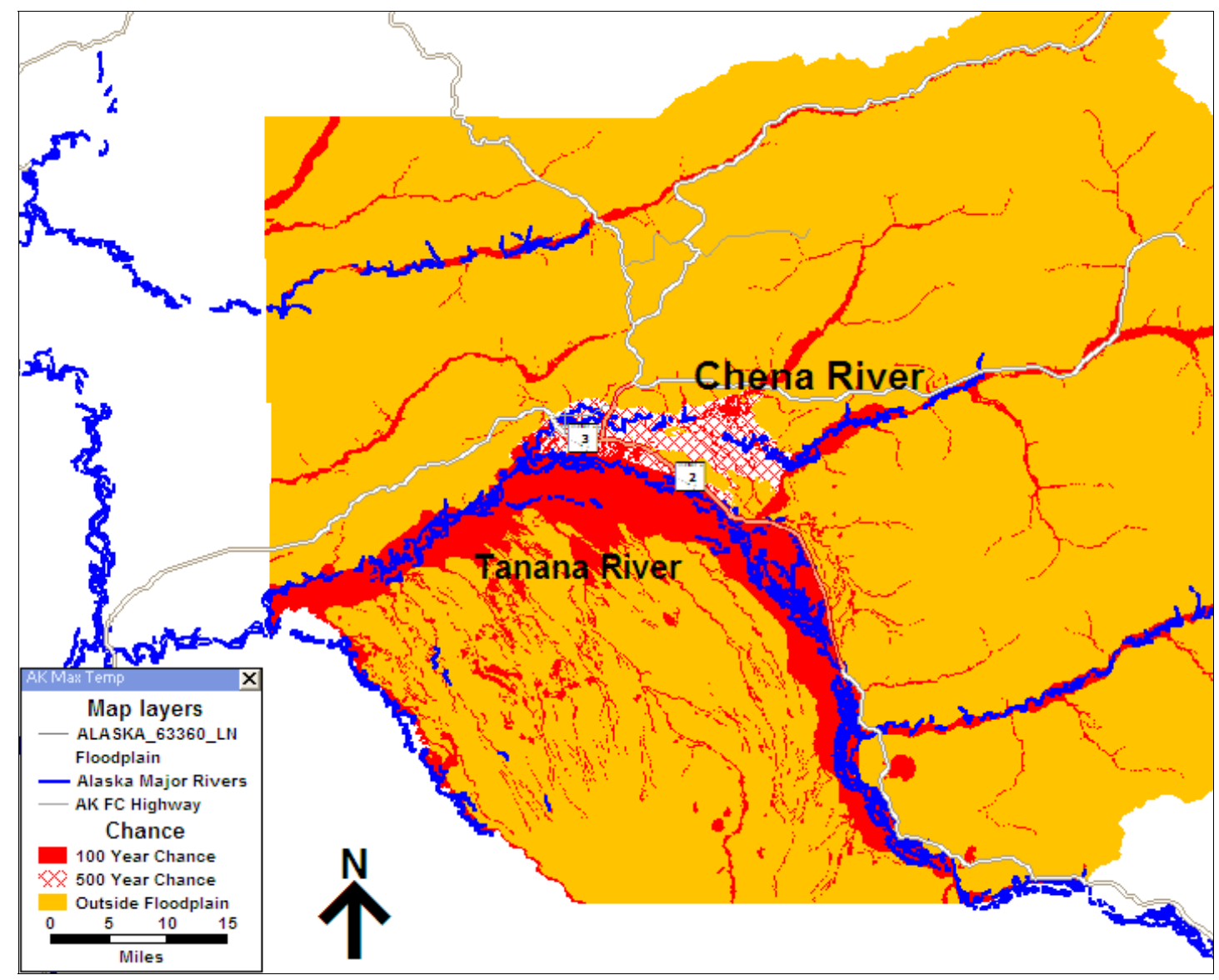

Figure 88 - FEMA's Floodplains in FNSB Major Rivers

Data for the identification of major rivers in Alaska are derived from the Alaska State Geo-spatial Data Clearinghouse (ASGDC). The major river locations are used to identify highways in close proximity of the rivers (Figure 89). These highways are at a greater risk for flooding events than highways away from rivers. 


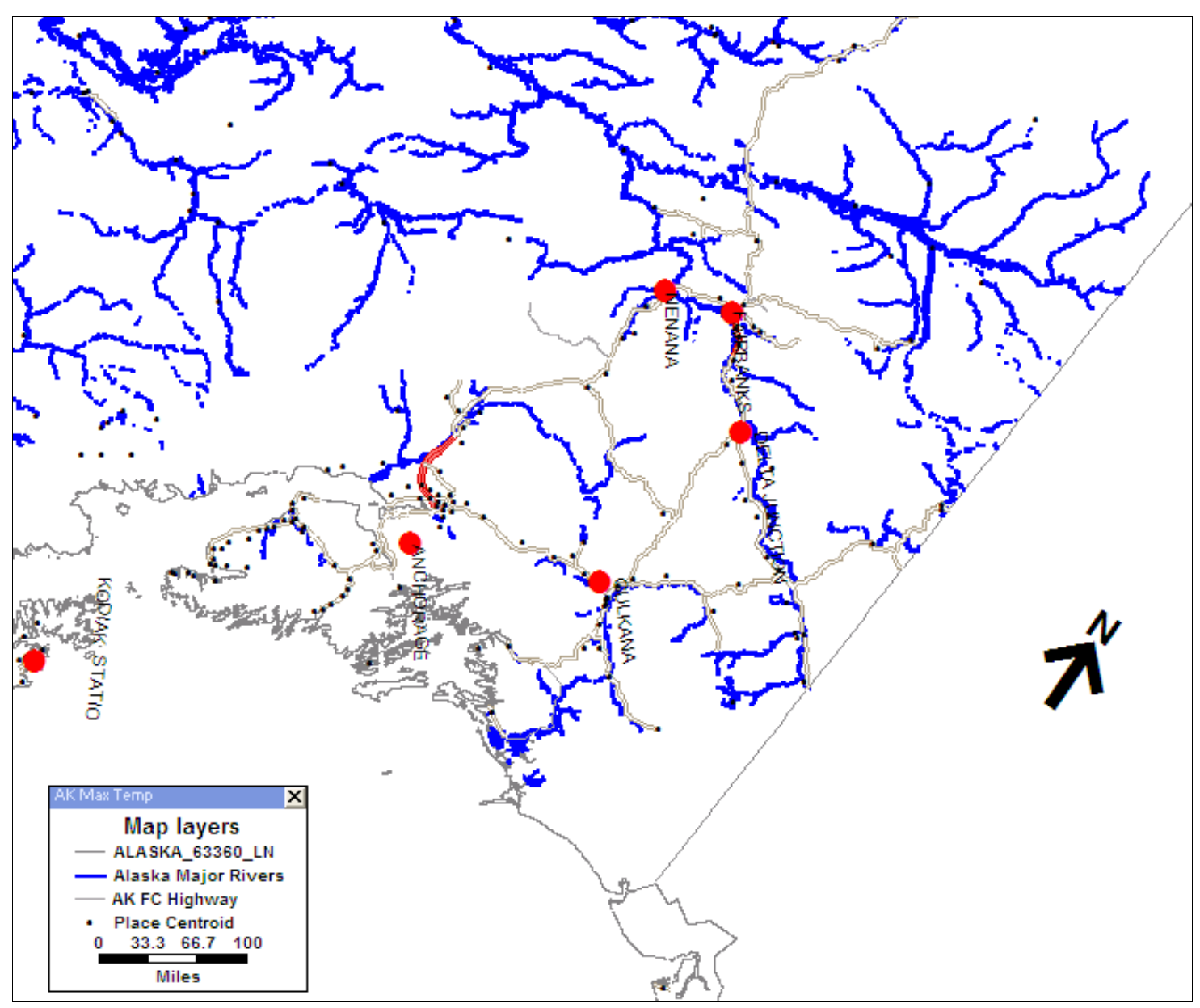

Figure 89 - Major Rivers and Alaska Highway Network

\section{Climate Change Risk Assessment}

Melting of Permafrost

By overlaying the highway network on top of the permafrost location layer, the distribution of highways in different permafrost zones was obtained (see Table 40). The Dalton Highway that reaches the Prudhoe Bay oil field accounts for most of the mileages in the continuous permafrost zones. 
Table 40 - Alaska Highway Mileage Distribution by Permafrost Types

\begin{tabular}{|lcc|}
\hline Permafrost Type & Total Miles & Percent total \\
\hline Continuous & 589 & $16 \%$ \\
\hline Discontinuous & 1,894 & $51 \%$ \\
\hline Isolated Patches & 14 & $<1 \%$ \\
\hline Sporadic & 267 & $7 \%$ \\
\hline None & 933 & $25 \%$ \\
\hline Total & 3,697 & $100 \%$ \\
\hline
\end{tabular}

If temperature continues to rise, permafrost in the presence high thawing index has higher chance of melting than areas with low thawing index. The thawing index contours are superimposed on top of the permafrost zones and identify the areas with discontinuous permafrost and thawing index over 3000 ( ${ }^{\circ} \mathrm{F}$-days). The area of high melting risk is shown in Figure 90. The map allows us to identify the mileage distribution of the highways located within this high melting risk area (i.e., discontinuous permafrost and thawing index $>3,000)$. Table 41 shows the results of this analysis. The George Parks Highway accounts for majority of the interstate mileage in the high melting risk area. The Steese, Richardson, and Alaska highways account for most of the rural principal and minor arterial portion. We also identify 64 airports and over 90 miles of the Alaska Railroad in the high melting risk area. 


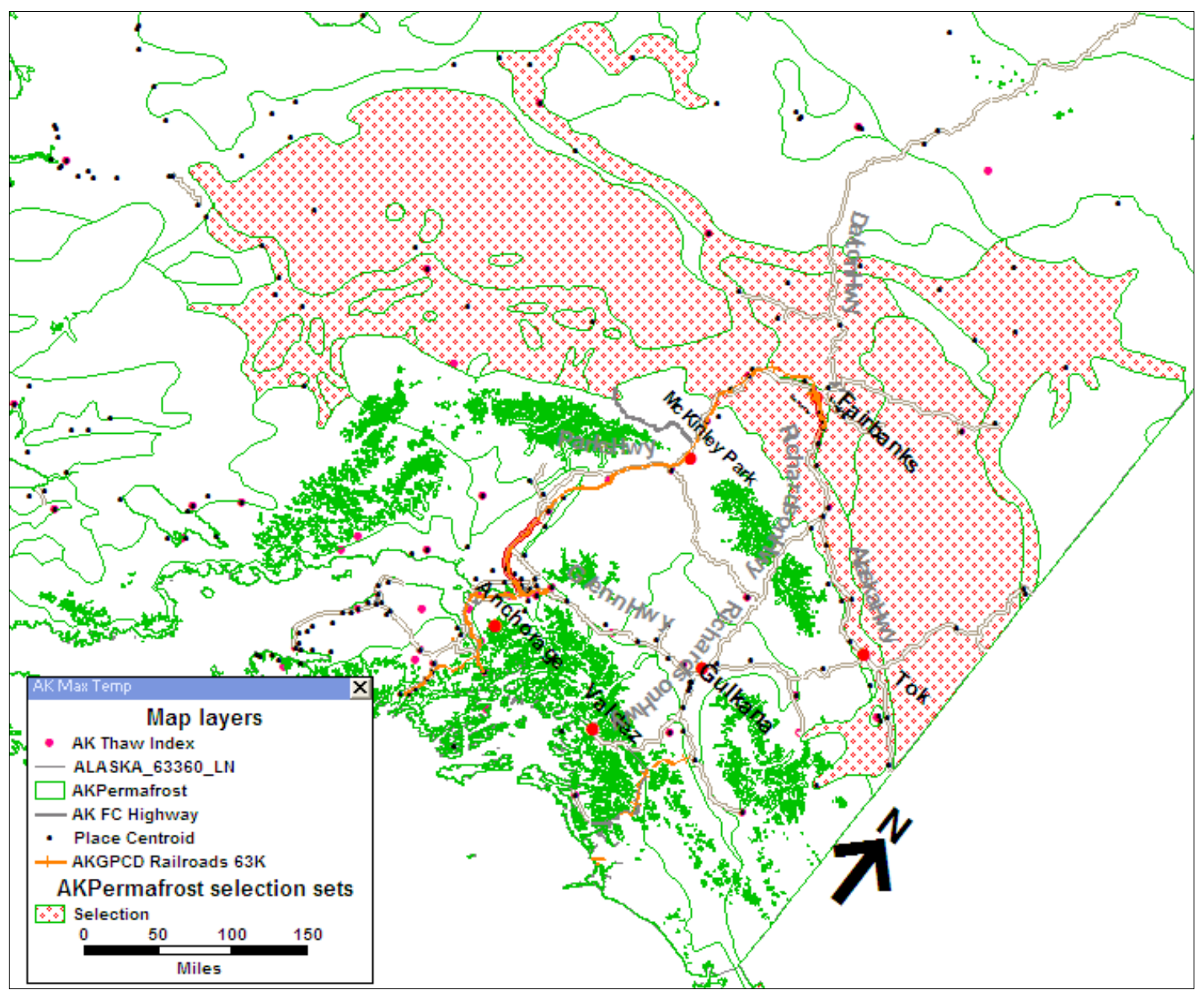

Figure 90 - Discontinuous Permafrost Areas with Thawing Index greater than 3000 ( ${ }^{0}$ F-days)

Table 41 - Mileage Distribution of Highways in High Melting Risk Area (Discontinuous Permafrost with Thawing Index $>3000$ )

\begin{tabular}{|l|rr|}
\hline Functional Class & Total Miles & Percent \\
\hline Rural Interstate & 393 & $34 \%$ \\
\hline Rural Minor Arterial & 506 & $44 \%$ \\
\hline Rural Principal Arterial & 8 & $1 \%$ \\
\hline State Route & 225 & $19 \%$ \\
\hline Urban Interstate & 14 & $1 \%$ \\
\hline Urban Principal Arterial & 16 & $1 \%$ \\
\hline Total & 1,163 & $100 \%$ \\
\hline
\end{tabular}




\section{Sea Level Rise Impacts}

Due to the lack of complete tide station data (i.e., only four stations area available with NAVD referenced datums) along the coastline of Alaska, the identification of impact area due to sea level rise cannot be performed to the extent possible for the Pacific Northwest. With only three tide stations (i.e., Anchorage, Nikiski, and Homer) along the western shore of the Kenai Peninsula, we performed a simplified version of the analysis.

With no additional stations for interpolation, we use individual datum at the three stations as the current sea surface. For example, we assumed that the elevation of high tide (relative to NAVD88) along the entire coast from Nikiski to Homer to be equal to Homer's water elevation at 13.42 feet (see Figure 91). For the entire shore near Anchorage, we assume that the high tide elevation is 24.94 feet (see Figure 91), We then add the projected global sea level rise scenarios to the base elevation and assess how far inland that the water may reach, based on the simplified assumption.

We assess the impacts based on the global SLR projection range of $19 \mathrm{~cm}$ (7 inches) to $59 \mathrm{~cm}$ (23 inches) by 2100 . We analyzed two 2100 sea level rise scenarios that correspond to the two ends of the projection range: 7 inches and 23 inches by 2100 . We use one-degree DEM grids obtained from USGS for analysis. With 7 inches of SLR projected for 2100 , no noticeable change from existing conditions is expected. The results of 23 inches by 2100 are included in Figure 91 and Figure 92. The shaded DEM grids (i.e., 210023 inch SLR Extent) in these figures identify the areas where the elevations of the grids are below the projected sea level rise. Thus, the areas extending from the coastline to the shaded grids delineate the extent where regular inundation could occur, if 
no additional barrier is created. The transportation infrastructures located in close proximity of these areas are at risk.

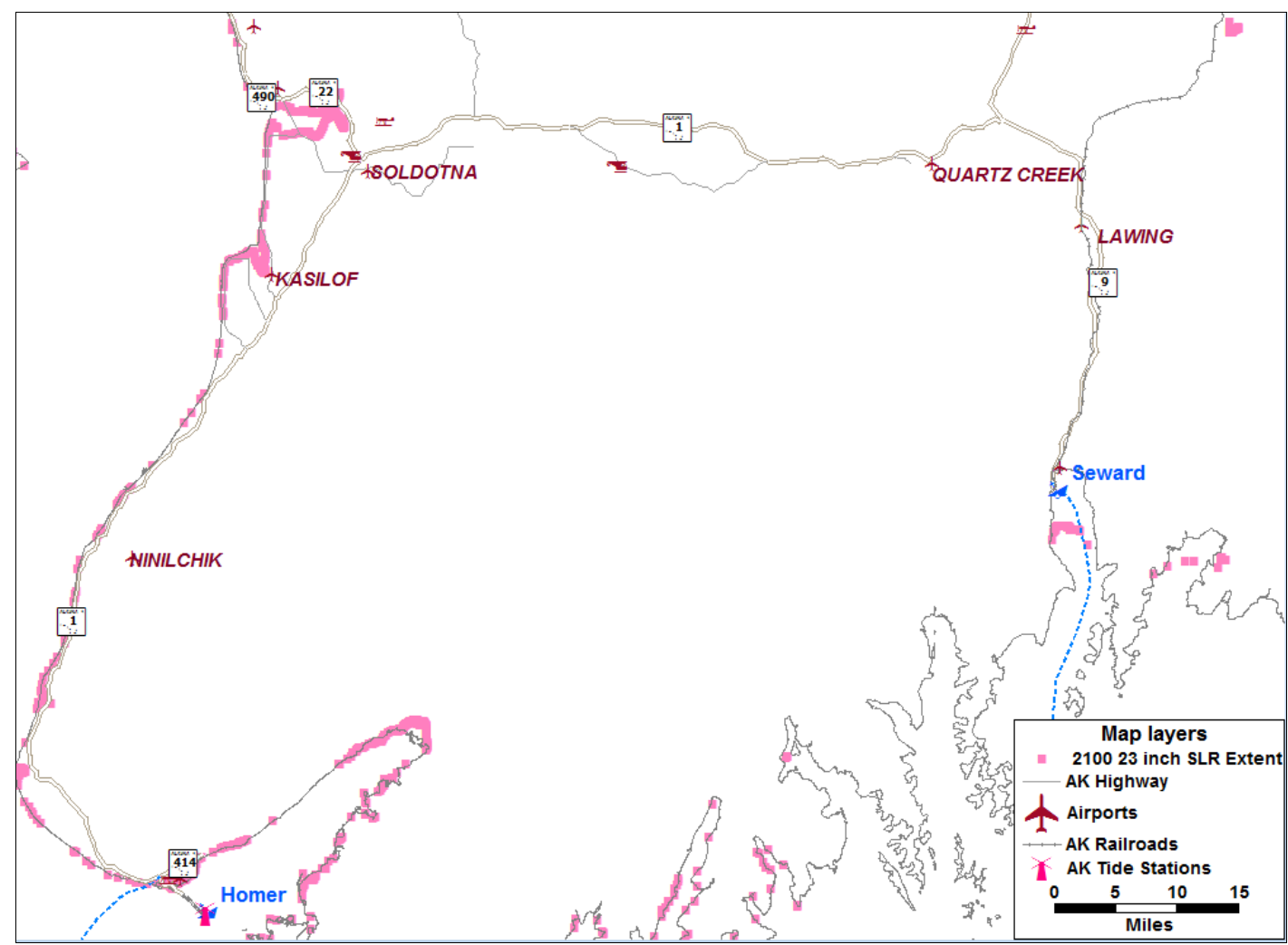

Figure 91 - Potential Inundation Area along Kenai Peninsula for Sea Level Rise Scenario: 23 inches by 2100 


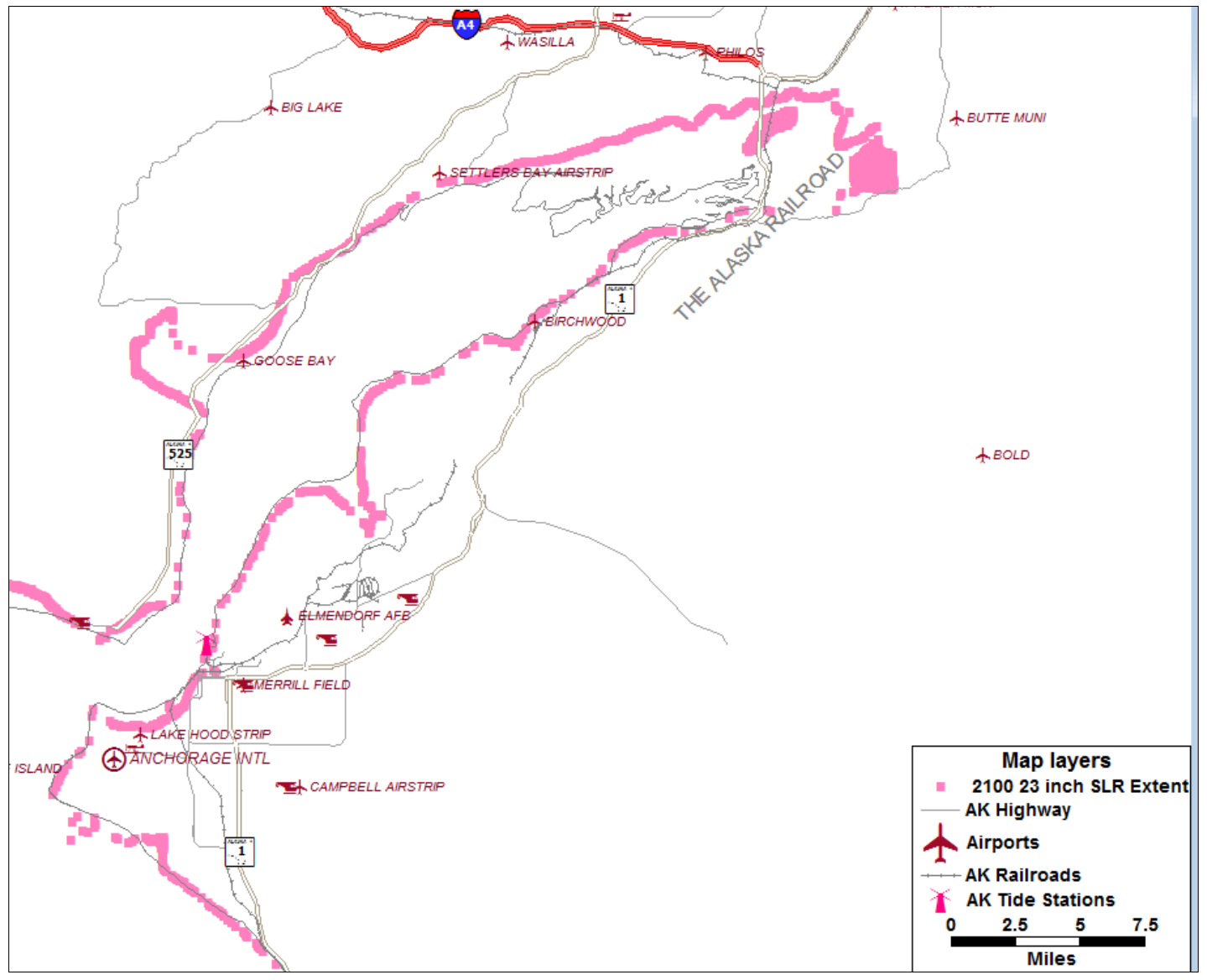

Figure 92 - Potential Inundation Area along Knik Arm for Sea Level Rise Scenario: 23 inches by 2100

\section{Flooding Events}

We identify the potential impact areas due to flooding events by using the FEMA Q3 data and a GIS layer of major rivers in Alaska. We also introduce the maximum monthly precipitation contour areas into the analysis. Figure 93 shows that the Alaska Highway between Delta Junction and the Canadian border runs along the Tanana River. The Richardson highway northerly of Delta Junction to Fairbanks also runs along the floodplain of Tanana River. A portion of the George Parks Highway southerly of 
Talkeetna runs along the Susitna River. An analysis with higher resolution data may be warranted for the highway segments that cross or are in close proximity of the rivers.

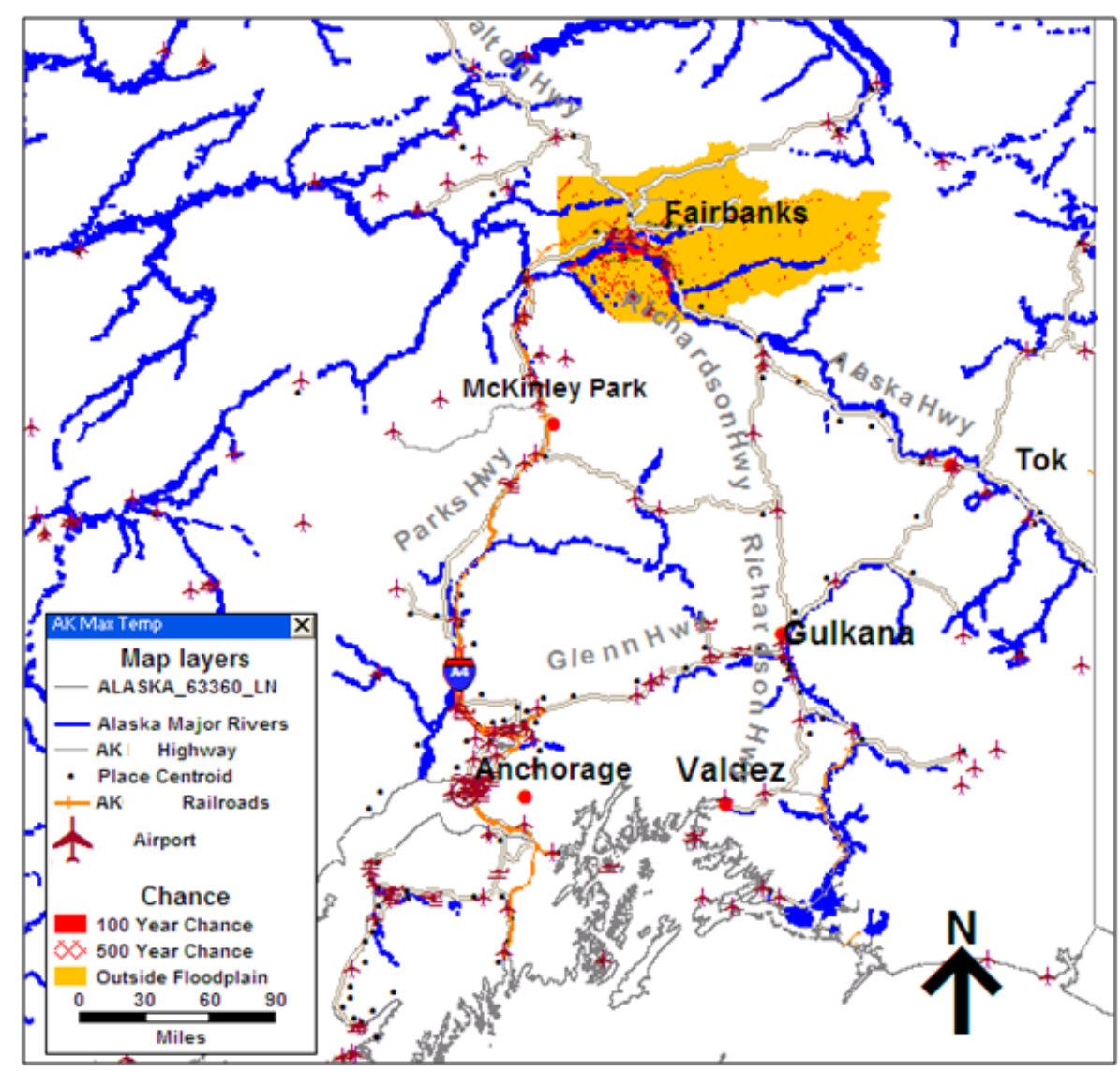

Figure 93 - The Relative Locations of Highways, Major Rivers, and FEMA Floodplain (FNSB)

Figure 94 shows that Richardson highway in the vicinity of Valdez is located in the Lowe River floodplain. The area also has high precipitation. This is the same area where a flooding event in October 2006 damaged several sections of Richardson Highway due to extreme storms. 


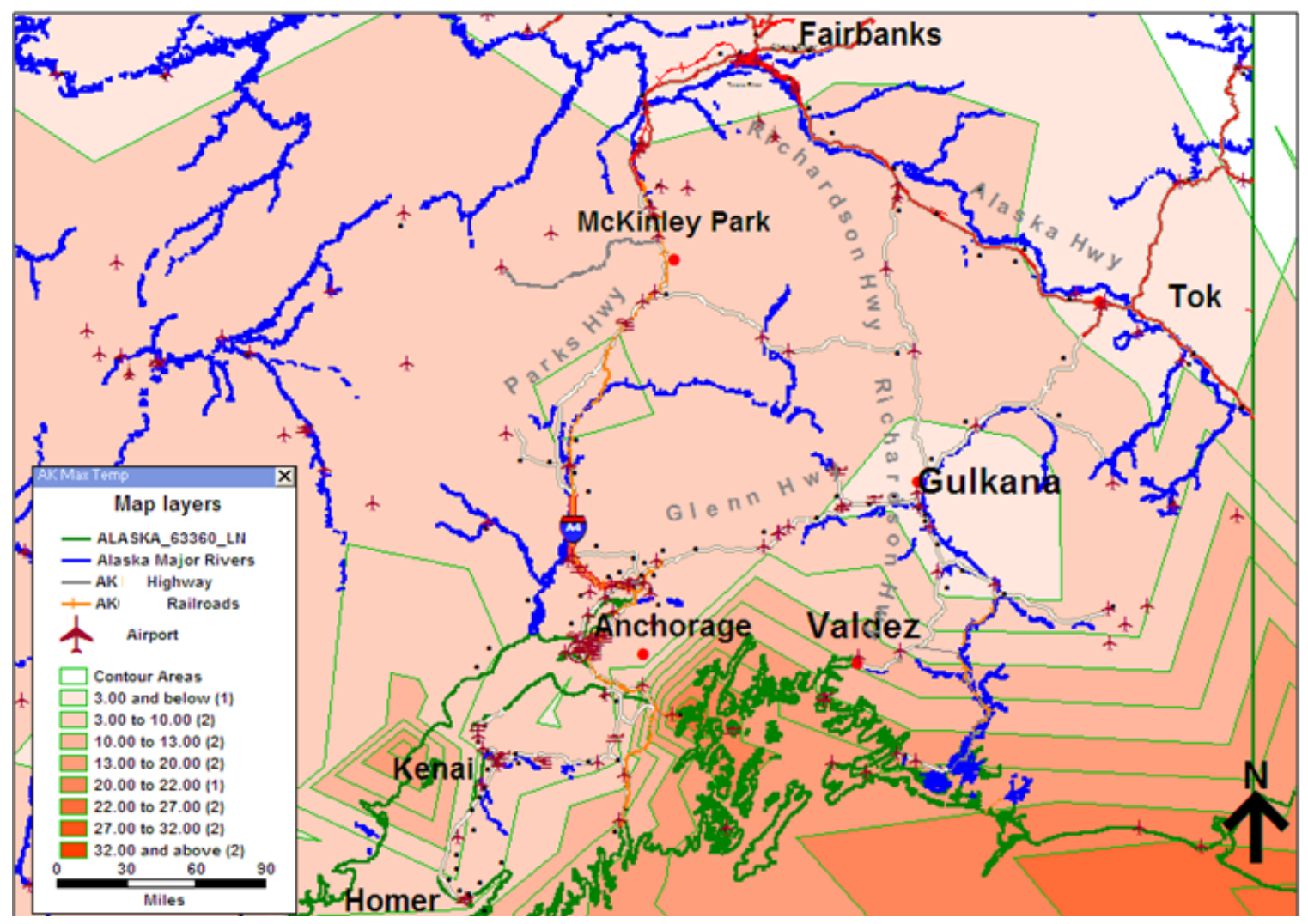

Figure 94 - Major Rivers, Highways, and Maximum Monthly Precipitation (inches) Contour Areas in the Vicinity of Prince William Sound

\section{Case Study Summary and Conclusions}

The case study followed FHWA's conceptual model to identify critical infrastructure that may be vulnerable to climate change impacts in the Pacific Northwest and Alaska. The study demonstrates that effective use of GIS and appropriate data appear to be the key to successful applications of the conceptual model. With the conclusion of this portion of the project, a comprehensive collection of GIS data is assembled that cover the four study states. It should be noted, however, that this analysis does not complete the FHWA framework for the study area. Although general areas where infrastructures are most vulnerable to climate change impacts were identified, the risk 
analysis was not carried out for the individual infrastructures within these areas. For such an analysis to be effective, more detailed, local data are needed for risk to be reasonably quantified.

The case study identifies critical transportation infrastructure associated with several climate change consequences: sea level rise, flooding events, landslides for Pacific Northwest, and permafrost melting for Alaska. The sea level rise analysis appears to result in reasonable identification of critical infrastructure in the study area. The assessment of flood risk associated with increasing rainfall intensity appears to be the most difficult due to the vast geographical coverage of this project and the large amount of hydrological data need to determine impacts. Existing FEMA floodplain data were employed for the purpose of approximating flood risk. but the analysis is limited to mostly qualitative assessment based on FEMA's floodplains. In the future, hydrological models should be applied for a robust quantitative assessment of climate change related flooding risks of specific areas in the Pacific Northwest and Alaska. For example, the Willamette Water $2100^{17}$ project, a collaboration of researchers from Oregon State University, the University of Oregon, and Portland State University, is a comprehensive examination of hydrological, ecological, and socio-economic factors in the Willamette River Basin and how climate change, population growth, and economic growth will alter the availability and the use of water in the basin. This research will be valuable to expand understanding of future hydrological flows of the basin for Oregon transportation professionals and could be integrated into this framework.

\footnotetext{
${ }^{17} \mathrm{http}: / /$ water.oregonstate.edu/ww2100/
} 
The analysis of landslide occurrence in the Pacific Northwest shows that locations with high landslide risks can be identified with rainfall intensity data (i.e., December's average precipitation). For example, the analysis shows that for Oregon most recorded landslides occurred in areas with average December precipitation of above 10 inches. Similar association between landslide occurrences and precipitation levels are also found for the States of Washington and Idaho.

For permafrost in Alaska, thawing index contours were established using updated temperature data. Note that many of these existing contours were created decades ago. The newly geo-coded temperature data and thawing index contours can be used in the future to help engineers in Alaska design infrastructure that better manages declining permafrost.

A promising future extension of the case study is to reduce the scale of the analysis from four states to those identified as high-risk areas in each state. The most effective way for the DOTs involved in this study to use the provided results is to work directly through the GIS data developed for the case study. Data from this study was delivered to WSDOT and is available for further use and analysis by the regional DOTs and other agencies. These data can help the DOTs identify specific areas and facilities that warrant detailed analysis with high resolution data. Note that such data may require additional effort to be retrieved or created (e.g., the layouts of airports, sea ports, and river ports need to be digitized for risk assessment of the ports to be accurate). With additional high resolution data and carefully conceived methods, the depth and extent of such a study can be further improved. 


\section{INCORPORATATING ADAPTATION INTO CURRENT AND LONG-RANGE PLANNING AND PROJECT DEVELOPMENT}

Climate change adaptation needs to become an ongoing activity for transportation agencies and departments. Results from the proceeding processes should be incorporated into an agency's overall planning and project development processes, and updated regularly as new information and methods become available. One suggested method for incorporating risk management into ongoing planning and project development processes is the use of Transport Asset Management (TAM) systems.

\section{Using Transportation Asset Management to Plan for Climate Change Adaptation}

In the 2010 paper Transportation Asset Management Systems and Climate Change: An Adaptive Systems Management Approach, Michael Meyer et al. outline how TAMs can be used to incorporate climate change adaptation into transportation planning (Meyer, 2010). The FHWA defines TAMs as:

"a systematic process of maintaining, upgrading, and operating physical assets costeffectively...Thus, asset management provides a framework for handling both shortand long-range planning (USDOT 1999)."

A TAM generally includes goals and policies for system performance; an inventory of all assets; condition assessment and performance monitoring for these assets; system improvement and optimization alternatives; short- and long-range plans; and implementation and monitoring. Meyer's approach incorporates climate change considerations into each element of the TAM. For example, he notes that identification of system vulnerabilities to climatic conditions may be included in asset inventory; risk to assets associated with weather 
events may be included in the condition assessment and performance modeling; and so on.

Meyer proposes that by, "incorporating the consideration of anticipated effects of climate change into an agency's infrastructure preservation and asset management process... transportation officials could end up with the most cost effective approach toward system adaptation to changing environmental conditions." This approach is advocated as a good use of resources since most transportation agencies already have some type of asset management system in place upon which to build. The City of Portland, for example, employs a TAM in the form of a computerized pavement management system to monitor current pavement conditions; project future conditions; evaluate alternatives for improvement, including reconstruction, rehabilitation and maintenance; and to prioritize repairs on the city's 1,700 miles of roadway based on cost effectiveness (Walker et al., 2010). Although this tool is primarily used to manage pavement quality, such a system could potentially be adapted to assist in climate change adaptation planning decisions. Given that much of climate change adaptation planning takes places at the local level where staff and funding resources are constrained, the effective re-use of existing tools as suggested by Meyer is particularly appealing (Wheeler, 2008).

\section{ADAPTATION PLANNING EFFORTS}

Organizations have begun to identify potential locations of transportation system vulnerabilities, assess risk and incorporate adaptation responses into their climate change planning efforts utilizing a variety of approaches. Summaries are provided below in Table 42. 


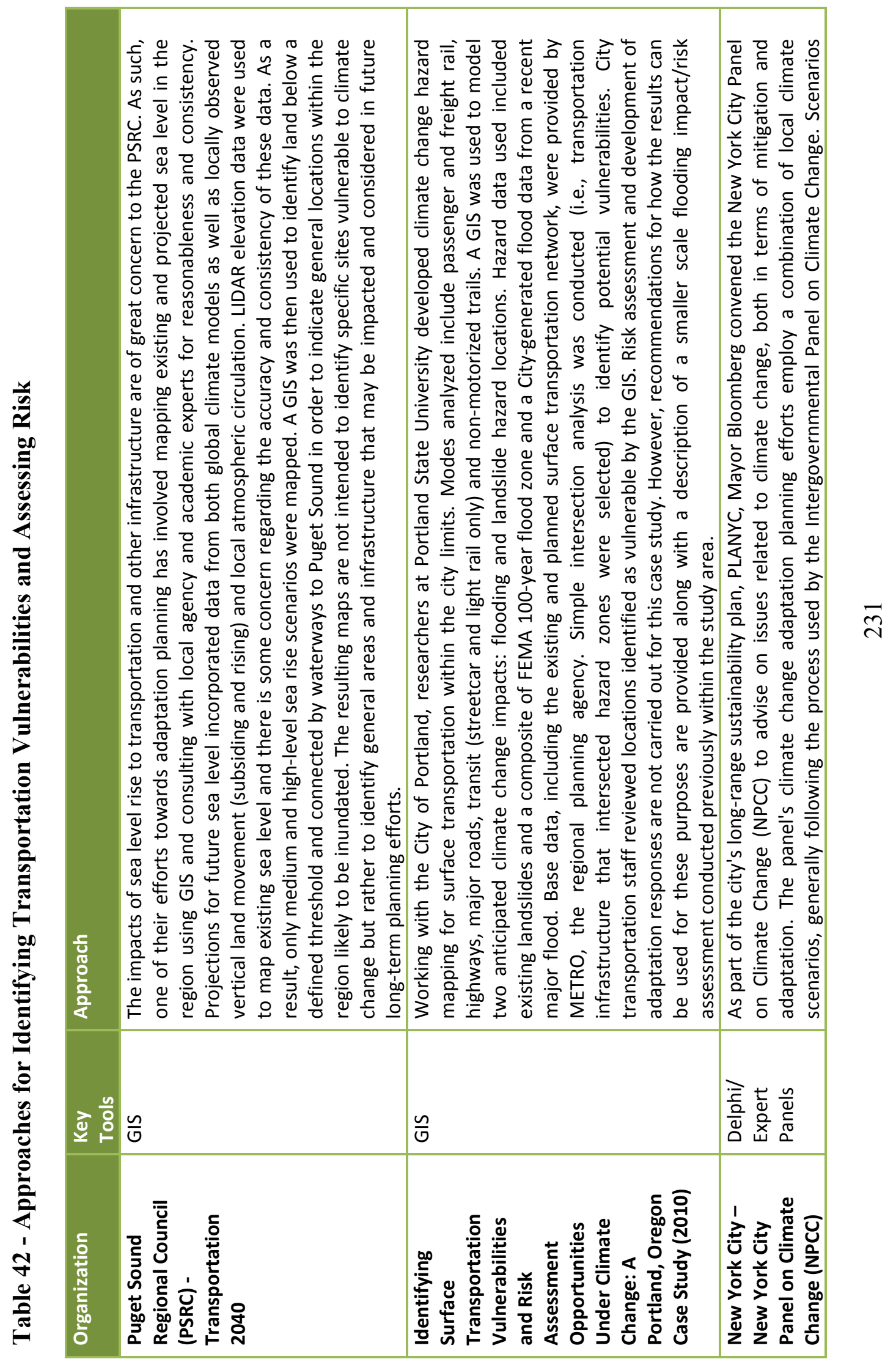




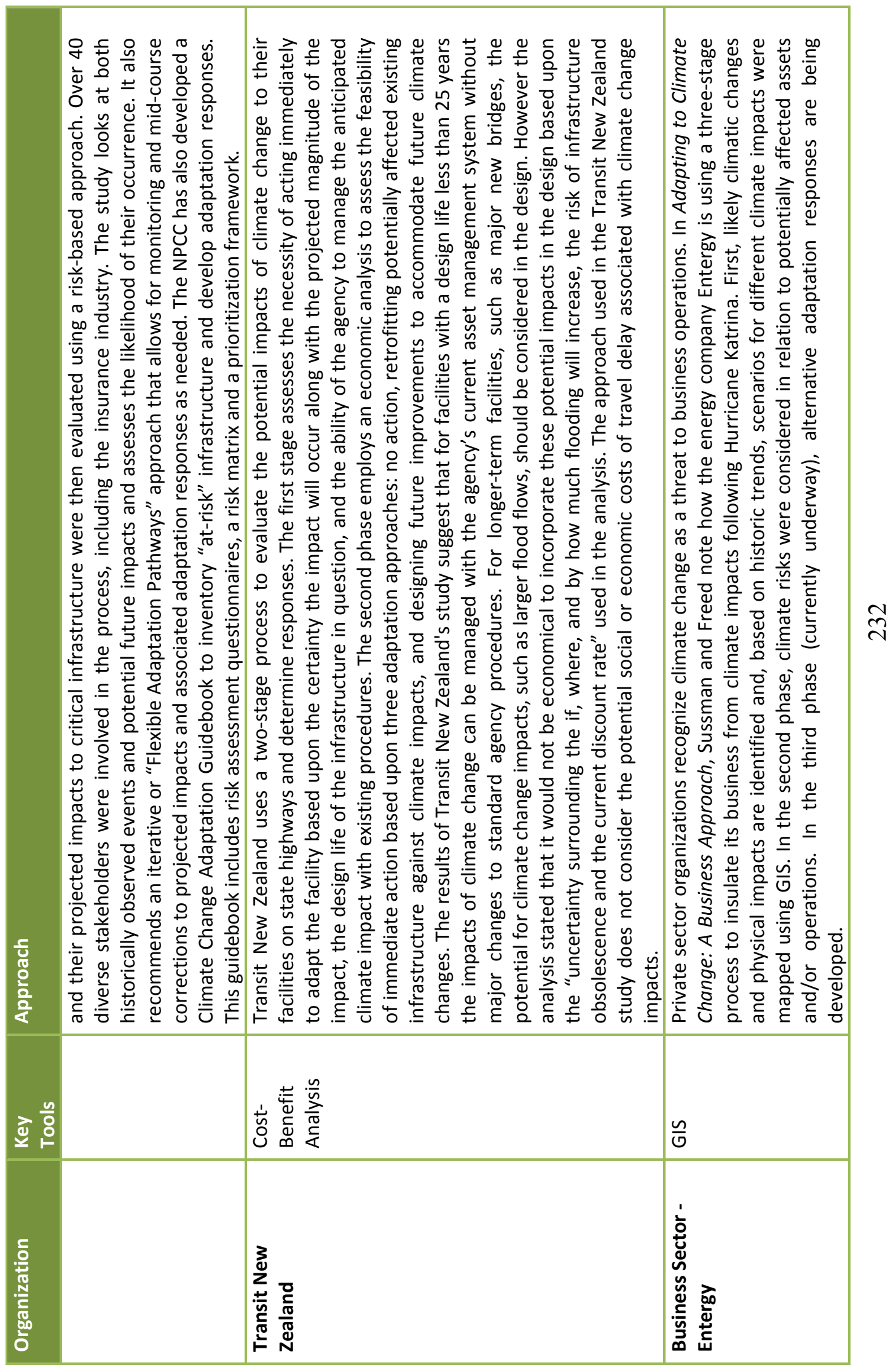




\section{FINDINGS AND RECOMMENDATIONS}

Resources such as high-resolution climate change models, GIS and TAMs offer methods to incorporate climate change adaptation into current and long-range planning processes. Specifically, this project shows that the use of GIS is promising for vulnerability assessments. However, several barriers and challenges remain. A brief discussion below highlights some the needs and challenges that should be addressed in future research:

- GIS remains a critical tool for climate change adaptation research at regional and local levels. The researchers believe a very effective method to identify the effect of climate change on surface transportation is by creating GIS models. GIS can apply sophisticated analysis uniformly over broad regions by combining preexisting datasets. There is a wealth of information available regarding the different aspects of both climate change and surface transportation. Different climate change models can be applied to identify affected areas, projected intensities and impacts to critical infrastructure. Surface transportation data, such as traffic volume, number of trucks carried, marine vessels carrying deliveries etc. can be intersected with climate change models to identify affected infrastructure. Furthermore, key information such as size, age, historic maintenance issues (i.e., flooding and landslide events, pavement deterioration, rail buckling, etc.) and redundancy in design can also be assigned to each infrastructure item. A sort/filter function with multiple criteria can be conducted quickly to identify critical infrastructure that might be affected by climate change. 
Additional data needs to be aggregated and added into the model used for this report; specifically, more state-level data could be integrated into the GIS platform. As more information is integrated - including travel volumes, historic maintenance records, and enriched, updated flood maps - the tool's power will be greatly enhanced.

\section{- Compounding uncertainties within the risk management processes are a} significant concern.

Each process within the climate change risk management framework contains uncertainties. There are uncertainties associated with inputs, assumptions and results of climate models, magnitude of vulnerabilities, and with predicting the probability of events occurring. These uncertainties will be understood with better data and the development and refinement of models, thus enriching the decision process. Figure 95 shows the compounding uncertainties involved in the use of vulnerability and risk assessments. Although these uncertainties do not justify inaction, they can present challenges to agencies making near-term decisions on planning and project designs based on future projections.

As explained throughout the report, there are uncertainties and assumptions made from emissions scenarios to climate modeling to localizing future impacts. One of the biggest challenges for planners, designers and decision makers is to understand the degrees of uncertainty throughout the adaptation evaluation process. Figure 95 depicts the compounded degrees of uncertainties. These uncertainties will be understood with better data and the development and refinement of models. For example, climate models can project a climate 
conditions at a 10-kilometer grid scale, but localized models have not been integrated with these future projections or developed that can be useful at the bridge or culvert level.

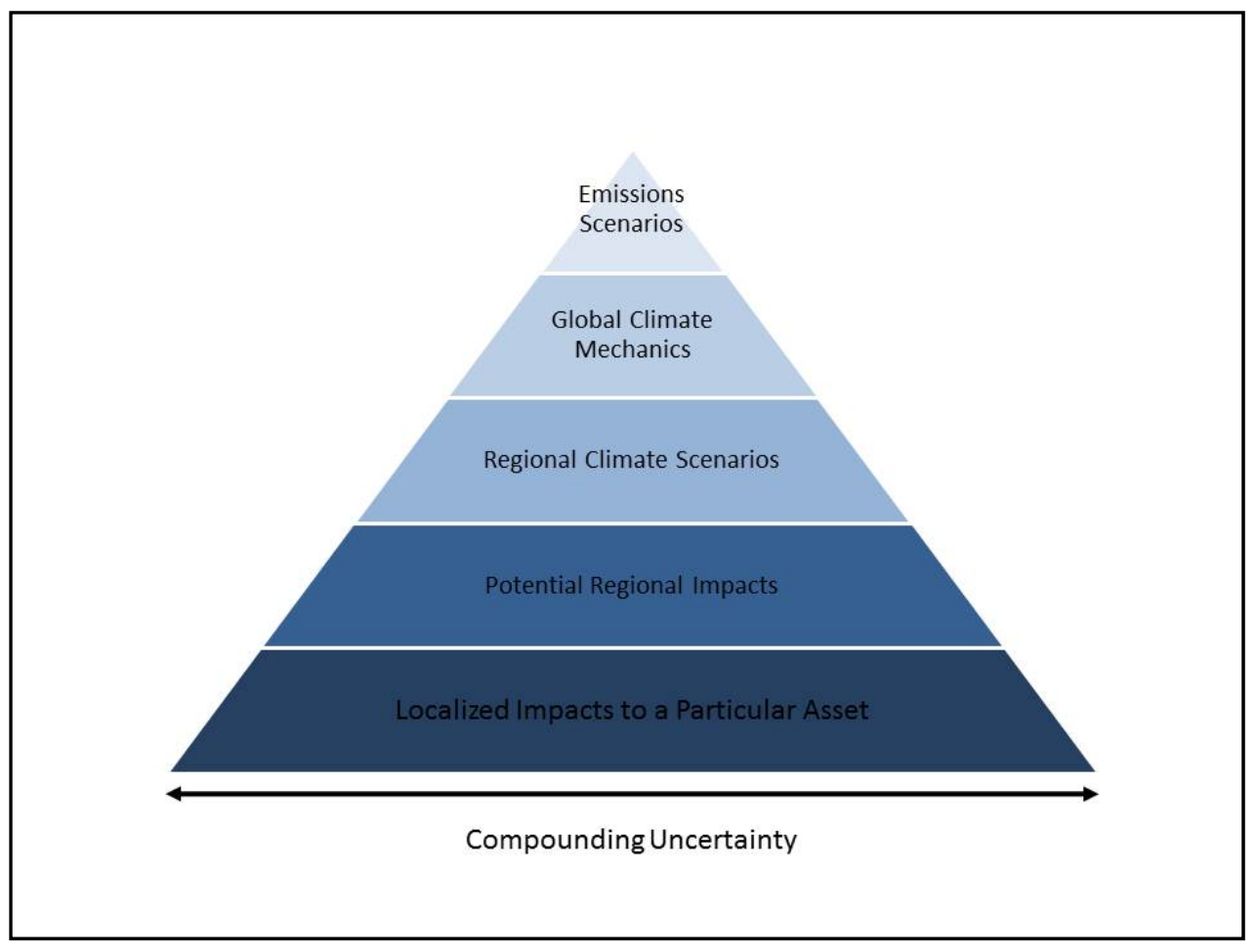

Figure 95 - Compounding uncertainties.

\section{- Planning and engineering staffs require guidance for developing} conservative yet adequate adaptation response alternatives.

As a result of the compounding uncertainties with risk management, professional staff lack guidance in order to design systems and infrastructure to a level that is adequate to withstand future climate impacts yet conservative in cost and not "over-engineered." Agencies will need to evaluate how to adjust standard practices and overcome institutional and discipline inertia that slow 
change. Agencies should spend time developing institutional knowledge and dialogue that will foster the discussions and improve decision making.

\section{- Capacity needs to be built for impact studies to be completed at the local}

level. Impact studies can be resource-intensive endeavors in terms of time, access to experts and funding. As most infrastructure planning and design will occur at the local level, it is important to provide planners and engineers with ways to minimize the amount of resources needed to conduct adaptation analysis and planning. States and regions may assist in this effort through the development of models, tools, data and guidelines that standardize climate projections/future scenarios as well as the resolution and format of existing condition data. Data clearinghouses may be employed at the state level to facilitate standardization as well as encourage cross-agency sharing of data. As discussed earlier in this report, climate impact models have been developed for individual regions, often at great expense. However, development of a generalized impact model(s) that can be inputted with local regional data and easily updated with new climate projections as they become available would greatly enhance capacity for adaptation planning at the local level.

- Expand NARCCAP coverage. Alaska is an exceptionally climatologically diverse locale. This leads to significant challenges when considering the impacts climate change may have on the state's transportation infrastructure. Unfortunately, NARCCAP coverage for Alaska is limited. However, an approach similar to that employed here for NARCCAP (using different data sets) may be useful in evaluating regional climate change effects within Alaska. 
- Continued research to improve GCMs and RCMs is needed. Improving climate models requires the continued development and evaluation of both GCMs and RCMs. GCMs are expected to improve in a number of ways:

- Enhancement of GCM ensembles. Improved ensembles will lead to increased confidence in the ranges of global climate projections by better identifying uncertainty. Climateprediction.net is currently seeking to build large model ensembles by allowing users to donate idle computer time to run yearly model increments.

- Improved evaluation of climate models. One such effort, the Climate Model Intercomparison Project, Phase 5 (CMIP5), will provide a framework for the coordination of climate model experiments. Among the goals of CMIP5 are the evaluation of models' ability to simulate the recent past, and to provide projections of future climate on two time scales, out to about 2035 and 2100. The primary focus of CMIP5 will be to improve understanding of factors responsible for differences in climate models projections.

- Improved use and availability of observations. These efforts will lead to new methods for using observations of past and present climate to more accurately constrain GCMs.

- Improved modeling of clouds and the Pacific. Projections for the tropical Pacific are a primary source of uncertainty in climate projections for the western and central United States. Clouds are the dominant source of uncertainty in current GCMs. 
- Improved decadal prediction. Integrating projections of decadal climate variability with climate change projections will help address planning horizons of a few years to a few decades.

- Development of RCM ensembles. Similar to GCM ensembles, RCM ensembles will help identify uncertainty in regional climate models.

- Development of region-specific climate model components. The reduction of RCM disparities in the representation of regional climate processes given accurate large-scale conditions.

- The incorporation of more robust hydrologic models. Current atmosphereocean climate models represent land surfaces in relatively simplistic ways. Uncertainty is still high in projecting future regional changes in runoff, water quality and water demand. More sophisticated hydrologic impact assessment models will be developed.

- Development of statistical downscaling techniques. These efforts will improve uncertainty estimates of local climate change for variables critical to land-management entities.

- While models continue to improve, guidelines should be used in climate science studies to provide consistently produced data. The overall need of planning entities is the availability of climate projections that are useful on the time scale at which resource planning and meeting infrastructure demands is conducted. Potential guidelines include: 
- Model agreement on change in relevant parameters. GCMs in many regions differ on how key parameters will change. A better understanding of the sources in the uncertainties in regional climate change is needed.

- Narrowing the range of model output. Across the numerous emissions scenarios and models, a wide range of projections is often given. Emission scenarios and model climate sensitivity will continue to be sources of uncertainty, but the improved use of observations may help constrain GCMs.

- Climate model resolutions at spatial and temporal scales useful for transportation and infrastructure planning. Higher resolutions in climate models are critical for infrastructure planning. GCM resolutions will likely improve from 100-400 kilometers to 50-200 kilometers over the next few years, but this is still too coarse for many planning needs. RCMs provide more appropriate resolutions.

- Improved projections within infrastructure planning horizons. Long-term climate projections can provide useful information, but climate projections for the next few years or decades are often more congruent with the time scales of infrastructure and transportation planning.

\section{- More research on road vulnerability to thermal conditions is needed.}

Thresholds for the extreme heat events and the heat wave metrics examined in this study need to be revisited. Definitions for "extreme temperatures" and "heat wave" need to be developed that are based on material performance, and operation and construction practices. Once these definitions are more developed, 
they can be incorporated into additional analysis to help evaluate the impacts of extreme events. Additionally, research should be conducted on the vulnerabilities of roads to changes in thermal conditions and the significance of extreme weather events and variability, including freeze and thaw effects on pavements (Natural Resources Canada, 2010). There is much to be learned from other areas of the country that already are experiencing temperatures the region may see in the future. Best practices, tools, standards and criteria should be researched and transferred to the region. In addition, existing tools like Mechanistic-Empirical Pavement Design Guide (MEPDG), AASHTOWare DARWin-ME and Texas Concreteworks should be further evaluated using regional climate scenarios to evaluate material performance ( $\mathrm{Li}$ et al., 2011). There is much to be learned from other areas of the country that already are experiencing temperatures the region may see in the future.

\section{- Site-specific research is needed to gauge impacts on coastal infrastructure.} Impacts to ports and marinas (Huppert, 2009), the key issues for shipping and navigation (including the Northwest Passage and inland shipping routes) and how changes in technology, land use policy, and other non-climatic factors affect society's vulnerability to climate change should be explored at a site-specific level (Natural Resources Canada, 2010). Increasing amount of the PNW and Alaska coastline has been mapped using airborne Light Detection and Ranging (LIDAR). This data will be important to incorporate into GIS tools and models to generate more high-resolution digital elevation maps. 
Additional research should focus on impacts of the reduction of winter Arctic ice and the possible increases of shipping routes in the Northwest Passage. Increased shipping through the passage will have impacts on the Pacific Northwest and Alaska regional transportation infrastructure. An economic analysis should be completed to study regional impacts of the changing shipping, but also an analysis of the supporting infrastructure (i.e., ports, freight terminals, and roadways) is needed to address the potential increase in shipments.

- Expand climate impacts analysis. This study focused on SLR, flooding, landslides and increased regional temperatures. Additional impacts - such as extreme rainfall events, coastal storm surge, and fog and high winds - warrant further research and evaluation. The region has the potential to experience more frequency and higher magnitudes of extreme rainfall events. These can not only cause flash flooding and landslides but unsafe conditions on the roadways. In addition, the region will potentially experience more fog, high winds and ice/sleet/snow events, all of which cause unsafe conditions to the traveling public and freight community. For example, high winds lead to major roads and bridge crossings being closed, especially for large loads like those carrying windmills and modular homes. Agencies, local governments and companies will need to understand where these events may occur and develop adaptation approaches to maintain safe road conditions. 
APPENDIX A

DEFINITIONS \& STATE RESOURCES 


\section{APPENDIX A - DEFINITIONS}

100-year flood

Adaptation

Anthropogenic

Climate

GIS

Greenhouse Gas (GHG)

Mitigation

Projection

Predictions

Shapefile

Weather
A one-hundred-year flood is calculated to be the level of flood water expected to be equaled or exceeded every 100 years on average. The 100-year flood is more accurately referred to as the $1 \%$ flood, since it is a flood that has a $1 \%$ chance of being equaled or exceeded in any single year.

Initiatives and measures to reduce the vulnerability of natural and human systems against actual or expected climate change effects

Created by humans.

Average weather conditions of the atmosphere over a long period of time.

Geographic Information Systems

Gases that absorb infrared radiation and trap the heat in the atmosphere, including water vapor, carbon dioxide, methane, and nitrous oxide and gases used for aerosols.

Policies and strategies that reduce greenhouse gas emissions and/or enhance greenhouse gas absorption and storage

A climate projection describes the climate of the future based on a number of assumptions (e.g., societal and technological trends) that may or may not come to fruition.

A climate prediction is a most likely description of the climate in the future.

A spatial data format that contains geometric and attribute data and can be displayed as points, lines or areas.

Weather is the conditions of the atmosphere are over a short period of time. 


\section{Appendix A - List of State Resources}

\section{Alaska}

Adaptation Advisory Group of the Governor's Sub-Cabinet on Climate Change http://www.climatechange.alaska.gov/aag/aag.htm

SNAP, the Scenarios Network for Alaska Planning http://www.snap.uaf.edu/

Alaska Center for Climate Assessment and Policy http://ine.uaf.edu/accap/

\section{Idaho}

Idaho Department of Water Resources Floodplain Management http://www.idwr.idaho.gov/WaterManagement/FloodPlainMgmt/default.htm

\section{Oregon}

ODOT's Climate Change Website http://www.oregon.gov/ODOT/TD/CLIMATECHANGE/index.shtml

ODOT's Climate Change Adaptation Website http://www.oregon.gov/ODOT/TD/CLIMATECHANGE/cc_adaptation.shtml

Oregon Statewide Adaptation Plan http://www.oregon.gov/ODOT/TD/CLIMATECHANGE/docs/Oregon.Statewide. Adaptation.Final.pdf

Oregon Climate Change Research Institute \& Oregon Climate Assessment Report http://occri.net/ocar

\section{Washington}

Washington Department of Ecology's Adaptation Website http://www.ecy.wa.gov/climatechange/adaptation.htm

Washington Department of Transportation's Climate Website http://www.wsdot.wa.gov/movingwashington http://www.wsdot.wa.gov/sustainabletransportation

Washington Topic Advisory Group Archive (TAG \#1) Built Environment, Infrastructure and Communities http://www.ecy.wa.gov/climatechange/tag_infrastructure.htm University of Washington: Center for Science in the Earth System http://cses.washington.edu

University of Washington: The Climate Impacts Group (CIG) http://cses.washington.edu/cig 


\section{APPENDIX B}

PORTLAND, OREGON CASE STUDY 


\section{APPENDIX B \\ PORTLAND, OREGON CASE STUDY}

The City of Portland, Oregon was selected as an illustrative case study for a number of reasons including:

- Access to GIS data;

- Access to City staff;

- Familiarity with the transportation system; and

- The small size of the study area (134 sq. mi.) (U.S. Census 2000). Portland's transportation network is truly multi-modal, offering driving, bicycling, walking, bus, light rail and streetcar options for passenger trips, as well as truck, rail and maritime options for freight trips. With approximately $7 \%$ of residents using a bicycle as their primary means of traveling to and from work, Portland has a relatively high rate of cycling compared to other U.S. cities (averaging less than $0.7 \%$ bicycle mode split nationwide) (Portland Office of the City Auditor 2009), and an established goal to increase bicycle use to $25 \%$ mode share by 2030 (City of Portland Bureau of Transportation 2009). Transit use is also relatively high with $10 \%$ using bus, streetcar or light rail as the primary means of transportation to and from work compared with $5 \%$ nationwide. $75 \%$ of residents report driving alone or with others as their primary mode of commute transportation compared with $86 \%$ nationwide (Bureau of Transportation Statistics.) Considering these statistics, it was important not to limit transportation hazard identification to personal automobile routes. Thus, transportation facilities used in the model include major arterials, rail lines (passenger and freight), 
bicycle facilities (bicycle routes and multiple-use paths), bus routes, and streetcar/light rail (including planned improvements).

In an online survey conducted in late fall 2009/winter 2010, transportation planners in the Pacific Northwest were asked about their climate change planning activities, focusing particularly on activities related to climate change adaptation for their transportation systems. Both in the online survey as well as in follow-up interviews, respondents (including City of Portland Transportation Bureau staff) indicated that of the potential climate changes impacts likely to occur in the Pacific Northwest, flooding/inundation was considered the biggest threat to the City's transportation infrastructure and operations due to the tremendous damage standing water has on roadway structures. This response is consistent with a 2007 Intergovernmental Panel on Climate Change (IPCC) report that named urban flooding as the most costly impact of climate change on transportation (IPCC 2007). Erosion and landslides associated with heavy precipitation were also of concern due to the city's topography — chiefly the steep, slide-prone hills directly west and southwest of the city center. Respondents expressed particular concern regarding how road closures and/or delays could not only impact travel delay but also potentially impede emergency response.

\section{STUDY DESCRIPTION}

In this case study, a GIS was used to model two anticipated climate change impacts, flooding and landslide hazard locations, that could leave the City of Portland's surface transportation networks vulnerable to the effects of climate change. Risk assessment and development of adaptation responses are not carried out for this case 
study. However, recommendations for how the results can be used for these purposes were provided.

Much of the GIS data used in the study was obtained through the Regional Land Information System (RLIS), a clearinghouse for spatial data managed by Metro, the regional government for the Portland metropolitan region (Table 43). Many jurisdictions lack the resources to collect and maintain a spatial data resource as comprehensive as RLIS. However, a significant amount of spatial data, including transportation networks, waterways and the Federal Emergency Management Agency (FEMA) 100-year flood map can be readily obtained online at no cost through several reputable data clearinghouses such as Geodata.gov, the United States Geological Survey (USGS) and the Economic and Social Research Institute (ESRI), to name a few. More specialized spatial data used in this study, including landslide hazards and planned transit improvements, were obtained through city and transit agency staff.

\section{Table 43 - Spatial Data Used in the Portland, Oregon Model}

\begin{tabular}{|c|c|c|}
\hline Shapefile Data & Source & Purpose \\
\hline $\begin{array}{l}\text { Surface transportation network - Major arterials, bus routes, } \\
\text { light rail system, planned transit rail improvements (streetcar and } \\
\text { light rail), bike routes, passenger and freight rail lines. }\end{array}$ & RLIS & Model vulnerabilities \\
\hline Major waterways & RLIS & Reference \\
\hline $\begin{array}{l}\text { Flood - Federal Emergency Management (FEMA) 100-year flood, } \\
1996 \text { flood. }\end{array}$ & RLIS & Model vulnerabilities \\
\hline Landslide Hazard Areas & $\begin{array}{l}\text { City of } \\
\text { Portland }\end{array}$ & Model vulnerabilities \\
\hline City Boundary & RLIS & Reference \\
\hline Land Use & RLIS & Model vulnerabilities \\
\hline
\end{tabular}

\section{GIS Processing}

Most shapefiles used in the model include data for the entire Metro region and 
were first clipped to the Portland city boundary. This clipping action limited analysis to only those areas within the Portland city limits and was done primarily to reduce processing time and keep the analysis at a manageable scale. Shapefiles of both the FEMA 100-year flood maps (last updated in 2004) and a shapefile delineating areas inundated during the 1996 flood were projected. Although the shapefiles are largely identical, some flooding in the 1996 flood occurred outside the 100-year flood boundary. In order to capture all areas of potential and recent flooding, these two shapefiles were combined using the "union" analysis tool to form a single flood polygon.

Next, a shapefile for a specific transportation network, for example, major arterials, was projected. Using the "select by location" analysis tool, segments of the major arterials were selected that intersected the flood polygon. The selected segments were then exported and reprojected as a "flood vulnerable" shapefile, representing the segments of major arterials that may be vulnerable to flooding (highlighted in red against the complete network). These "red segments" of roadway are portions of the roadway that intersect with areas historically known to flood and which are likely vulnerable to more frequent and/or intense flooding as a result of climate change. An identical process was carried out for each of the transportation system network shapefiles. Following identification of potential flood vulnerabilities, an identical analysis was performed using a landslide hazard polygon. These "hazard" shapefiles where then layered over base shapefiles of the transportation network, along with land use zoning and major waterways for reference.

Each of the transportation shapefiles comprise multiple segments of varying length. When selecting features that intersect the flood or landslide hazard areas, portions 
of a segment that lie outside of the hazard area may be selected as well. This action provides generalized locations of potential hazards. However, for greater accuracy, a listing of vulnerable segments was compiled by mode based upon a description of the segment including the intersections nearest to the hazard area (for example, "Lombard Street between Ramsey Street and Burgard Street”). A complete listing of segments potentially vulnerable to flooding and/or landslide by facility type can be found at the webpage for this project on the Portland State University Intelligent Transportation Systems Lab website: http://www.its.pdx.edu/project.php?id=2010-02.

\section{Results}

While all segments of the transportation system network that intersect the flood and landslide polygons were identified as potentially vulnerable to flood or landslide, they will not all be flooded during an extreme event. Although it can be added to the model with more advanced GIS data analysis, this model does not incorporate elevation data and thus requires further analysis to determine if intersecting transportation routes are at an elevation susceptible to flooding. For example, several bridges were selected as vulnerable to flooding although it is known that, due to the height of these bridges, flooding is unlikely. As this model is intended as a preliminary assessment, the focus is on areas that may be subject to flooding rather than specific segments. In this case, although the bridge itself is unlikely to flood, the model highlights potential issues for travelers accessing the bridge (as lower-elevation approaches may be susceptible to flooding), bridge clearance limitations for river traffic, and/or potential scour to bridge abutments as a result of higher water flow. 
In addition to identifying the locations of transportation segments vulnerable to flood and landslide, for several modes the GIS shapefile also provides length data, allowing for a tally of affected transportation segments within the Portland city limits:

- Major Roadways: The model identified 40 miles of major arterials (approximately seven percent of major roadways) potentially affected by flooding, primarily located adjacent to major waterways. Roughly 70 miles of major roadways (approximately 13 percent of major roadways) were identified as vulnerable to landslide, primarily in the West Hills area. This mileage could increase substantially if local roads are included in the analysis.

- Roughly 70 miles (or approximately 18 percent) of railways (comprising both passenger and freight lines) within the city limits were identified as vulnerable to flood, primarily near rail yard facilities adjacent to the Willamette River in northeast Portland. The model identifies roughly 50 miles (approximately 13 percent) of railways as vulnerable to landslide.

Mileage of transit routes vulnerable to flood and landslide were not calculated for transit modes (bus, streetcar and light rail) due to a large portion of identified segments that extended outside of the hazard areas and a lack of data regarding lengths of affected route segments. Bus routes were primarily impacted by flooding in areas outside of the downtown core, particularly in northern parts of the city. Fortunately, bus routes can be easily detoured (or truncated). Similarly, light rail may also be truncated using "crossovers" that allow trains to turn around and "pocket tracks" which allow trains to pass one another, located approximately every 7.5 minutes (in travel time) along the light rail alignments according to a TriMet (the regional transit agency) representative. 
Further, the light rail vehicles have engines on both ends allowing the train to operate in either direction. Segment length data were also unavailable for bicycle lanes and multiuse paths; however, the model does indicate that routes directly parallel to the river's edge, including major multi-use pathways, are potentially at risk for flooding. Notably, many bicycle facilities are located along these open space areas vulnerable to flooding. Fortunately, there are typically nearby alternative routes (local streets) available.

The majority of facilities potentially affected by landslide occurred in the hilly, western area of the city where there are fewer major arterials, bicycle facilities, and rail lines. However, because there are fewer alternate routes in the event of a landslide, these routes carry greater risk. It is notable that Barbur Boulevard, identified by the model as landslide-vulnerable, is also recommended by the regional planning agency as a future high capacity transit corridor (Collette 2009).

\section{Validation}

In order to validate the results from the model, reports of previous landslide and flooding incidents were compared with the GIS output. City transportation staff members were also consulted for a list of locations known to have flooding and/or landslide problems. Overall, the results from the model were consistent with known experience, with the exception of Willamette bridge flooding. Conveniently, much of the analysis for this study occurred during a series of heavy precipitation events in Portland during which two landslides occurred along segments of a bicycle route and major arterial identified as vulnerable in the model (Krough 2010, Fox 12 2010). 
This model has been shown effective at identifying transportation system vulnerabilities to historical hazards and may be used by local planning staff to begin the process of preparing for climate change. However, while future flooding and landslide activity are likely to occur in the vicinity of known hazard areas, they also have the potential to expand to new areas based on different future climate scenarios. Thus, in order to strengthen the model's potential to identify new hazards, shapefiles representing a range of flood and landslide hazards under different climate scenarios need to be developed and incorporated into the model. Such shapefiles should be edited as new climate change information becomes available. 
Portland Climate Change Flood Vulnerability - Major Roadways

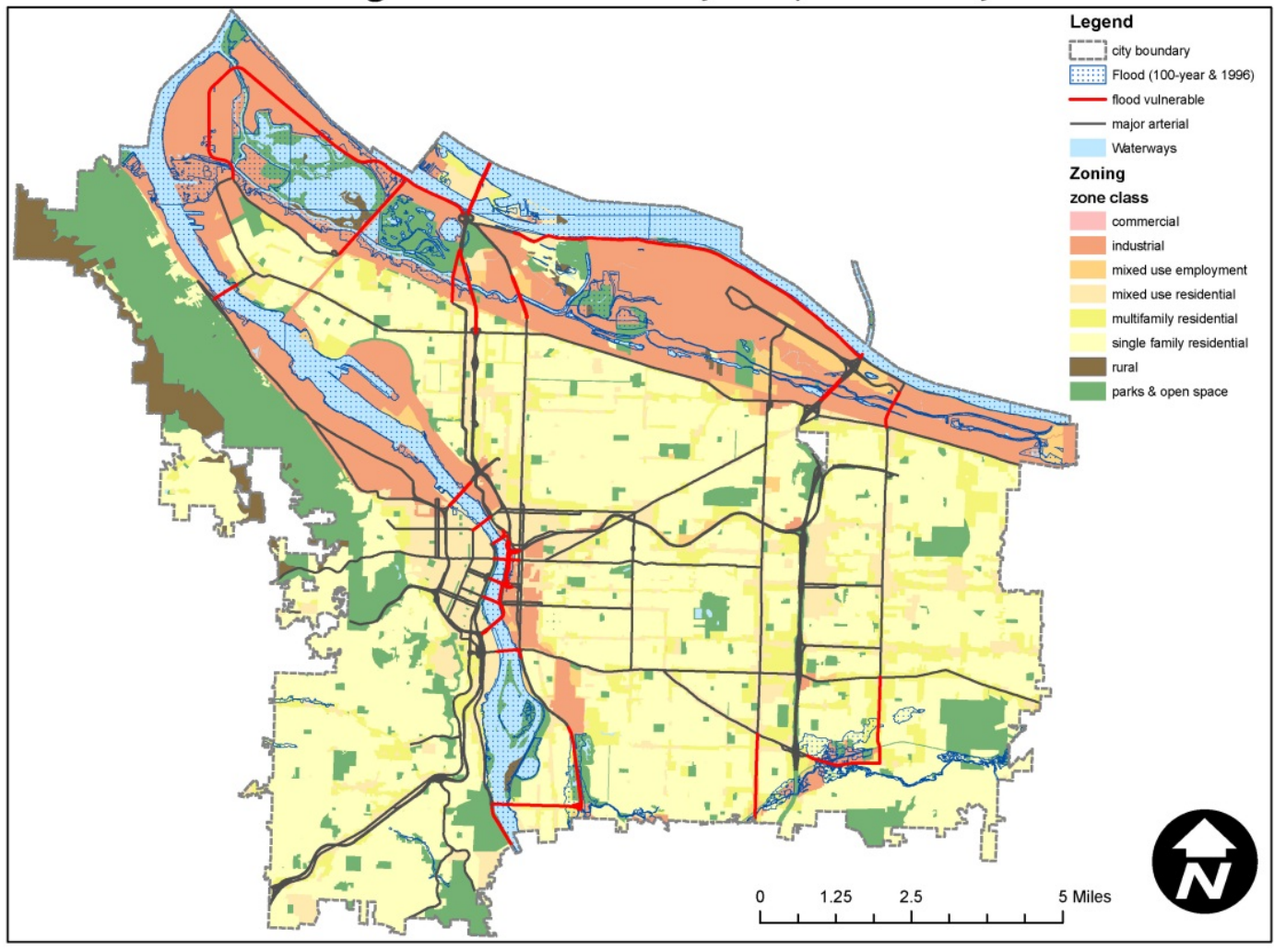

Figure 96 - Flood Vulnerability on Major Roadways 


\section{Portland Climate Change Flood Vulnerability - Light Rail \& Streetcar*}

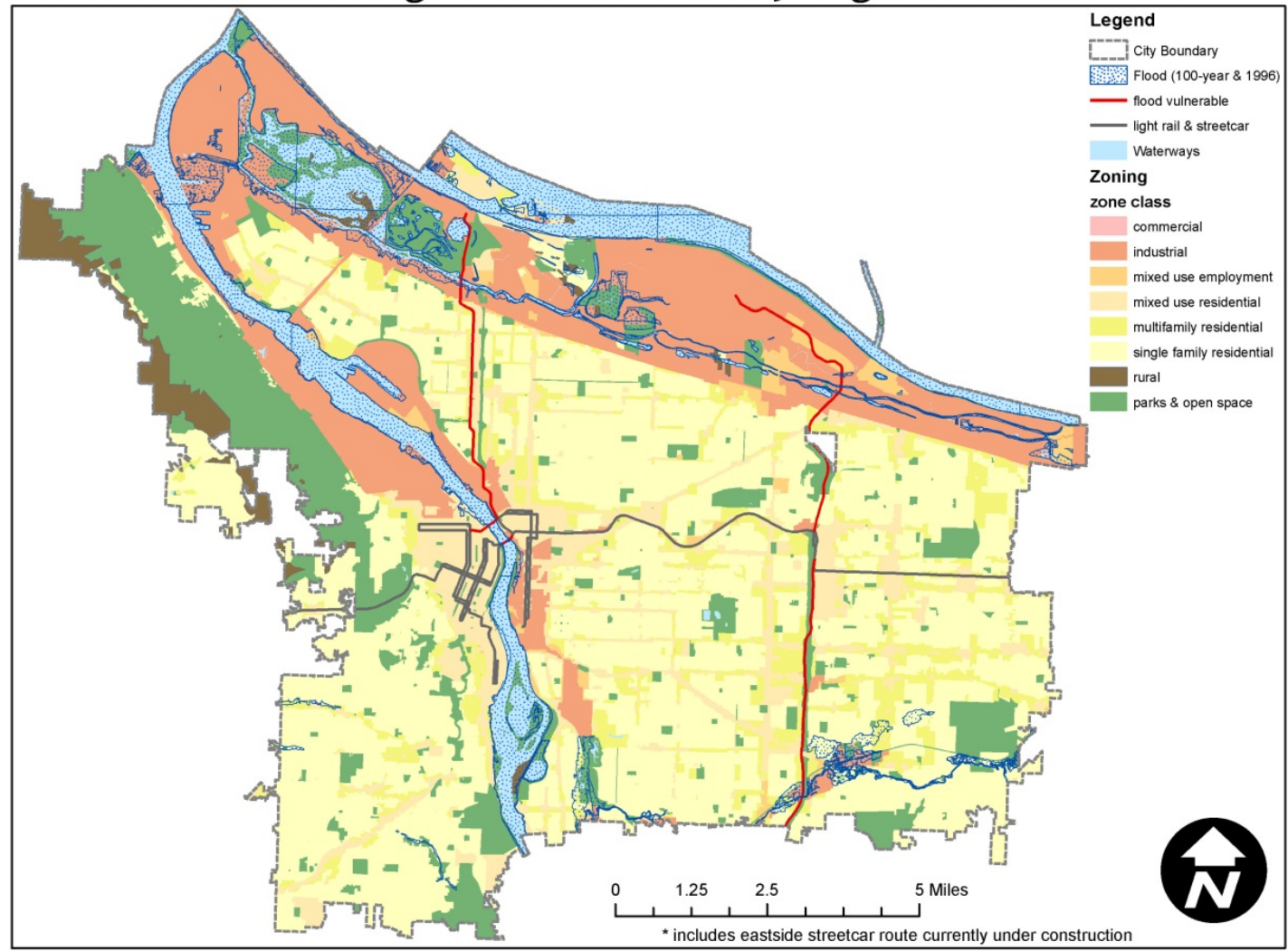

Figure 97 - Flood Vulnerability on Transit (Light Rail and Streetcar Only) 
Portland Climate Change Flood Vulnerability - Rail

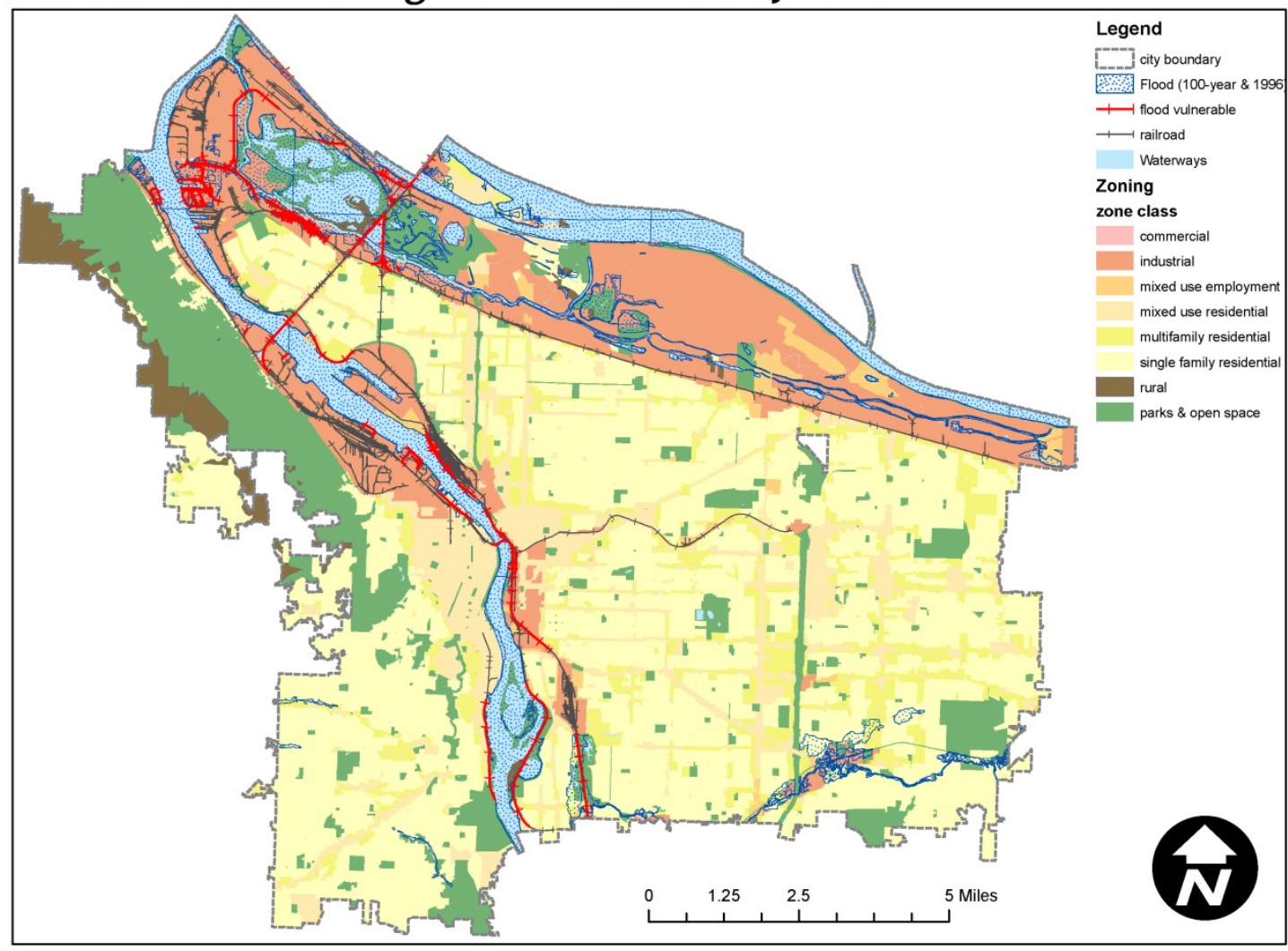

Figure 98 - Flood Vulnerability on Rail 
Portland Climate Change Flood Vulnerability - Bike Lanes \& Paths

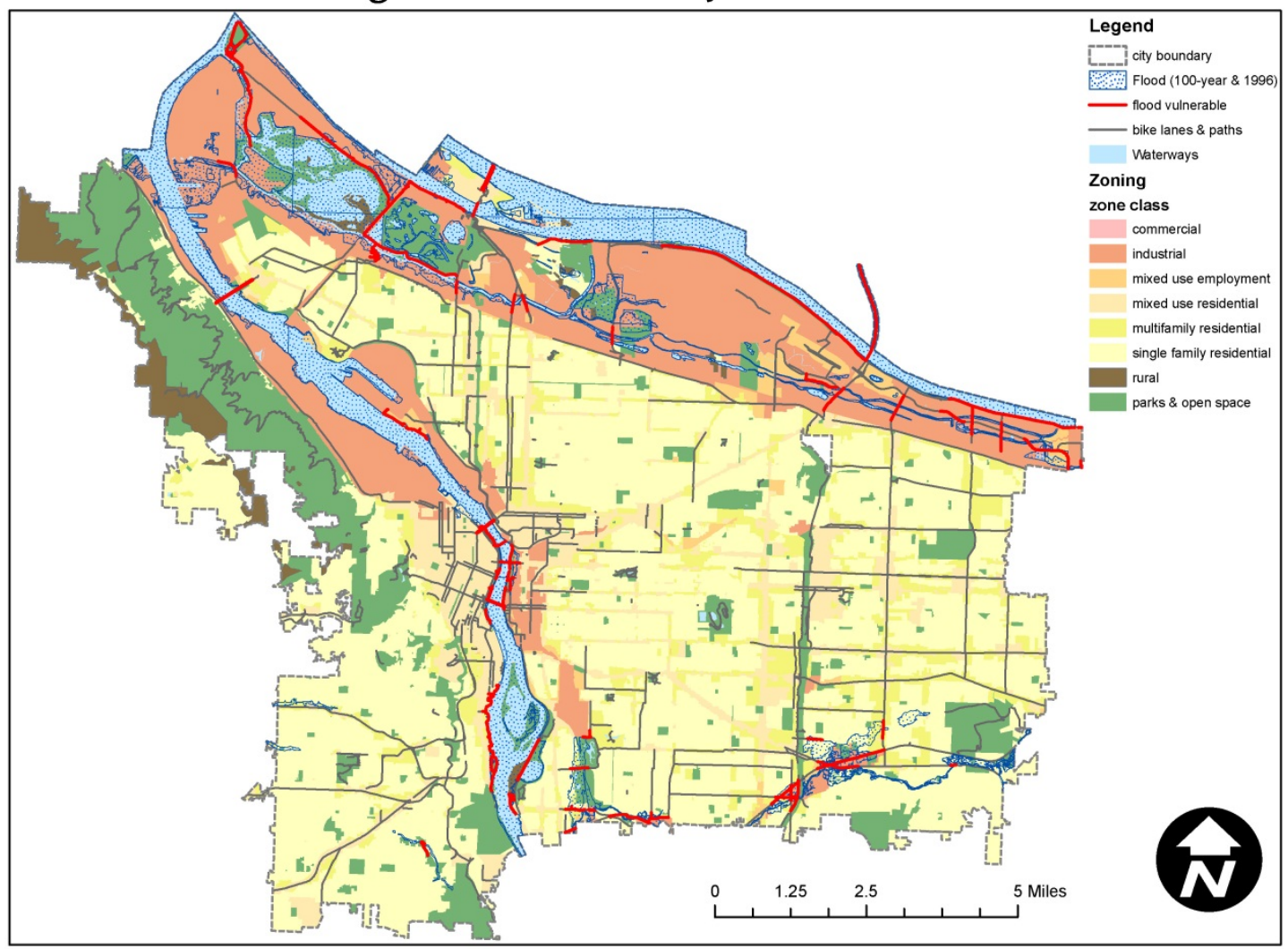

Figure 99 - Flood Vulnerability on Bike Lanes and Paths 
Portland Climate Change Landslide Vulnerability - Major Roadways

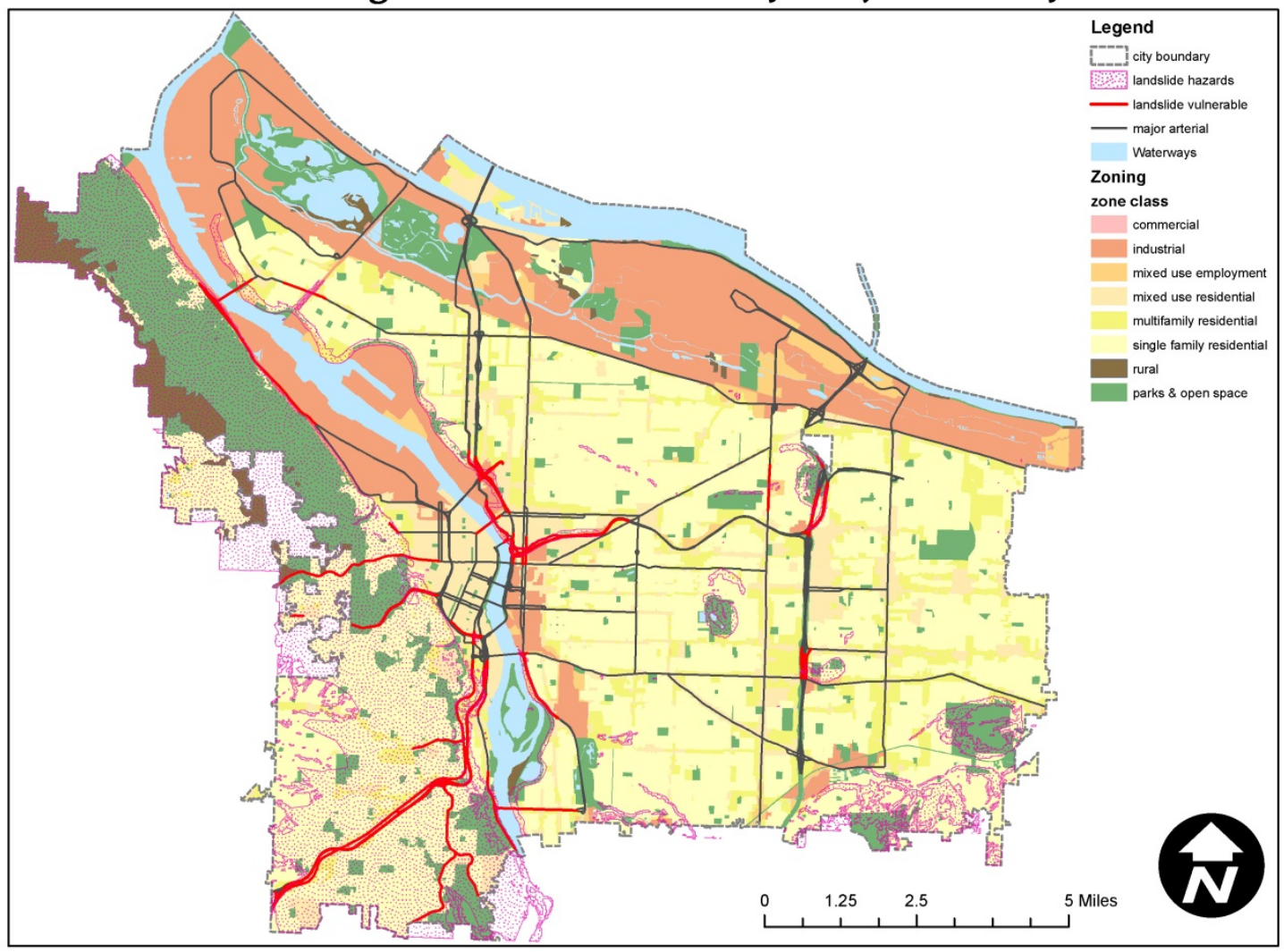

Figure 100 - Landslide Vulnerability on Major Roadways 
Portland Climate Change Landslide Vulnerability - Bike Lanes \& Paths

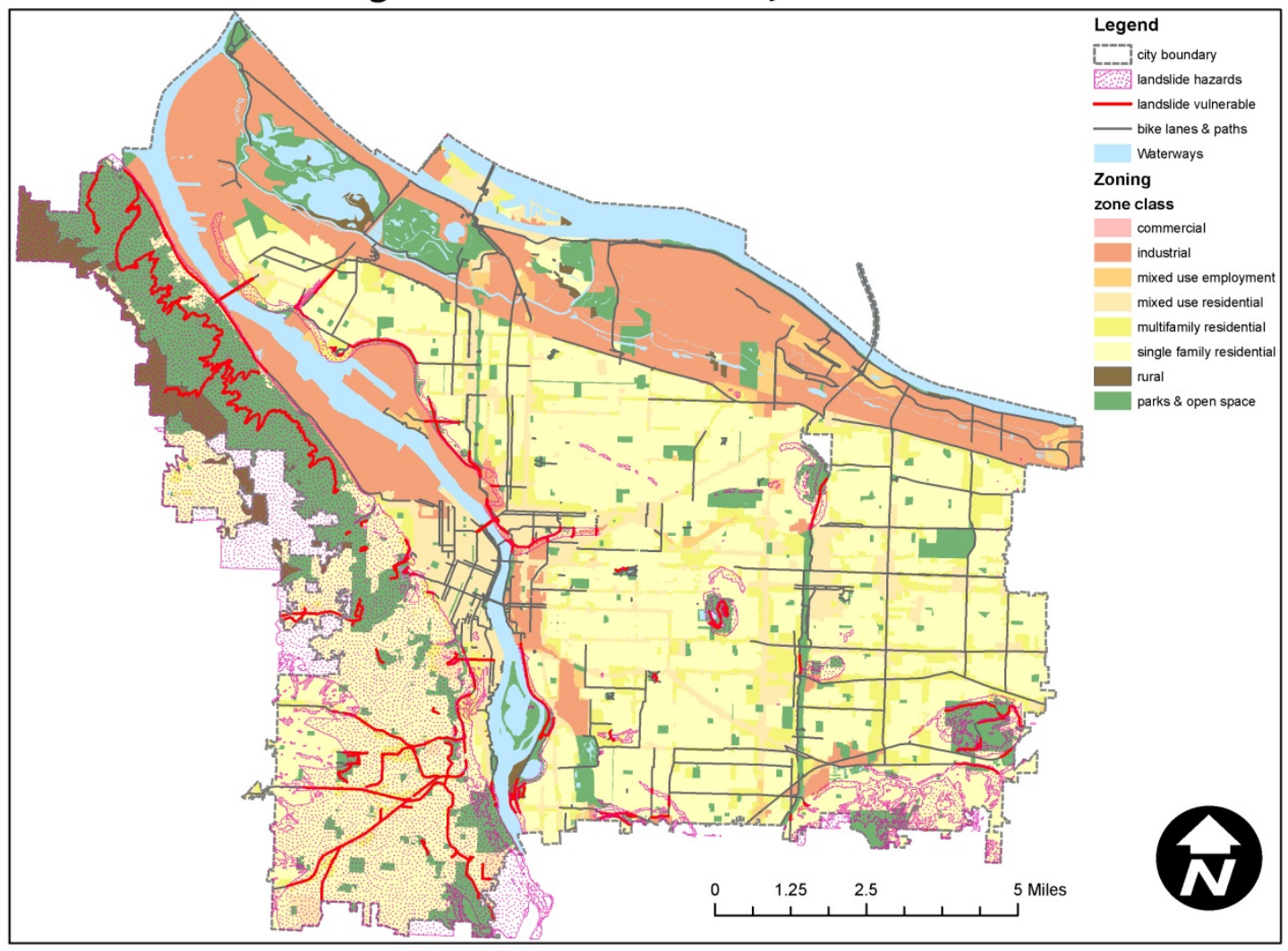

Figure 101 - Landslide Vulnerability on Bike Lanes and Paths 


\section{Portland Climate Change Landslide Vulnerability - Light Rail \& Streetcar*}

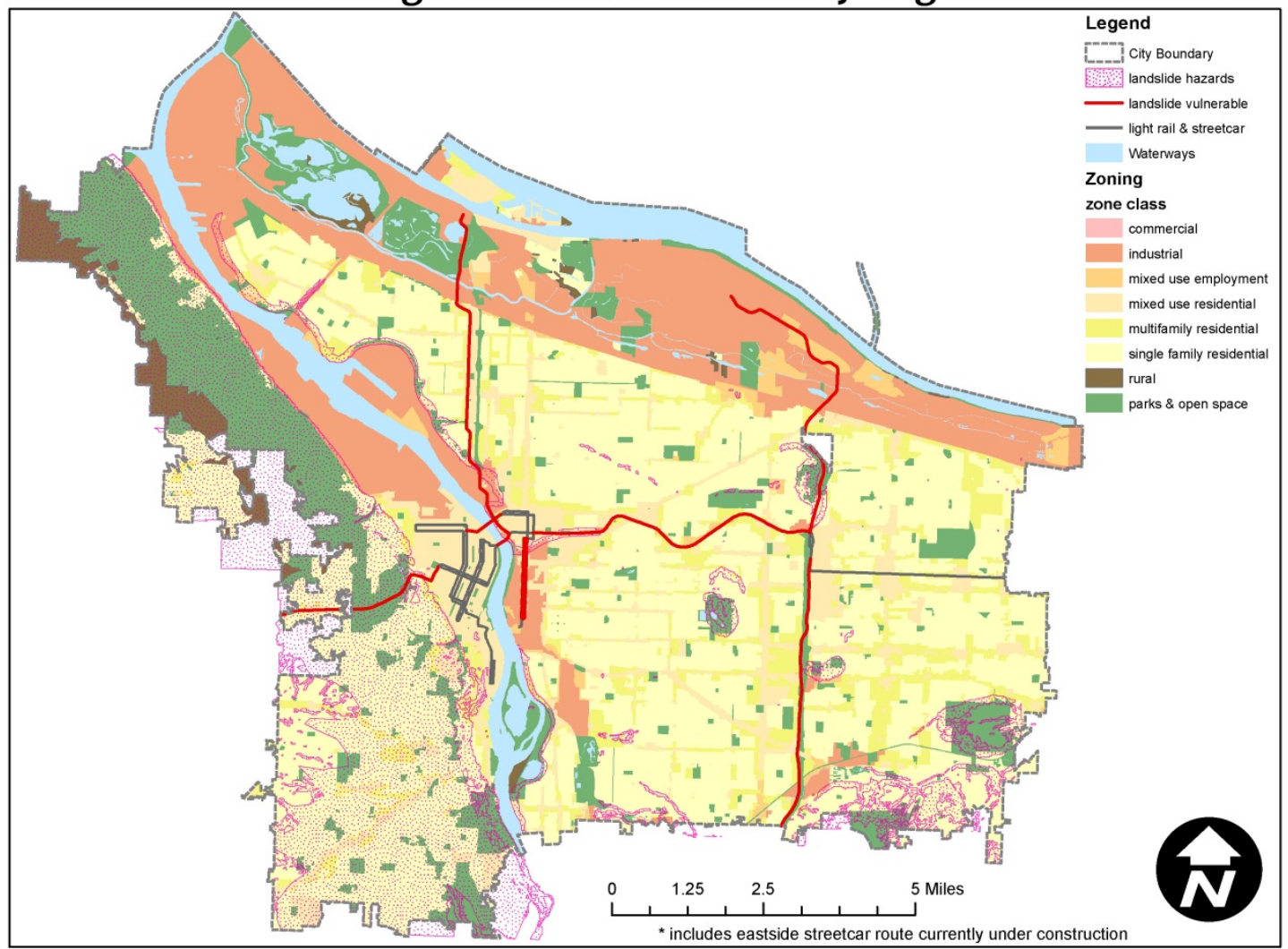

Figure 102 - Landslide Vulnerability on Transit (Light Rail and Streetcar Only) 


\section{Portland Climate Change Landslide Vulnerability - Rail}

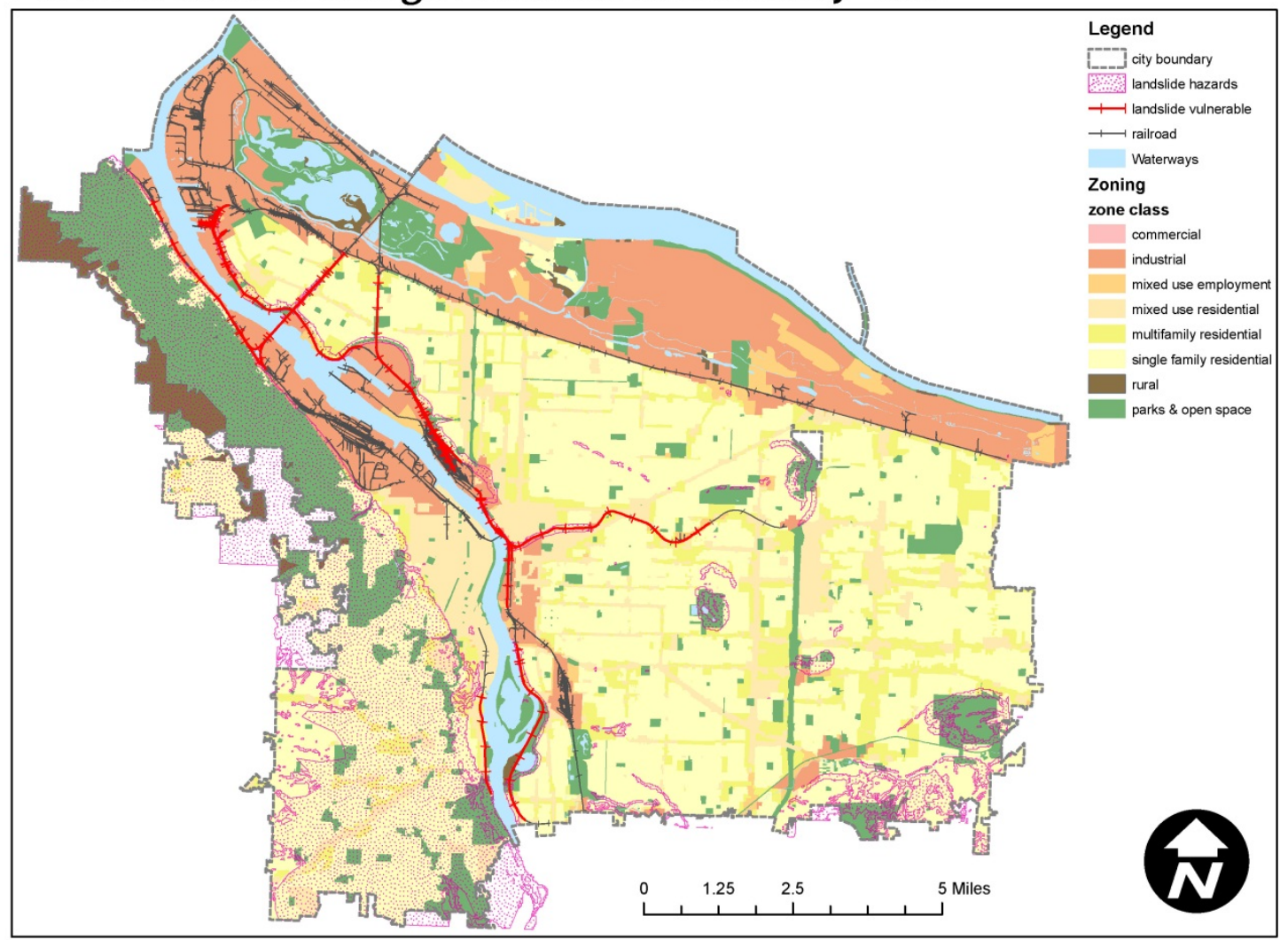

Figure 103 - Landslide Vulnerability on Rail 


\section{LIST OF WORKS CITED}

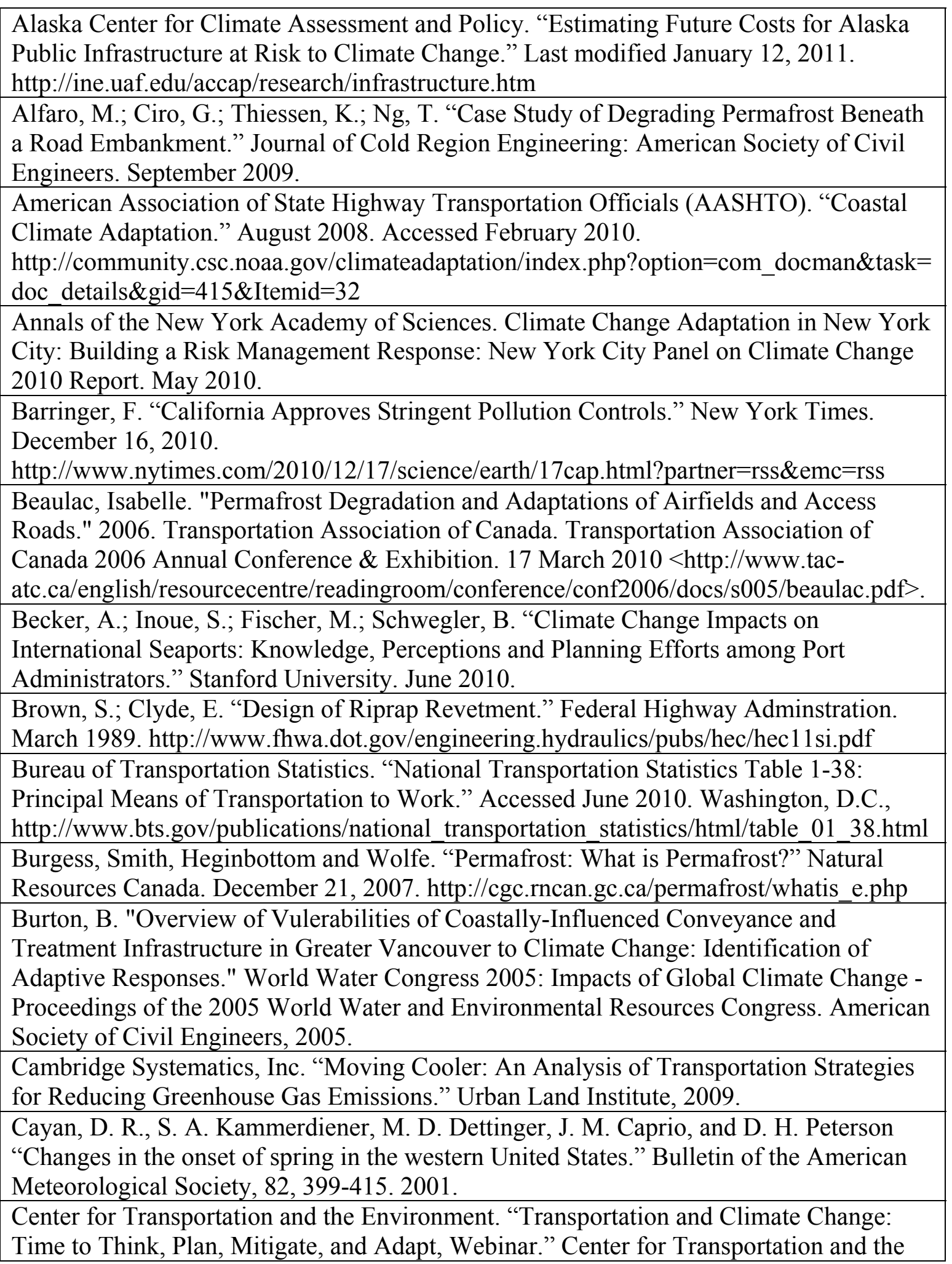


Environment National Broadcast Series, 2008.

http://cte.ncsu.edu/CTE/TechTransfer/Teleconferences/archive.asp.

Chang, H., M. Lafrenz, I.-W. Jung, M. Figliozzi, D. Platman, and C. Pederson (2010), Potential impacts of climate change on flood-induced travel disruption: A case study of Portland in Oregon, USA, Annals of the Association of American Geographers 100(4):938-952.

City of Portland Bureau of Transportation. "Portland Bicycle Master Plan for 2030." Portland, Oregon, 2010.

http://www.portlandonline.com/transportation/index.cfm?c=44597\&a=289122

City of Portland. "Street Paving and Repair." City of Portland Office of Transportation, 2010. http://www.portlandonline.com/transportation/index.cfm?c=47261

Climate Change Science Program (CCSP). 2008. Impacts of Climate Change and Variability on Transportation Systems and Infrastructure: Gulf Coast Study, Phase I. A Report by the U.S. Climate Change Science Program and the Subcommittee on Global Change Research. Savonis, M. J., V.R. Burkett, and J.R. Potter (eds.). Washington, DC: Department of Transportation.

Climate Impacts Group (CIG), University of Washington, The Washington Climate Change Impacts Assessment, June, 2009, http://cses.washington.edu/cig/

Climate Impacts Group. "Preparing for Climate Change: A Guidebook for Local, Regional, and State Governments, 2007." http://www.icleiusa.org/actioncenter/planning/adaptation-guidebook/.

Collette, C. "Barbur corridor recommended as next high capacity transit corridor." Metro Council District 2 News. December 17, 2009.

http://news.oregonmetro.gov/3/post.cfm/barbur-corridor-recommended-as-next-highcapacity-transit-corridor.

Committee on Climate Change and U.S. Transportation, National Research Council.

"Potential Impacts of Climate Change on U.S. Transportation Special Report 290.

Transportation Research Board, Washington D.C. 2008.

http://onlinepubs.trb.org/onlinepubs/sr/sr290.pdf

Congressional Natural Hazards Caucus Fact Sheet. "Flood Map Modernization."

American Geological Institute. Accessed May 24, 2011.

http://www.agiweb.org/gap/workgroup/floodmap0602.pdf

Culshaw, Brian. "The Smart Bridge of the Future." Proceedings of the 3rd International Conference on Smart Materials, Structures and Systems - Smart Optics. Acireale, Sicily, Italy, 2008.

Dunn, Kerry. "Application of Smart Materials/Technology at the Savannah River Site." Office of Scientific \& Technical Information. 16 March 2010

$<$ http://sti.srs.gov/fulltext/ms9800722/ms9800722.pdf $>$.

Federal Emergency Management Agency (FEMA). "Map Modernization." Federal Emergency Management Agency. August 13, 2010. Accessed May 24, 2011.

http://www.fema.gov/plan/prevent/fhm/mm main.shtm

Federal Emergency Management Agency (FEMA). FY10 Flood Mapping Progress

Report and Production Plan: Flood Map Modernization and Risk Mapping, Assessment, and Planning, National Flood Insurance Program. Version 1.0 July 2010

Federal Highway Administration (FHWA) "Literature Review: Climate Change 
Vulnerability Assessment, Risk Assessment, and Adaptation Approaches." Highways and Climate Change. 2009.

http://www.fhwa.dot.gov/hep/climate/ccvaraaa.htm\#Toc236233837

Federal Highway Administration (FHWA) Bridge Programs NBO Data: Tables of

Frequently Requested NBI Information. Wednesday, November 11, 2009. Federal

Highway Administration. http://www.fhwa.dot.gov/bridge/britab.cfm

Federal Highway Administration (FHWA) "Assessing Vulnerability and Risk of Climate Change Effects on Transportation Infrastructure: Pilot of the Conceptual Model,"

Highways and Climate Change. 2010a.

http://www.fhwa.dot.gov/HEP/climate/conceptual_model62410.pdf

Federal Highway Administration (FHWA) "Regional Climate Change Effects: Useful Information for Transportation agencies." Highways and Climate Change. 2010.

http://www.fhwa.dot.gov/hep/climate/climate_effects/index.cfm

Forsberg, R.; Keller, R.; Jacobsen, M. "Laser Monitoring of Ice Elevations and Sea-Ice

Thickness in Greenland." International Archives of Photogrammetry and Remote Sensing, Volume XXIV-3/W4. October 2001.

Fox 12 Oregon, "Slide Shuts Down Highway 26 On-ramp." KPTV.com Traffic. June 9, 2010. http://www.kptv.com/traffic/23818808/detail.html

Oliver W. Frauenfeld, * Tingjun Zhang and James L. McCreight (2007) Northern

hemisphere freezing/thawing index variations over the twentieth century, International Journal of Climatology, 27: 47-63 (2007).

Gregoire, C. "Governor Gregoire's Flood Disaster Declaration Request to President Obama." January 21, 2009.

Grinsted, A.,Moore, J.C., Jevrejeva, S., 2009, Reconstructing sea level from paleo and projected temperatures 200 to 2100AD. Climate Dynamics.

Haire, A. and Figliozzi, M. "Preparing Transportation Infrastructure for the consequences of Climate Chnage: A Review of Canadian and US Efforts." 8th International

Transportation Specialty Conference. Winnipeg, Manitoba, Canada: Canadian Society for Civil Engineering, 2010.

Hartgen, David. "17th Annual Report on the Performance of State Highway Systems (1984-2006)." 2008. Reason Foundation. 12 February 2010

<http://itd.idaho.gov/taskforce/resources/Hartgen\%20Report\%20July\%202008.pdf >.

Hauser, R., S. Archer, P. Backlund, J. Hatfield, A. Janetos, D. Lettenmaier, M.G. Ryan, D. Schimeland M. Walsh. (2009). The Effects of Climate Change on US Ecosystems, U.S. Department of Agriculture,

www.usda.gov/oce/global_change/sap_2007_FinalReport.htm.

Hawkins, E., Sutton, R., 2009, The Potential to Narrow Uncertainty in Regional Climate Predictions, Bulletin of the American Meteorological Society, August, 90:1095-1107.

Huppert, Daniel. "The Washington Climate Change Impacts Assessment: Evaluating Washington's Future in a Changing Climate, Chapter 8 - Impacts of Climate Change on the Coasts of Washington State." 2009. Climate Impacts Group. 1 February 2010 $<$ http://cses.washington.edu/db/pdf/wacciach8coasts651.pdf $>$

Idaho EPSCoR. "Water Resources in a Changing Climate: Idaho Climate Change." http://www.idahoclimatechange.org/index.html

Instanes, Arne. "Impacts of a Changing Climate on Infrastructure: Buildings, Support 
Systems, and Industrial Facilities." 2006 IEEE EIC Climate Change Technology Conference. Institute of Electrical and Electronics Engineers Computer Society, 2006. Intergovernmental Panel on Climate Change (IPCC). 2007. Climate Change 2007: Impacts, Adaptation and Vulnerability. Contribution of Working Group II to the Fourth Assessment Report of the Intergovernmental Panel on Climate Change, eds. M.L. Parry, O.F. Canziani, J.P. Palutikof, P.J. van der Linden and C.E. Hanson. Cambridge, UK : Cambridge University Press, $976 \mathrm{pp}$.

Jaffe, E. “Obama’s \$556 Billion Transportation Budget Plan Emphasizes Rail Spending." The Infrastructurist. February 15, 2011. http://www.infrastructurist.com/2011/02/15/obamas-556-billion-transportation-planemphasizes-rail-spending/

Karl, T. R., Melillo, J.M., Peterson, T.C., (eds.), Global Climate Change Impacts in the United States, Cambridge University Press, 2009, http://globalchange.gov/publications/reports/scientific-assessments/us-impacts Kinsella, Y. and McGuire, F., Climate Change Uncertainty and the State Highway Network: A Moving Target. Transit New Zealand. Auckland, New Zealand, 2005. Kirshen, Paul. "Interdependencies of Urban Climate Change Impacts and Adaptation Strategies: A Case Study of Metropolitan Boston USA." Climatic Change 86. January 2008.

Krough, D. "Landslide Closes Portion of Forest Park Trail." KGW.com. June 16, 2010. http://www.kgw.com/news/local/Landslide-closes-section-of-Forest-Park-trail96498264.html

Kutz, M. Handbook of Transportation Engineering. Myer Kutz. McGraw-Hill: New York. 2004.

Le Quere, C., Raupach, M. R., Canadell, J. G., Marland, G., 2009, Trends in the sources and sinks of carbon dioxide, Nature Geoscience, Nov 17, 2:831-836.

Li, Qiang, L. Mills, S. McNeil, The Implications of Climate Change on Pavement Performance and Design. University of Delware UTC, September 25, 2011. Marine Terminal Statistics. The Port of Portland, 04 2010. Web. 24 Sep 2010. http://www.portofportland.com/SelfPost/A_201091716152ExecDirReport.pdf. McKenzie, K. "Climate Change: A New Challenge for Coastal Development and Infrastructure Design." 31st Annual Conference of the Canadian Society for Civil Engineering. Moncton, New Brunswick, Canada, 2003. 391-400.

McNeil S. "Special Report 299: Reducing Transportation Greenhouse Gas Emissions and Energy Consumption: A Research Agenda: Adaptation Research Programs and Funding." University of Delaware: Transportation Research Board, October 2009. http://onlinepubs.trb.org/onlinepubs/sr/SR299Adaptation.pdf. Meyer, M. "Design Standards for U.S. Transportation Infrastructure: The Implications of Climate Change." 2008. http://onlinepubs.trb.org/onlinepubs/sr/sr290meyer.pdf Meyer, M. Amekudzi, A. and O'Har, J., Transportation Asset Management Systems and Climate Change: An Adaptive Systems Management Approach. In Transportation Researc Record: Journal of the Transportation Research Board, No 2160, Transportation Research Board of the National Academies, Washington, DC pp. 12-20, 2010.

Mills, Brian. "Climate Change and the Performance of Pavement Infrastructure in Southern Canada: Context and Case Study." 2006 IEEE EIC Climate Change Technology 
Conference, EICCCC 2006. Ottawa, ON, Canada: Institute of Electrical and Electronics Engineers Computer Society, 2007.

Mote, P. Trends in snow water equivalent in the Pacific Northwest and their climatic causes. Geophysical Research Letters 30(12) 1601, doi: 10.1029/2003GL017258, 2003.

Mote, P.M., E. Salathé, and C. Peacock. Scenarios of future climate for the Pacific Northwest. University of Washington Climate Impacts Group, Technical Report, October 2005a, 11pp. Available via the internet at http://www.cses.washington.edu/cig.

Mote, P.W., A.F. Hamlet, and D.P. Lettenmaier. 2005b. Variability and trends in mountain snowpacks in western North America. In K. Elder, B. McGurk, and J. Lea (eds.), Proceedings of the Western Snow Conference, April 19-22, 2004, Richmond, British Columbia, pp. 15-22, Soda Springs, CA: Western Snow Conference.

Mote, P., Petersen, A., Reeder, S., Shipman, H., Binder, L.W., 2008, Sea Level Rise in the Coastal Waters of Washington State, A report by the University of Washington Climate Impacts Group and the Washington Department of Ecology.

Muthumani, K. Structural Application of Smart Materials. March 16, 2010 $<$ http://www.dbtindia.nic.in/women/paper15.htm $>$.

Natural Resources Canada. "Climate Change Impacts and Adaptation: A Canadian Perspective - Adaptation in the Transportation Sector. October 2, 2007. Accessed January 19, 2010. http://www.adaptation.rncan.gc.ca/perspective/transport_5_e.php National Research Council of the National Academies (NRC). 2008. Potential Impacts of Climate Change on U.S. Transportation. Transportation Research Board Special Report 290. Washington, DC: Transportation Research Board.

NCHRP "Draft Research Results Digest: Changes to the Mechanistic-Empirical Pavement Design Guide Software Through Version 0.900.” 1-37A (MechanisticEmpirical), July 2006. http://onlinepubs.trb.org/onlinepubs/archive/mepdg/software.htm NOAA. Digital Coast. NOAA Coastal Services Center. 2010. http://www.csc.noaa.gov/digitalcoast/tools/index.html\#all\&hazards

Noble, D. "An Overview of the Risk Management Approach to Adaptation to Climate Change in Canada." Natural Resources Canada Climate Change Impacts and Adaptation Directorate, March 2005.

North American Regional Climate Change Assessment Program. "About NARCCAP." 2007. http://www.narccap.ucar.edu/

Office of the City Auditor. "City of Portland 2009 Resident Survey Results." Portland, Oregon, 2009, http://www.portlandonline.com/auditor/index.cfm?c=49566\&a=270760 Oregon Climate Change Research Institute (2010), Oregon Climate Assessment Report, K.D. Dello and P.W. Mote (eds). College of Oceanic and Atmospheric Sciences, Oregon State University, Corvallis, OR. http://occri.net/ocar

Oregon Department of Fish and Wildlife. Assessment of Road Culverts for Fish Passage Problems on State- and County-Owned Roads Statewide Summary Report, September 1999: http://www.dfw.state.or.us/fish/passage/inventories.asp

Parry et al. "Climate Change 2007: Impacts, Adaptation and Vulnerability." Contribution of Working Group II to the Fourth Assessment Report of the Intergovernmental Panel on Climate Change. Cambridge, United Kingdom: IPCC - Intergovernmental Panel on Climate Change, 2007. http://www.ipcc.ch/pdf/assessment-report/ar4/wg2/ar4-wg2spm.pdf 
Pfeffer, W.T, Harper, J.T., O'Neel, S., 2008, Kinematic Constraints on Glacier Contributions to 21st-Century Sea-Level Rise. Science 321(5894): 1340-1343.

Puget Sound Regional Council. Final Draft Transportation 2040: Appendix L Climate Change Background. April 2010.

Rahmstorf, S. 2007. A Semi-Empirical Approach to Projecting Future Sea-Level Rise. Science 315(5810): 368-370.

Robinson, Nidia. "Nanotechnology and MEMS-based systems for civil infrastructure safety and security: Opportunities and challenges." Smart Structures and Materials 2006 Sensors and Smart Structures Technologies for Civil, Mechanical, and Aerospace Systems. San Diego, CA, 2006.

Rohling, E.J., K. Grant, Ch. Hemleben, M. Siddall, B.A.A. Hoogakker, M. Bolshaw, and M. Kucera, 2007, High rates of sea-level rise during the last interglacial period. Nature Geoscience 1:38-42.

Ruggiero, P., Komar, P. D., Allan, J. C., 2010, Increasing wave heights and extreme value projections: The wave climate of the US Pacific Northwest, Coastal Engineering, May, 57:539-552.

Sackin, Douglas. "MEMS for Civil Infrastructure: Smart Aggregate for Concrete." Structures Congress 2000: Advanced Technology in Structural Engineering. American Society of Civil Engineers, 2000.

Savonis, Michael J. "The Impact of Climate Change on Transportation in the Gulf Coast." Technical Council on Lifeline Earthquake Engineering Conference, TCLEE 2009: Lifeline Earthquake Engineering in a Multihazard Environment. American Society of Civil Engineers, 2009. 670-680.

Seaport Statistics. The Port of Seattle. 2010. Web. September 24th, 2010.

http://www.portseattle.org/downloads/seaport/mcps.pdf.

SNAP (Scenarios Network for Alaska Planning) 2008. Preliminary Report to the Governor Subcabinet on Climate Change. http://www.snap.uaf.edu/downloads/fact-sheets-and-shortdocuments-0

SNAP (Scenarios Network for Alaska Planning) 2009. Climate Change Impacts on Water Availability in Alaska. http://www.snap.uaf.edu/projects/climate-change-impacts-wateravailability-alaska

Solman, et al., "Regional Climate Projections". In: Climate Change 2007: The Physical Science Basis. Contribution of Working Group I to the Fourth Assessment Report of the Intergovernmental Panel on Climate Change (Cambridge, United Kingdom and New York, NY: Cambridge University Press, 2007.), http://www.ipcc.ch/pdf/assessmentreport/ar4/wg1/ar4-wg1-chapter11.pdf.

State of Alaska. "2008 Public Road Miles: Paved/Unpaved Summary by ADOT\&PF Region, Ownership and Functional Class." Alaska Highway Data - Public Road Miles, Transportation \& Public Facilities, State of Alaska. 18 March 2010 $\leq$ http://www.dot.state.ak.us/stwdplng/highwaydata/pub/cprm/2008fflassmilessum.pdf $>$. State of Alaska. "2008 Certified Public Road Mileage Report." 2008. Alaska Highway Data - Public Road Miles, Transportation \& Public Facilities, State of Alaska. 18 March $2010 \leq$ http://www.dot.state.ak.us/stwdplng/highwaydata/pub/cprm/2008cprm.pdf $>$.

Sussman, F. and Freed, J., Adapting to Climate Change: A Business Approach. Pew Centes on Global Climate Change. April 2008. 
Sutherst, R. W. Climate change and invasive species: a conceptual framework, in Invasive Species in a Changing World, edited, pp. 211-240, Island Press, New York, 2000.

Tague, C., G. Grant, M. Farrell, J. Choate, and A. Jefferson, Deep groundwater mediates streamflow response to climate warming in the Oregon Cascades, Climatic Change, 86, 189-210, (2008).

Tighe, Susan et al. "Evaluating Climate Change Impact on Low-Volume Roads in Southern Canada." Transportation Research Record: Journal of the Transportation Research Board. No 2053. 2008: 9-16.

Ting, M.; Koomey, J; Pomeranz, M. "Preliminary Evaluation of the Lifecycle Cost and Market Barriers of Reflective Pavement." Energy Analysis Department: Ernest Orlando Lawrence Berkeley National Laboratory. November 2001.

TriMet. Portland-Milwaukie Light Rail Project Navigational Results Report. October 2010. http://trimet.org/pdfs/pm/FEIS/Navigational Final Oct2010.pdf

TriMet. "SOP 434 Weather Operating Instructions," 2010.

UK Highways. Climate Adaptation Plan, England, United Kingdom, 2008 United States Bureau of the Census, State and County "Quickfacts: Portland, Oregon." 2000. Washington, D.C., http://quickfacts.census.gov/qfd/states/41/4159000.html United States Department of Transportation (US DOT), Asset Management Primer, Washington, D.C., 1999, http://assetmanagement.transportation.org/tam/aashto.nsf/All+Documents/3F885001659 BB65185256B180058688C/\$FILE/amprimer.pdf United States Department of Transportation (US DOT), Center for Climate Change and Environmental Forecasting, The Potential Impacts of Global Sea Level Rise on Transportation Infrastructure Part 1: Methodology, October 2008 http://climate.dot.gov/impacts-adaptations/sea_level_rise.html United States Global Change Research Program (USGCRP). What We Do: Modeling, 2011. http://www.globalchange.gov/what-we-do/modeling

University of Alaska Fairbanks. "Scenarios Network for Alaska Planning (SNAP)." Last Updated May 3, 2011. http://www.snap.uaf.edu/

US Department of Transporation Federal Highway Administration. "Highways of the Future-A Strategic Plan for Highway Infrastructure Research and Development." July 2008. Turner-Fairbank Highway Research Center. 16 March 2010

http://www.tfhrc.gov/infrastructure/pubs/08068.pdf

United States General Accounting Office (USGAO). Report to the Chairman,

Subcommittee on Housing and Community Opportunity, Committee on Financial Services, House of Representatives: FLOOD MAP MODERNIZATION Program Strategy Shows Promise, but Challenges Remain, GAO-04-417, March 2004.

United States General Accounting Office (USGAO). Report to Congressional Requester: FEMA Flood Maps: Some Standards and Processes in Place to Promote Map Accuracy and Outreach, but Opportunities Exist to Address Implementation Challenges, GAO-1117, December 2, 2010.

Walker, L.; Figliozzi, M.; Haire, A; MacArthur, J. "Climate Action Plans and Long Range Transportation Plans in the Pacific Northwest: A Review of the State of the Practice." Transportation Research Board 90th Annual Meeting, 2011.

Walker, L.; Figliozzi, M.; Haire, A; MacArthur, J. "Identifying Surface Transportation 
Vulnerabilities and Risk Assessment Opportunities Under Climate Change: Case Study in Portland, Oregon." Transportation Research Record. Planning, Vol. 1, 2244, pg. 41-49, 2011.

Washington State Department of Fish and Wildlife. Progress Performance Report For WSDOT Fish Passage Inventory, June 2011: http://www.wsdot.wa.gov/environment/biology/fp/fishpassage.htm\#5 Washington State Department of Transportation Freight Systems Division. "Stormrelated closures of I-5 and I-90: Freight Transportation Economic Impact Assessment Report." Final Research Report WA-RD 708.1. WSDOT, 2008

Washington State Ferry System. "Service Plans and Investment Needs." Washington State Department of Transportation. June 10, 2009. http://www.wsdot.wa.gov/NR /rdonlyres/41834AOB-DABC-48FA-9700DF0298AA65B4/58553/ServicePlanandInvestmentNeedsrevised.pdf Wendler, G., M. Shulski and B. Moore 2010. "Changes in the climate of the Alaskan North Slope and the ice concentration of the adjacent Beaufort Sea." Theoretical and Applied Climatology 99:67-74

Wheeler, S. "State and Municipal Climate Change Plans: The First Generation." Journal of the American Planning Association. Vol 74, No. 4 (2008): 481-496.

Wolcott, J.; Ridgway, J.; Little, R. "Van Buren Bridge Replacement Project." Oregon Department of Transportation. Updated October 2, 2009. http://www.oregon.gov/ODOT/HWY/REGION2/VanBurenStreetBridge.shtml\#Overview World Port Source. www.worldportsource.com 



\section{GOTREC \\ AND EDUCATION CONSORTIUM}

P.O. Box 751

Portland, OR 97207

OTREC is dedicated to stimulating and conducting collaborative multi-disciplinary research on multi-modal surface transportation issues, educating a diverse array of current practitioners and future leaders in the transportation field, and encouraging implementation of relevant research results. 